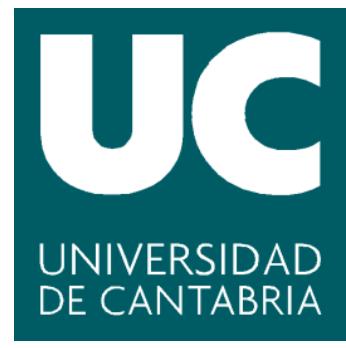

UNIVERSIDAD DE CANTABRIA

Departamento de Administración de Empresas

\title{
Riesgo soberano y política monetaria: efectos sobre los préstamos bancarios y el crédito comercial
}

Doctoranda: María Cantero Sáiz

Dirección: Dra. María Begoña Torre Olmo

Dr. Sergio Sanfilippo Azofra

Santander, Marzo de 2015 



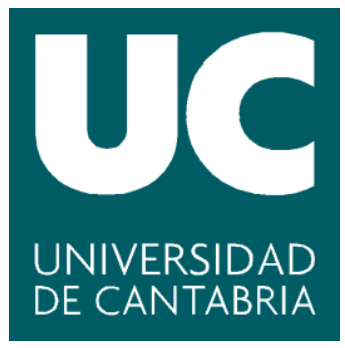

UNIVERSITY OF CANTABRIA

Business Management Department

\title{
Sovereign risk and monetary policy: effects on bank loans and trade credit
}

\author{
PhD Student: María Cantero Sáiz \\ Supervisors: Dr. María Begoña Torre Olmo \\ Dr. Sergio Sanfilippo Azofra
}

Santander, March 2015 

A mis padres 



\section{Agradecimientos}

La realización de esta tesis doctoral no hubiera sido posible sin aquellas personas que me han acompañado y facilitado su apoyo, consejo y ánimo a lo largo de este proceso, a las cuales mediante estas líneas, quiero expresar mi más sincero y profundo agradecimiento.

En primer lugar, a mis directores de tesis, la Dra. Begoña Torre Olmo y el Dr. Sergio Sanfilippo Azofra, no sólo por su labor en la realización de este trabajo, sino también por su apoyo constante, por mostrarse accesibles en todo momento, y por haber depositado su confianza en mí a lo largo de todas las tareas que he realizado bajo su dirección.

De igual manera, al Dr. Carlos López Gutiérrez, por su inestimable consejo, por tener siempre la puerta abierta para resolver dudas y solucionar todo tipo de problemas que han surgido en el desarrollo de este trabajo.

A todos mis compañeros y compañeras del Departamento de Administración de Empresas, y de la Facultad de Ciencias Económicas y Empresariales de la Universidad de Cantabria, con los que he compartido gran parte de mi trabajo, les agradezco toda la ayuda que me han prestado, así como los buenos momentos que he pasado en su compañía.

También quiero dar las gracias a la Fundación de la Universidad de Cantabria para el Estudio y la Investigación del Sector Financiero (Fundación UCEIF) y a la Cátedra de Imagen y Proyección Regional de la Universidad de Cantabria, por su apoyo económico, sin el cual, no hubiera podido llevar a cabo esta investigación. 
Este agradecimiento es extensible al Dr. Raphael Markellos y al Dr. Apostolos Kourtis de la Norwich Business School, Universidad de East Anglia del Reino Unido, por sus consejos y atenciones durante mi estancia pre-doctoral en Norwich.

Pero mi mayor agradecimiento se lo debo a mis padres, por apoyarme en todas las decisiones que he tomado a lo largo de la vida y, especialmente, por enseñarme a luchar por lo que quiero. Y a mis abuelos, que siempre han creído en mí y confiado en mis posibilidades.

Me gustaría dedicar unas líneas a mis amigas y amigos para compensarlos por el tiempo que no hemos podido disfrutar juntos durante la realización de este trabajo. En particular, a mi amiga y gran compañera de estudios en la facultad, Gema, por ser una de las mejores amistades que he tenido en mi vida, por su inigualable carácter, y por estar siempre ahí cuando lo he necesitado.

Por último, no puedo finalizar sin mostrar un agradecimiento muy especial a Mario, por su cariño e incondicional apoyo, por creer en mí cuando yo dejo de hacerlo y, sobre todo, por saber dibujarme siempre una sonrisa. 
ÍNDICE 

ÍNDICE ..........................................................................................................................

RESUMEN................................................................................................................................... vii

ABSTRACT ................................................................................................................................ ix

INTRODUCCIÓN.................................................................................................................... xi

CAPÍTULO I: LA POLÍTICA MONETARIA DEL BANCO CENTRAL EUROPEO Y

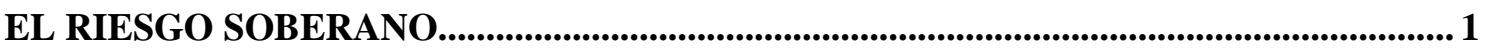

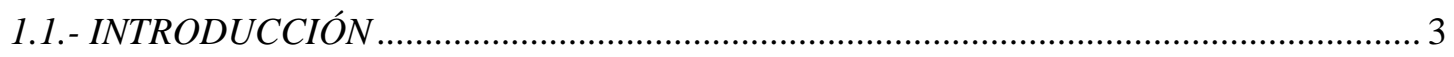

1.2.- LA POLÍTICA MONETARIA DEL BANCO CENTRAL EUROPEO ………………….... 4

1.2.1.- Marco institucional y organización de la política monetaria del BCE........................ 5

1.2.2.- Estrategia de política monetaria del BCE …............................................................... 8

1.2.3.- Instrumentación de la política monetaria del BCE ................................................ 10

1.2.3.1.- Las operaciones de mercado abierto ................................................................. 10

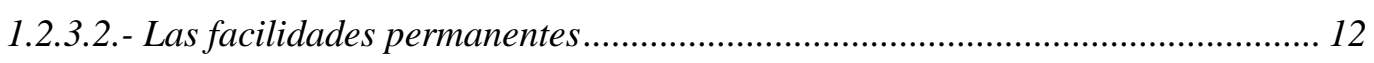

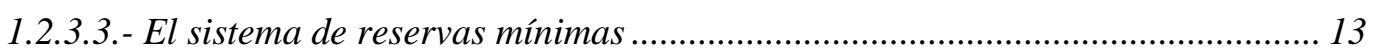

1.3.- CANALES DE TRANSMISIÓN DE LA POLÍTICA MONETARIA ….............................. 14

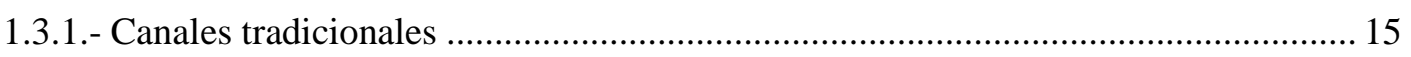

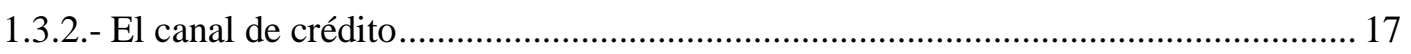

1.4.- RIESGO SOBERANO Y POLÍTICA MONETARIA ….................................................. 20

1.4.1.- Influencia del riesgo soberano sobre el canal de crédito de la política monetaria ... 22 1.5.- ANÁLISIS COMPARATIVO DE LA ACTUACIÓN DE POLÍTICA MONETARIA DEL BCE ANTES Y DESPUÉS DEL ESTALLIDO DE LA CRISIS ................................................ 31

1.5.1.- Los años previos a la crisis (1999-otoño de 2008)................................................... 31

1.5.2.- Los años posteriores al estallido de la crisis (otoño de 2008-actualidad) ................. 34

1.5.2.1.- La crisis económico-financiera (otoño de 2008-primavera de 2010)................ 34

1.5.2.2.- La crisis de deuda soberana (primavera de 2010-actualidad)......................... 37

CAPÍTULO II: RELACIÓN ENTRE EL RIESGO SOBERANO Y EL CANAL DE

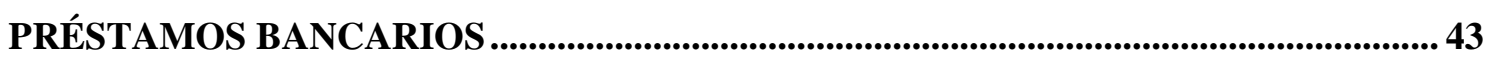

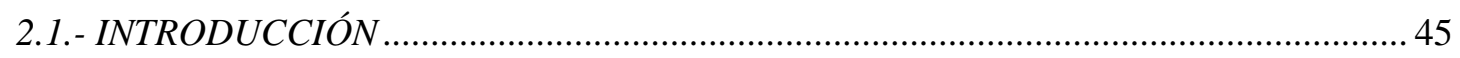

2.2.- EL CANAL DE PRÉSTAMOS BANCARIOS COMO MECANISMO DE

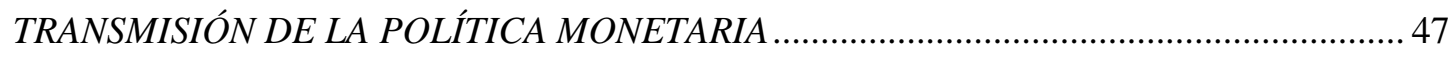

2.2.1.- El canal de préstamos bancarios con datos macroeconómicos o agregados ............. 49

2.2.1.1.- Evidencias empíricas en Estados Unidos ......................................................... 49

2.2.1.2.- Evidencias empíricas en Europa..................................................................... 53

2.2.2.- El canal de préstamos bancarios con datos microeconómicos o desagregados ........ 56

2.2.2.1.- Tamaño y canal de préstamos bancarios......................................................... 56 
2.2.2.2. - Liquidez y canal de préstamos bancarios.....

2.2.2.3- Capital y canal de préstamos bancarios................................................... 61

2.2.2.4.- Riesgo de crédito y canal de préstamos bancarios ....................................... 62

2.2.2.5.- Concentración bancaria, competencia y canal de préstamos bancarios.......... 64

2.3. - RIESGO SOBERANO Y CANAL DE PRÉSTAMOS BANCARIOS .............................. 67

2.4. - ANÁLISIS EMPÍRICO DEL CANAL DE PRÉSTAMOS BANCARIOS......................... 77

2.4.1.- Composición y características de la muestra ................................................... 77

2.4.2.- Desarrollo del modelo econométrico y variables utilizadas en el análisis .............. 79

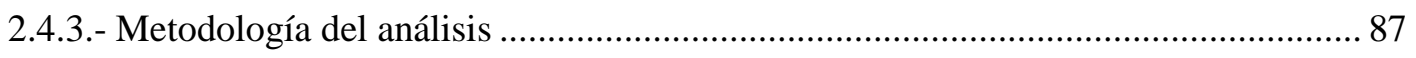

2.4.3.1.- Estimador GMM de la metodología de datos de panel dinámicos .................. 88

2.4.3.2. - Estimador System-GMM de la metodología de datos de panel dinámicos....... 91

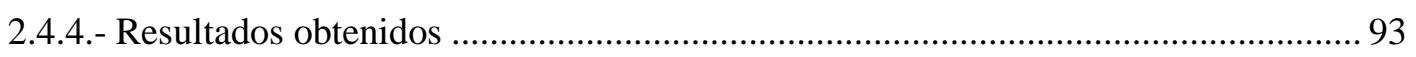

2.4.5.- Análisis de robustez ............................................................................ 107

\section{CAPÍTULO III: RELACIÓN ENTRE EL RIESGO SOBERANO Y EL CANAL DE} CRÉDITO COMERCIAL ...................................................................................................... 115

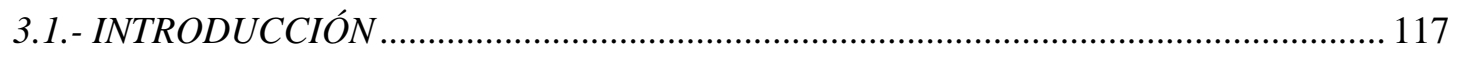

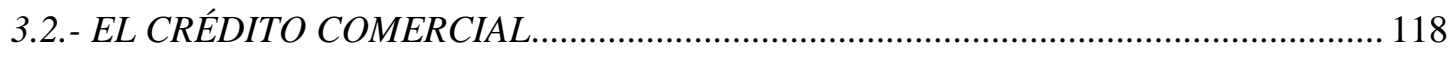

3.2.1.- Motivos que justifican la existencia del crédito comercial ................................ 118

3.2.2.- El canal de crédito comercial .................................................................. 122

3.2.2.1.- El crédito comercial como fuente de financiación sustitutiva a los préstamos bancarios....................................................................................................... 125

3.2.2.2. - El crédito comercial como fuente de financiación complementaria a los préstamos bancarios ..................................................................................... 129

3.3. - INFLUENCIA DEL RIESGO SOBERANO SOBRE EL CANAL DE CRÉDITO

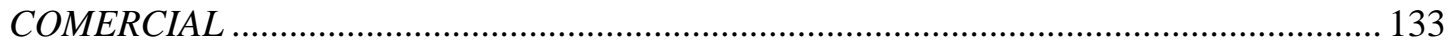

3.4. - ANÁLISIS EMPÍRICO DEL CANAL DE CRÉDITO COMERCIAL ........................... 139

3.4.1.- Composición y características de la muestra ............................................... 139

3.4.2.- Desarrollo del modelo econométrico y variables utilizadas en el análisis del crédito

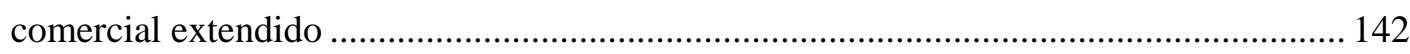

3.4.3.- Resultados obtenidos en el análisis del crédito comercial extendido. 149

3.4.4.- Desarrollo del modelo econométrico y variables utilizadas en el análisis del crédito comercial recibido ....................................................................................... 154

3.4.5.- Resultados obtenidos en el análisis del crédito comercial recibido ..................... 160

3.4.6.- Desarrollo del modelo econométrico y variables utilizadas en el análisis del crédito

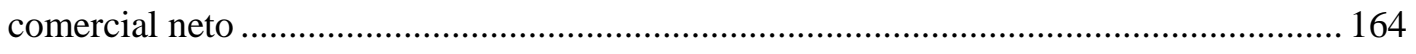

3.4.7.- Resultados obtenidos en el análisis del crédito comercial neto ........................... 169

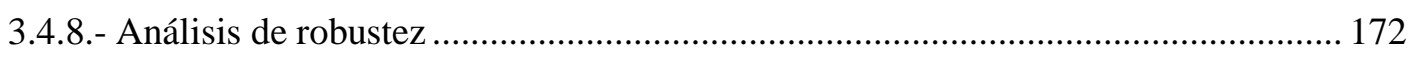


3.4.8.1.- Crédito comercial extendido

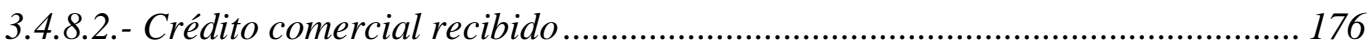

3.4.8.3.- Crédito comercial neto ............................................................................... 179

CONCLUSIONES............................................................................................................................. 183

CONCLUSIONS ........................................................................................................................... 191

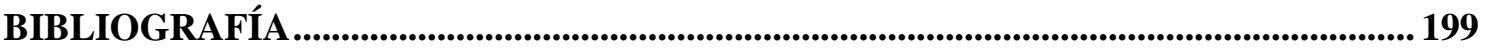





\section{RESUMEN}

El objetivo de esta tesis es analizar la influencia del riesgo soberano sobre el canal de crédito de la política monetaria desde una doble perspectiva. La primera parte examina cómo el riesgo soberano determina los efectos de la política monetaria sobre los préstamos bancarios, y se comprueba si dichos efectos difieren durante restricciones y expansiones monetarias. La segunda parte estudia el impacto del riesgo soberano sobre el crédito comercial, tanto directamente como a través de la política monetaria.

Para el análisis de la primera parte, se utiliza una muestra de 3.028 bancos de 12 países de la zona euro (UE-11 más Grecia) durante 1999-2012. Los resultados indican que los bancos que operan en países con mayor riesgo soberano contraen más su oferta de préstamos cuando se produce una política monetaria restrictiva. Sin embargo, durante una política monetaria expansiva no existen suficientes evidencias de que los bancos ubicados en países con mayor riesgo soberano incrementen su oferta crediticia en menor medida. Asimismo, los bancos en países con un riesgo soberano muy elevado reducen su oferta de préstamos durante restricciones y expansiones monetarias.

La segunda parte se analiza mediante una muestra de 17.366 empresas de los mismos 12 países de la primera parte durante 2005-2012. Los resultados muestran que, durante la crisis, el crédito comercial extendido y el neto (diferencia entre el crédito comercial extendido y recibido) descienden a medida que aumenta el riesgo soberano. Sin embargo, en los años de crisis, el crédito comercial recibido se incrementa cuanto mayor es el riesgo soberano, pero solo cuando éste es bajo o moderado, mientras que cuando es elevado, subidas del mismo ocasionan un descenso del crédito comercial recibido. Asimismo, una política monetaria restrictiva sólo conduce a un aumento del crédito comercial en países con riesgo soberano relativamente bajo. 



\begin{abstract}
The purpose of this thesis is to analyze the influence of sovereign risk on the credit channel of monetary policy from a double perspective. The first part examines how sovereign risk determines the effects of monetary policy on bank loans and tests whether these effects differ during monetary contractions and expansions. The second part studies the impact of sovereign risk on trade credit, both directly and through the monetary policy.
\end{abstract}

For the analysis of the first part, we use a sample of 3,028 banks from 12 euro zone countries (EU-11 plus Greece) between 1999 and 2012. We find that banks which operate in higher sovereign risk countries reduce their loan supply more following a monetary contraction. However, during an expansionary monetary policy, there is not enough evidence that banks in higher sovereign risk countries increase their lending supply to a lesser extent. Additionally, banks in countries with a very high sovereign risk reduce their credit supply both during monetary contractions and expansions.

The second part is analyzed through a sample of 17,366 firms from the same 12 countries of the first part between 2005 and 2012. The results show that during the crisis trade credit supplied and net trade credit (the difference between trade credits supplied and received) decline as sovereign risk rises. However, during the crisis trade credit received increases with the level of the sovereign risk, but only when it is low and moderate. On the contrary, trade credit received reduces as sovereign risk increases when it is high. Additionally, a restrictive monetary policy only leads to an increase in trade credit in countries with relatively low sovereign risk. 



\section{INTRODUCCIÓN}



El objetivo de esta tesis doctoral consiste en analizar cómo el riesgo soberano afecta al canal de crédito de la política monetaria desde una doble vertiente. Por un lado, se estudia cómo el riesgo soberano determina los efectos de la política monetaria sobre los préstamos bancarios durante períodos de restricción y expansión monetaria. Por otro lado, se examinan los efectos del riesgo soberano sobre el crédito comercial entre empresas no financieras, tanto de forma directa como mediante la política monetaria.

La crisis financiera que comenzó en 2008 se ha visto intensificada en Europa, y especialmente en la zona euro, como consecuencia de la crisis de deuda soberana a partir de 2010. En este contexto se produjo un fuerte aumento del riesgo soberano en varios países de la zona euro, que provocó un empeoramiento de las condiciones de financiación de los bancos nacionales, dando lugar a una reducción de la oferta de préstamos. Dado que el sector bancario desempeña un papel fundamental en la transmisión de los impulsos monetarios a la economía real (Bernanke y Blinder, 1988), la disminución de la oferta crediticia ocasionada por el riesgo soberano, ha supuesto que 
la política monetaria común del Banco Central Europeo haya tenido efectos heterogéneos por países. Esta reducción en la oferta de préstamos ha resaltado la importancia del crédito comercial como vía de financiación alternativa a los préstamos para el sector empresarial (Banco Central Europeo, 2012b). Sin embargo, el aumento del riesgo soberano ha supuesto graves restricciones de financiación para todas las empresas y ha incrementado su riesgo de impago, lo cual ha limitado su capacidad para conceder y recibir créditos comerciales y ha acentúado aún más las asimetrías en el mecanismo de transmisión de la política monetaria (Corsetti et al., 2013; Pianeselli y Zaghini, 2014; Broner et al., 2014).

Ante este escenario, resulta interesante analizar y cuantificar los efectos del riesgo soberano sobre el proceso de transmisión monetaria a través del crédito, con el fin de identificar las disfunciones que se producen entre países durante dicho proceso. Con ese objetivo, esta tesis se ha estructurado en tres capítulos: en el primero se realiza un análisis descriptivo del contexto en el que se apoya la investigación, mientras que en el segundo y el tercero se llevan a cabo dos análisis empíricos sobre la relación entre el riesgo soberano y la transmisión de la política monetaria a través de los préstamos bancarios y del crédito comercial respectivamente.

El primer capítulo tiene como objetivo situar la política monetaria del Banco Central Europeo en el contexto de los cambios recientes que han tenido lugar como consecuencia de la crisis y del posterior aumento del riesgo soberano. En la primera parte del mismo se describen los principales aspectos relativos a la política monetaria común del Banco Central Europeo, es decir, su marco institucional y organización, su estrategia y su instrumentación. En segundo lugar, se desarrollan los distintos canales por los que las decisiones de política monetaria afectan a la economía, tales como el canal de tipos de interés, el canal de tipo de cambio, el canal de precios de los activos, el 
canal de las expectativas y el canal de crédito (Mishkin, 1995). A continuación, se realiza un análisis descriptivo de los efectos que el riesgo soberano ha ejercido sobre las condiciones de financiación de los sectores bancario y empresarial y la transmisión de la política monetaria en la zona euro. La última parte del capítulo se dedica al estudio del marco de actuación que ha seguido el Banco Central Europeo para hacer frente a la crisis y a los problemas de riesgo soberano, estableciendo una comparativa entre la política monetaria de los años previos y posteriores al estallido de la crisis.

El segundo capítulo se centra en analizar los efectos del riesgo soberano sobre el canal de préstamos bancarios (bank lending channel), al ser uno de los mecanismos integrados dentro del canal de crédito de la política monetaria. En primer lugar, se lleva a cabo una revisión teórica del canal de préstamos bancarios. Dicho canal sostiene que una política monetaria restrictiva conduce a una disminución de la oferta de crédito, puesto que influye negativamente sobre las condiciones de financiación de los bancos (Bernanke y Blinder, 1988). Sin embargo, esta disminución crediticia va a depender de la capacidad de los bancos para acceder a fuentes de financiación. En este sentido, la mayor parte de la literatura apunta a que los bancos más pequeños, ilíquidos, menos capitalizados, con mayor riesgo de crédito y que operan en mercados menos concentrados y más competitivos son más sensibles a las restricciones monetarias, debido a sus mayores problemas para obtener financiación (Kashyap y Stein, 1995a; 1995b; 2000; Kishan y Opiela, 2000; 2006; Altunbas et al., 2010; Olivero et al., 2011a).

En segundo lugar, se describen los efectos del riesgo soberano sobre la situación financiera de los bancos, ya que, desde el comienzo de la crisis de deuda soberana, su aumento ha supuesto un significativo deterioro de la calidad crediticia y las condiciones de financiación de los bancos de los países más afectados (Committee on the Global Financial System, 2011; Banco Central Europeo, 2012a). Además, los problemas de 
financiación, ocasionados por el aumento del riesgo soberano, han inducido a los bancos a acaparar mayores niveles de liquidez por cautela (Freixas et al., 1999; Davies y Ng, 2011; Unsal y Cáceres, 2011). Estos factores han repercutido negativamente sobre la oferta crediticia $y$, por tanto, sobre el funcionamiento del canal de préstamos bancarios, argumento que justifica el objetivo de este segundo capítulo, que consiste en analizar cómo el riesgo soberano condiciona los efectos de la política monetaria sobre los préstamos durante restricciones y expansiones monetarias.

Para la contrastación de este objetivo se realiza, en la última parte de este segundo capítulo, un análisis empírico a partir de una muestra de 3.028 entidades de crédito de 12 países de la zona euro (UE-11 más Grecia) durante 1999-2012. La elección de esta muestra permite el análisis del canal de préstamos bancarios de la política monetaria común evitando el sesgo que supondría la existencia de régimenes monetarios distintos. A partir de la formulación del modelo empírico y del estudio de las variables empleadas, se muestra la metodología del análisis y se concluye con la explicación de los resultados obtenidos.

El tercer capítulo se dedica a examinar los efectos del riesgo soberano sobre el canal de crédito comercial (trade credit channel) como otro de los mecanismos que forman parte del canal de crédito de la política monetaria. La primera parte gira en torno a los principales aspectos que subyacen al crédito comercial y los trabajos empíricos más relevantes sobre el mismo. El canal de crédito comercial afirma que cuando se produce una restricción monetaria, el crédito comercial que se conceden las empresas no financieras aumenta para compensar la reducción de la oferta de préstamos. En esta situación, las empresas menos vulnerables redistribuyen recursos hacia las empresas más débiles mediante la concesión de créditos comerciales (Meltzer, 1960; Kohler et al., 2000; Mateut et al., 2006). 
En la segunda parte del capítulo se describe la influencia del riesgo soberano sobre el canal de crédito comercial, ya que las restricciones en la oferta de préstamos causadas por la crisis y el mayor riesgo soberano, obligarán a las empresas a recurrir al crédito comercial como fuente de financiación alternativa. Sin embargo, es posible que el riesgo soberano esté afectando negativamente al crédito comercial, alterando el mecanismo de transmisión de la política monetaria, por varias razones. En primer lugar, un mayor riesgo soberano no solo ha tenido severas repercusiones sobre los mercados bancarios, sino también sobre otros segmentos de financiación, tales como los mercados de capitales, lo que supone importantes limitaciones para todas las empresas (Banco Central Europeo, 2010a; 2012b; Pianeselli y Zaghini, 2014). Estos problemas financieros implican que las empresas tradicionalmente proveedoras de crédito comercial ya no puedan canalizar recursos hacia aquellas más vulnerables. En segundo lugar, el empeoramiento del riesgo soberano ha incrementado el riesgo de crédito de las empresas nacionales y, por lo tanto, su probabilidad de impago y la posibilidad de contagio a sus acreedores (Bedendo y Colla, 2013; Corsetti et al., 2013; Klein y Stellner, 2014). Este deterioro de la solvencia ha mermado la capacidad de las empresas para poder obtener y extender crédito comercial. En tercer lugar, las fuertes restricciones financieras están haciendo que las empresas acumulen mayores niveles de liquidez por precaución, reduciendo su propensión a extender créditos comerciales (Campello et al., 2010; Acharya et al., 2013). Todos estos planteamientos sustentan nuestras hipótesis de que cuando el riesgo soberano aumenta, el crédito comercial disminuye, limitando los efectos positivos que sobre el mismo tienen las restricciones monetarias.

Para contrastar nuestras hipótesis, en la tercera parte del capítulo se realiza un análisis empírico a partir de una muestra de 17.366 empresas no financieras 
pertenecientes a 12 países de la zona euro (UE-11 más Grecia) durante 2005-2012. Dicho análisis se realiza para tres indicadores de crédito comercial: el crédito comercial que extienden las empresas a sus clientes, el que reciben de sus proveedores y el neto (diferencia entre el crédito comercial extendido y recibido). Para cada uno de estos tres indicadores de crédito comercial se describe, en primer lugar, el modelo utilizado, a continuación la metodología del análisis y, por último, se muestran los resultados obtenidos.

Tras la exposición de los resultados que se derivan de este tercer capítulo, el trabajo finaliza con un apartado en el que se resumen las principales conclusiones obtenidas y otro que recoge las referencias bibliográficas utilizadas. 
CAPÍTULO I

\section{LA POLÍTICA MONETARIA DEL BANCO CENTRAL EUROPEO Y EL RIESGO SOBERANO}





\section{1.- INTRODUCCIÓN}

El 1 de enero de 1999 se creó una nueva moneda, el euro, que actualmente es la moneda oficial de 19 países europeos. A partir de ese momento, el Banco Central Europeo (BCE) asumió la responsabilidad de la política monetaria única dentro de la Unión Económica y Monetaria (UEM), lo que supuso un hito en el largo y complejo proceso de integración de los países de Europa. El BCE ejecuta la política monetaria de un conjunto de países que gozan de gran autonomía, hecho que le distingue de otros Bancos Centrales comparables, como el Sistema de la Reserva Federal estadounidense o el Banco de Japón, autoridades monetarias de sus respectivos países.

La crisis financiera que comenzó en 2008, y su agravamiento en Europa tras el estallido de la crisis de deuda soberana en 2010, han puesto de manifiesto algunas debilidades del funcionamiento de la UEM y de la política monetaria común del BCE. Dicha crisis tuvo un serio impacto sobre la situación presupuestaria de algunos países, lo que generó una creciente preocupación por el riesgo soberano. Su aumento en ciertos 
países se extendió rápidamente a los costes de financiación de sus bancos, dando lugar a una fuerte contracción del crédito bancario, lo que supuso que las decisiones de política monetaria del BCE tuviesen efectos muy heterogéneos entre países.

Con objeto de contextualizar todos estos cambios, en este primer capítulo se realiza un análisis descriptivo de la política monetaria del BCE y de los posibles efectos que está teniendo el riesgo soberano sobre el mecanismo de transmisión de la misma para, en los próximos dos capítulos, analizar más detalladamente estos efectos mediante dos análisis empíricos. Así, este capítulo se estructura como sigue. En primer lugar, se describe el funcionamiento de la política monetaria única del BCE. En segundo lugar, se presentan los distintos canales de transmisión por los que las decisiones de política monetaria afectan a la economía real. En tercer lugar, se hace referencia al riesgo soberano y su influencia sobre la transmisión de la política monetaria a través del canal de crédito. Finalmente, se describe la actuación que ha seguido el BCE para hacer frente a las distorsiones en la transmisión de la política monetaria que ocasionó la crisis y el aumento del riesgo soberano. Para ello se realiza una comparativa entre el marco de actuación que caracterizó a los años previos y posteriores al estallido de la crisis.

\section{2.- LA POLÍTICA MONETARIA DEL BANCO CENTRAL EUROPEO}

El objetivo primordial de la política monetaria del BCE es el mantenimiento de la estabilidad de precios (Banco Central Europeo, 2011a). Cuantitativamente, el BCE en 1998 definió la estabilidad de precios como un incremento interanual del Índice Armonizado de Precios de Consumo (IAPC) ${ }^{1}$ de la zona euro inferior al $2 \%$. En mayo de 2003 el BCE revisó la definición anterior fijando un objetivo de inflación por debajo del $2 \%$, pero próxima a este valor, en el medio plazo. De acuerdo a esta revisión, no

\footnotetext{
${ }^{1}$ El IAPC es un indicador de las variaciones que, a lo largo del tiempo, experimenta el precio de una cesta representativa del gasto de los consumidores en la zona euro.
} 
solo la inflación por encima del 2\%, sino también la deflación, son incompatibles con la estabilidad de precios. Asimismo, la referencia a "medio plazo" responde al hecho de que es difícil que la política monetaria pueda ajustar la evolución de la inflación en horizontes breves de tiempo.

Una vez definido el objetivo de la política monetaria del BCE, en este epígrafe se abordan las siguientes cuestiones. En primer lugar, se describen los aspectos institucionales más relevantes que configuran la política monetaria del BCE. En segundo lugar, se desarrolla la estrategia de política monetaria seguida por el BCE para el cumplimiento de su objetivo. Finalmente, se describen los instrumentos de política monetaria que tiene el BCE a su disposición.

\subsection{1.- Marco institucional y organización de la política monetaria del BCE}

La base jurídica de la política monetaria única se asienta sobre el Tratado de la Unión Monetaria (TUE), el Tratado de Funcionamiento de la Unión Europea (TFUE) y los Estatutos del Sistema Europeo de Bancos Centrales y del Banco Central Europeo (Estatutos del SEBC). En ellos se determina la creación del BCE, del Eurosistema y del Sistema Europeo de Bancos Centrales (SEBC).

El Eurosistema está compuesto por el BCE y los Bancos Centrales Nacionales (BCN) de los Estados miembros de la UE que forman parte de la zona euro ${ }^{2}$. Por su parte, el SEBC está integrado por el BCE y los BCN de todos los Estados miembros de la UE, es decir, incluye también los $\mathrm{BCN}$ de los Estados miembros que aún no han adoptado el euro ${ }^{3}$ (apartado 1 del artículo 282 del TFUE).

\footnotetext{
${ }^{2}$ La zona euro se compone actualmente de los siguientes 19 países: Alemania, Austria, Bélgica, Chipre, Eslovaquia, Eslovenia, España, Estonia, Finlandia, Francia, Grecia, Holanda, Irlanda, Italia, Letonia, Lituania, Luxemburgo, Malta y Portugal.

${ }^{3}$ Los Estados de la UE que no pertenecen a la zona euro son los siguientes: Bulgaria, Croacia, Dinamarca, Hungría, Polonia, Reino Unido, República Checa, Rumanía y Suecia.
} 
El BCE es el núcleo del Eurosistema y del SEBC y, en el desempeño de sus funciones, es fundamental que sea independiente de toda influencia política para salvaguardar el objetivo de la estabilidad de precios $^{4}$ (artículo 130 del TFUE). Los BCN de la zona euro, al formar parte del Eurosistema, desempeñan las funciones que le han sido encomendadas según las normas establecidas por los órganos rectores del BCE. Por su parte, los BCN de los Estados miembros de la UE que no han adoptado el euro no pueden participar en la toma y ejecución de decisiones de política monetaria que afectan a la zona euro, por lo que mantienen sus legislaciones específicas para la ejecución de sus políticas monetarias. Asimismo, el BCE tiene personalidad jurídica propia conforme al derecho público internacional, mientras que cada uno de los $\mathrm{BCN}$ tiene personalidad jurídica propia según la legislación de su respectivo Estado miembro (apartado 1 del artículo 13 del TUE y apartado 3 del artículo 282 del TFUE).

El Eurosistema y el SEBC están gobernados por los órganos rectores del BCE (apartado 1 del artículo 129 del TFUE, artículos 43, 44 y 46 del SEBC y apartado 2 del artículo 141 del TFUE). En este sentido, el BCE ha contado tradicionalmente con tres órganos rectores: el Consejo de Gobierno, el Comité Ejecutivo y el Consejo General. Recientemente, el BCE ha asumido la tarea de supervisar a las entidades de crédito de los países miembros a través de un nuevo órgano rector para el correcto funcionamiento de esta tarea: el Consejo de Supervisión.

El Consejo de Gobierno del BCE es el responsable de formular la política monetaria en la zona euro, así como de adoptar las orientaciones y decisiones precisas que garanticen el cumplimiento de las funciones del Eurosistema (artículo 12.1 de los Estatutos del SEBC).

\footnotetext{
${ }^{4}$ Varios estudios indican que la independencia del Banco Central favorece el mantenimiento de la estabilidad de precios (Alesina, 1988; Grilli et al., 1991; Alesina y Summers, 1993; Arnone y Romelli, 2013).
} 
El Comité Ejecutivo del $\mathrm{BCE}$ es el responsable de ejecutar las decisiones de política monetaria tomadas por el Consejo de Gobierno y de la gestión diaria del BCE, a la vez que se encarga también de dar las instrucciones necesarias a los $\mathrm{BCN}$ de la zona euro (artículos 12.1 y 12.2 de los Estatutos del SEBC).

El Consejo General representa el nexo de unión entre los Estados miembros de la UE y los países de la zona euro, por lo que continuará existiendo mientras haya países de la UE que no hayan adoptado el euro. Su función principal, por tanto, es la de coordinar la política monetaria entre los países de la zona euro y el resto de países de la UE (artículos 43, 44 y 46 de los Estatutos del SEBC y apartado 2 del artículo 141 del TFUE).

El Consejo de Supervisión se ocupa de la planificación y ejecución de las funciones de supervisión asumidas por el BCE desde el 4 de noviembre de 2014 al entrar en vigor el Mecanismo Único de Supervisión (MUS), uno de los pilares de la Unión Bancaria ${ }^{5}$. Para evitar interferencias entre las funciones de política monetaria y las de supervisión, en la práctica se realiza una división operativa entre los distintos órganos.

La Figura 1.1 muestra un esquema del marco institucional y la organización de la política monetaria del BCE.

\footnotetext{
${ }^{5}$ La Unión Bancaria tiene como propósito que todos los bancos de la zona euro estén sujetos a las mismas normas, independientemente de su país de origen, con el fin de restaurar la confianza en el sector bancario y se articula en torno a tres pilares (Banco de España, 2014). El primer pilar, el Mecanismo Único de Supervisión, el único que ha entrado en vigor por el momento, se basa en el establecimiento del BCE como supervisor único para garantizar la seguridad y la solidez del sistema bancario. El segundo pilar, el Mecanismo Único de Resolución, pretende centralizar todas las decisiones y acciones que hagan posible la resolución ordenada de las entidades en dificultades a partir de unos criterios unificados. El tercer pilar, la Directiva sobre Sistemas de Garantía de Depósitos, establece una normativa común con el objetivo de mejorar la protección de los depósitos, mantener la confianza de los depositantes y fortalecer la red de seguridad.
} 
Figura 1.1: Marco institucional y organización de la política monetaria del BCE

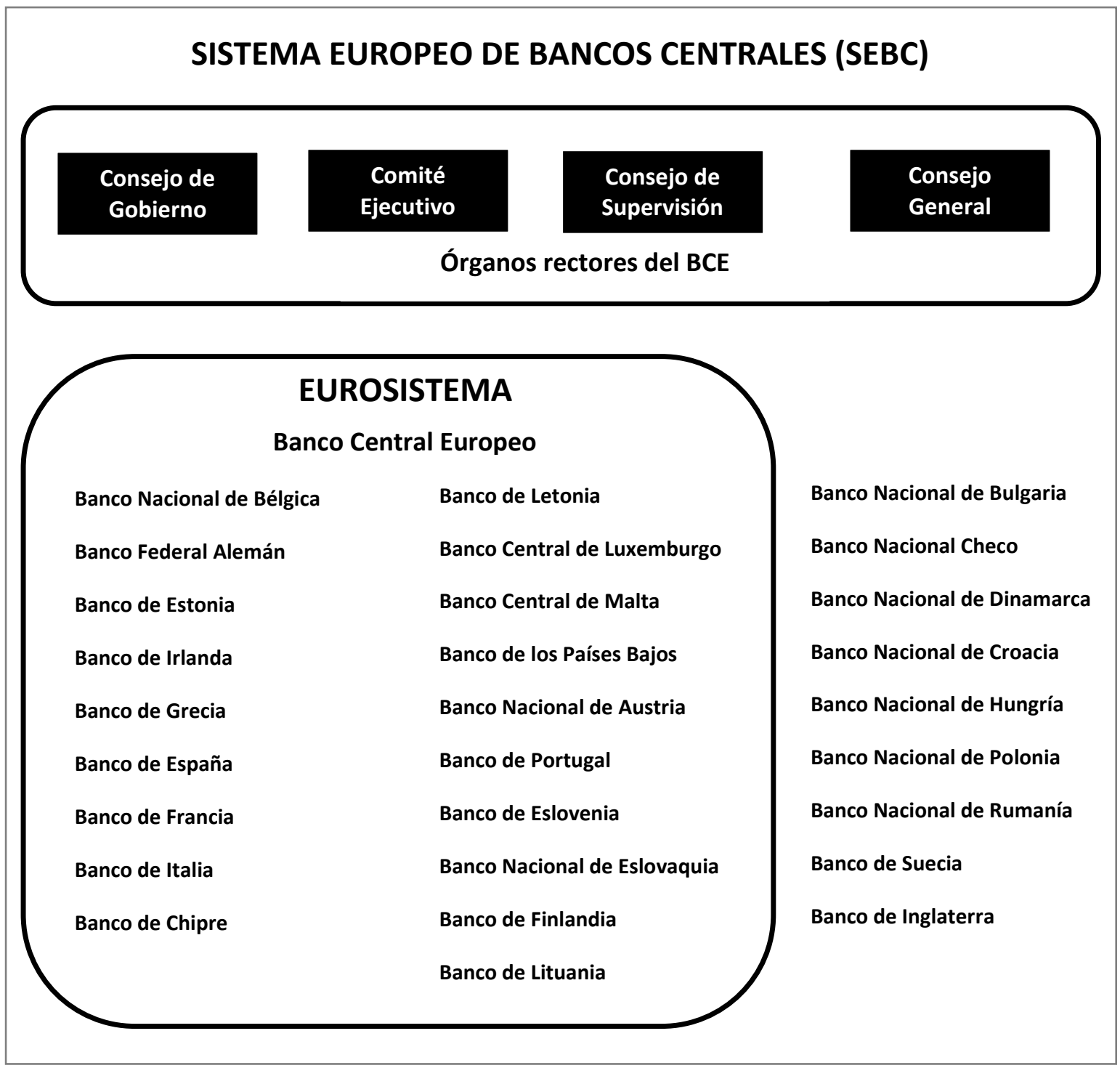

Fuente: adaptado del Informe Anual del Banco Central Europeo (2013).

\subsection{2.- Estrategia de política monetaria del BCE}

La estrategia de política monetaria del BCE se articula en torno a dos elementos principales. El primero de ellos consiste en una definición cuantitativa de la estabilidad de precios, es decir, hacer público un objetivo numérico para la tasa de inflación de toda la zona euro, la cual, como se mencionó anteriormente, ha de estar por debajo del $2 \%$ en el medio plazo, pero cercana a este valor para evitar la deflación (Banco Central Europeo, 2011a). 
El segundo de los elementos de la estrategia de política monetaria del BCE consiste en un análisis de los riesgos para la estabilidad de precios a través de dos pilares basados en dos perspectivas analíticas complementarias: el análisis económico y el análisis monetario (Banco Central Europeo, 2012c; 2013).

El primer pilar, el análisis económico, se encarga de evaluar los determinantes del comportamiento de los precios a corto y a medio plazo. Este análisis focaliza su interés en la actividad real y en la situación financiera de la economía, considerando la influencia que ejerce sobre los precios la interacción entre la oferta y la demanda en los mercados de bienes, servicios y factores. Se analizan indicadores de la economía real, la evolución de los mercados financieros y del tipo de cambio, así como las proyecciones macroeconómicas para la zona euro entre otros.

El segundo pilar, el análisis monetario, se basa en las relaciones entre el crecimiento monetario y la inflación a medio y largo plazo. Este enfoque se centra en el análisis de las tendencias monetarias, al tener en cuenta una amplia variedad de agregados monetarios, principalmente el M3 y sus componentes ${ }^{6}$, y realizar una evaluación pormenorizada del crédito y la liquidez.

La Figura 1.2 resume los principales elementos de la estrategia de política monetaria del BCE.

\footnotetext{
${ }^{6} \mathrm{El} \mathrm{M} 3$ y sus componentes hace referencia a tres agregados monetarios (M1, M2 y M3) que se diferencian en el grado de liquidez de los activos que incluyen. El M1 es un agregado estrecho que comprende el efectivo y los depósitos a la vista. El M2 es un agregado intermedio que incluye el M1, los depósitos a plazo hasta 2 años y los depósitos disponibles con previo aviso de 3 meses. El M3 se compone del M2, las cesiones temporales, las participaciones en fondos del mercado monetario e instrumentos del mercado monetario y los valores de renta fija de hasta 2 años, emitidos por las instituciones financieras monetarias.
} 
Figura 1.2: La estrategia de política monetaria del BCE

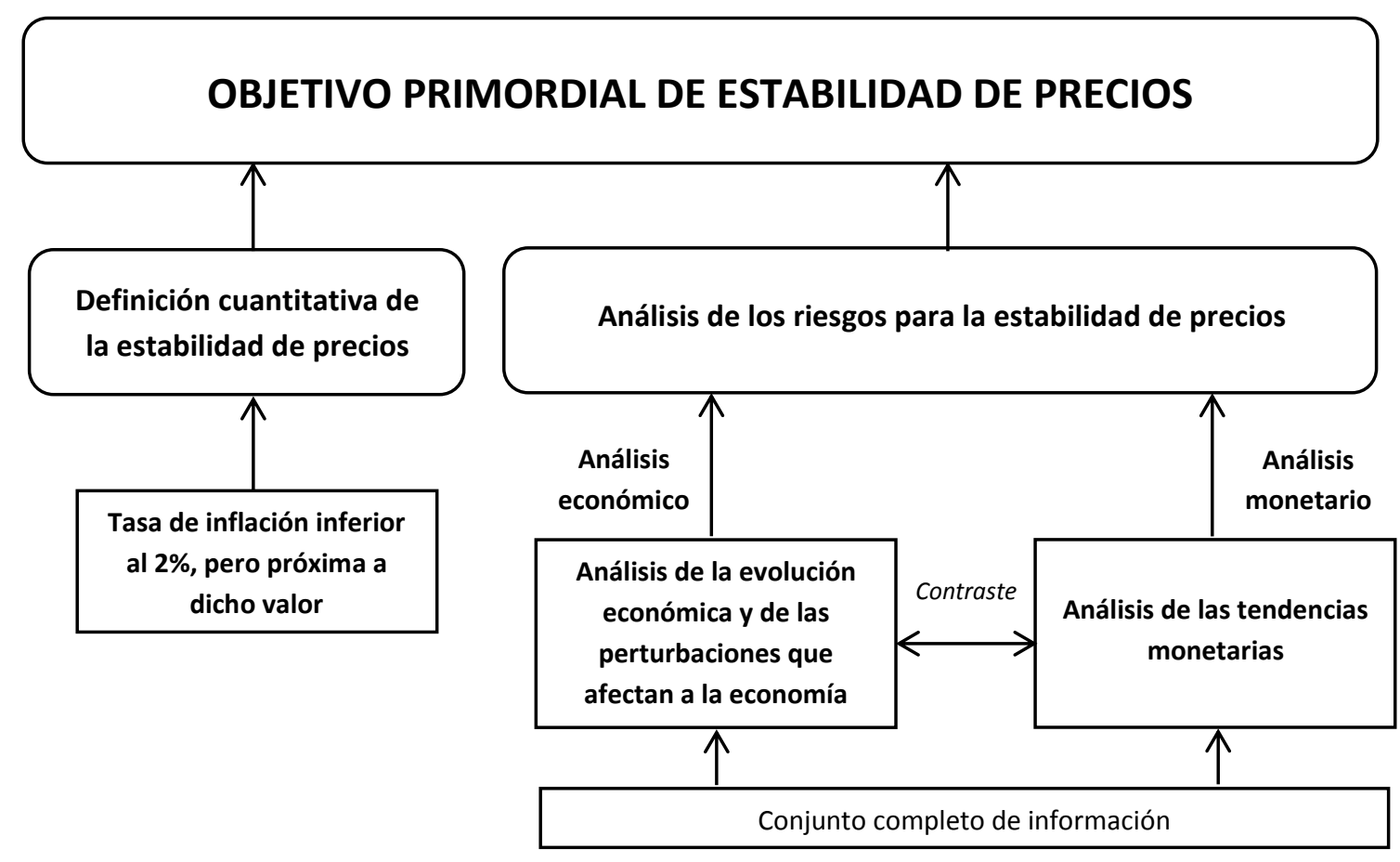

Fuente: adaptado del Banco Central Europeo (2011a).

\subsection{3.- Instrumentación de la política monetaria del BCE}

Para alcanzar el objetivo prioritario de mantener la estabilidad de precios en la zona euro, el BCE cuenta con tres tipos de instrumentos: las operaciones de mercado abierto, las facilidades permanentes y el sistema de reservas mínimas (Banco Central Europeo, 2011a).

\subsubsection{1.- Las operaciones de mercado abierto}

Las operaciones de mercado abierto sirven para controlar los tipos de interés, gestionar la situación de liquidez del mercado y orientar la política monetaria. Incluyen las operaciones principales de financiación (OPF), las operaciones de financiación a más largo plazo (OFPML), las operaciones de ajuste y las operaciones estructurales. 


\section{- Las operaciones principales de financiación (OPF)}

Las OPF constituyen el instrumento principal de política monetaria del BCE. Son operaciones temporales $^{7}$ de inyección regular de liquidez al sistema bancario ejecutadas cada semana y que, generalmente, tienen un plazo de una semana ${ }^{8}$. A través de las mismas, el BCE presta fondos a sus entidades de contrapartida, siempre y cuando éstas posean los activos de garantía exigidos. Las OPF se ejecutan mediante subastas estándar $^{9}$ que pueden ser a tipo de interés fijo o variable. En el primer caso, el tipo de interés es determinado previamente por el $\mathrm{BCE}$, mientras que en el segundo caso, las entidades de contrapartida pujan por el volumen de liquidez y el tipo de interés al que desean llevar a cabo la operación ${ }^{10}$.

\section{- Las operaciones de financiación a más largo plazo (OFPML)}

Las OFPML son operaciones temporales de financiación a más largo plazo, de periodicidad mensual y que normalmente tienen un vencimiento de 3 meses $^{11}$. Su objetivo es dotar de liquidez a más largo plazo al sistema bancario y facilitar el acceso a financiación a mayores plazos. Al igual que las OPF, las OFPML se realizan mediante subastas estándar, aunque éstas últimas se han ejecutado normalmente mediante subastas a tipo de interés variable.

\footnotetext{
${ }^{7}$ Las operaciones temporales son transacciones en las que el BCE compra o vende activos de garantía admitidos mediante cesiones temporales o efectúa operaciones de crédito empleando como garantía dichos activos.

${ }^{8}$ Antes del 10 de marzo de 2004 tenían un vencimiento de dos semanas.

${ }^{9}$ El término "estándar" indica que son operaciones realizadas de acuerdo a un calendario anunciado previamente y ejecutadas dentro de las 24 horas que median entre el anuncio de la subasta y la notificación del resultado.

${ }^{10}$ Desde principios de 1999 y hasta junio de 2000, las OPF se ejecutaron a través de subastas con tipos de interés fijo, mientras que a partir del 27 de junio de 2000 se realizaron con subastas de tipo de interés variable con un mínimo de puja, debido a las numerosas "sobrepujas" que se fueron produciendo en las OPF a tipo de interés fijo. A partir del 15 de octubre de 2008, las OPF se realizaron mediante subastas a tipo de interés fijo con adjudicación plena para reducir las disfuncionalidades observadas en los mercados monetarios por falta de liquidez de las entidades de crédito.

${ }^{11}$ El BCE puede, asimismo, realizar OFPML adicionales con otros vencimientos más largos. En este sentido y como veremos posteriormente, desde el estallido de la crisis los vencimientos de las OFPML se han ampliado.
} 


\section{- Las operaciones de ajuste}

Las operaciones de ajuste son operaciones de mercado abierto que no tienen periodicidad ni vencimiento normalizados. Pueden ser operaciones de absorción o de inyección de liquidez y su objetivo es regular la situación de liquidez del mercado monetario, así como controlar los tipos de interés para atenuar los efectos que en éstos causan las fluctuaciones inesperadas de liquidez en el mercado. Las operaciones de ajuste se realizan mediante subastas rápidas, en una hora, o mediante procedimientos bilaterales donde el BCE opera con un número limitado de entidades de contrapartida sin que exista subasta. Asimismo, se ejecutan principalmente como operaciones temporales, aunque también pueden realizarse bajo la forma de swaps de divisas o de captación de depósitos a plazo fijo.

\section{- Las operaciones estructurales}

Las operaciones estructurales tienen por objeto ajustar el volumen de liquidez disponible en el mercado en un plazo más largo. Pueden ser de absorción o de inyección de liquidez y poseer o no periodicidad regular. Asimismo, pueden realizarse mediante operaciones temporales, operaciones simples ${ }^{12}$ o mediante la emisión de certificados de deuda del $\mathrm{BCE}{ }^{13}$.

\subsubsection{2.- Las facilidades permanentes}

Las facilidades permanentes sirven para proporcionar y absorber liquidez a un día, señalar la orientación de la política monetaria, controlar los tipos de interés a corto plazo del mercado monetario y disminuir su volatilidad. Existen dos tipos de facilidades permanentes que el BCE ofrece a sus entidades de contrapartida: la facilidad marginal

\footnotetext{
${ }^{12}$ El Eurosistema realiza compras o ventas simples de activos admitidos en el mercado.

${ }^{13}$ Las operaciones temporales y las emisiones de certificados de deuda se realizan normalmente mediante subastas estándar y las operaciones simples mediante convenios bilaterales.
} 
de crédito, mediante la cual éstas pueden obtener financiación de los $\mathrm{BCN}$, y la facilidad de depósito, por la que las entidades financieras suelen realizar depósitos en los BCN. Ambas son facilidades a un día y las entidades que operan con el BCE pueden recurrir a ellas por iniciativa propia. Los tipos de interés de estas facilidades suponen un límite máximo y mínimo al tipo de interés del mercado interbancario a un día.

\subsubsection{3.- El sistema de reservas mínimas}

El sistema de reservas mínimas consiste en exigir a las entidades de crédito de la zona euro el mantenimiento de un porcentaje mínimo del pasivo de su balance como reservas en los $\mathrm{BCN}^{14}$, con el fin de estabilizar los tipos de interés del mercado monetario y ampliar el déficit estructural de liquidez del sistema interbancario. Las entidades deben cumplir el porcentaje de reservas mínimas como promedio mensual de los saldos diarios de liquidez que tengan en los $\mathrm{BCN}$, por lo que pueden registrar déficits y superávits diarios de liquidez.

La Tabla 1.1 recoge un resumen de las principales características de los instrumentos de política monetaria con los que cuenta el BCE.

\footnotetext{
${ }^{14}$ Desde 1999 hasta 2011 dicho porcentaje fue de un 2\%. Sin embargo, en diciembre de 2011 el BCE decidió reducir el coeficiente mínimo de reservas del $2 \%$ al $1 \%$ como medida de apoyo al crédito.
} 
Tabla 1.1: Instrumentos de política monetaria del BCE

\begin{tabular}{|c|c|c|c|c|}
\hline \multirow[b]{2}{*}{ Instrumentos } & \multicolumn{2}{|c|}{ Tipo de operación } & \multirow[b]{2}{*}{ Vencimiento } & \multirow[b]{2}{*}{ Periodicidad } \\
\hline & $\begin{array}{l}\text { Inyección de } \\
\text { liquidez }\end{array}$ & $\begin{array}{l}\text { Absorción de } \\
\text { liquidez }\end{array}$ & & \\
\hline \multicolumn{5}{|c|}{ Operaciones de mercado abierto } \\
\hline $\begin{array}{l}\text { Operaciones } \\
\text { principales de } \\
\text { financiación }(O P F)\end{array}$ & $\begin{array}{l}\text {-Operaciones } \\
\text { temporales }\end{array}$ & - & Una semana & Semanal \\
\hline $\begin{array}{l}\text { Operaciones de } \\
\text { financiación a plazo } \\
\text { más largo (OFPML) }\end{array}$ & $\begin{array}{l}\text {-Operaciones } \\
\text { temporales }\end{array}$ & - & Tres meses $(a)$ & Mensual \\
\hline Operaciones de ajuste & $\begin{array}{l}\text {-Operaciones } \\
\text { temporales } \\
\text {-Swaps de } \\
\text { divisas }\end{array}$ & $\begin{array}{l}\text {-Operaciones } \\
\text { temporales } \\
\text {-Depósitos a } \\
\text { plazo fijo } \\
\text {-Swaps de } \\
\text { divisas }\end{array}$ & Sin normalizar & No regular \\
\hline $\begin{array}{l}\text { Operaciones } \\
\text { estructurales }\end{array}$ & $\begin{array}{l}\text {-Operaciones } \\
\text { temporales } \\
\text {-Compras } \\
\text { simples }\end{array}$ & $\begin{array}{l}\text {-Emisión de } \\
\text { certificados de } \\
\text { deuda del } \\
\text { BCE } \\
\text {-Ventas } \\
\text { simples }\end{array}$ & $\begin{array}{l}\text { Normalizado/sin } \\
\text { normalizar }\end{array}$ & $\begin{array}{l}\text { Regular/ no } \\
\text { regular } \\
\text { No regular }\end{array}$ \\
\hline \multicolumn{5}{|c|}{ Facilidades permanentes } \\
\hline $\begin{array}{l}\text { Facilidad marginal de } \\
\text { crédito }\end{array}$ & $\begin{array}{l}\text {-Operaciones } \\
\text { temporales }\end{array}$ & - & -Un día & $\begin{array}{l}\text {-Acceso a } \\
\text { discreción de } \\
\text { las entidades } \\
\text { de } \\
\text { contrapartida }\end{array}$ \\
\hline Facilidad de depósito & - & -Depósitos & -Un día & $\begin{array}{l}\text {-Acceso a } \\
\text { discreción de } \\
\text { las entidades } \\
\text { de } \\
\text { contrapartida }\end{array}$ \\
\hline \multicolumn{5}{|c|}{ Sistema de reservas mínimas } \\
\hline $\begin{array}{l}\text { Consiste en exigir a } \\
\text { porcentaje. Su cumpli } \\
\text { base de reservas. }\end{array}$ & $\begin{array}{l}\text { entidades que } \\
\text { nto es como }\end{array}$ & io mensual & Dalle cent & $\begin{array}{l}\mathrm{r} \text { valor de un } \\
\text { función de la }\end{array}$ \\
\hline
\end{tabular}

(a) Durante la crisis el vencimiento de estas operaciones se ha ampliado por encima de tres meses.

Fuente: adaptado del Banco Central Europeo (2011a).

\section{3.- CANALES DE TRANSMISIÓN DE LA POLÍTICA MONETARIA}

Una vez explicado el funcionamiento de la política monetaria del BCE, en este epígrafe se presentan los distintos canales por los que las decisiones de política monetaria afectan a la economía, en general, y al nivel de precios en particular. 
La transmisión de las decisiones de política monetaria a la economía real se produce a través de cinco canales básicos (Mishkin, 1995): canal de tipos de interés, canal de tipo de cambio, canal de precios de los activos, canal de las expectativas y canal de crédito. Los cuatro primeros son considerados los canales tradicionales de transmisión de la política monetaria y tienen en común que no consideran la existencia del sector financiero. En cambio, el quinto, referente al canal de crédito y objeto de estudio de esta tesis doctoral, considera que el sector financiero desempeña un papel crucial en el mecanismo de transmisión de la política monetaria, al amplificar los efectos de los canales tradicionales (Bernanke y Blinder, 1988).

\subsection{1.- Canales tradicionales}

Los canales tradicionales de transmisión de la política monetaria incluyen, como comentamos anteriormente, el canal de tipos de interés, el canal de tipo de cambio, el canal del precio de los activos y el canal de las expectativas. A continuación explicamos cada uno de estos canales.

En primer lugar, el canal de tipos de interés es el mecanismo más convencional de la literatura económica y el que se utiliza como marco general para representar el efecto conjunto de todos los canales. En virtud del mismo, una política monetaria restrictiva que incrementa los tipos de interés oficiales, trae consigo un aumento de los tipos de interés nominales a corto plazo de los mercados financieros. Este hecho hace que, como consecuencia de la existencia de rigideces en los precios, el tipo de interés real a largo plazo también se eleve. Puesto que los tipos de interés reales son una medida del coste financiero de la inversión empresarial y el gasto de los hogares, una subida de los mismos generará una caída en la inversión de capital fijo, la inversión residencial y el consumo duradero y no duradero. Dicha caída se traducirá en una disminución de la demanda agregada, la producción real y los precios (Mishkin, 1995). 
En segundo lugar, el canal de tipo de cambio es un mecanismo cuya importancia depende del grado de apertura externa de una economía al comercio internacional, en particular del grado de integración financiera con el exterior o grado de movilidad del capital. Bajo un régimen de tipo de cambio flexible, variaciones en los tipos de interés originan modificaciones en el tipo de cambio (Menon, 1995). En este sentido, un incremento del tipo de interés nacional, tras una política monetaria contractiva, hace que los depósitos en moneda nacional se vuelvan más atractivos en relación a los depósitos en moneda extranjera. Este hecho provoca una apreciación de la moneda nacional y encarece el precio de los bienes nacionales en comparación con los extranjeros, desembocando en una caída de las exportaciones netas, la producción agregada y los precios (Taylor, 1995; Obstfeld y Rogoff, 1995).

En tercer lugar, el canal de precios de los activos se centra en los efectos que la política monetaria tiene sobre el precio de otros activos distintos a los tipos de interés o el tipo de cambio, y se compone de dos vías a la hora de explicar el proceso de transmisión monetaria. La primera vía, la teoría de la $q$ de Tobin (1969), aporta un mecanismo por el que la política monetaria afecta a la economía a través de sus efectos en los títulos de renta variable de las empresas ${ }^{15}$. Así, una subida de tipos de interés, fruto de una política monetaria restrictiva, hace que los bonos se vuelvan más atractivos en relación a los títulos de renta variable, provocando una bajada del precio de las acciones de las empresas. Ante esta situación, el valor de mercado de las empresas, y por tanto la $q$ de Tobin, se reducirá, lo que provocará un descenso de la inversión empresarial, el nivel de producción y los precios. La segundo vía, la teoría del “ciclo de

\footnotetext{
${ }^{15}$ La $q$ de Tobin es el cociente entre el valor de la empresa en el mercado bursátil y el coste de reposición del capital (Tobin, 1969). Si la $q$ es alta, el valor de mercado de la empresa es elevado en relación con el coste de reposición del capital, por lo que adquirir nuevas instalaciones y bienes de equipo es barato en relación con el valor de mercado de la empresa, lo que hace que la inversión aumente. En cambio, si la $q$ es baja las empresas no tienen incentivos a realizar nuevas inversiones, ya que su valor de mercado es pequeño en relación a su coste de reposición del capital.
} 
vida” de Modigliani (1971), afirma que el consumo está determinado por los recursos que los agentes económicos esperan generar a lo largo de su vida. En este sentido, una política monetaria restrictiva provoca una reducción del precio de las acciones, traduciéndose en una disminución de la riqueza financiera de los agentes que las poseen y, por tanto, de su gasto en consumo. Este menor gasto en consumo origina, en última instancia, una disminución en la producción agregada y los precios de la economía.

En cuarto lugar, el canal de las expectativas refleja la influencia ejercida por la comunicación de la política monetaria en la formación de expectativas inflacionistas de los agentes económicos (Woodford, 1999; Sack y Wieland, 2000). Para que el canal de las expectativas favorezca la transmisión monetaria, resulta crucial que la política monetaria goce de un alto grado de credibilidad, ya que será la que configure las expectativas de los agentes sobre la evolución futura de la actividad y los precios. Este canal es difícil de cuantificar, pero es relevante puesto que condiciona las decisiones de gasto de los agentes y la formación de precios en la economía (Berben et al., 2004) ${ }^{16}$.

\subsection{2.- El canal de crédito}

Los canales tradicionales han suscitado la crítica de algunos autores, al prescindir de la existencia del sector financiero. La realidad de que las instituciones financieras desempeñan una importante labor en la transmisión de la política monetaria como nexo entre las decisiones del Banco Central y la actividad económica, ha dado lugar a un quinto canal de transmisión de la política monetaria: el canal de crédito ${ }^{17}$. El estudio de este canal se desagrega principalmente en tres versiones: el canal de hojas de balance, el canal de préstamos bancarios y el canal de crédito comercial.

\footnotetext{
${ }^{16}$ En realidad, el canal de las expectativas es un mecanismo que está presente en el resto de canales, pero, dada su importancia, en la literatura se ha considerado como un canal adicional.

${ }^{17}$ Este canal no es un mecanismo paralelo o independiente al resto de canales, sino que amplifica los efectos de los canales tradicionales (Bernanke y Gertler, 1995).
} 
En primer lugar, el canal de hojas de balance (balance sheet channel) analiza los efectos que la política monetaria tiene sobre la situación financiera de las empresas (Bernanke y Gertler, 1995). Por un lado, una política monetaria restrictiva que eleva los tipos de interés, produce un descenso del valor de los activos que pueden utilizarse como colateral en las operaciones crediticias. Por otro lado, una subida de tipos de interés, a raíz de una restricción monetaria, aumenta los gastos financieros de las empresas y reduce sus flujos de caja. En este escenario, los prestamistas se verán incentivados a exigir mayores tipos de interés por los préstamos concedidos, pudiendo incluso restringir la oferta de crédito. El empeoramiento de las condiciones de financiación de las empresas hará que reduzcan sus actividades de inversión, lo cual tendrá efectos sobre la producción agregada y el nivel de precios.

En segundo lugar, el canal de préstamos bancarios (bank lending channel) parte de la perspectiva de las entidades financieras, por su destacado papel como oferentes de crédito (Bernanke y Blinder, 1988). Por un lado, una política monetaria restrictiva que aumenta el coeficiente mínimo de reservas que las entidades deben poseer en el Banco Central, hace que se reduzca la base de depósitos para poder satisfacer las nuevas exigencias de reservas (Kashyap y Stein, 1995a; Walsh, 2003). Por otro lado, una política monetaria contractiva que eleva los tipos de interés, hace que los depósitos se vuelvan menos atractivos en comparación con otros activos, lo que provoca que los depositantes retiren sus fondos en busca de otras oportunidades de inversión más rentables (Kishan y Opiela, 2000; Ehrmann et al., 2003). Asimismo, una subida de tipos de interés como consecuencia de una restricción monetaria, encarece el coste que tiene para los bancos la financiación vía mercados (Bernanke, 2007; Disyatat, 2011). Dado que los depósitos bancarios y la financiación vía mercados constituyen una fuente de fondos para los bancos, una disminución de éstos hará que los bancos restrinjan su 
oferta crediticia. La reducción de préstamos limitará las actividades de inversión de las empresas, principalmente de aquellas que más dependan de la financiación bancaria, lo cual impactará sobre la producción agregada de la economía y, en última instancia, sobre el nivel de precios.

En tercer lugar, el canal de crédito comercial (trade credit channel) subraya el destacado papel que juega el crédito comercial como fuente de financiación alternativa al crédito bancario. En virtud de este canal, una restricción monetaria provoca un aumento del volumen de crédito comercial para contrarrestar la disminución del crédito bancario, es decir, las empresas menos vulnerables financieramente redistribuyen fondos mediante la extensión de créditos comerciales a las empresas más débiles y con más problemas para acceder a los préstamos bancarios (Meltzer, 1960; Kohler et al., 2000; Mateut et al., 2006). De esta manera, al compensar la bajada de préstamos con crédito comercial, las empresas pueden proteger mejor sus actividades de inversión, suavizando así los efectos que las restricciones monetarias tienen sobre la economía real y los precios (Mateut, 2005).

En el contexto del canal de crédito, el canal de préstamos bancarios (bank lending channel) y el canal de crédito comercial (trade credit channel) son objeto de análisis de los capítulos 2 y 3 respectivamente de esta tesis doctoral.

La Figura 1.3 muestra un esquema del funcionamiento de los canales de transmisión de la política monetaria explicados anteriormente. 
Figura 1.3: Canales de transmisión de la política monetaria

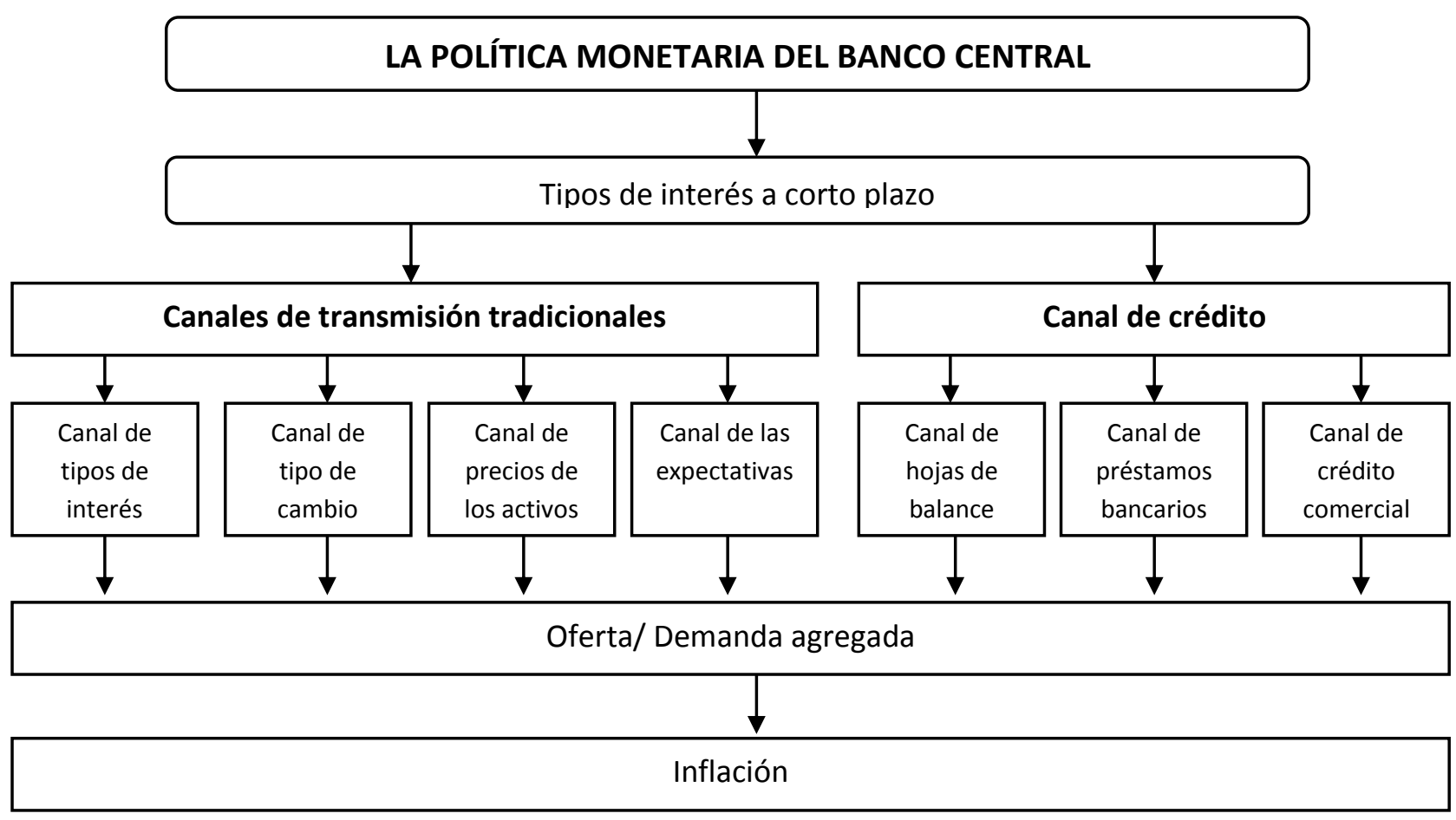

Fuente: elaboración propia.

\section{4.- RIESGO SOBERANO Y POLÍTICA MONETARIA}

El riesgo soberano hace referencia a la posible incapacidad de un país para hacer frente a sus obligaciones de pago (Cantor y Packer, 1996; García-Gámez y VicénsOtero, 2006; Haddad y Hakim, 2007) ${ }^{18}$. Su estudio ha despertado recientemente un profundo y renovado interés en Europa a raíz de la crisis y varios trabajos han examinado la influencia que ejerce el riesgo soberano sobre el riesgo de crédito y los costes de financiación de los bancos.

Por lo que respecta al riesgo de crédito de los bancos, Goldman Sachs (2010) revela que en los años de crisis de deuda en la zona euro, los CDS (Credit Default

\footnotetext{
${ }^{18}$ Puesto que el riesgo soberano ejerce un impacto significativo sobre la economía y las posibilidades de crecimiento de los países, diversos trabajos han analizado la influencia que tiene el mismo sobre distintas variables económicas. Por ejemplo, algunos trabajos encuentran que el riesgo soberano afecta negativamente a la inversión directa extranjera que reciben los países (Schnitzer, 1999; 2002; Reinhart y Rogoff, 2004; Maliar et al., 2008; Chen et al., 2014), mientras que otros estudios indican que un mayor riesgo soberano acorta los vencimientos de los bonos de deuda pública (Xie et al., 2009; Lee et al., 2011; Broner et al., 2013) y reduce la rentabilidad de las acciones en los mercados bursátiles (Brooks et al., 2004; Ferreira y Gama, 2007; Hooper et al., 2008; Arnold, 2012; Chan-Lau et al., 2014).
} 
Swap) bancarios están positivamente correlacionados con los CDS soberanos de sus respectivos países. Asimismo, Demirgüç-Kunt y Huizinga (2013) encuentran que durante la crisis financiera, el incremento de la prima de los CDS de los bancos responde significativamente al deterioro de las finanzas públicas. De Bruyckere et al. (2013), a partir de una muestra de entidades europeas durante 2007-2012, indican que un aumento del riesgo soberano se traduce en un aumento del riesgo bancario, especialmente para los bancos que llevan a cabo menos actividades bancarias tradicionales, que tienen menores niveles de capital y una estructura de financiación más débil. Bessler y Kurmann (2014) con una muestra de bancos comerciales de Estados Unidos y Europa, revelan que durante la crisis, el riesgo soberano ha sido uno de los principales determinantes del riesgo sobre los rendimientos de las acciones de los bancos. Asimismo, varios trabajos encuentran que una reducción del rating de un país, fruto de un mayor riesgo soberano, incide negativamente sobre el rating de los bancos nacionales, incrementando su riesgo de crédito (Arezki et al., 2011; Williams et al., 2013; Adelino y Ferreira, 2014; Alsakka et al., 2014).

En relación a los costes de financiación de los bancos, Popov y van Horen (2013) aprecian que un mayor riesgo soberano afecta negativamente a los títulos de deuda pública que mantienen las entidades europeas en sus balances, lo que incrementa sus costes de financiación. Del mismo modo, Bofondi et al. (2013) muestran que el riesgo soberano en Italia provoca un aumento de los costes de financiación de los bancos del país $^{19}$. Babihuga y Spaltro (2014), a partir de una muestra internacional de bancos, señalan al riesgo soberano como uno de los principales factores que explican el incremento de los costes de financiación de los bancos.

\footnotetext{
${ }^{19}$ Otros trabajos centrados en los bancos italianos obtienen un resultado similar (Zoli, 2013; Del Giovane et al., 2013; Albertazzi et al., 2014).
} 
El riesgo soberano no sólo afecta a los bancos sino también al riesgo de crédito y las condiciones de financiación de las empresas nacionales. Así, Borenzstein et al. (2013) muestran que una disminución del rating soberano incrementa el riesgo de crédito de las empresas no financieras del país al reducir su calificación de rating. Por su parte, Bedendo y Colla (2013) y Corsetti et al. (2013) reflejan que el riesgo soberano, a través de su influencia sobre el riesgo de crédito, incrementa los costes de financiación del sector empresarial. En la misma línea, Klein y Stellner (2014) encuentran que en los años de crisis el riesgo de crédito del sector privado empresarial en Europa se ha visto fuertemente condicionado por el riesgo soberano. A su vez, varios estudios muestran que el riesgo soberano incrementa el coste que soportan las empresas no financieras a la hora de emitir bonos en el mercado (Eichengreen y Moody, 2000; Fostel y Kaminsky, 2007; Cavallo y Valenzuela, 2010; Díaz et al., 2013; Pianeselli y Zaghini, 2014). Broner et al. (2014) revelan que durante la crisis de deuda en Europa, el riesgo soberano ha producido un fuerte incremento de los costes de financiación del sector empresarial.

\subsection{1.- Influencia del riesgo soberano sobre el canal de crédito de la política monetaria}

Tal y como se ha mostrado anteriormente, trabajos recientes de riesgo soberano apuntan a que éste afecta negativamente a la calidad crediticia y a las condiciones de financiación de los bancos y las empresas del país. En lo que respecta a los bancos, el empeoramiento de sus condiciones financieras, causado por un mayor riesgo soberano, ha podido repercutir negativamente sobre su oferta de préstamos, alterando así el mecanismo de transmisión de la política monetaria a través del canal de crédito explicado en el epígrafe anterior. Sin embargo, a pesar de la importancia que esta cuestión puede suponer, no existen apenas trabajos en la literatura que analicen los efectos del riesgo soberano sobre la transmisión de la política monetaria vía canal de 
crédito. Puesto que dicho canal es objeto de estudio en esta tesis, a continuación se realiza un análisis descriptivo de la posible influencia que el riesgo soberano puede tener sobre el canal de crédito de la política monetaria de la zona euro para, en los siguientes capítulos, examinar con más detalle dicha influencia mediante dos análisis empíricos.

Durante la crisis, el riesgo soberano ha afectado a los costes de financiación de los bancos vía depósitos, tal y como se oberva en la Figura 1.4. Ésta recoge la evolución de los tipos de interés sobre los depósitos bancarios de los hogares y empresas no financieras.

Figura 1.4: Evolución de los tipos de interés (\%) sobre depósitos bancarios de hogares y empresas

Figura 1.4a: Todos los depósitos

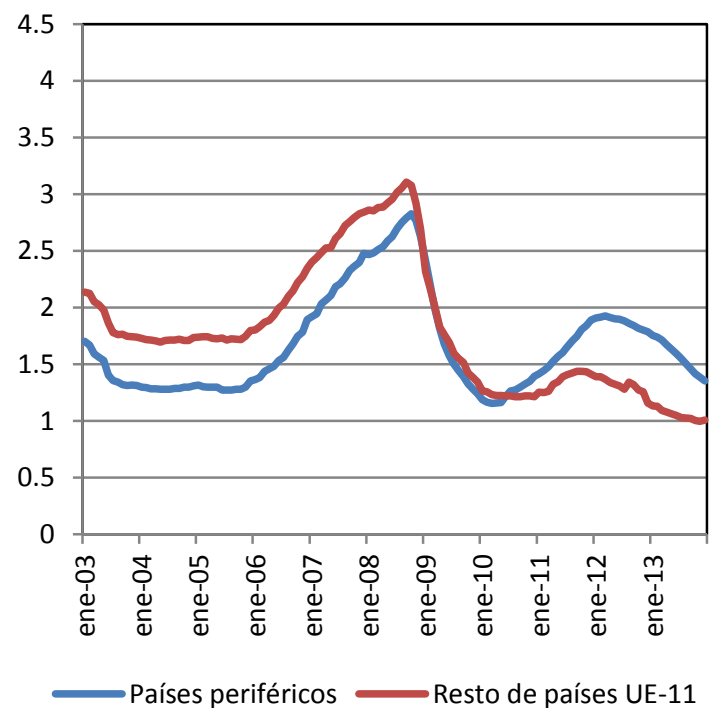

Figura 1.4b: Depósitos a plazo

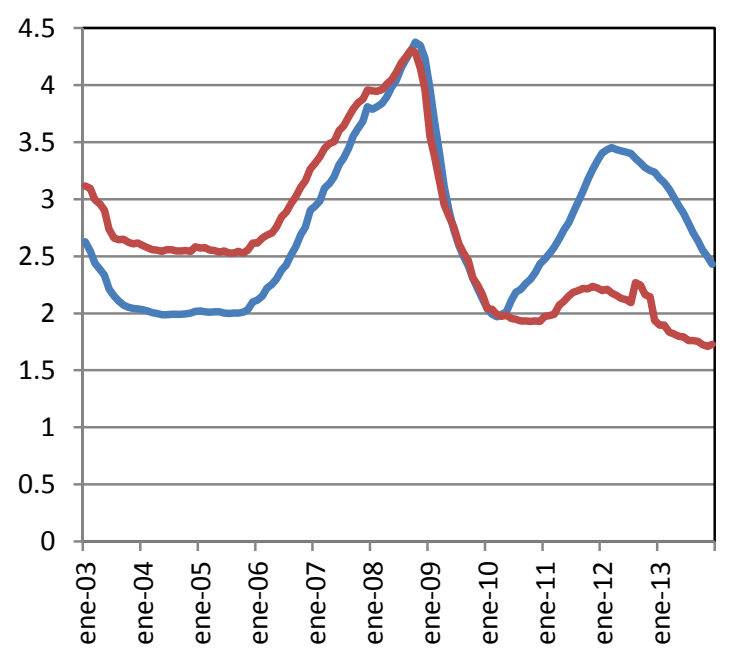

Países periféricos Resto de países UE-11

Datos mensuales promedio ponderado para cada grupo de países. Países periféricos: Portugal, Irlanda, Italia, Grecia y España. Resto de países UE-11: Alemania, Austria, Bélgica, Finlandia, Francia, Holanda y Luxemburgo. (Figura 1.4a): Incluye depósitos a la vista y depósitos a plazo.

Fuente: elaboración propia a partir de datos del BCE. 
En los años de crisis, todos los bancos han experimentado notables presiones financieras, sin embargo, los países de la periferia, que son los que tienen un mayor nivel de riesgo soberano, han soportado mayores tipos de interés a la hora de captar depósitos, principalmente a plazo (véase Figura 1.4b). Las diferencias en el coste de los depósitos entre países periféricos y el resto de países de la UE-11 son más pronunciadas a partir de 2010, coincidiendo con el inicio de la crisis de deuda soberana. Esto refleja la mayor rentabilidad exigida por los depositantes para compensar el aumento del riesgo soberano y, también indica que los bancos se vieron forzados a ofrecer condiciones más atractivas para atraer depósitos y contrarrestar la reducción de financiación vía mercado que trajo consigo el aumento del riesgo soberano.

El riesgo soberano no sólo ha impactado sobre los costes de financión vía depósitos de los bancos, sino también sobre los costes de su financiación en los mercados financieros. La Figura 1.5a muestra la evolución de los costes de financiación en los mercados mayoristas a través de la prima sobre los CDS (Credit Default Swap) de los principales bancos de varios países de la zona euro según el volumen de activos. Concretamente, se comparan los CDS de los bancos con mayor activo de los países más afectados por el riesgo soberano (Portugal, Irlanda, Italia, Grecia y España) con el CDS del banco con mayor activo de Alemania (el país con el nivel de riesgo soberano más bajo de la zona euro). La prima sobre los CDS se incrementó para todos los bancos analizados a partir de 2010, sin embargo, los aumentos han sido mucho más notorios para los bancos de los países con mayor nivel de riesgo soberano. A su vez, la Figura $1.5 \mathrm{~b}$ refleja la correlación entre el CDS de cada uno de los bancos analizados y el CDS soberano de su respectivo país durante 2009-2012. Dicha correlación fue mucho más alta en los países con mayor riesgo soberano en comparación con Alemania, reflejando 
que el acceso a financiación mayorista de los bancos de estos países ha estado más condicionado por el nivel de riesgo soberano de su país de origen.

Figura 1.5: Evolución de los costes de financiación de los bancos en los mercados

\section{mayoristas}

Figura 1.5a: Prima del CDS bancario sobre bonos senior a 5 años

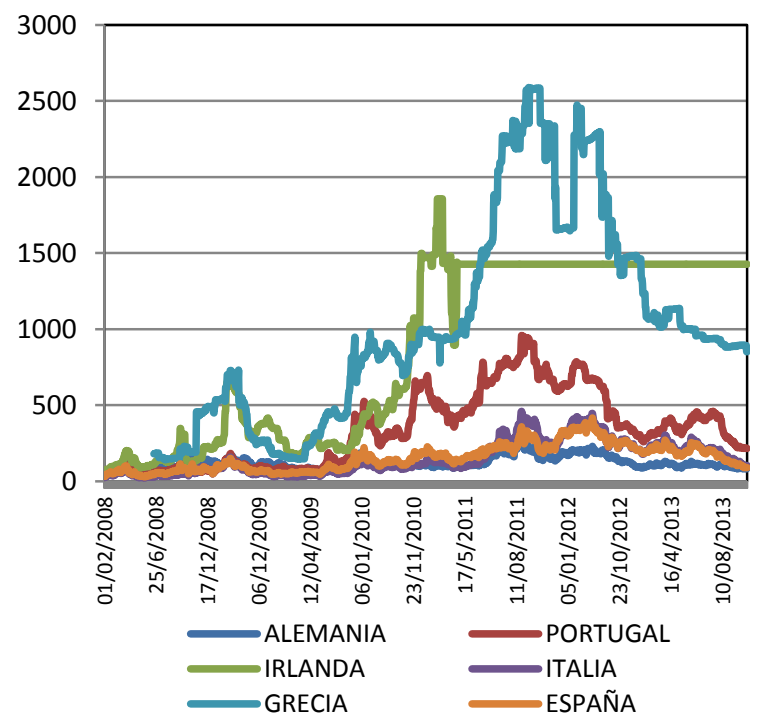

Figura 1.5b: Correlación (\%) entre el CDS soberano y bancario

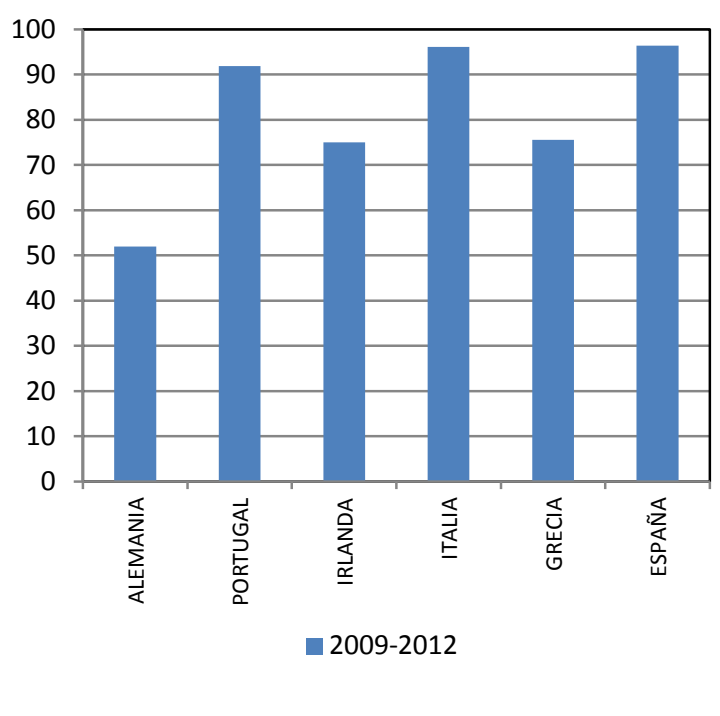

Se han seleccionado las principales entidades bancarias de cada país, en función del volumen de sus activos, para las que se cuenta con datos suficientes en la base de datos Datastream. Entidades bancarias seleccionadas: Deutsche Bank (Alemania), Novo Banco (Portugal), Allied Irish Bank (Irlanda), Intesa Sanpaolo (Italia), Alpha Bank (Grecia) y Banco Santander (España).

Fuente: elaboración propia a partir de datos de Datastream.

Por otro lado, el deterioro de las condiciones de financiación de los bancos, provocado por el riesgo soberano, ha podido obligarles a incrementar sus reservas de liquidez, por precaución, para protegerse contra posibles restricciones de financiación. En este sentido, la Figura 1.6 muestra la evolución de la proporción media de liquidez sobre activos de la banca de varios países. En general, la banca de todos los países ha incrementado sus reservas de liquidez durante la crisis. No obstante, dicho incremento ha sido más pronunciado en varios países con elevado riesgo soberano como Portugal, Irlanda y España (véase Figuras 1.6a, 1.6b, 1.6c y 1.6d). 
Figura 1.6: Evolución de la proporción de liquidez mantenida por las entidades de crédito

Figura 1.6a: Resto de países UE-11

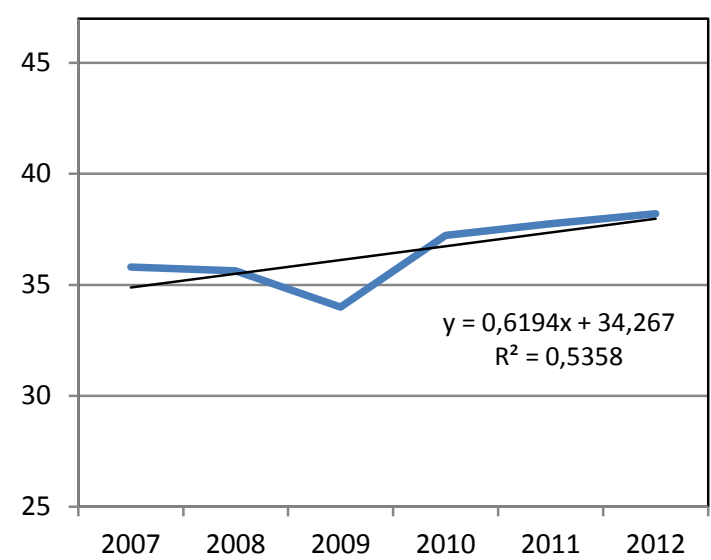

Figura 1.6c: Irlanda

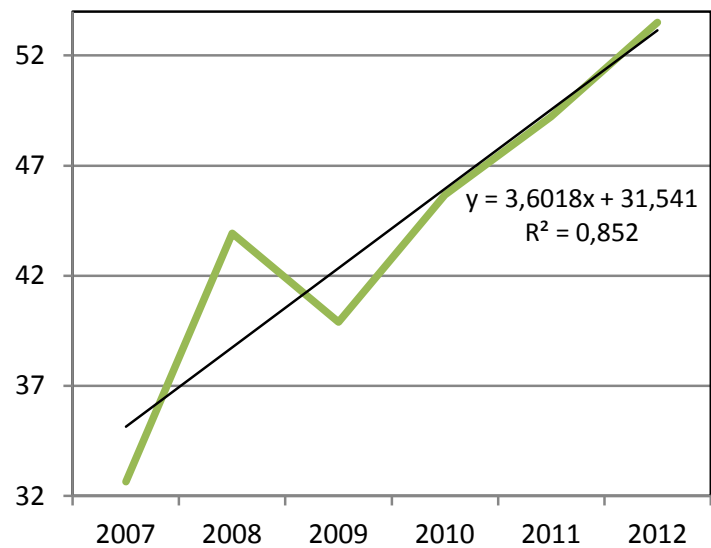

Figura 1.6e: Italia

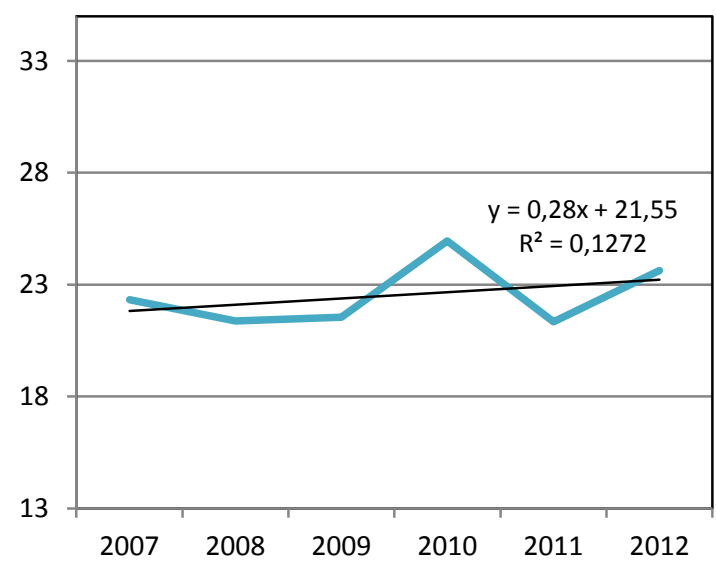

Figura 1.6b: Portugal

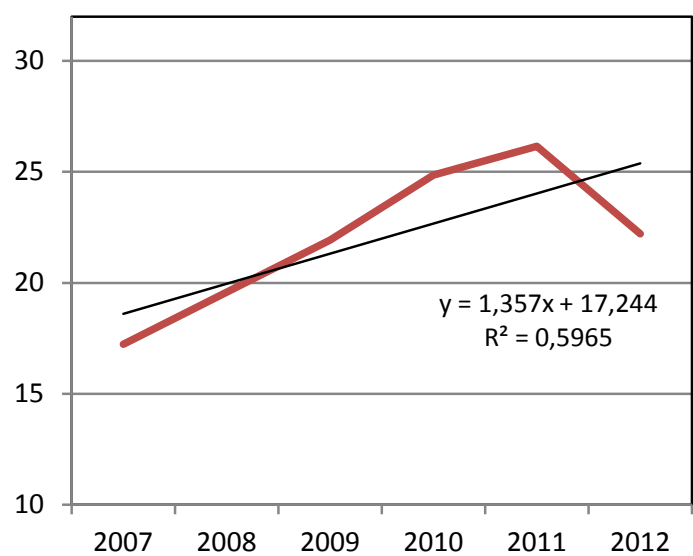

Figura 1.6d: España

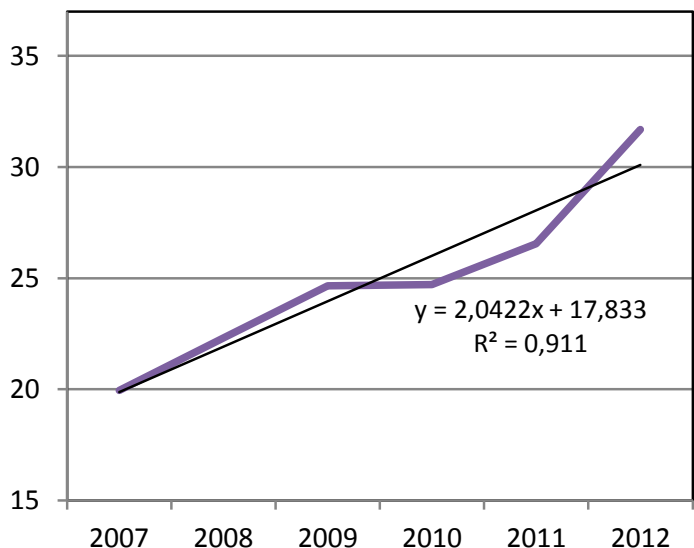

Figura 1.6f: Grecia

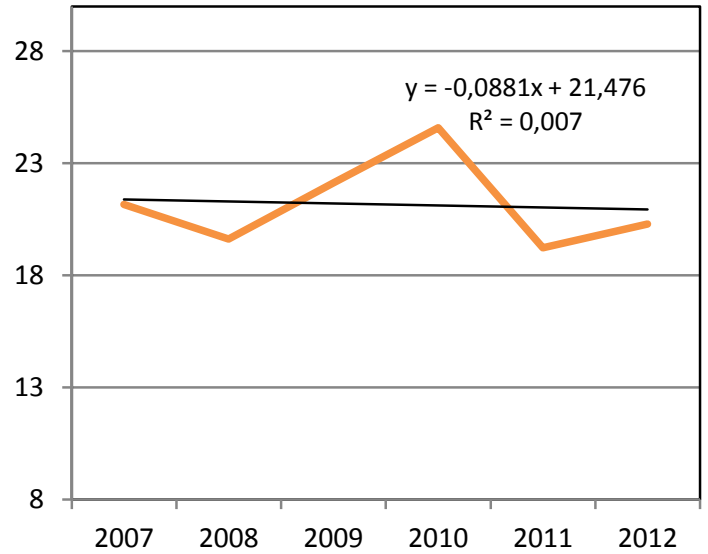

El eje vertical representa la proporción media anual de liquidez sobre el total activo (\%) ponderada por el tamaño de las entidades de crédito de cada país. Muestra de 22.191 entidades. (Figura 1.6a): Resto de países UE-11: Alemania, Austria, Bélgica, Finlandia, Francia, Holanda y Luxemburgo.

Fuente: elaboración propia a partir de datos de BankScope. 
Sin embargo, no todos los países con elevado riesgo soberano se han visto afectados por este hecho. Así, los bancos italianos no aumentan tanto su liquidez, probablemente debido a que el riesgo soberano en Italia se incrementó en menor medida y de forma más tardía que en los países anteriores (véase Figura 1.6e). Por su parte, los bancos griegos apenas han modificado su liquidez (véase Figura 1.6f), lo cual puede deberse a que el Banco Central griego empleó el paquete de rescate y la liquidez proporcionada por el Eurosistema para impulsar el crédito interno y retrasar así la recesión (Tornell y Westermann, 2011).

Los efectos del riesgo soberano sobre los costes de financiación y la liquidez de las entidades de crédito han podido repercutir en el volumen de los préstamos bancarios concedidos. La Figura 1.7 muestra la relación entre el riesgo soberano y el crecimiento de la concesión de préstamos bancarios a hogares y empresas no financieras.

Figura 1.7: Relación entre el riesgo soberano y el crecimiento de los préstamos concedidos

Figura 1.7a: Gráfico de dispersión entre la prima de riesgo y el crecimiento del crédito concedido

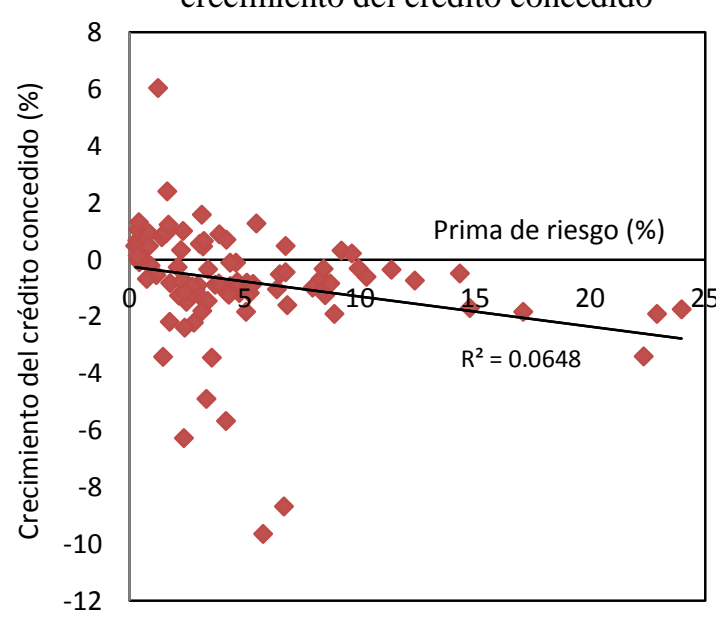

Figura 1.7b: Gráfico de dispersión entre la prima de riesgo y el crecimiento del crédito concedido: Países periféricos vs.

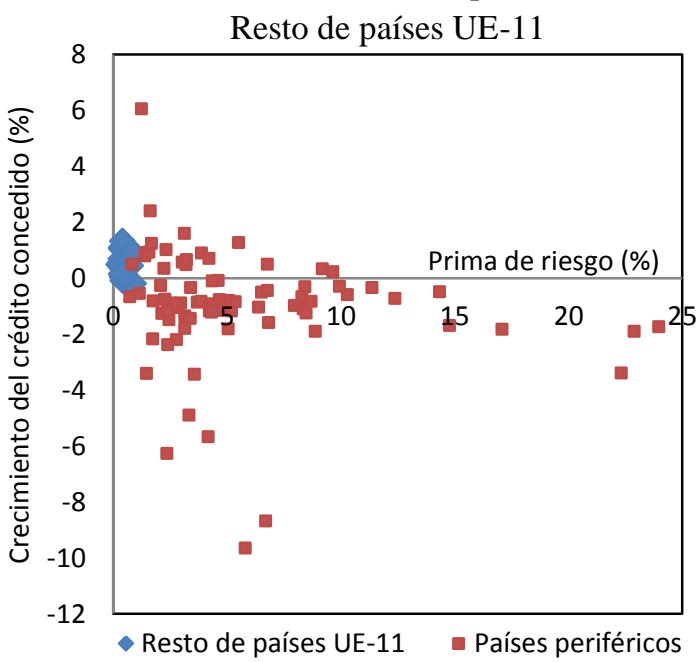

La prima de riesgo (eje horizontal) representa el diferencial en el bono de referencia a 10 años con respecto a Alemania. (Figura 1.7a): Datos para la UE-11 y Grecia entre el primer trimestre de 2010 y el cuarto trimestre de 2013. (Figura 1.7b): Resto de países UE-11: Alemania, Austria, Bélgica, Finlandia, Francia, Holanda y Luxemburgo. Países periféricos: Portugal, Irlanda, Italia, Grecia y España. Período considerado: entre el primer trimestre de 2010 y el cuarto trimestre de 2013.

Fuente: elaboración propia a partir de datos del BIS y la OCDE. 
La Figura 1.7a indica que primas de riesgo altas (superiores al 5\%) llevan aparejadas reducciones en la tasa de crecimiento de los préstamos concedidos. Por su parte, la Figura $1.7 \mathrm{~b}$ refleja que este efecto ha sido más notable en los países más afectados por el riesgo soberano.

No sólo se ha visto afectado el volumen de préstamos, sino también el tipo de interés que aplican los bancos a sus clientes por los mismos. La Figura 1.8 muestra la evolución de los tipos de interés del crédito a empresas.

Figura 1.8: Evolución de los tipos de interés de las operaciones de crédito a empresas

Figura 1.8a: Tipo de interés (\%) de las operaciones de crédito a empresas, más de 1 millón de euros

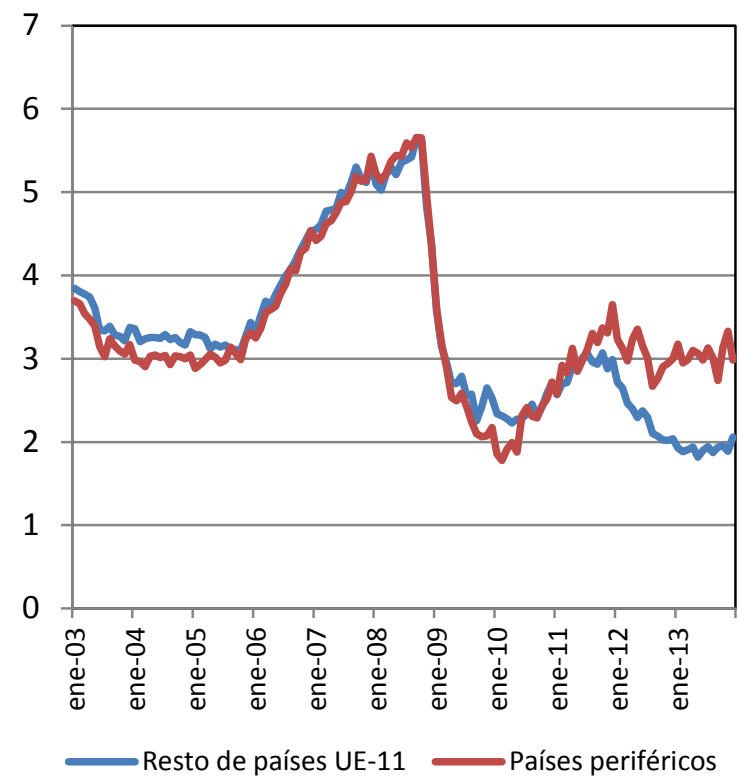

Figura 1.8b: Tipo de interés $(\%)$ de las operaciones de crédito a empresas, hasta 1 millón de euros

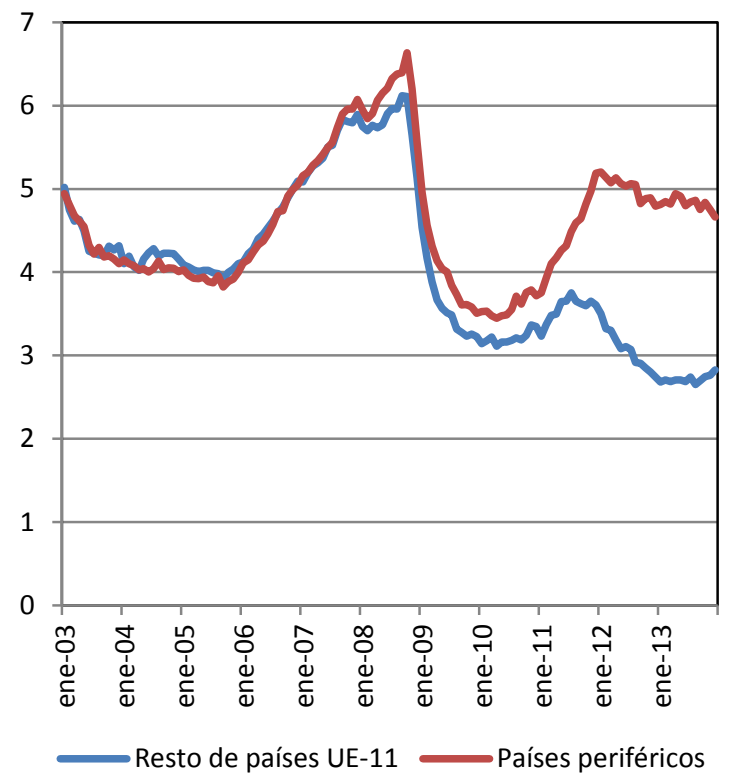

Datos mensuales promedio ponderado para cada grupo de países. Países periféricos: Portugal, Irlanda, Italia, Grecia y España. Resto de países UE-11: Alemania, Austria, Bélgica, Finlandia, Francia, Holanda y Luxemburgo. (Figura 1.8a): El resto de países UE-11 no incluye Bélgica. Los préstamos por cuantía superior a 1 millón de euros se suelen asociar a las grandes empresas. (Figura 1.8b): Los préstamos por cuantía inferior a 1 millón de euros se suelen vincular a las pequeñas y medianas empresas.

Fuente: elaboración propia a partir de datos del BCE.

Los tipos de interés han sido sensiblemente más altos en los países de la periferia que en el resto de países UE-11, principalmente a partir de 2011, lo que revela las distintas condiciones de financiación que han aplicado los bancos a sus clientes. 
Asimismo, las pequeñas y medianas empresas han sido las más afectadas por la crisis de deuda, ya que dependen principalmente de la financiación bancaria (véase Figura 1.8b).

La menor disponibilidad de crédito bancario y su mayor coste ha resaltado la importancia que tiene el crédito comercial como fuente de financiación alternativa a los préstamos. La Figura 1.9 muestra la evolución de la proporción media de crédito comercial extendido sobre ventas durante los años de crisis para varios países europeos. Dicho crédito comercial se incrementó en los primeros años de la crisis, en los países periféricos en 2009 y en el resto de países UE-11 de forma más tardía en 2010. Sin embargo, durante los años de crisis de deuda (2011-2012), se observa una reducción del crédito comercial, si bien es cierto, en los países periféricos éste disminuyó hasta situarse ligeramente por debajo de los niveles que existían al comienzo de la crisis en 2008, algo que no sucede en el resto de países de la UE-11. En cualquier caso, los países periféricos utilizan en mayor medida el crédito comercial.

\section{Figura 1.9: Evolución del crédito comercial extendido}

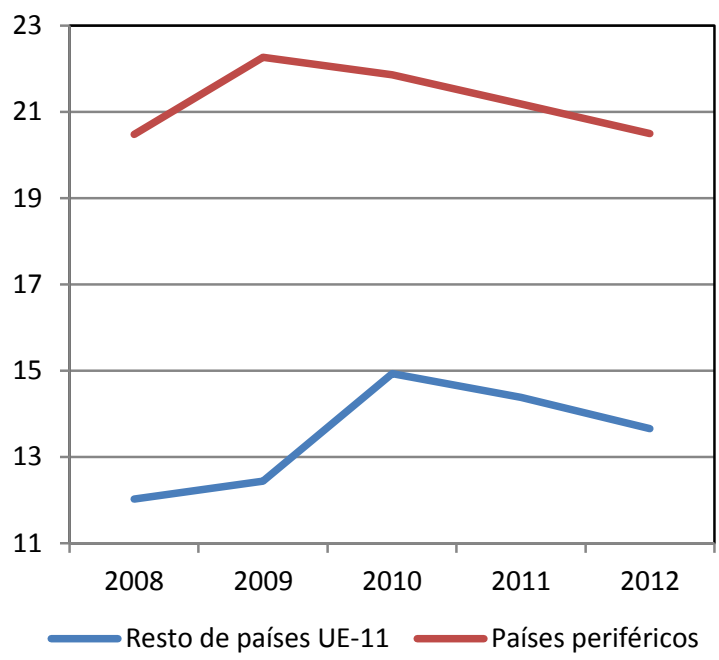

El eje vertical muestra la proporción media anual $(\%)$ de crédito comercial extendido a clientes sobre los ingresos por ventas ponderada por el total de ingresos por ventas de las empresas de cada grupo de países. Muestra de 90.416 grandes y medianas empresas no financieras. Resto de países UE-11: Alemania, Austria, Bélgica, Finlandia, Francia, Holanda y Luxemburgo. Países periféricos: Portugal, Irlanda, Italia, Grecia y España.

Fuente: elaboración propia a partir de datos de Amadeus. 
Finalmente, las divergencias observadas en la oferta crediticia en función del riesgo soberano, están condicionando el mecanismo de transmisión de la política monetaria a través del canal de préstamos bancarios explicado en el epígrafe anterior. A este respecto, la Figura 1.10 muestra la evolución del crecimiento del crédito en relación a los tipos de interés del BCE en varios países de la zona euro. Aunque el BCE redujo drásticamente sus tipos de interés tras el incio de la crisis de deuda (2011 y 2012) para fomentar el crédito, la Figura 1.10b indica que los países periféricos experimentaron tasas de crecimiento de préstamos mayoritariamente negativas (Italia principalmente a partir de 2012). Sin embargo, el resto de países UE-11 presentaron un comportamiento distinto, ya que en algunos trimestres experimentaron tasas de crecimiento de préstamos positivas y en otros apenas hubo variaciones (véase Figura 1.10a).

Figura 1.10: Evolución del crédito bancario y de los tipos de interés del BCE

Figura 1.10a: Resto de países UE-11

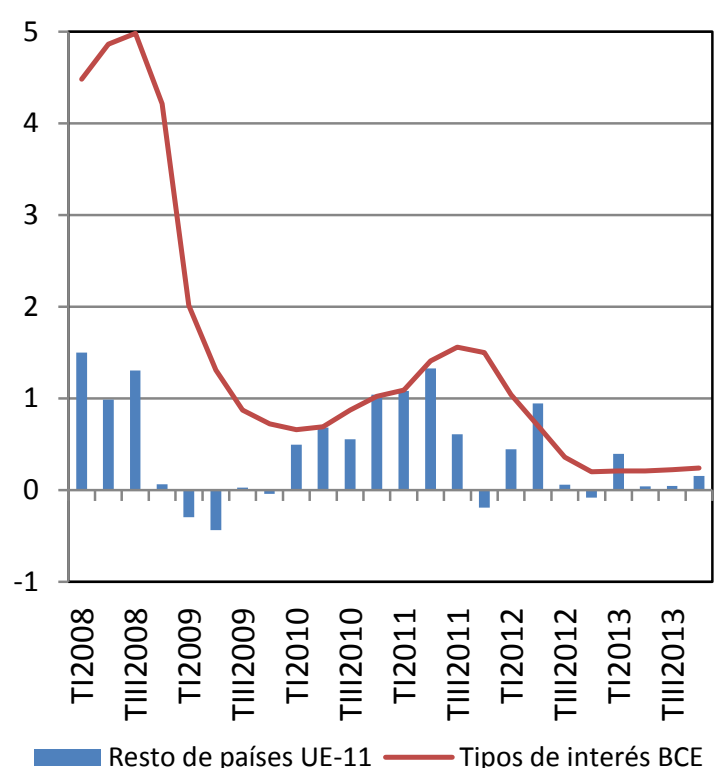

Figura 1.10b: Países periféricos

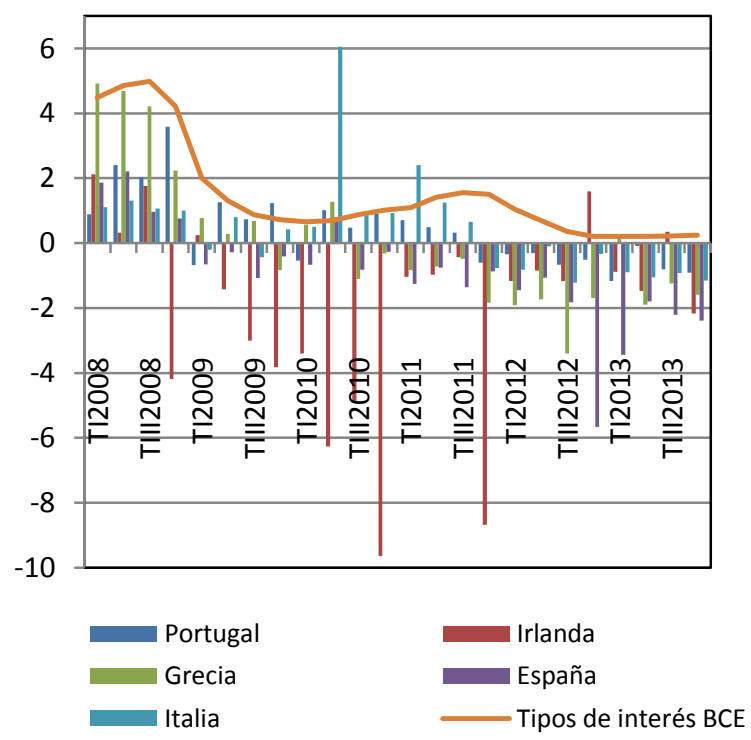

La línea representa la evolución de los tipos de interés a corto plazo (\%) del mercado monetario. Las barras representan la tasa de crecimiento/decrecimiento (\%) con respecto al trimestre anterior de la concesión de crédito bancario doméstico a hogares y empresas no financieras. (Figura 1.10a): Resto de países UE-11: Alemania, Austria, Bélgica, Finlandia, Francia, Holanda y Luxemburgo.

Fuente: elaboración propia a partir de datos del BIS y la OCDE. 


\section{5.- ANÁlisis COMPARATIVO dE LA ACTUACIÓN DE POLÍtICA MONETARIA DEL BCE ANTES Y DESPUÉS DEL ESTALLIDO DE LA CRISIS}

La crisis económico-financiera que comenzó en septiembre de 2008, y el posterior incremento del riesgo soberano, han puesto de manifiesto las debilidades de la UEM y han supuesto cambios muy relevantes en la forma en la que el BCE conduce la política monetaria (L`Hotellerie-Fallois y Vallés, 2013; Berganza et al., 2014). Por este motivo, en el presente epígrafe se realiza un análisis comparativo del marco de actuación de la política monetaria del BCE antes y después del estallido de la crisis.

\subsection{1.- Los años previos a la crisis (1999-otoño de 2008)}

A partir de la adopción del euro como moneda común, el BCE se responsabilizó de la política monetaria del conjunto de la UEM, quedando la política fiscal en el ámbito de competencias de cada uno de los países miembros. En este período la política monetaria del BCE se caracterizó por poseer un objetivo único y claro, el de la estabilidad de precios, un marco de actuación independiente con respecto a otras políticas y por la utilización de un conjunto reducido y bien definido de instrumentos convencionales, limitados fundamentalmente a los tipos de interés (L`Hotellerie-Fallois y Vallés, 2013). Durante estos años se pueden distinguir cinco etapas en la actuación de la política monetaria del BCE, reflejadas en la Figura 1.11 (Banco Central Europeo, 2011a). 
Figura 1.11: Tipos de interés (\%) de la política monetaria del BCE durante los años precrisis (1999-otoño de 2008)

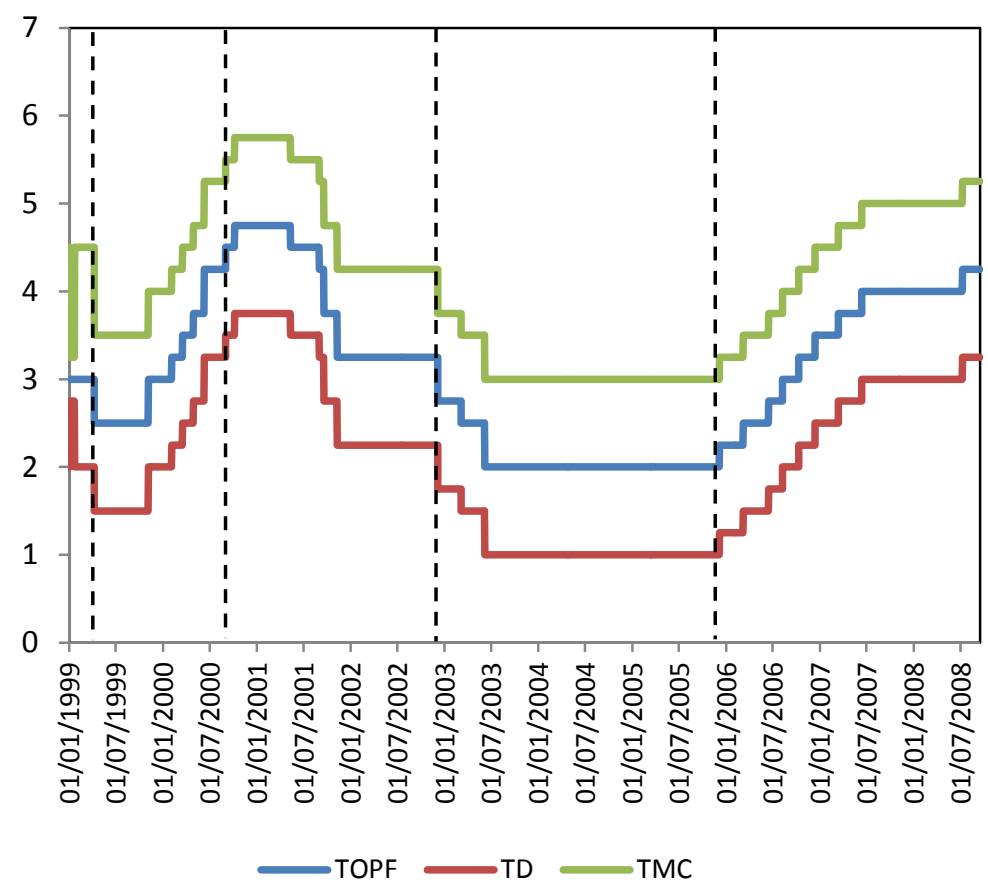

TOPF: Tipo de las operaciones principales de financiación. TD: Tipo de la facilidad de depósito. TMC: Tipo de la facilidad marginal de crédito.

Fuente: elaboración propia a partir de datos del BCE.

La primera etapa, que abarca desde mediados de 1998 hasta mediados de 1999, se corresponde con el período de transición a la Unión Monetaria y se caracterizó por la existencia de una reducida inflación. En este contexto, los tipos de interés oficiales del BCE se redujeron 50 puntos básicos, situándose el tipo fijo de las OPF en un 2,5\% al finalizar esta etapa.

La segunda etapa se extiende desde mediados de 1999 hasta finales de 2000 y se corresponde con un período de subida de tipos de interés, debido al incremento gradual de las presiones inflacionistas y a la depreciación del tipo de cambio del euro en un entorno de fuerte crecimiento económico. En concreto, los tipos de interés se incrementaron 225 puntos básicos, lo que supuso que el tipo de las OPF se situase en un $4,75 \%$. 
La tercera etapa, comprendida entre principios de 2001 y mediados de 2003 , viene marcada por los atentados terroristas cometidos el 11 de septiembre de 2001 en Estados Unidos, lo cual debilitó las perspectivas de crecimiento económico y contuvo las presiones inflacionistas. Ante este escenario, el BCE bajó los tipos de interés un total de 275 puntos básicos, lo que situó a los tipos de las OPF en un $2 \%$.

La cuarta etapa tiene lugar entre mediados de 2003 y finales de 2005 y se caracteriza por una recuperación de la actividad económica, unas condiciones favorables de financiación y una disminución de la incertidumbre y de la aversión al riesgo. Este entorno, unido a la contención de las presiones inflacionistas, hizo que el BCE no modificase los tipos de interés.

Durante la quinta etapa, que abarca desde finales de 2005 hasta otoño de 2008, surgieron importantes riesgos que amenazaban la estabilidad de precios, debido al espectacular crecimiento económico y la fuerte expansión del crédito. Ante esta situación, el BCE elevó los tipos de interés un total de 225 puntos básicos hasta situar los tipos de las OPF en un 4,25\%. En esta etapa también cabe destacar las primeras señales de tensiones que sacudieron a los mercados financieros en agosto de 2007. En este contexto, el BCE reaccionó con rapidez introduciendo ajustes en el mercado interbancario para evitar distorsiones en su funcionamiento. Así, facilitó liquidez a un día de manera ilimitada, se amplió la provisión de liquidez a las entidades financieras mediante OFPML con vencimientos a 3 y 6 meses y se establecieron líneas swap con otros Bancos Centrales. 


\subsection{2.- Los años posteriores al estallido de la crisis (otoño de 2008- actualidad)}

La crisis financiera que comenzó en 2008 trajo consigo una gran recesión e importantes desequilibrios que obligaron al BCE a actuar en un entorno muy complicado en el que dejaron de ser suficientes el conjunto de instrumentos convencionales de política monetaria (Berganza et al., 2014). Además del mantenimiento de la estabilidad de precios, el BCE tuvo una especial preocupación por garantizar la estabilidad financiera, lo cual hizo que implementase una serie de medidas no convencionales que han supuesto un cambio de instrumentación de gran envergadura.

El período de crisis en Europa se puede dividir en dos etapas: una primera que abarca desde otoño de 2008 hasta la primavera de 2010 y que se corresponde con la crisis económico-financiera y, una segunda, que se extiende desde la primavera de 2010 hasta la actualidad y que hace referencia a la crisis de deuda soberana. A continuación desarrollamos los aspectos más importantes de la actuación de política monetaria del BCE durante cada una de ellas.

\subsubsection{1.- La crisis económico-financiera (otoño de 2008-primavera de 2010)}

En Europa la crisis financiera que comenzó con la crisis subprime en Estados Unidos, se consideró inicialmente un problema puramente bancario, por lo que los gobiernos de cada país pusieron cuantiosos recursos financieros a disposición de los bancos en aras de devolver la confianza al sector bancario e impulsar el crédito a la economía. Este gran apoyo a la banca tuvo un fuerte impacto sobre el déficit de los países más afectados, poniendo en serio peligro la sostenibilidad de sus finanzas públicas (véase Figura 1.12). 


\section{Figura 1.12: Medidas de apoyo al sector bancario}

Figura 1.12a: Evolución de las ayudas financieras a la banca por parte de los gobiernos, \% sobre el PIB

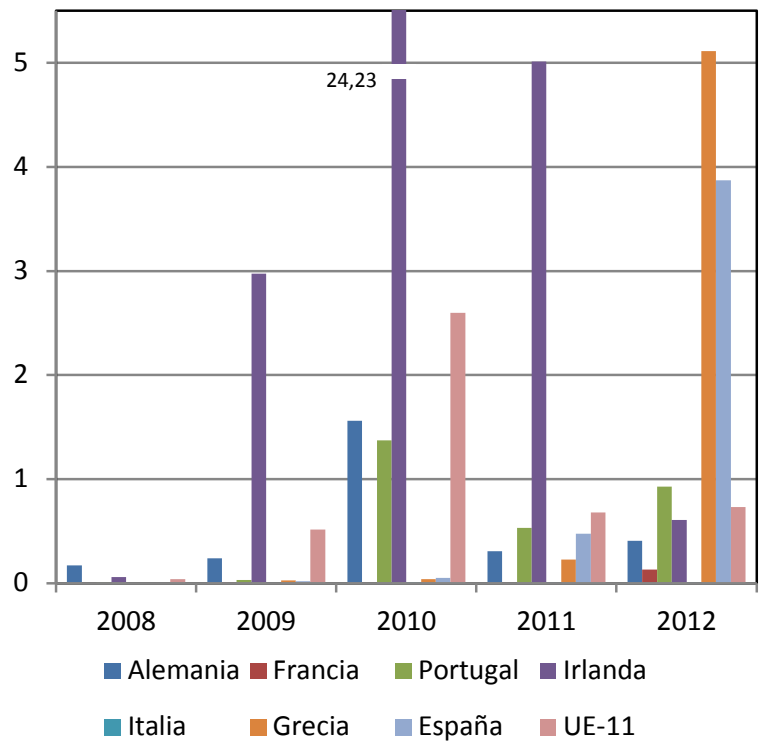

Figura 1.12b: Impacto de las ayudas financieras a la banca sobre el déficit/superávit de los gobiernos, \% sobre el PIB

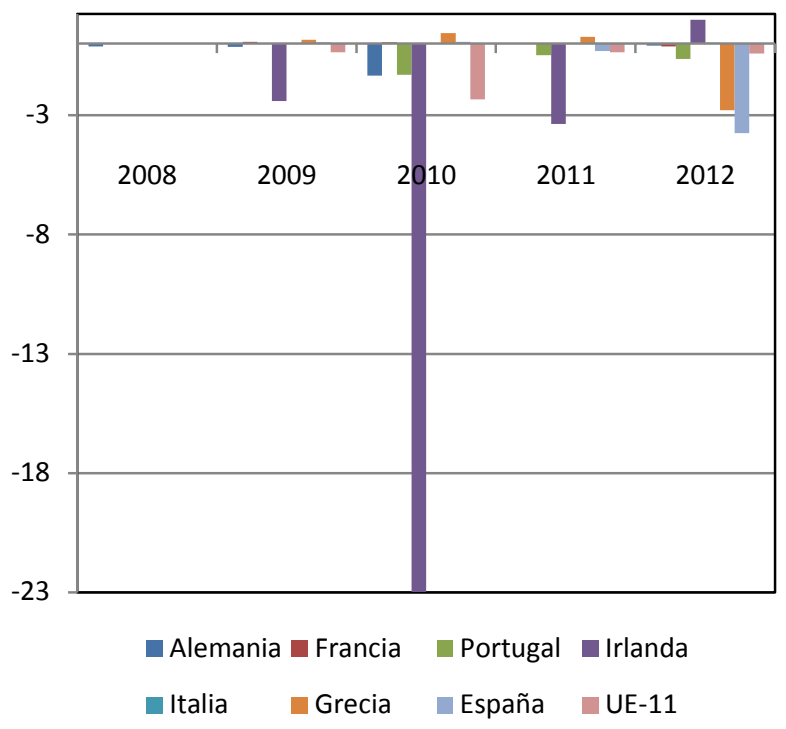

Para el cálculo de la cuantía total de las ayudas se considera: 1) Los intereses asociados a la financiación empleada para costear la ayuda, principalmente los derivados de las emisiones de deuda; 2) Las concesiones de fondos en forma de inyecciones de capital y 3) Los pagos derivados de las garantías que el gobierno otorga a las instituciones financieras.

Fuente: elaboración propia a partir de datos de EuroStat.

Ante esta situación, el BCE también intervino para estabilizar los mercados financieros a través de la reducción de tipos de interés. En concreto, durante los últimos meses del año 2008 redujo los tipos de interés oficiales en 175 puntos básicos. Sin embargo, varios meses más tarde, ante la debilidad de las perspectivas económicas, volvió a bajar los tipos de interés oficiales. De esta manera, el tipo de las OPF disminuyó 325 puntos básicos hasta el $1 \%$ entre octubre de 2008 y mayo de 2009 y se estrecharon los diferenciales entre los tipos de interés de las OPF y los de las facilidades permanentes (véase Figura 1.13). 
Figura 1.13: Tipos de interés (\%) de la política monetaria del BCE durante la primera etapa de la crisis (otoño de 2008-primavera de 2010)

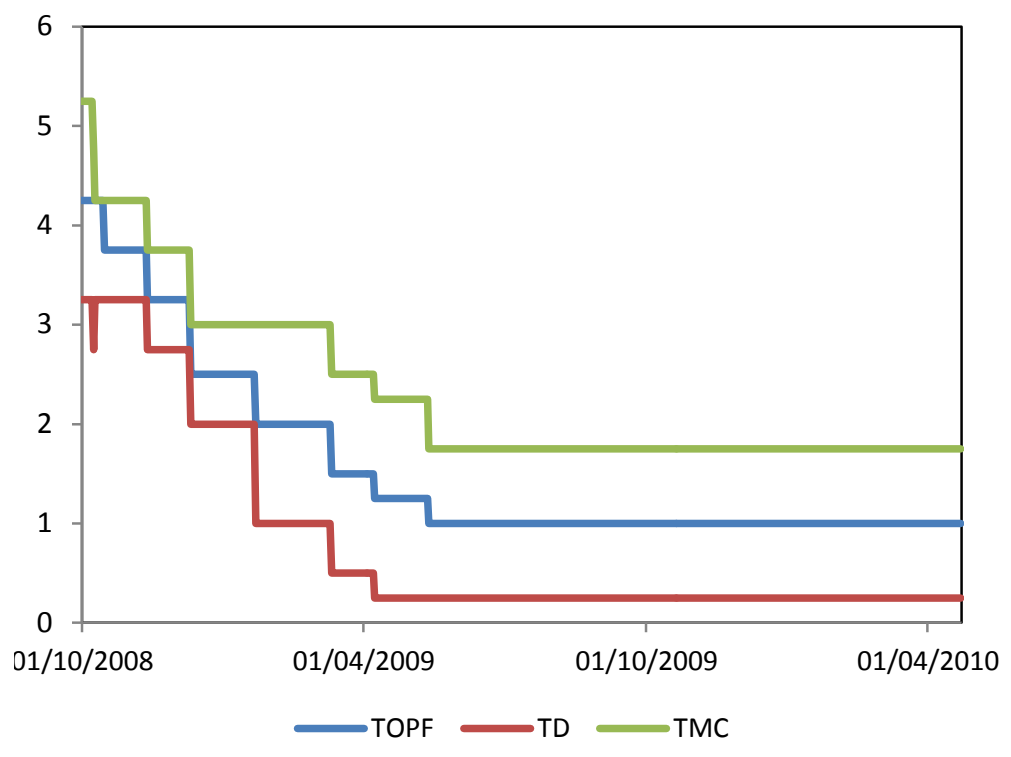

TOPF: Tipo de las operaciones principales de financiación. TD: Tipo de la facilidad de depósito. TMC: Tipo de la facilidad marginal de crédito.

Fuente: elaboración propia a partir de datos del BCE.

Adicionalmente, el BCE puso en práctica una serie de medidas no convencionales de carácter temporal dirigidas a mejorar las condiciones de financiación e impulsar la corriente de crédito hacia la economía, las cuales se concretaron en las siguientes actuaciones (Banco Central Europeo, 2008; 2009; 2010b).

En primer lugar, se realizaron inyecciones de liquidez mediante la ampliación del vencimiento de las OFPML hasta un máximo de 12 meses $^{20}$, con el fin de reducir los problemas de financiación del sector bancario y fomentar el crédito (véase Figura 1.14). En segundo lugar, se puso en marcha un procedimiento de subasta a tipo de interés fijo con adjudicación plena para todas las operaciones de financiación. De esta forma, las entidades podían acceder de manera ilimitada a la liquidez del Banco Central al tipo

\footnotetext{
${ }^{20}$ Tal y como se comentó anteriormente, durante el período de tensiones financieras previo al estallido de la crisis, el BCE había aumentado la provisión de liquidez mediante OFPML con vencimientos a 3 y 6 meses.
} 
principal de financiación, siempre y cuando estuviesen respaldadas con los activos de garantía oportunos. En tercer lugar, se amplió el rango de activos de garantía que las entidades podían emplear para obtener liquidez del Banco Central y así facilitar su acceso a financiación. Finalmente, el BCE instauró en mayo de 2009 un programa de adquisiciones de bonos garantizados (Covered Bond Purchase Programme, CBPP).

Figura 1.14: Inyecciones de liquidez del BCE por plazos durante la primera etapa de la crisis (otoño de 2008-primavera de 2010)

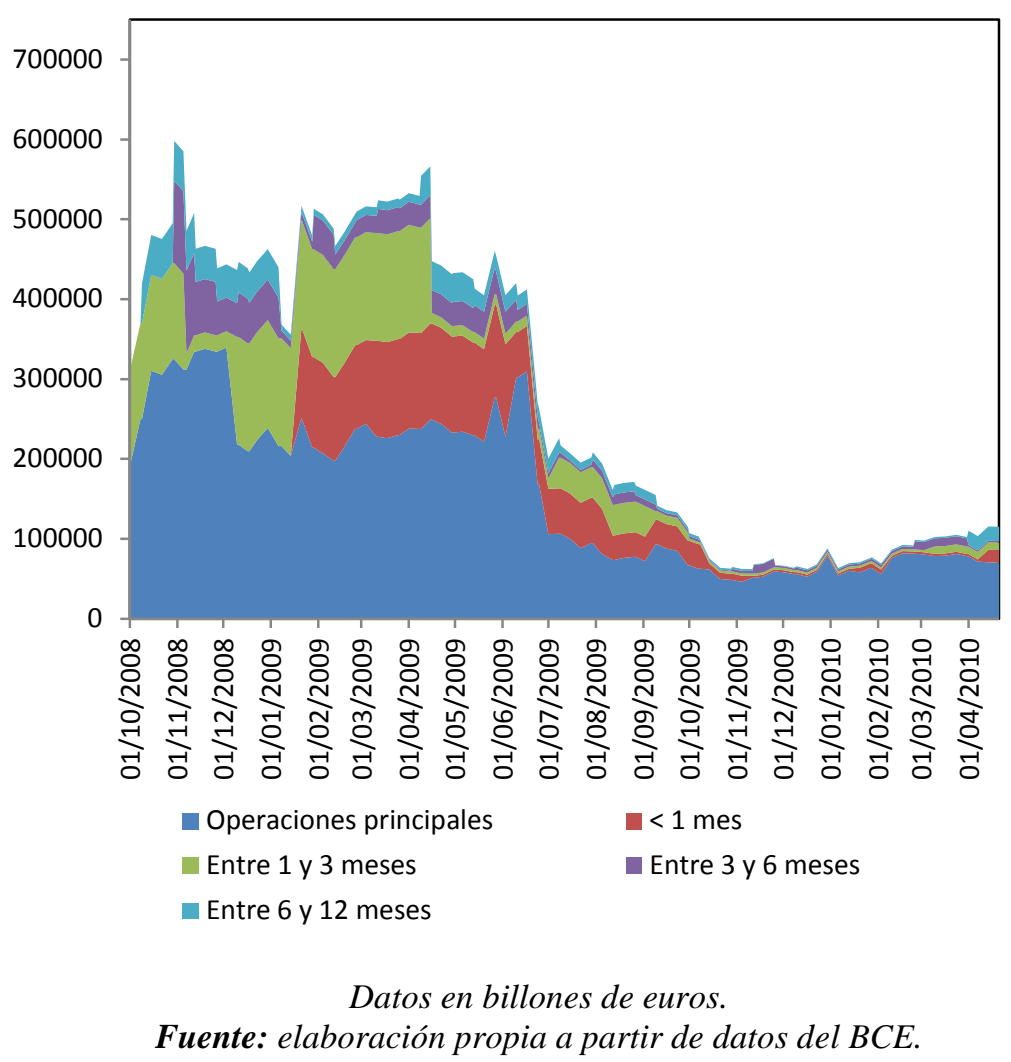

\subsubsection{2.- La crisis de deuda soberana (primavera de 2010-actualidad)}

El origen de la crisis de deuda soberana se remonta a la primavera de 2010 , cuando Grecia solicitó asistencia financiera a la zona euro y al Fondo Monetario Internacional, al conocerse que su déficit fiscal era mucho más elevado de lo que se pensaba, pero se propagó rápidamente a otros países, afectando principalmente a la periferia europea (Portugal, Irlanda, Italia y España). 
Las tensiones soberanas impactaron negativamente en la confianza de los inversores, generando una creciente preocupación por el riesgo soberano. Esto dio lugar a considerables incrementos en los rendimientos de deuda pública de los países más afectados, así como a progresivas rebajas de su calificación crediticia por parte de las agencias de rating (véase Figura 1.15).

Figura 1.15: Evolución del riesgo soberano en la zona euro

Figura 1.15a: Diferencial en puntos básicos en el bono de referencia a 10 años con respecto a Alemania

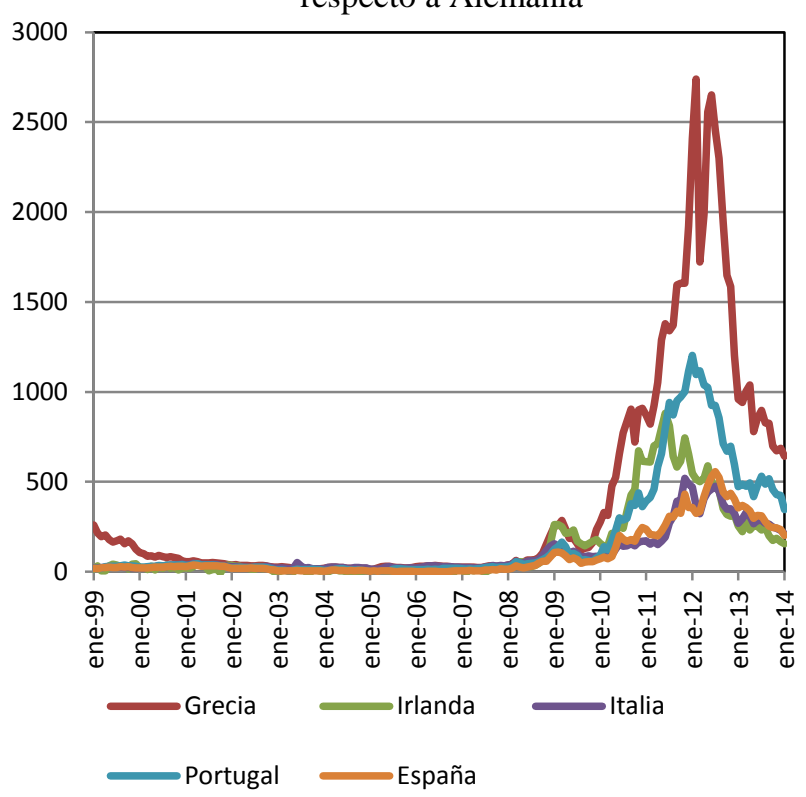

Figura 1.15b: Rating soberano

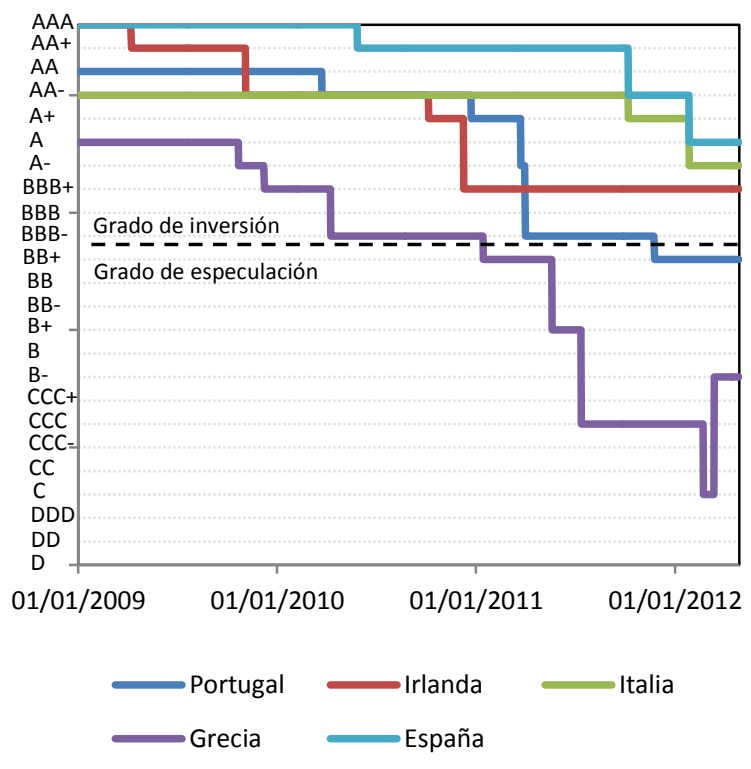

Fuente: elaboración propia a partir de datos de la OCDE y Fitch Ratings.

Las debilidades del sector público se contagiaron a las condiciones de financiación del sector bancario, lo cual supuso un riesgo para la estabilidad financiera y la transmisión de la política monetaria. Ante esta situación tan problemática, el BCE intervino de nuevo mediante la adopción de varias medidas para favorecer el acceso a financiación de los bancos y conseguir una transmisión más homogénea de la política monetaria. Así, continuó llevando a cabo sucesivas bajadas de tipos de interés hasta 
situarse actualmente el tipo de las OPF en un mínimo histórico de 0,05\% y las facilidades de depósito en un valor negativo de -0,20\% (véase Figura 1.16) ${ }^{21}$.

\section{Figura 1.16: Tipo de interés (\%) de la política monetaria del BCE durante la segunda} etapa de la crisis (primavera de 2010 -actualidad)

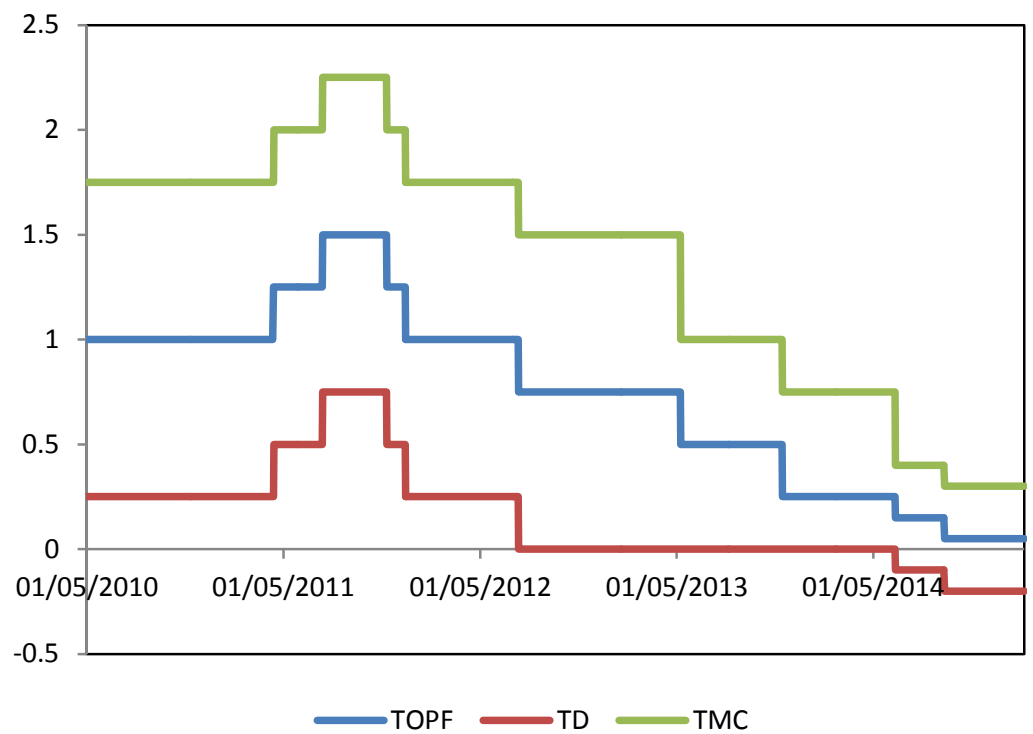

TOPF: Tipo de las operaciones principales de financiación. TD: Tipo de la facilidad de depósito. TMC: Tipo de la facilidad marginal de crédito.

Fuente: elaboración propia a partir de datos del BCE.

Estas bajadas de tipos de interés vinieron acompañados de nuevas medidas complementarias (Banco Central Europeo, 2011b; 2012c; 2013). En primer lugar, en mayo de 2010 se introdujo el Programa de Compra de Valores (Securities Markets Program) para hacer frente al mal funcionamiento de algunos mercados de valores y garantizar una transmisión fluida y homogénea de la política monetaria ${ }^{22}$. En segundo lugar, se pusieron en marcha nuevos programas de adquisición de bonos garantizados en 2011 (Covered Bond Purchase Programme 2, CBPP2) y en 2014 (Covered Bond

\footnotetext{
${ }^{21}$ En primavera y verano de 2011 el BCE realizó una subida de tipos de interés de un total de 50 puntos básicos para hacer frente a la existencia de presiones inflacionistas que surgieron en el primer semestre de ese año, siendo la única subida de tipos de interés realizada por el BCE desde que comenzara la crisis financiera en 2008.

${ }^{22}$ El Programa de Compra de Valores fue sustituido en agosto de 2012 por el anuncio del BCE de realizar Operaciones Monetaristas de Compraventa (Outright Monetary Transaction), pero aún no ha sido solicitado por ningún país miembro.
} 
Purchase Programme 3, CBPP3), así como programas de compras de bonos de titulización de activos $(A B S)^{23}$. En tercer lugar, se amplió la provisión de liquidez mediante la extensión de los vencimientos de las OFPML hasta 3 y 4 años (véase Figura 1.17), a la vez que se siguieron manteniendo las subastas a tipo de interés fijo con adjudicación plena que se habían puesto en marcha al comienzo de la crisis. En cuarto lugar, se implantaron medidas en materia de activos con garantía para asegurar el acceso a liquidez de los bancos y se redujo el coeficiente de reservas mínimas de un $2 \%$ a un $1 \%$ de la base de reservas. Asimismo, se adoptaron acuerdos de provisión de liquidez en moneda extranjera con otros Bancos Centrales (líneas swap).

Figura 1.17: Inyecciones de liquidez del BCE por plazos durante la segunda etapa de la crisis (primavera de 2010-actualidad)

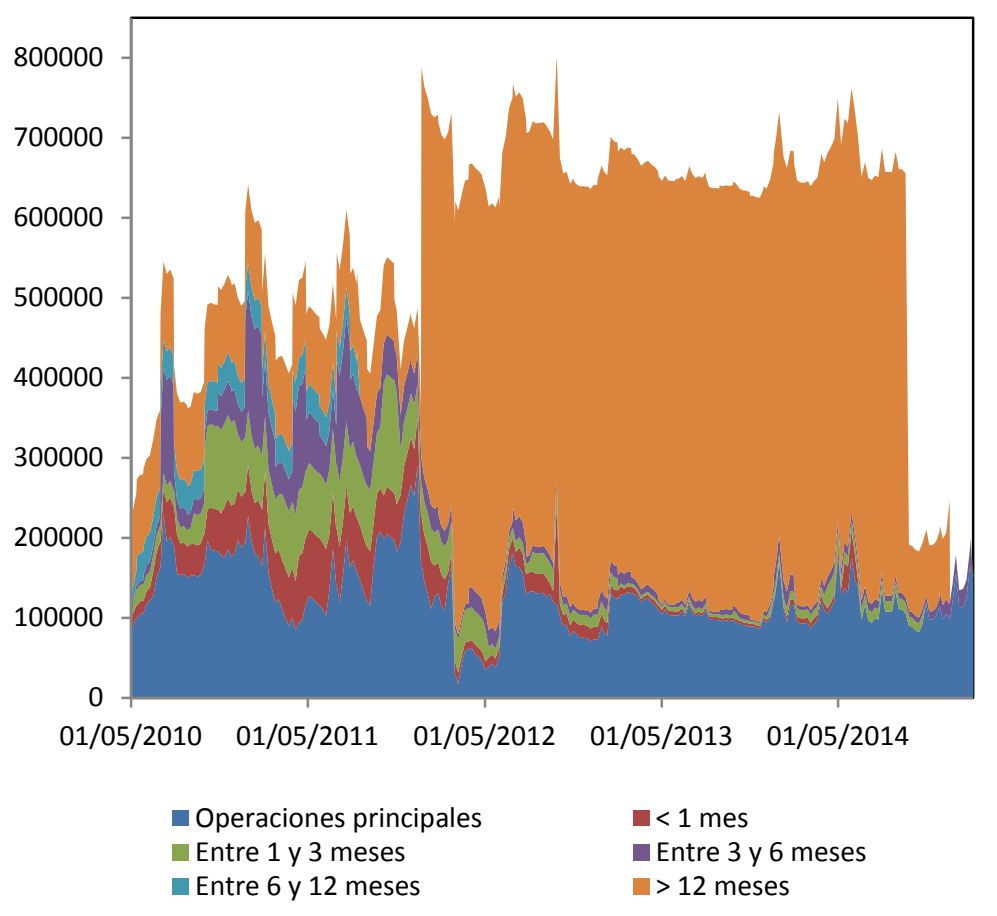

Datos en billones de euros.

Fuente: elaboración propia a partir de datos del BCE.

\footnotetext{
${ }^{23}$ Recientemente, en enero de 2015, el BCE anunció la ampliación de su programa de compras mensuales de activos para incluir bonos soberanos con el objetivo de mantener la estabilidad de precios, tras un período prolongado de baja inflación. Las compras mensuales ascenderán a 60.000 millones de euros y se prevé que continúen al menos hasta septiembre de 2016.
} 
A modo de síntesis, la Tabla 1.2 recoge las principales diferencias entre la política monetaria que existió en los años previos a la crisis y la que tuvo lugar posteriormente.

Tabla 1.2: Comparativa de la política monetaria del BCE antes y durante la crisis

\begin{tabular}{|c|c|c|}
\hline $\begin{array}{c}\text { La política } \\
\text { monetaria del }\end{array}$ & Antes de la crisis (1999-2008) & Durante la crisis (2008-actualidad) \\
\hline Objetivo & $\begin{array}{l}\text {-El objetivo } \text { primordial es } \\
\text { garantizar la estabilidad de } \\
\text { precios. }\end{array}$ & $\begin{array}{l}\text {-El objetivo primordial es garantizar la } \\
\text { estabilidad de precios, si bien el BCE } \\
\text { tiene también una especial preocupación } \\
\text { por garantizar la estabilidad financiera. }\end{array}$ \\
\hline $\begin{array}{c}\text { Marco } \\
\text { institucional }\end{array}$ & $\begin{array}{l}\text { Tres órganos rectores: } \\
\text {-Consejo de Gobierno. } \\
\text {-Comité Ejecutivo. } \\
\text {-Consejo General. }\end{array}$ & $\begin{array}{l}\text { Cuatro órganos rectores: } \\
\text {-Consejo de Gobierno. } \\
\text {-Comité Ejecutivo. } \\
\text {-Consejo General. } \\
\text {-Consejo de Supervisión }(a) \text {. } \\
\text { La supervisión de los principales bancos } \\
\text { de la zona euro recae sobre el } \operatorname{BCE}(a) \text {. }\end{array}$ \\
\hline Instrumentos & $\begin{array}{l}\text {-Instrumentos convencionales } \\
\text { basados fundamentalmente en } \\
\text { los tipos de interés. }\end{array}$ & $\begin{array}{l}\text {-Los instrumentos convencionales } \\
\text { basados en los tipos de interés se } \\
\text { combinan con medidas complementarias } \\
\text { de apoyo al crédito y a la estabilidad } \\
\text { financiera. }\end{array}$ \\
\hline $\begin{array}{c}\text { Medidas de } \\
\text { política } \\
\text { monetaria } \\
\text { complementarias }\end{array}$ & -Prácticamente inexistentes. & $\begin{array}{l}\text {-Ampliación del vencimiento de las } \\
\text { OFPML. } \\
\text {-Subastas a tipo de interés fijo con } \\
\text { adjudicación plena para todas las } \\
\text { operaciones de financiación. } \\
\text {-Ampliación del rango de activos de } \\
\text { garantía. } \\
\text {-Adquisiciones de bonos garantizados y } \\
\text { de bonos de titulización de activos. } \\
\text {-Programa de Compra de Valores } \\
\text { (Securities Markets Program/ Outright } \\
\text { Monetary Transaction). } \\
\text {-Reducción del coeficiente mínimo de } \\
\text { reservas. } \\
\text {-Acuerdos de provisión de liquidez en } \\
\text { moneda extranjera con otros Bancos } \\
\text { Centrales (líneas swap). }\end{array}$ \\
\hline
\end{tabular}

(a) Desde el 4 de noviembre de 2014

Fuente: elaboración propia. 



\section{CAPÍTULO II RELACIÓN ENTRE EL RIESGO SOBERANO Y EL CANAL DE PRÉSTAMOS BANCARIOS}





\section{1.- INTRODUCCIÓN}

El objetivo de este capítulo es analizar cómo el riesgo soberano condiciona los efectos de la política monetaria sobre el crédito bancario y comprobar si dichos efectos varían durante regímenes monetarios restrictivos y expansivos.

El interés por este tema responde a las disfunciones que ha tenido la política monetaria en la zona euro desde 2008. El papel que desempeña el sector bancario como oferente de crédito es esencial para comprender la interdependencia entre la política monetaria y la economía real, argumento que justifica el canal de transmisión de la política monetaria denominado canal de préstamos bancarios (bank lending channel), tal y como se expuso en el capítulo anterior. De acuerdo a dicho canal, las decisiones de política monetaria alteran la oferta de préstamos bancarios al incidir sobre el acceso a fondos prestables de las instituciones de crédito (Bernanke y Blinder, 1988). Este canal 
ha despertado un renovado interés en los últimos años ${ }^{24}$, debido principalmente a los problemas por los que ha atravesado el sector bancario durante la crisis.

La intensificación de la crisis en Europa supuso un notable aumento del riesgo soberano en algunos países, que se contagió rápidamente a los costes de financiación de sus bancos nacionales. El empeoramiento de las condiciones de financiación provocó una fuerte contracción del crédito bancario, haciendo que los efectos del canal de préstamos de la política monetaria fuesen distintos en cada país de la zona euro, como consecuencia de diferentes niveles de riesgo soberano. Estas divergencias provocaron un proceso de fragmentación financiera e introdujeron importantes distorsiones en la transmisión de la política monetaria.

El análisis y la cuantificación del posible impacto que el riesgo soberano tiene sobre el proceso de transmisión de la política monetaria es sumamente interesante para identificar los diferentes efectos que se producen entre países durante dicho proceso. Es por ello, que constituye el grueso de este capítulo examinar cómo la influencia de la política monetaria sobre los préstamos bancarios se ve determinada por el riesgo soberano durante períodos de restricción y expansión monetaria.

Desde esta perspectiva, los epígrafes siguientes se organizan como sigue: en la primera parte se desarrolla el cuerpo teórico que subyace al canal de préstamos bancarios, en la segunda se presentan las relaciones existentes entre el riesgo soberano y el canal de préstamos bancarios de la política monetaria, algo que apenas se ha trabajado en la literatura financiera y menos para Europa. Por último, los planteamientos

\footnotetext{
${ }^{24}$ Véase, entre otros, Opiela (2008); Isakova (2008); Matousek y Sarantis (2009); Brissimis y Delis (2009); Altunbas et al. (2009; 2010); Gambacorta y Marques-Ibanez (2011); Disyatat (2011); Said (2013).
} 
propuestos proporcionan el marco de referencia necesario para plantear las hipótesis que se contrastan empíricamente en la tercera parte de este capítulo.

\section{2.- EL CANAL DE PRÉSTAMOS BANCARIOS COMO MECANISMO DE TRANSMISIÓN DE LA POLÍTICA MONETARIA}

La política monetaria ejerce su influencia a través de diversos canales, tal y como se mostró en el capítulo 1: el canal de tipos de interés, el canal de tipo de cambio, el canal de precios de los activos, el canal de las expectativas y el canal de crédito (Mishkin, 1995). Dentro del canal de crédito, se encuentra el canal de préstamos bancarios (bank lending channel), en el cual nos centraremos en este capítulo 2 y en los efectos que, sobre el mismo, tiene el riesgo soberano. Este canal basa su atención en las entidades financieras, dado el destacado papel que éstas juegan como oferentes de crédito y sostiene que la política monetaria modifica la oferta crediticia al influir sobre el acceso a fondos prestables de las entidades bancarias (Bernanke y Blinder, 1988).

Una política monetaria restrictiva que eleva el nivel mínimo de reservas que las entidades deben mantener en el Banco Central, limita la disponibilidad de depósitos debido al mayor volumen de reservas requeridas (Kashyap y Stein, 1995a; Walsh, 2003). Asimismo, una política monetaria contractiva que aumenta los tipos de interés reduce los rendimientos de los depósitos en relación a otros activos, disminuyendo la preferencia de los depositantes por mantenerlos (Kishan y Opiela, 2000; Ehrmann et al., 2003). Como consecuencia, una disminución de los depósitos provocará una reducción de la oferta de préstamos y, por tanto, de la inversión empresarial, el producto y los precios.

Para que todo este proceso funcione deben cumplirse una serie de supuestos específicos (Bernanke y Blinder, 1988). En primer lugar, las empresas deben depender 
del crédito bancario y no ser capaces de sustituir la caída de la financiación bancaria, originada por una política monetaria restrictiva, con otro tipo de fondos. En segundo lugar, el Banco Central ha de ser capaz de afectar a la oferta de crédito. Así, en el caso de una política monetaria contractiva, los bancos no han de poder compensar la caída de depósitos recurriendo a otras fuentes de financiación alternativas. En tercer lugar, es preciso que existan imperfecciones en el ajuste del nivel agregado de precios, puesto que la política monetaria no tendría ningún efecto si los precios nominales se ajustasen de manera inmediata y proporcional a los cambios inducidos sobre la base monetaria.

Estos supuestos de partida han sido rebatidos en la literatura por otros autores, especialmente el segundo, relacionado con la inexistencia de sustitutos perfectos a los depósitos bancarios como fuente de financiación para los bancos. En este sentido, Romer y Romer (1990) afirman que los bancos pueden compensar fácilmente la reducción de depósitos con otras fuentes de financiación, tales como la emisión de títulos de deuda.

La existencia de fuentes de financiación alternativas a los depósitos bancarios ha llevado a algunos autores a formular un nuevo mecanismo que sustenta el canal de préstamos bancarios, el cual se centra en la financiación que las entidades de crédito obtienen de los mercados financieros (Bernanke 2007; Disyatat, 2011). De acuerdo a este nuevo mecanismo, una política monetaria restrictiva da lugar a un aumento de la percepción del riesgo que los inversores tienen de los bancos y reduce la solidez de sus balances, encareciendo el coste de su financiación externa vía mercados, lo que conduce a una disminución de su oferta crediticia.

En resumen, el mecanismo que se deriva del canal de préstamos bancarios implica que una política monetaria restrictiva reduce la base de depósitos (Bernanke y Blinder, 
1988) y/o incrementa el coste de financiación externa de los bancos (Disyatat, 2011), lo cual conlleva una disminución de la oferta de préstamos.

En relación a este tema, se pueden distinguir dos líneas de investigación: una que se apoya en datos macroeconómicos o agregados y otra sostenida en el empleo de información microeconómica o desagregada, a fin de recoger la heterogeneidad de los bancos. A continuación se desarrolla cada una de ellas.

\subsection{1.- El canal de préstamos bancarios con datos macroeconómicos o agregados}

Los trabajos del canal de préstamos bancarios con datos agregados tratan de determinar el poder explicativo de los préstamos bancarios sobre variables macroeconómicas como el Producto Interior Bruto (PIB), el desempleo o la inflación, cuando se produce una variación de la política monetaria ${ }^{25}$. La mayor parte de estos trabajos se han centrado en analizar Estados Unidos y Europa, obteniendo evidencias distintas en cada caso. Así, mientras que en Estados Unidos el canal de préstamos bancarios ha ido perdiendo importancia, en Europa este canal puede ser un elemento más relevante, aunque controvertido, en el proceso de transmisión de la política monetaria. A continuación se explican los principales estudios empíricos que se han llevado a cabo en cada una de estas dos regiones.

\subsubsection{1.- Evidencias empíricas en Estados Unidos}

Si bien existen una serie de trabajos pioneros que sugieren la existencia de un canal de préstamos bancarios en Estados Unidos ${ }^{26}$, el trabajo de Bernanke y Blinder (1992) es uno de los más destacados y relevantes. Estos autores muestran que una

\footnotetext{
${ }^{25}$ La mayor parte de estos trabajos emplean una metodología de Vectores Autorregresivos (VAR), la cual consiste en un sistema de ecuaciones simultáneas en el que cada una de las variables es explicada por sus propios retardos y los del resto de variables del sistema, lo que permite analizar sistemas de variables de series de tiempo interrelacionadas (Sims, 1980).

${ }^{26}$ Véase, entre otros, Brunner y Meltzer (1963), Bernanke (1983; 1986) y Fackler y Rogers (1993).
} 
restricción monetaria reduce inmediatamente los activos bancarios y, con un cierto retardo el crédito, poniendo de manifiesto la importancia del canal de préstamos bancarios como mecanismo de transmisión de la política monetaria. Sin embargo, otros trabajos, aunque obtienen un resultado parecido, no lo interpretan de la misma manera. Así, King (1986), Romer y Romer (1990) y Ramey (1993) encuentran que cuando se produce una política monetaria restrictiva, los préstamos se contraen de forma tardía, lo cual, según estos autores, responde únicamente al descenso de la demanda. Esto revelaría que la política monetaria en Estados Unidos solamente se transmite a través del canal de tipos de interés, descartando la existencia de un canal de préstamos bancarios.

En cualquier caso, el problema subyacente en el análisis con datos agregados es la imposibilidad de distinguir si la contracción de préstamos bancarios tras una política monetaria restrictiva, se debe a factores de oferta como plantean Bernanke y Blinder (1992) o si, por el contrario, se debe a factores de demanda como sugieren los trabajos de King (1986), Romer y Romer (1990) y Ramey (1993).

Para solucionar este problema de identificación entre la oferta y la demanda de crédito, Kashyap et al. (1993) proponen comparar los efectos que la política monetaria ejerce sobre los préstamos bancarios y otras fuentes de financiación ${ }^{27}$. Sus resultados soportarían la existencia de un canal de préstamos bancarios, puesto que una contracción monetaria conduce a una disminución del volumen de crédito bancario y a un aumento de las emisiones de títulos de renta fija a corto plazo, indicando que las empresas incrementan su demanda de fuentes de financiación alternativas para compensar las restricciones en la oferta de préstamos.

\footnotetext{
${ }^{27}$ Estos autores desarrollan un modelo que considera la decisión conjunta de una empresa de financiar sus proyectos de inversión a través de préstamos bancarios y la emisión de títulos de renta fija a corto plazo.
} 
Friedman y Kuttner (1993) realizan un estudio similar, pero considerando no sólo las cantidades, sino también el precio relativo de las diferentes fuentes de financiación a corto plazo. Sus resultados muestran que una restricción monetaria afecta significativamente tanto al precio como al volumen de financiación y, en última instancia, a la producción.

Por su parte Douglas (1996), en un trabajo parecido al de Kashyap et al. (1993), no encuentra evidencias a favor del canal de préstamos bancarios cuando se utilizan las reservas bancarias como indicador de la política monetaria, en lugar de los tipos de interés. A su vez, Oliner y Rudebusch (1995), utilizando un mayor número de fuentes de financiación alternativas que Kashyap et al. (1993) e introduciendo un componente microeconómico en su estimación mediante la distinción de empresas grandes y pequeñas, tampoco apoyan la existencia de un canal de préstamos bancarios. La explicación podría estar en el hecho de que, ante una restricción monetaria, se produce una reasignación de recursos financieros de las empresas pequeñas hacia las grandes.

Kashyap et al. (1996), en respuesta al trabajo de Oliner y Rudebusch (1995), amplían su trabajo de 1993 considerando el tamaño empresarial y, nuevamente, se manifiestan sobre la importancia del canal de préstamos bancarios. Tras una contracción monetaria, las empresas pequeñas aumentan su demanda de crédito comercial, por lo que aumentan las cuentas de crédito comercial a cobrar por parte de las grandes empresas, normalmente proveedoras de este tipo de crédito. Para ello, las empresas grandes tendrían que aumentar a su vez sus emisiones de títulos de renta fija, lo cual explicaría los resultados de Oliner y Rudebusch (1995), sin descartar la existencia del canal de préstamos bancarios. En la misma línea irían los trabajos sectoriales como el de Ludvigson (1998), centrado en el sector del automóvil y distinguiendo también entre crédito bancario y no bancario. 
Con independencia del enfoque, parece evidente la falta de consenso entre los primeros trabajos que analizaron la importancia del canal de préstamos bancarios en Estados Unidos durante principios de los años 90 fundamentalmente. Son trabajos posteriores los que llevan a concluir que dicho canal ha ido perdiendo relevancia, debido principalmente a factores intrínsecos de la industria bancaria americana.

Por un lado, el canal de préstamos bancarios en Estados Unidos se ha visto afectado por la presencia de cambios regulatorios. Así, Thakor (1996) encuentra que los requerimientos de capital de Basilea pueden reducir la efectividad de las expansiones monetarias a la hora de incrementar la oferta crediticia. Recientemente, Milcheva (2013) analiza los efectos del crédito bancario sobre el mercado de la vivienda estadounidense y muestra que las variaciones en la oferta de crédito afectan al precio de la vivienda por cuestiones no relacionadas con la política monetaria, como son los cambios en la regulación, la percepción del riesgo o la innovación. Por otro lado, Morgan (1998) establece que tras una política monetaria restrictiva, únicamente se reducen los préstamos sin compromiso contractual, mientras que los préstamos con compromiso permanecen inalterados. De la misma manera, el surgimiento de fuentes financieras alternativas al crédito bancario también ha debilitado el proceso de transmisión monetaria a través de la oferta de préstamos. Así, Perez (1998) indica que los procesos de innovación financiera en Estados Unidos favorecieron la aparición de fuentes alternativas a la financiación bancaria, lo cual restó importancia al canal de préstamos bancarios $^{28}$. Asimismo, la orientación del sistema financiero americano hacia el mercado ha contribuido a mitigar la efectividad del canal de préstamos bancarios. De este modo, Brissimis y Magginas (2005), empleando una muestra de varios países,

\footnotetext{
${ }^{28}$ En un estudio posterior, Driscoll (2004) también pone de manifiesto que la existencia de fuentes financieras alternativas a la banca han mitigado los efectos del canal de préstamos bancarios, al encontrar que los impulsos monetarios, pese a influir sobre la oferta de préstamos, apenas tienen impacto sobre la economía estadounidense.
} 
encuentran que el canal de préstamos bancarios no opera en países donde el sistema financiero está más orientado al mercado que a la banca, como es el caso de Estados Unidos.

\subsubsection{2.- Evidencias empíricas en Europa}

La evidencia empírica del canal de préstamos bancarios con datos agregados apunta a que este canal es más importante en Europa que en Estados Unidos, debido a la mayor dependencia de la financiación bancaria por parte del sector empresarial que existe en el continente europeo $^{29}$ (Peek y Rosengren, 2013; Ferri et al., 2014). Aun así, los resultados no son concluyentes.

Un primer grupo de investigaciones soportan la existencia del canal de préstamos bancarios. Así, Buttiglione y Ferri (1994) encuentran que los préstamos bancarios desempeñan una labor crucial en el proceso de transmisión de la política monetaria en Italia $^{30}$. Escrivá y Haldane (1994) revelan la existencia de un canal de préstamos como mecanismo de transmisión monetaria en España, mientras que Holtemöller (2002) y Hülsewig et al. (2004) lo hacen para Alemania. En cambio, De Bondt (1999b), a partir de una muestra de países europeos, obtiene evidencias mixtas sobre la relevancia del canal de préstamos bancarios. Así, este canal es significativo en Alemania, Francia e Italia, mientras que no lo es en Reino Unido, Bélgica y Holanda. A su vez, los trabajos de Dale y Haldane (1993a; 1993b; 1995) y de Chrystal y Mizen (2002) muestran que el canal de préstamos bancarios es relevante en Reino Unido. Por su parte, Iacoviello y Minetti (2008) indican que los préstamos bancarios son un importante canal de transmisión de los shocks monetarios en el mercado de la vivienda de ciertos países de

\footnotetext{
${ }^{29}$ Según un estudio llevado a cabo por la European Banking Federation en 2012, el total de activos del sector bancario en Europa supone un 349\% del Producto Interior Bruto (PIB), mientras que en Estados Unidos es de un $78 \%$. Asimismo, la proporción de préstamos bancarios sobre PIB equivale a un $144 \%$ en Europa y a un $45 \%$ en Estados Unidos.

${ }^{30}$ Otros trabajos centrados en la economía italiana obtienen un resultado similar (Angeloni et al., 1995; Bagliano y Favero, 1995; Fanelli y Paruolo, 1999; Chiades y Gambacorta, 2000).
} 
Europa. Trabajos más recientes como los de Cappiello et al. (2010), Rondorf (2012) y Ciccarelli et al. (2014) encuentran evidencias a favor del canal de préstamos bancarios en los países de la zona euro ${ }^{31}$.

Por otro lado, un grupo de trabajos han encontrado evidencias negativas sobre la existencia del canal de préstamos bancarios en Europa. Así, Goux (1996) y Bellando y Pollin (1996) muestran que el crédito no es significativo en la transmisión de los impulsos monetarios en Francia. Otros trabajos obtienen un resultado similar para el caso de Alemania (Tsatsaronis, 1995; Barran et al., 1995; Guender y Moersch, 1997; Küppers, 2001). Del mismo modo, Garretsen y Swank (1998), Van Ees et al. (1999) y Kakes (2000) encuentran que el canal de préstamos bancarios no es efectivo en Holanda, debido a que los bancos utilizan sus activos líquidos para protegerse de las restricciones monetarias. Por su parte, Angeloni et al. (2003) analizan un amplio conjunto de países europeos y muestran que en la mayoría de ellos la transmisión de la política monetaria se explica principalmente a través del canal tradicional de tipos de interés, lo cual restaría importancia al canal de crédito $^{32}$.

La Tabla 2.1 recoge un resumen de las principales evidencias empíricas del canal de préstamos bancarios encontradas por los trabajos que utilizan datos agregados.

\footnotetext{
${ }^{31}$ Otros estudios también han mostrado la importancia del canal de préstamos bancarios en otros países europeos como Finlandia (Anari et al., 2002), Europa Central y del Este (Héricourt, 2006), Grecia (Markidou y Nikolaidou, 2008) y Suecia (Papadamou y Siriopoulos, 2012).

${ }^{32}$ Creel y Levasseur (2006) obtienen un resultado similar para una muestra de países europeos más reducida.
} 
Tabla 2.1: Resumen de las principales evidencias empíricas del canal de préstamos bancarios con datos macroeconómicos o agregados

\begin{tabular}{|c|c|c|c|}
\hline Ámbito de estudio & \multicolumn{2}{|c|}{ Evidencias } & Autores \\
\hline \multirow[b]{3}{*}{ Estados Unidos } & \begin{tabular}{lllll}
-Los primeros & \multicolumn{2}{c}{ trabajos } & se \\
caracterizan por & una falta & de \\
consenso. & & & &
\end{tabular} & $\begin{array}{l}\text {-Evidencias a favor de la existencia } \\
\text { de un canal de préstamos bancarios. }\end{array}$ & $\begin{array}{l}\text { Brunner y Meltzer (1963), Bernanke (1983; 1986), } \\
\text { Bernanke y Blinder (1992), Kashyap et al. }(1993 ; 1996) \text {, } \\
\text { Fackler y Rogers (1993), Friedman y Kuttner (1993), } \\
\text { Ludvigson (1998). }\end{array}$ \\
\hline & & $\begin{array}{l}\text {-Evidencias en contra de la existencia } \\
\text { de un canal de préstamos bancarios. }\end{array}$ & $\begin{array}{l}\text { King (1986), Romer y Romer (1990), Ramey (1993), } \\
\text { Oliner y Rudebusch (1995), Douglas (1996). }\end{array}$ \\
\hline & \multicolumn{2}{|c|}{$\begin{array}{l}\text { El canal de préstamos bancarios va perdiendo importancia: } \\
\text {-Cambios en la regulación, la percepción del riesgo y la innovación. } \\
\text {-Existencia de préstamos con compromiso contractual. } \\
\text {-Aparición de fuentes de financiación alternativas al crédito bancario. } \\
\text {-Orientación del sistema financiero hacia el mercado. }\end{array}$} & $\begin{array}{l}\text { Thakor (1996), Morgan (1998), Perez (1998), Driscoll } \\
\text { (2004), Brissimis y Magginas (2005), Milcheva (2013). }\end{array}$ \\
\hline \multirow[t]{2}{*}{ Europa } & \multirow[t]{2}{*}{$\begin{array}{l}\text {-El canal de préstamos bancarios es } \\
\text { más relevante que en Estados } \\
\text { Unidos, debido a la mayor } \\
\text { dependencia de la financiación } \\
\text { bancaria y a la mayor importancia } \\
\text { que tiene la banca en el sistema } \\
\text { financiero. Aún así, no se han } \\
\text { alcanzado evidencias concluyentes. }\end{array}$} & $\begin{array}{l}\text {-Evidencias a favor de la existencia } \\
\text { de un canal de préstamos bancarios. }\end{array}$ & $\begin{array}{l}\text { Dale y Haldane (1993a; 1993b; 1995), Buttiglione y Ferri } \\
\text { (1994), Escrivá y Haldane (1994), Angeloni et al. (1995), } \\
\text { Bagliano y Favero (1995), Fanelli y Paruolo (1999), De } \\
\text { Bondt (1999b), Chiades y Gambacorta (2000), Chrystal y } \\
\text { Mizen (2002), Anari et al. (2002), Holtemöller (2002), } \\
\text { Hülsewig et al. (2004), Héricourt (2006), Markidou y } \\
\text { Nikolaidou (2008), Iacoviello y Minetti (2008), Cappiello } \\
\text { et al. (2010), Papadamou y Siriopoulos (2012) Rondorf } \\
\text { (2012), Ciccarelli } \text { et al. (2014). }\end{array}$ \\
\hline & & $\begin{array}{l}\text {-Evidencias en contra de la existencia } \\
\text { de un canal de préstamos bancarios. }\end{array}$ & $\begin{array}{l}\text { Tsatsaronis (1995), Barran et al. (1995), Goux (1996), } \\
\text { Bellando y Pollin (1996), Guender y Moersch (1997), } \\
\text { Garretsen y Swank (1998), Van Ees et al. (1999), De } \\
\text { Bondt (1999b), Kakes (2000), Küppers (2001), Angeloni } \\
\text { et al. (2003), Creel y Levasseur (2006). }\end{array}$ \\
\hline
\end{tabular}

Fuente: elaboración propia. 


\subsection{2.- El canal de préstamos bancarios con datos microeconómicos o desagregados}

El estudio del canal de préstamos bancarios con un enfoque agregado ha sido criticado en la literatura debido a un problema fundamental de identificación entre la oferta y la demanda de crédito. Este problema ha propiciado la aparición de otro tipo de trabajos basados en el empleo de información microeconómica o desagregada de bancos, que analizan cómo la oferta de préstamos reacciona a shocks monetarios en función de ciertas variables relacionadas con la salud financiera de las entidades de crédito. Así, los bancos con una peor salud financiera tienen más dificultades para acceder a fuentes de financiación alternativas a los depósitos cuando se produce una restricción monetaria (Kishan y Opiela, 2006). Además, su coste de financiación externa vía mercados se encarece en mayor medida tras una política monetaria restrictiva (Disyatat, 2011). La salud financiera de los bancos se ha medido tradicionalmente a través de tres variables: tamaño, liquidez y capital (Kashyap y Stein, 1995a; 1995b; 2000; Kishan y Opiela, 2000; 2006), mientras que más recientemente se ha considerado el riesgo de crédito de los bancos (Altunbas et al., 2010; Bogoev, 2010; Gambacorta y Marques-Ibanez, 2011). Asimismo, un cierto número de estudios ha analizado la concentración del mercado bancario como otro determinante de la oferta de crédito ante shocks monetarios (Adams y Amel, 2005; 2011; Olivero et al., 2011a). A continuación se explica en detalle cada una de estas variables y su relación con el canal de préstamos bancarios.

\subsubsection{1.- Tamaño y canal de préstamos bancarios}

El tamaño de las entidades de crédito es uno de los principales indicadores de la capacidad de los bancos para acceder a fuentes de fondos $y$, por tanto, proteger su oferta 
de préstamos de políticas monetarias restrictivas. Diversos motivos pueden conducir a que las entidades pequeñas sean más sensibles a las restricciones monetarias (Peltzman, 1969; Kashyap y Stein, 1995a; 1995b; Kishan y Opiela, 2000). En primer lugar, los bancos pequeños suelen poseer estructuras de capital más simples y tienden a financiar sus préstamos a través de transacciones y depósitos de ahorro. Por tanto, cuando se reduce la oferta monetaria, estas entidades no son capaces de mantener su actividad crediticia recurriendo a fuentes de financiación alternativas. En segundo lugar, las entidades pequeñas, a diferencia de las grandes, tienen mayor dificultad para emitir activos financieros, como por ejemplo certificados de depósitos, para contrarrestar la disminución de la base de depósitos tras una restricción monetaria. En tercer lugar, las entidades pequeñas soportan mayores costes derivados de asimetrías informativas a la hora de obtener fondos no asegurados para financiar sus préstamos.

A partir de estos planteamientos, trabajos más recientes en Estados Unidos establecen que las restricciones monetarias tienen una mayor influencia sobre los bancos pequeños independientes que no están afiliados a otra entidad bancaria de mayor tamaño (Campello, 2002). Cetorelli y Goldberg (2012) encuentran que los bancos globales más grandes pueden aislar mejor su oferta de préstamos de los movimientos de la política monetaria. A su vez, Jonas y King (2013) muestran que una subida de los tipos de interés de la Reserva Federal solamente conduce a una reducción de la oferta de préstamos para los bancos más pequeños, mientras que los grandes no se ven afectados.

En cambio, un reducido número de trabajos no posiciona el tamaño como relevante al explicar la reacción de la oferta de préstamos de los bancos americanos a las decisiones de política monetaria. Así, Holod y Peek (2007) muestran que los bancos cotizados, al margen de su tamaño, son menos sensibles a shocks monetarios. A su vez, 
Dave et al. (2013) revelan que una restricción monetaria reduce la oferta crediticia de todas las entidades, independientemente de su tamaño.

Atendiendo a la evidencia empírica europea, el canal de préstamos bancarios se transmite principalmente a través de los bancos más pequeños con activos ilíquidos en Alemania, Holanda y Bélgica (De Bondt, 1999b), y en Italia y Francia según King (2000). Por su parte, Kakes y Sturm (2002) encuentran que, tras una contracción monetaria, la oferta de préstamos de los bancos pequeños de Alemania se reduce de forma más notoria que la oferta crediticia de las entidades más grandes. De Haan (2003) obtiene un resultado similar para Holanda y Jimborean (2009) para varios países de Europa Central y del Este. Atendiendo a trabajos más recientes, De Santis y Surico (2013) muestran que los efectos de la política monetaria son más pronunciados para las pequeñas cajas de ahorro de Italia, mientras que Ferri et al. (2014) encuentran la misma evidencia para los bancos de la zona euro.

Por el contrario, también hay trabajos en Europa que no encuentran que el tamaño de las entidades condicione el proceso de transmisión de la política monetaria. En este sentido, Favero et al. (1999), considerando los distintos tamaños de las entidades de varios países europeos, no obtienen evidencias que sustenten la importancia de un canal de préstamos bancarios durante la restricción monetaria de 1992. A su vez, Ehrmann et al. (2003) no encuentran diferencias en la reacción de la oferta de préstamos a las actuaciones de política monetaria para una muestra de bancos europeos con diferentes $\operatorname{tamaños}^{33}$.

\footnotetext{
${ }^{33}$ Otros trabajos encuentran un resultado similar para el caso concreto de Suiza (Steudler y Zurlinden, 1998), España (Hernando y Martínez-Pagés, 2001), Portugal (Farinha y Marques, 2001), Austria (Kaufmann, 2001), Finlandia (Topi y Vilmunen, 2001) e Italia (Gambacorta, 2005).
} 


\subsubsection{2.- Liquidez y canal de préstamos bancarios}

La liquidez de las entidades de crédito es otro factor que condiciona los efectos de la política monetaria sobre los préstamos bancarios. Existen dos razones fundamentales por las que las entidades más ilíquidas pueden ser más sensibles a las variaciones de política monetaria (Stein, 1998; Chatelain et al., 2003). Por un lado, los activos líquidos pueden utilizarse para proteger la cartera de préstamos de los shocks monetarios, por lo que las entidades con problemas de liquidez no pueden mantener su oferta crediticia cuando se endurecen las condiciones monetarias, al no disponer de suficiente efectivo para atender a la demanda de préstamos. Por otro lado, las entidades más líquidas suelen tener más facilidad para acceder a fuentes de financiación, protegiendo en mayor medida su oferta crediticia de una restricción monetaria. Por el contrario, las entidades con menores reservas de liquidez no pueden compensar de forma rápida y sin coste la pérdida de depósitos que se produce tras una política monetaria restrictiva.

Ciertos trabajos estadounidenses confirman esta relación entre la liquidez y la reacción de la oferta crediticia a shocks monetarios. Así, Kashyap y Stein (2000) revelan que las entidades más ilíquidas y de menor tamaño reaccionan con más intensidad a shocks monetarios. Por su parte, Loutskina (2005) y Loutskina y Strahan (2009) muestran que los bancos con balances más líquidos, a través de una mayor titulización de activos, son menos sensibles a los cambios en la política monetaria. En cambio, otros trabajos centrados en Estados Unidos obtienen resultados distintos. Así, Ashcraft (2006) no revela que una mayor disposición de liquidez reduzca la probabilidad de sufrir restricciones financieras $y$, por tanto, la sensibilidad de las entidades a los movimientos de la política monetaria. Brissimis y Delis (2009), utilizando una muestra de países de la OCDE, no evidencian un canal de préstamos bancarios en Estados Unidos, ni que se produzcan diferencias en la reacción del crédito 
a shocks monetarios en función de variables específicas de los bancos como la liquidez. A su vez, Baum et al. (2013) encuentran que en períodos de incertidumbre los bancos más líquidos tienden a ser prudentes y contraen más su oferta crediticia ante shocks monetarios.

Por lo que respecta a Europa, las entidades con menores reservas de liquidez son más sensibles a la política monetaria (Ehrmann et al., 2003). Así lo proponen también Loupias et al. (2003) para el caso de los bancos de Francia y Gambacorta (2005) para los de Italia. A su vez, Brissimis et al. (2001), a partir de una muestra de bancos griegos entre 1995 y 2000, muestran que los bancos más líquidos y de mayor tamaño pueden preservar mejor su oferta de crédito de las decisiones de política monetaria. Matousek y Sarantis (2009) obtienen un resultado similar para las entidades de varios países de Europa Central y del Este. Trabajos más recientes como el de Jiménez y Ongena (2012) proponen que las contracciones monetarias reducen de manera más pronunciada la oferta de crédito de las entidades de España con baja liquidez, mientras que De Santis y Surico (2013) obtienen la misma evidencia para las cooperativas y cajas de ahorro alemanas.

Ciertos trabajos europeos encuentran el resultado opuesto. Así, Jimborean (2009), para una muestra de entidades de Europa Central y del Este, indican que a corto plazo los bancos líquidos reducen más su oferta de préstamos que los bancos ilíquidos cuando varían las condiciones de la política monetaria. Bogoev (2010) encuentra que los bancos de Macedonia con mayores niveles de liquidez responden de forma más pronunciada a los movimientos de política monetaria, lo cual puede deberse a la existencia de un exceso estructural de liquidez. 


\subsubsection{3- Capital y canal de préstamos bancarios}

El capital es otro factor que ha sido tenido en cuenta en los estudios del canal de préstamos bancarios con datos desagregados, de manera que los efectos de las restricciones monetarias son más intensos para las entidades menos capitalizadas por tres motivos (Peek y Rosengren, 1995; Jayaratne y Morgan, 2000; Bernanke, 2007). El primero de ellos es que el mercado percibe un mayor riesgo en las entidades con bajos niveles de capital, dado que poseen menos fondos propios con los que hacer frente a posibles pérdidas, y eso dificulta su acceso a fuentes de financiación vía mercados. En segundo lugar, las entidades menos capitalizadas están más expuestas a problemas de información asimétrica, ya que existe un mayor desconocimiento sobre ellas. El tercero y último hace referencia a que cuando los niveles de capital son bajos, es más probable que surja el problema de riesgo moral, dado que al disponer de menos fondos propios, las entidades tendrán un incentivo mayor a asumir riesgos excesivos. Estos problemas de información asimétrica y riesgo moral asociados a entidades poco capitalizadas contribuyen a elevar sus costes de financiación.

Respecto a las evidencias empíricas en Estados Unidos, Kishan y Opiela (2000) y Van den Heuvel (2002) muestran que los bancos menos capitalizados restringen su oferta de préstamos en mayor medida cuando se produce una política monetaria restrictiva. En un estudio posterior, Kishan y Opiela (2006) también obtienen este mismo resultado, pero además reflejan que tras los acuerdos de Basilea, las expansiones monetarias no son efectivas a la hora de impulsar la oferta crediticia de los bancos con bajos niveles de capital. Asimismo, Ashcraft (2006) revela que un reducido capital incrementa la sensibilidad de la oferta crediticia a los movimientos de la política monetaria. Más recientemente, Van den Heuvel (2012) encuentra que los sectores 
bancarios con bajos niveles de capital se ven más afectados por las variaciones de los tipos de interés de la Reserva Federal.

En Europa, Peek y Rosengren (1995), en un análisis del Reino Unido, muestran que los bancos sin restricciones de capital son más capaces de aumentar su oferta de préstamos cuando se relajan las condiciones monetarias. Por otro lado, Altunbas et al. (2002) utilizan una muestra de bancos europeos, encontrando que aquellos con niveles bajos de capital responden con más intensidad a las actuaciones de política monetaria con independencia de su tamaño. Por otra parte, en Holanda una restricción monetaria reduce los préstamos sin garantías, especialmente los concedidos por los bancos menos capitalizados (De Haan, 2003). Westerlund (2003), a partir de un panel de bancos de Suecia entre 1998 y 2003, revela que las entidades con menores niveles de capital tienen más limitaciones para hacer frente a shocks monetarios y Gambacorta y Mistrulli (2004) obtienen un resultado similar para las entidades italianas. Atendiendo a trabajos más recientes, Jiménez y Ongena (2012), utilizando una amplia muestra de bancos y empresas de España, encuentran una relación negativa entre los tipos de interés de la política monetaria y las concesiones de préstamos, más intensa en los bancos con niveles más bajos de capital. De la misma manera, De Santis y Surico (2013) indican que los bancos de Alemania menos capitalizados se ven más afectados por las contracciones monetarias.

\subsubsection{4.- Riesgo de crédito y canal de préstamos bancarios}

El riesgo de crédito es otra variable que ha sido analizada en los trabajos del canal de préstamos bancarios con datos desagregados. Las entidades con un riesgo de crédito mayor son más sensibles a las contracciones monetarias, porque tienen más dificultades para obtener financiación vía mercados. Así, los inversores penalizan a las entidades 
que no llevan una adecuada gestión de riesgos exigiéndolas una rentabilidad mayor (Blum, 2002; Goyal, 2005; Maechler y McDill, 2006; Kishan y Opiela, 2012).

Los trabajos empíricos que incorporan el riesgo de crédito son relativamente recientes y se centran mayoritariamente en Europa. Así, Chmielewski (2006) encuentra que los efectos de la política monetaria sobre el crédito son más importantes en las entidades de Polonia con mayor riesgo de crédito. Holod y Peek (2007) reflejan que un mayor riesgo de crédito, medido a través de la proporción de préstamos impagados, provoca una reducción más pronunciada de la oferta crediticia cuando se endurecen las condiciones de política monetaria en Estados Unidos. En cambio, Pruteanu-Podpiera (2007) obtiene el resultado opuesto para una muestra de bancos checos, es decir, el riesgo de crédito afecta positivamente a la oferta de préstamos cuando se contrae la política monetaria. Por su parte, Bouvatier y Lepetit (2008), a partir de una muestra de bancos europeos entre 1992 y 2004, revelan que un mayor volumen de provisiones por préstamos fallidos para hacer frente al riesgo de crédito amplifica las fluctuaciones de crédito. De la misma manera, Bogoev (2010) muestra que los bancos de Macedonia con mayor riesgo de crédito se ven más afectados por una política monetaria restrictiva. Altunbas et al. (2010), a partir de una muestra de entidades europeas entre 1999 y 2005 , indican que los bancos con menor riesgo de crédito son menos sensibles a la política monetaria y, por tanto, reducen su oferta de préstamos en menor medida cuando suben los tipos de interés. Sin embargo, la capacidad de estos bancos para aislar su oferta crediticia de restricciones monetarias depende del ciclo económico, siendo menor en períodos de recesión. Gambacorta y Marques-Ibanez (2011) encuentran que la oferta de préstamos de los bancos de Europa y Estados Unidos con mayor riesgo, medido a través de la probabilidad de impago esperada, se contrae más durante restricciones monetarias. 


\subsubsection{5.- Concentración bancaria, competencia y canal de préstamos bancarios}

La concentración bancaria y el nivel de competencia constituyen otras de las variables que se han empleado en la literatura que analiza el canal de préstamos bancarios con información desagregada. Un mercado bancario más concentrado y menos competitivo puede reducir la efectividad del canal de préstamos bancarios por dos motivos (Kashyap y Stein, 1995a; 1995b; 2000; Olivero et al., 2011a). Por un lado, los mercados bancarios más concentrados normalmente están integrados por entidades más grandes con una mayor cuota de mercado. Este tipo de entidades gozan, generalmente, de unas condiciones más ventajosas de financiación, lo que les permite aislar mejor su oferta crediticia de shocks monetarios. Por otro lado, los procesos de concentración bancaria suelen dar lugar a operaciones de adquisición de entidades pequeñas y financieramente débiles por parte de entidades más grandes y solventes, mejorando el acceso a fuentes alternativas de fondos para el sector bancario en su conjunto.

A partir de los planteamientos anteriores, la mayoría de los estudios empíricos han encontrado que las entidades que operan en mercados con mayores niveles de concentración bancaria y menor competencia son menos sensibles a shocks monetarios. Así, Adams y Amel (2005) muestran que los efectos de la política monetaria sobre el canal de crédito son más notorios en los mercados más competitivos, generalmente en las zonas urbanas, que en los mercados menos competitivos típicos de las zonas rurales de Estados Unidos ${ }^{34}$. De forma análoga, Brissimis et al. (2012), considerando tanto Estados Unidos como Europa, encuentran que el canal de préstamos de la política monetaria es más efectivo en sectores bancarios con una mayor competencia. En

\footnotetext{
${ }^{34}$ En un estudio posterior, Adams y Amel (2011) consideran la concentración bancaria para analizar el canal de préstamos bancarios, obteniendo resultados similares. En este sentido, el canal de préstamos bancarios es más intenso cuanto menor es la concentración del mercado bancario.
} 
cambio, Gunji et al. (2009), a partir de una muestra de bancos de varios países del mundo, indican que la competencia en el sector de la banca debilita la transmisión de la política monetaria. Por lo que respecta a los trabajos que se centran solamente en Europa, Kashyap y Stein (1997) y Cechetti (1999) afirman que el impacto de la política monetaria común difiere por países, debido a la existencia de estructuras de mercado heterogéneas. Estos autores encuentran que los países de la zona euro con una mayor proporción de bancos pequeños son más sensibles a las variaciones de política monetaria. De la misma manera, De Santis y Surico (2013) revelan que los países europeos con mayores niveles de concentración bancaria ajustan menos su oferta de préstamos en respuesta a un shock monetario. Por su parte, Leroy (2014), utilizando una muestra de bancos europeos antes y durante la crisis, encuentra que la oferta de crédito de las entidades con mayor poder de mercado y que operan en industrias bancarias más concentradas se ve menos afectada por restricciones monetarias ${ }^{35}$.

A diferencia de los estudios para Estados Unidos y Europa, los trabajos para otras regiones del mundo se caracterizan por una falta de consenso. Así, Olivero et al. (2011a) encuentran que un mercado más competitivo, medido a través de índices de concentración bancaria, mejora la eficacia del canal de préstamos bancarios en Asia y Latinoamérica. Sin embargo, en otro trabajo, Olivero et al. (2011b) utilizan una muestra similar, revelando que las entidades que operan en sectores bancarios con mayor competencia son menos sensibles a las restricciones monetarias. A su vez, Amidu y Wolfe (2013) obtienen un resultado parecido para una muestra de países emergentes.

La Tabla 2.2 refleja, de forma resumida, las principales evidencias empíricas del canal de préstamos bancarios con datos desagregados para cada uno de los indicadores descritos anteriormente.

\footnotetext{
${ }^{35}$ Fungácová et al. (2014) obtienen resultados similares, pero sólo durante los años previos a la crisis.
} 
Tabla 2.2: Resumen de las principales evidencias empíricas del canal de préstamos bancarios con datos desagregados

\begin{tabular}{|c|c|c|c|}
\hline Indicador & Resultados & Ámbito de estudio & Autores \\
\hline \multirow{4}{*}{ Tamaño } & \multirow{2}{*}{$\begin{array}{l}\text {-Los bancos más pequeños son más sensibles } \\
\text { a las restricciones monetarias. }\end{array}$} & Estados Unidos & $\begin{array}{l}\text { Kashyap y Stein (1995a; 1995b; 2000), Kishan y Opiela (2000; } \\
\text { 2006), Campello (2002), Cetorelli y Goldberg (2012), Jonas y King } \\
\text { (2013). }\end{array}$ \\
\hline & & Europa & $\begin{array}{l}\text { De Bondt (1999a), King (2000), Kakes y Sturm (2002), De Haan } \\
\text { (2003), Jimborean (2009), De Santis y Surico (2013), Ferri et al. } \\
\text { (2014). }\end{array}$ \\
\hline & \multirow[b]{2}{*}{$\begin{array}{l}\text {-El tamaño no condiciona al canal de } \\
\text { préstamos bancarios }\end{array}$} & Estados Unidos & Holod y Peek (2007), Dave et al. (2013). \\
\hline & & Europa & $\begin{array}{l}\text { Steudler y Zurlinden (1998), Favero et al. (1999), Hernando y } \\
\text { Martínez-Pagés (2001), Farinha y Marques (2001), Kaufmann } \\
\text { (2001), Topi y Vilmunen (2001), Ehrmann et al. (2003), } \\
\text { Gambacorta (2005). }\end{array}$ \\
\hline \multirow{4}{*}{ Liquidez } & \multirow[b]{2}{*}{$\begin{array}{l}\text {-Los bancos más ilíquidos son más sensibles } \\
\text { a las restricciones monetarias. }\end{array}$} & Estados Unidos & $\begin{array}{l}\text { Kashyap y Stein (2000), Loutskina (2005), Loutskina y Strahan } \\
\text { (2009). }\end{array}$ \\
\hline & & Europa & $\begin{array}{l}\text { Brissimis et al. (2001), Loupias et al. (2003), Ehrmann et al. (2003), } \\
\text { Gambacorta (2005), Matousek y Sarantis (2009), Jiménez y Ongena } \\
\text { (2012), De Santis y Surico (2013). }\end{array}$ \\
\hline & \multirow{2}{*}{$\begin{array}{l}\text {-Una mayor liquidez acentúa/ no condiciona } \\
\text { el canal de préstamos bancarios. }\end{array}$} & Estados Unidos & Ashcraft (2006), Brissimis y Delis (2009), Baum et al. (2013). \\
\hline & & Europa & Jimborean (2009), Bogoev (2010). \\
\hline \multirow[b]{2}{*}{ Capital } & \multirow{2}{*}{$\begin{array}{l}\text {-Los bancos con menores niveles de capital } \\
\text { son más sensibles a las restricciones } \\
\text { monetarias. }\end{array}$} & Estados Unidos & $\begin{array}{l}\text { Kishan y Opiela (2000; 2006), Van den Heuvel (2002; 2012), } \\
\text { Ashcraft (2006). }\end{array}$ \\
\hline & & Europa & $\begin{array}{l}\text { Peek y Rosengren (1995), Altunbas et al. (2002), De Haan (2003), } \\
\text { Westerlund (2003), Gambacorta y Mistrulli (2004), Jiménez y } \\
\text { Ongena (2012), De Santis y Surico (2013). }\end{array}$ \\
\hline Riesgo de crédito & $\begin{array}{l}\text {-Los bancos con mayor riesgo de crédito } \\
\text { suelen ser más sensibles a las restricciones } \\
\text { monetarias. }\end{array}$ & $\begin{array}{l}\text { Estados Unidos y } \\
\text { Europa }\end{array}$ & $\begin{array}{l}\text { Chmielewski (2006), Holod y Peek (2007), Pruteanu-Podpiera } \\
\text { (2007), Bouvatier y Lepetit (2008), Bogoev (2010), Altunbas et al. } \\
\text { (2010), Gambacorta y Marques-Ibanez (2011). }\end{array}$ \\
\hline \multirow[t]{2}{*}{$\begin{array}{l}\text { Concentración y } \\
\text { competencia bancaria }\end{array}$} & $\begin{array}{l}\text {-Los bancos en mercados bancarios más } \\
\text { concentrados y menos competitivos suelen } \\
\text { ser menos sensibles a las restricciones } \\
\text { monetarias. }\end{array}$ & $\begin{array}{l}\text { Estados Unidos y } \\
\text { Europa }\end{array}$ & $\begin{array}{l}\text { Kashyap y Stein (1997), Cechetti (1999), Adams y Amel (2005; } \\
\text { 2011), Gunji et al. (2009), Brissimis et al. (2012), De Santis y } \\
\text { Surico (2013), Leroy (2014) Fungácová et al. (2014). }\end{array}$ \\
\hline & $\begin{array}{l}\text {-Falta de consenso acerca del impacto de la } \\
\text { concentración y la competencia bancaria } \\
\text { sobre el canal de préstamos bancarios. }\end{array}$ & Países emergentes & Olivero et al. (2011a; 2011b), Amidu y Wolfe (2013). \\
\hline
\end{tabular}




\section{3.- RIESGO SOBERANO Y CANAL DE PRÉSTAMOS BANCARIOS}

En Europa ha sido creciente la preocupación por el impacto que el riesgo soberano puede ejercer sobre los intermediarios financieros, sus balances y su capacidad para conceder crédito. La crisis financiera provocó un fuerte deterioro de las finanzas de muchos países, aumentando la preocupación de los inversores por el riesgo soberano. La zona euro se ha visto especialmente afectada, puesto que la deuda de varios de sus países miembros ha perdido el status de libre de riesgo. La apreciación de un mayor riesgo soberano ha incrementado el coste y reducido la disponibilidad de financiación de sus bancos, dando lugar a grandes divergencias en las condiciones financieras de la banca de los distintos países (Banco Central Europeo, 2012a).

La existencia de problemas de financiación bancaria, como consecuencia de un elevado riesgo soberano, puede ser un factor muy relevante que condiciona la oferta de crédito. Por lo tanto, además de los indicadores considerados en la literatura del canal de préstamos bancarios con datos desagregados (tamaño, liquidez, capital, riesgo de crédito y concentración bancaria), resulta interesante analizar el efecto del riesgo soberano sobre el canal de préstamos bancarios.

Existen diferentes canales mediante los cuales un aumento del riesgo soberano se transmite a las condiciones de financiación de los bancos nacionales (Committee on the Global Financial System, 2011): canal de tenencias de activos (asset holdings channel), canal de liquidez/colateral (liquidity/collateral channel), canal de rating soberano (sovereign rating channel) y canal de garantías del gobierno (government guarantees channel). A continuación procedemos a explicar cada uno de ellos.

En primer lugar, de acuerdo al canal de tenencias de activos (asset holdings channel), un mayor riesgo soberano produce pérdidas en los títulos de deuda soberana 
que las entidades poseen en su balance ${ }^{36}$, debilitándolo y haciendo que el acceso a financiación sea más difícil y costoso (Trichet, 2010; Alter y Schuler, 2012; Correa et al., 2012). Este mecanismo es muy relevante en Europa, dado que los bancos de la zona euro están expuestos en gran medida a la deuda soberana de su país de origen (Committee on the Global Financial System, 2011; Breton et al., 2012).

Así, Popov y van Horen (2013), a partir de un conjunto de bancos europeos, muestran que una reducción del valor de los bonos extranjeros de deuda soberana mantenidos por las entidades en sus balances, fruto de un mayor riesgo soberano, conducen a un incremento de sus costes de financiación y disminuyen su oferta de préstamos. Por su parte, De Marco (2013) encuentra que ante un aumento del riesgo soberano, los bancos de Europa con balances más expuestos a la deuda soberana, reducen su oferta de préstamos en mayor medida. A su vez, Gennaioli et al. (2014) analizan 18 crisis de deuda soberana durante 1998-2012 y revelan que la correlación entre las tenencias de bonos de deuda pública de los bancos en sus balances y sus préstamos futuros es positiva en épocas normales, mientras que en épocas de crisis es negativa.

En segundo lugar, el canal de liquidez/colateral (liquidity/collateral channel) sostiene que un mayor riesgo soberano reduce el valor de las garantías de los bancos para acceder a financiación mayorista y obtener liquidez del Banco Central (Trichet, 2010; Davies y Ng, 2011; Allen y Moessner, 2012). Esto es debido a que los títulos de deuda pública se utilizan como colaterales para que las entidades puedan recibir crédito del Banco Central. En este sentido, el trabajo de Correa et al. (2012) muestra que los bancos europeos son menos capaces de obtener financiación en dólares del mercado

\footnotetext{
${ }^{36}$ Los bancos suelen poseer títulos de deuda pública en sus balances, lo que tradicionalmente les ha permitido mantener menos niveles de capital regulatorio, ya que los títulos de deuda pública siempre han sido considerados libres de riesgo (Barth et al., 2012).
} 
monetario estadounidense, debido a la reducción de los colaterales causada por el riesgo soberano. Asimismo, De Bruyckere et al. (2013), a partir de una muestra de entidades europeas durante 2007-2012, encuentran que un mayor riesgo soberano afecta negativamente a los colaterales de los bancos, especialmente a aquellos con una mayor proporción de bonos de deuda soberana y que más dependen de fuentes de financiación a corto plazo.

En tercer lugar, el canal de rating soberano (sovereign rating channel) afirma que las rebajas del rating de un país van acompañadas habitualmente de bajadas en el rating individual de sus bancos nacionales, lo cual incrementa su riesgo de crédito y restringe su acceso a financiación (Committee on the Global Financial System, 2011). Cuando un país no posee un rating próximo al máximo de la escala de puntuación, por ejemplo triple A o similar, los bancos nacionales se verán penalizados, independientemente de su fortaleza financiera. Esto se debe a que el rating soberano de un país suele comportarse como un límite del rating máximo al que pueden aspirar las instituciones de crédito nacionales (Peter y Grandes, 2005; Borensztein et al., 2013). En este sentido, Arezki et al. (2011), a partir de una muestra de países europeos, revelan que los descensos en el rating soberano de un país afectan negativamente al mercado bancario, especialmente si el rating del país en cuestión está cerca del grado de especulación. A partir de una muestra de países emergentes, Williams et al. (2013) indican que las variaciones de los ratings soberanos ejercen un impacto significativo sobre los ratings bancarios. Por su parte, Alsakka et al. (2014), para una muestra de países europeos, encuentran que las rebajas de rating soberano de un país conducen a rebajas en el rating de sus bancos nacionales, especialmente durante los años de crisis y para los países periféricos. Además, esta correlación es significativamente más alta en las bajadas que en los aumentos de calificación (Ferri et al., 2001). Recientemente, Adelino y Ferreira (2014), 
a partir de un conjunto de varios países del mundo, muestran que las rebajas en el rating soberano perjudican al rating de los bancos nacionales, reduciendo su disposición a conceder préstamos e incrementando el tipo de los mismos.

En cuarto lugar, de acuerdo al canal de garantías del gobierno (government guarantees channel), el deterioro del riesgo soberano reduce los beneficios que ciertos bancos obtienen de las garantías que les conceden sus respectivos gobiernos. Las entidades sistémicas han disfrutado siempre explícita o implícitamente de garantías gubernamentales, debido a los efectos adversos que su quiebra originaría sobre el conjunto de la economía, contribuyendo a reducir sus costes de financiación (Correa et al., 2012). Sin embargo, un aumento del riesgo soberano da lugar a que el valor de dichas garantías se reduzca (Gray y Malone, 2012).

En este sentido, varios trabajos han encontrado que el riesgo soberano repercute sobre el apoyo que obtienen las entidades por parte del gobierno. Así, Brown y Dinc (2011), a partir de datos de países emergentes, muestran que aquellos con mayores niveles de déficit público son menos propensos a rescatar a los bancos nacionales con problemas. Schich y Lindh (2012), a través de una muestra de entidades grandes pertenecientes a varios países de Europa, encuentran que las garantías que obtienen los bancos de sus gobiernos son más pequeñas cuanto menor es la solvencia de su país. A su vez, Grande et al. (2011) encuentran que los bancos que han recibido más garantías gubernamentales durante la crisis de deuda han podido expandir más su oferta de préstamos bancarios. Por su parte, Puri et al. (2011) revelan que durante la crisis las cajas de ahorro alemanas reducen significativamente sus préstamos una vez que han utilizado las garantías que reciben de los Landesbanken. 
La Tabla 2.3 muestra un resumen de los canales por los cuales el riesgo soberano afecta a las condiciones de financiación de los bancos.

Tabla 2.3: Resumen de los canales por los que el riesgo soberano afecta a las condiciones de financiación de los bancos

\begin{tabular}{|c|c|c|}
\hline Canales & Resultados & Autores \\
\hline $\begin{array}{l}\text { Canal de tenencias de } \\
\text { activos } \\
\text { (asset holdings channel) }\end{array}$ & $\begin{array}{l}\text {-El riesgo soberano afecta } \\
\text { negativamente a los títulos de deuda } \\
\text { pública que mantienen las entidades en } \\
\text { sus balances, lo cual incrementa el } \\
\text { coste y reduce la disponibilidad de } \\
\text { financiación para los bancos. }\end{array}$ & $\begin{array}{l}\text { Trichet (2010), Committee } \\
\text { on the Global Financial } \\
\text { System (2011), Alter y } \\
\text { Schuler (2012), Correa et } \\
\text { al. (2012), Breton et al. } \\
\text { (2012), Popov y van Horen } \\
\text { (2013), De Marco (2013), } \\
\text { Gennaioli et al. (2014). }\end{array}$ \\
\hline $\begin{array}{l}\text { Canal de liquidez/ } \\
\text { colateral } \\
\text { (liquidity/collateral } \\
\text { channel) }\end{array}$ & $\begin{array}{l}\text {-El riesgo soberano reduce el valor de } \\
\text { los colaterales que poseen los bancos, } \\
\text { lo que limita su acceso a financiación } \\
\text { en los mercados. }\end{array}$ & $\begin{array}{l}\text { Trichet (2010), Davies y } \\
\mathrm{Ng} \text { (2011), Allen y } \\
\text { Moessner (2012), Correa et } \\
\text { al. (2012), De Bruyckere et } \\
\text { al. (2013). }\end{array}$ \\
\hline $\begin{array}{l}\text { Canal de rating } \\
\text { soberano } \\
\text { (sovereign rating } \\
\text { channel) }\end{array}$ & $\begin{array}{l}\text {-Los descensos en el rating soberano } \\
\text { de un país generan rebajas en el rating } \\
\text { de sus bancos nacionales, lo que } \\
\text { incrementa su riesgo y restringe su } \\
\text { acceso a financiación. }\end{array}$ & 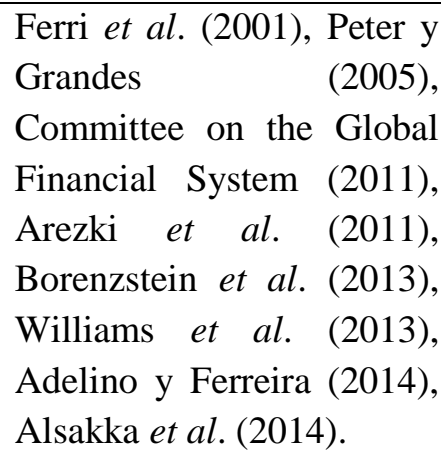 \\
\hline $\begin{array}{l}\text { Canal de garantías del } \\
\text { gobierno } \\
\text { (government guarantees } \\
\text { channel) }\end{array}$ & $\begin{array}{l}\text {-El riesgo soberano incrementa los } \\
\text { costes de financiación de las entidades } \\
\text { sistémicas al reducir las garantías que } \\
\text { éstas reciben de sus gobiernos. }\end{array}$ & $\begin{array}{l}\text { Grande et al. (2011), Puri } \\
\text { et al. (2011), Brown y Dinc } \\
(2011) \text {, Correa et al. } \\
(2012) \text {, Gray y Malone } \\
(2012) \text {, Schich y Lindh } \\
(2012) \text {. }\end{array}$ \\
\hline
\end{tabular}

Fuente: elaboración propia.

Por lo tanto, todos estos canales indican que un incremento del riesgo soberano de un país encarece los costes de financiación de los bancos nacionales, lo cual ha sido analizado por varios trabajos europeos a raíz de la crisis de deuda soberana. Así, Bofondi et al. (2013) examinan como la crisis de deuda en Italia se ha transmitido a la 
oferta de préstamos a través del incremento de los costes de financiación de los bancos. Sus resultados revelan que los bancos italianos han reducido más su oferta de préstamos que sus competidores extranjeros. Por su parte, Albertazzi et al. (2014) indican que un aumento de la prima de riesgo en Italia va acompañada de un incremento en el coste de la financiación mayorista y de ciertas vías de financiación minorista para los bancos, lo cual produce una reducción de la oferta crediticia y unos mayores tipos de interés para los préstamos. Además, este efecto es más pronunciado para los bancos más grandes y durante períodos de turbulencias financieras ${ }^{37}$. Neri (2013), a partir de una muestra de países de la zona euro, sostiene que los tipos de interés de los préstamos han sido más elevados en los países que han tenido un mayor riesgo soberano. Recientemente, Babihuga y Spaltro (2014), a partir de una muestra internacional de bancos entre 2001 y 2012, encuentran que el mayor riesgo soberano es uno de los determinantes del incremento producido en los costes de financiación de los bancos.

En resumen, las condiciones de financiación son más desfavorables para los bancos ubicados en países con riesgo soberano elevado, lo cual se va a trasladar a su oferta de préstamos y a su precio. Pero además, estas condiciones de financiación menos ventajosas van a hacer que el canal de préstamos bancarios de la política monetaria se transmita de forma muy heterogénea entre países.

Una política monetaria restrictiva provoca una reducción de préstamos, ya que afecta al acceso de los bancos a fondos prestables (depósitos y financiación vía mercados) y a su coste. Esta reducción será más pronunciada para las entidades localizadas en países con riesgo soberano alto porque soportan costes financieros superiores y mayores dificultades para acceder a fondos procedentes de los depósitos y

\footnotetext{
${ }^{37}$ Otros trabajos centrados en el caso italiano obtienen resultados similares (Zoli, 2013; Del Giovane et al., 2013).
} 
de los mercados financieros. Cuando el riesgo soberano es muy elevado, los depositantes tenderán a exigir mayores compensaciones o, incluso, pueden retirar sus fondos. Así, en estos años se han producido retiradas masivas de depósitos en aquellos bancos europeos más afectados por tensiones de riesgo soberano y, además, han tenido más dificultades para captar nuevos depósitos (Committee on the Global Financial System, 2011). Por otro lado, cuando el riesgo soberano es muy alto, el acceso a financiación externa para los bancos depende fundamentalmente del rating soberano de su país de origen en lugar de su rating individual. De acuerdo al Banco Central Europeo (2012a), el acceso a financiación vía mercados financieros ha sido más complicado para los bancos fuertemente afectados por la crisis de deuda soberana. En consecuencia, estos problemas financieros ocasionados por un elevado riesgo soberano, deberían amplificar las restricciones de crédito derivadas de una política monetaria contractiva.

Por otro lado, una política monetaria expansiva produce un aumento de las reservas bancarias y de la base de depósitos, lo que alivia las fricciones financieras e incrementa los recursos que las entidades de crédito tienen disponibles para prestar. Además, una bajada de tipos de interés, a raíz de una expansión monetaria, conduce a un aumento del valor de los activos y del margen de beneficios que obtienen los bancos, lo cual produce una mejoría de la calidad de sus balances, permitiéndoles conceder más préstamos (Gibson, 1997; Boivin et al., 2010). Asimismo, tipos de interés más bajos reducen el riesgo de la cartera de préstamos de las entidades, que las induce a expandir su oferta de crédito y a relajar sus normas de concesión de préstamos (Jiménez et al., 2008; Ioannidou et al., 2009; Maddaloni y Peydro, 2011; Paligorova y Santos, 2012). Sin embargo, los bancos ubicados en países con alto riesgo soberano se verán menos beneficiados de las expansiones monetarias, ya que su acceso a financiación es más limitado y costoso. Por lo tanto, deberían ser menos capaces de transmitir plenamente 
los efectos expansivos que sobre el crédito tiene la relajación de las condiciones monetarias.

El Gráfico 2.1 resume las posibles relaciones existentes entre el riesgo soberano y el canal de préstamos bancarios de la política monetaria de acuerdo con los planteamientos anteriores. En el lado izquierdo se muestra el funcionamiento del canal de préstamos bancarios, mientras que en el derecho se recogen los distintos canales de propagación del riesgo soberano a las condiciones de financiación de la banca.

\section{Gráfico 2.1: Cuadro-resumen de las relaciones entre la política monetaria y el riesgo}

\section{soberano}

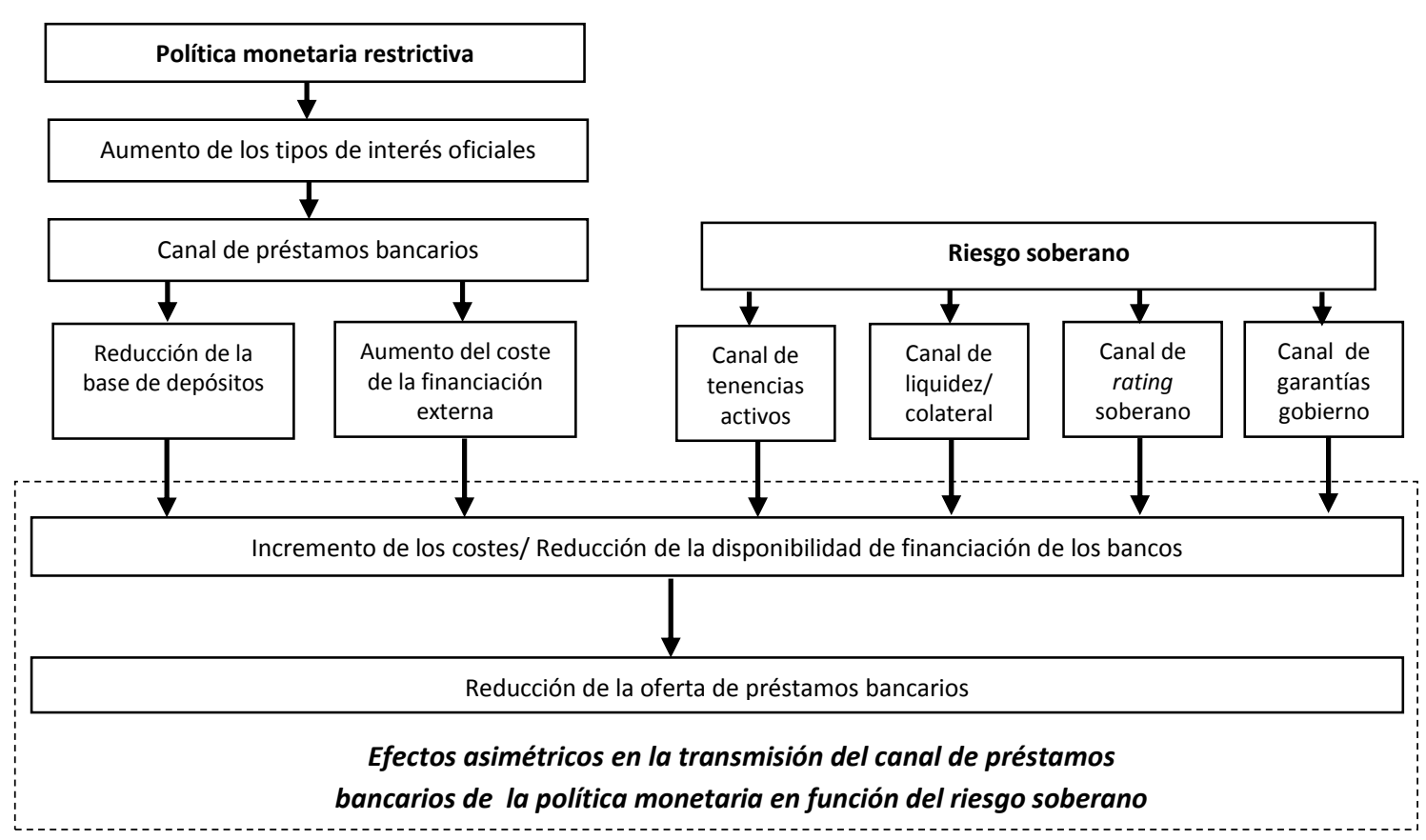

Fuente: elaboración propia.

El riesgo soberano también puede condicionar la reacción de la oferta de préstamos a shocks monetarios a través de la liquidez que, por cautela, mantengan las entidades de crédito. Un mayor riesgo soberano acentúa las restricciones financieras de los bancos, obligándoles a incrementar sus niveles de liquidez por precaución, mermando su oferta de préstamos. Este hecho va a acentuar la restricción del crédito 
tras una política monetaria restrictiva y a limitar el aumento de la oferta de préstamos ante una política monetaria expansiva. En este sentido, en épocas de crisis, los bancos tienden a acumular reservas de liquidez en detrimento de su oferta de préstamos (Benmelech y Bergman, 2012). Sin embargo, esta acumulación de liquidez tiende a ser más pronunciada para aquellos bancos localizados en países con problemas de riesgo soberano debido a dos razones fundamentales.

En primer lugar, los bancos tienden a acumular más liquidez cuando tienen más incertidumbres sobre su acceso futuro a financiación y cuando soportan más dificultades para obtener financiación externa (Freixas et al., 1999; Zawadowski, 2011; Acharya et al., 2011). La anticipación de estos problemas hacen que reduzcan su oferta de préstamos (Brunnermeier y Oehmke, 2012). El riesgo soberano genera importantes incertidumbres sobre la calidad crediticia de los balances de los bancos nacionales y restringe su acceso a financiación. Por lo tanto, los bancos que operen en países con mayor riesgo soberano serán más propensos a sufrir shocks financieros, lo que les inducirá a acumular mayores niveles de liquidez (Committee on the Global Financial System, 2011; Davies y Ng, 2011; Banco Central Europeo, 2012a).

En segundo lugar, las entidades son más propensas a acaparar liquidez en detrimento de su oferta crediticia a medida que aumenta su riesgo de refinanciación (Acharya y Skeie, 2011; Acharya y Merrouche, 2013). En este contexto, mayores costes financieros conducen a un aumento del riesgo de refinanciación, ya que la deuda tiene que ser refinanciada a un coste superior (Cáceres et al., 2010; Unsal y Cáceres, 2011). Dado que los bancos en países con alto riesgo soberano soportan mayores costes financieros, su riesgo de refinanciación también será más alto, lo que les incentivará a acumular mayores reservas de liquidez. 
La Tabla 2.4 recoge un resumen de los motivos que explican el mayor acaparamiento de liquidez por parte de los bancos en países con más riesgo soberano.

Tabla 2.4: Motivos que justifican el mayor acaparamiento de liquidez por los bancos que operan en países con mayor riesgo soberano

\begin{tabular}{|c|c|c|}
\hline Motivo & Explicación & Autores \\
\hline $\begin{array}{c}\text { Dificultades } e \\
\text { incertidumbres } \\
\text { financieras }\end{array}$ & $\begin{array}{l}\text {-Los bancos en países con mayor } \\
\text { riesgo soberano tienen más } \\
\text { incertidumbres sobre su acceso futuro a } \\
\text { financiación. } \\
\text {-Los bancos en países con mayor } \\
\text { riesgo soberano soportan mayores } \\
\text { dificultades para acceder a financiación } \\
\text { externa. }\end{array}$ & $\begin{array}{llll}\begin{array}{l}\text { Freixas } \\
\text { Acharya } \text { et } a l .\end{array} & (1999), \\
\text { Davies y } \mathrm{Ng} & (2011), \\
\text { Zawadowski } & & (2011), \\
\text { Committee on the } & \text { Global } \\
\text { Financial System } & (2011), \\
\text { Banco Central Europeo } \\
\text { (2012a), Brunnermeier y } \\
\text { Oehmke (2012). }\end{array}$ \\
\hline $\begin{array}{l}\text { Riesgo de } \\
\text { refinanciación }\end{array}$ & $\begin{array}{l}\text {-Los bancos en países con elevado } \\
\text { riesgo soberano tienen mayores costes } \\
\text { financieros y un riesgo de } \\
\text { refinanciación superior. }\end{array}$ & $\begin{array}{l}\text { Cáceres et al. (2010), Unsal } \\
\text { y Cáceres (2011), Acharya y } \\
\text { Skeie (2011), Acharya y } \\
\text { Merrouche (2013). }\end{array}$ \\
\hline
\end{tabular}

Fuente: elaboración propia.

A partir de los argumentos expuestos, nos permitimos concluir con la formulación de nuestra tesis:

Las entidades bancarias en países con mayor riesgo soberano soportarán más restricciones financieras y tenderán a acumular más liquidez, por precaución, lo cual afectará negativamente a su oferta crediticia ante variaciones de política monetaria.

Este hecho nos lleva a proponer las siguientes hipótesis:

Hipótesis 1: cuanto mayor es el riesgo soberano, mayor es la reducción de préstamos bancarios originada por una política monetaria restrictiva.

Hipótesis 2: cuanto mayor es el riesgo soberano, menor es el incremento de préstamos bancarios originado por una política monetaria expansiva. 


\section{4.- ANÁLISIS EMPÍRICO DEL CANAL DE PRÉSTAMOS BANCARIOS}

\subsection{1.- Composición y características de la muestra}

El contraste empírico de las hipótesis 1 y 2 se realiza para una muestra de entidades de crédito pertenecientes a 12 países de la zona euro ${ }^{38}$ entre 1999 y 2012 . La inclusión de estos países nos va a permitir analizar los efectos que el riesgo soberano tiene sobre el canal de préstamos bancarios de la política monetaria, evitando el sesgo causado por diferentes regímenes monetarios. Asimismo, el horizonte temporal seleccionado abarca casi todo el período en el que el BCE ha ejercido la política monetaria única en la zona euro, así como una gran parte de la crisis financiera.

La información contable para el presente estudio se ha obtenido de la base de datos BankScope (Bureau Van Dijk), que contiene las cuentas anuales detalladas y otro tipo de información de índole económico-financiera de un gran número de entidades de crédito del mundo. Se han incluido tres tipos de entidades de crédito: banca comercial, cajas de ahorro y cooperativas de crédito y, dado que se realiza un análisis internacional, ha sido preciso obtener cierta información agregada de los países donde se sitúan dichas entidades. Para ello, se ha recurrido a las bases de datos "World Development Indicators" del Banco Mundial, las estadísticas de la OCDE, el BCE y EuroStat.

De acuerdo con Favero et al. (1999), Arena et al. (2007) y Olivero et al. (2011a), se han suprimido de la muestra las entidades que cumplen alguna de las siguientes condiciones: 1) entidades con valores negativos de activo, préstamos, depósitos, ingresos por intereses y gastos; 2) entidades con una tasa de crecimiento para los préstamos y/o para los depósitos superior al 300\%; 3) entidades con un volumen de préstamos 100 veces mayor que los depósitos; 4) entidades con una actividad marginal

\footnotetext{
${ }^{38}$ La UE-11 (Alemania, Austria, Bélgica, Finlandia, Francia, España, Holanda, Irlanda, Italia, Luxemburgo y Portugal) más Grecia.
} 
de préstamo, definidas como aquellas cuyo ratio de préstamos sobre depósitos es inferior al 10\%; y 5) entidades cuyo activo total varía en más de un $75 \%$ en un año, que son las que probablemente han participado en operaciones de fusión o adquisición.

Dado que nuestro análisis utiliza una metodología System-GMM y se incluyen datos retardados y retardos de variaciones, es necesario eliminar también aquellas entidades para las que no se cuenta con datos durante, al menos, 6 años consecutivos. Esta condición es esencial para efectuar el test de correlación serial de segundo orden, que sirve para garantizar la robustez de las estimaciones realizadas con la metodología System-GMM de datos de panel dinámicos (Arellano y Bond, 1991).

La Tabla 2.5 muestra el número de entidades y observaciones por país y la distribución temporal de la muestra.

Tabla 2.5: Composición de la muestra

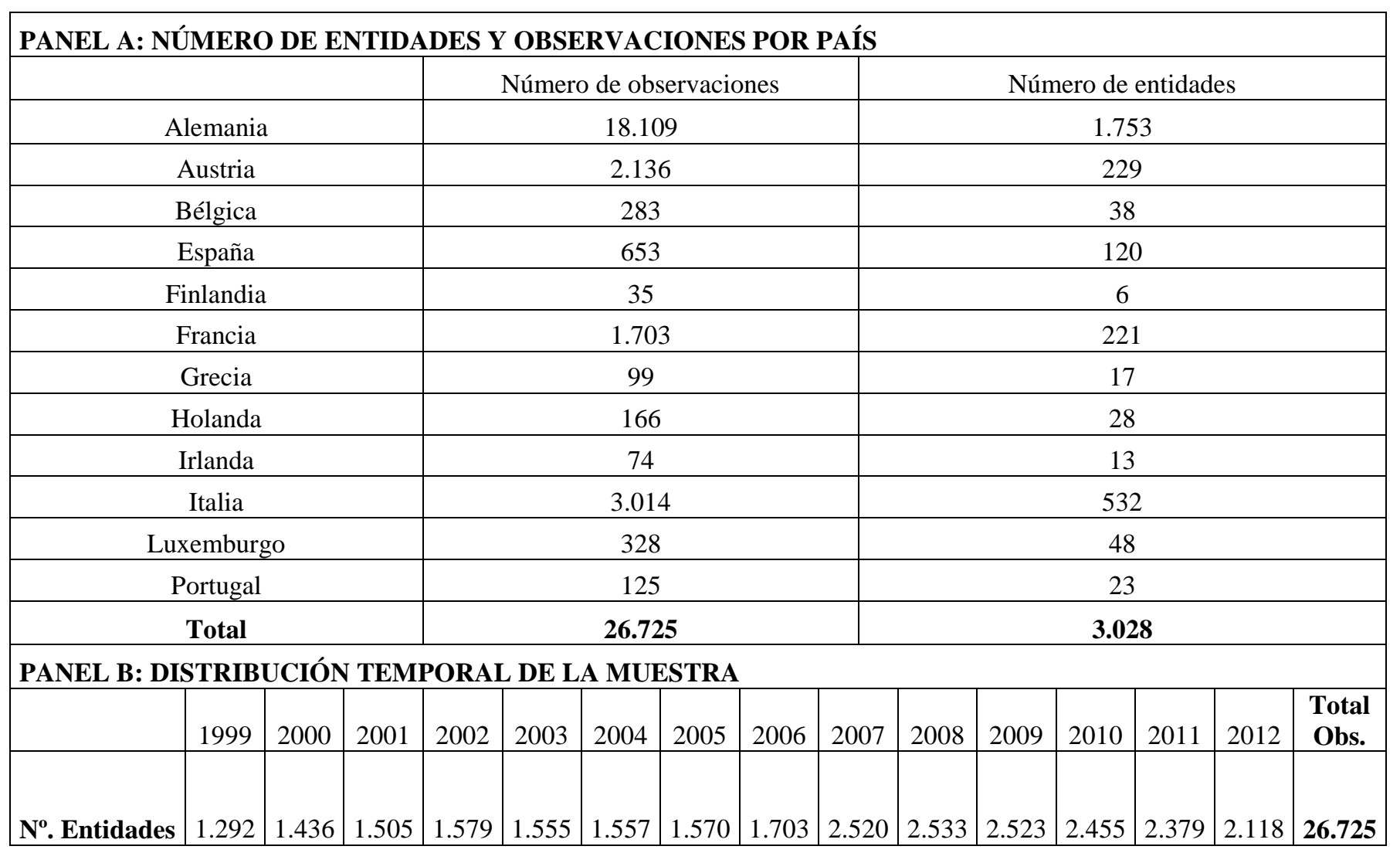




\subsection{2.- Desarrollo del modelo econométrico y variables utilizadas en el análisis}

Las hipótesis 1 y 2 son contrastadas mediante el siguiente modelo basado en el enfoque propuesto por Kashyap y Stein (1995a). En dicho enfoque se explica la oferta de préstamos a través de una serie de variables de control y unos indicadores de política monetaria. Sin embargo, nuestra tesis incorpora la importancia que tiene el riesgo soberano a través de la inclusión del mismo y sus interacciones con la política monetaria:

$$
\begin{aligned}
& \Delta \ln (\text { Prestam })_{\mathrm{i}, \mathrm{t}}=\alpha_{0}+\alpha_{1} \Delta \ln (\text { Prestam })_{\mathrm{i}, \mathrm{t}-1}+\sum_{\mathrm{j}=0}^{1} \delta_{\mathrm{j}} \Delta \ln (\mathrm{PIB})_{\mathrm{m}, \mathrm{t}-\mathrm{j}}+\sum_{\mathrm{j}=0}^{1} \beta_{\mathrm{j}} \Delta \mathrm{i}_{\mathrm{m}, \mathrm{t}-\mathrm{j}}+ \\
& \rho_{1} \text { TAMAÑO }_{i, t-1}+\rho_{2} \text { LIQUIDEZ }_{i, t-1}+\rho_{3} \text { CAPITAL }_{i, t-1}+\rho_{4} \text { RIESGO }_{i, t-1}+ \\
& \sum_{\mathrm{j}=0}^{1} \tau_{\mathrm{j}} \Delta \mathrm{i}_{\mathrm{m}, \mathrm{t}-\mathrm{j}} * \text { TAMAÑ }_{\mathrm{i}, \mathrm{t}-1}+\sum_{\mathrm{j}=0}^{1} \theta_{\mathrm{j}} \Delta \mathrm{i}_{\mathrm{m}, \mathrm{t}-\mathrm{j}} * \text { LIQUIDEZ }_{\mathrm{i}, \mathrm{t}-1}+ \\
& \sum_{\mathrm{j}=0}^{1} \mu_{\mathrm{j}} \Delta \mathrm{i}_{\mathrm{m}, \mathrm{t}-\mathrm{j}} * \text { CAPITAL }_{\mathrm{i}, \mathrm{t}-1}+\sum_{\mathrm{j}=0}^{1} \varphi_{\mathrm{j}} \Delta \mathrm{i}_{\mathrm{m}, \mathrm{t}-\mathrm{j}} * \mathrm{RIESGO}_{\mathrm{i}, \mathrm{t}-1}+ \\
& \rho_{5} \mathrm{CONC}_{\mathrm{m}, \mathrm{t}}+\sum_{\mathrm{j}=0}^{1} \omega_{\mathrm{j}} \Delta \mathrm{i}_{\mathrm{m}, \mathrm{t}-\mathrm{j}} * \mathrm{CONC}_{\mathrm{m}, \mathrm{t}}+\rho_{6} \mathrm{RS}_{\mathrm{m}, \mathrm{t}}+\sum_{\mathrm{j}=0}^{1} \gamma_{\mathrm{j}} \Delta \mathrm{i}_{\mathrm{m}, \mathrm{t}-\mathrm{j}} * \mathrm{RS}_{\mathrm{m}, \mathrm{t}}+ \\
& \sum_{\mathrm{j}=0}^{1} \epsilon_{\mathrm{j}}\left(\Delta \mathrm{i}_{\mathrm{m}, \mathrm{t}-\mathrm{j}} * \mathrm{RS}_{\mathrm{m}, \mathrm{t}}\right)^{2}+\sum_{\mathrm{t}=1}^{13} \pi_{\mathrm{t}} \mathrm{Año} \mathrm{t}_{\mathrm{t}}+\sum_{\mathrm{m}=1}^{11} \vartheta_{\mathrm{m}} \text { País }_{\mathrm{m}}+\varepsilon_{\mathrm{i}, \mathrm{t}}
\end{aligned}
$$

La variable dependiente, $\Delta \ln (\text { Prestam })_{i, t}$, es la variación del logaritmo de los préstamos de la entidad $i$ en el año $t$ con respecto al año $t$ - 1 , generalmente utilizada en la literatura del canal de préstamos bancarios (Ehrmann et al., 2003; Gambacorta, 2005; Jimborean, 2009; Olivero et al., 2011a; Gambacorta and Marques-Ibanez, 2011). Al igual que en estudios previos, se incluye como variable independiente la variación del logaritmo de los préstamos retardada un año, $\Delta \ln \left(\right.$ Prestam $_{i, t-1}$, para capturar posibles efectos de arrastre de la variable dependiente.

La variable $\Delta \ln (P I B)$ representa la variación del logaritmo del Producto Interior Bruto (PIB) nominal y sirve para controlar factores de demanda de préstamos. 
Condiciones económicas favorables incrementan el número de proyectos de inversión rentables, lo que contribuye a impulsar la demanda de crédito, por lo que esta variable sirve para capturar los movimientos cíclicos de la economía (Kashyap et al., 1993). Un gran número de trabajos revelan que el crecimiento del PIB incide positivamente en la oferta de crédito (Gambacorta, 2005; Jimborean, 2009; Matousek y Sarantis, 2009; Altunbas et al., 2009; 2010; Wu et al., 2011). En consecuencia, se espera una relación positiva entre esta variable y el crecimiento de préstamos.

El indicador de política monetaria $\Delta i$ se mide como la variación en los tipos de interés a corto plazo del mercado monetario, ampliamente utilizado por trabajos previos (De Bondt, 1999a; Ehrmann et al., 2003; Altunbas et al., 2010; Olivero et al., 2011a). En este sentido, se incluye el indicador de política monetaria actual y retardado un período $\left(\Delta i_{m, t}\right.$ y $\left.\Delta i_{m, t-1}\right)$, ya que las entidades pueden no responder de manera inmediata a las decisiones de política monetaria. Se espera que un aumento del tipo de interés a corto plazo del mercado monetario produzca una reducción en la oferta de préstamos.

Asimismo, se introducen en el modelo (1) cuatro variables relacionadas con características específicas de las entidades de crédito $^{39}$ :

TAMAÑN: el tamaño de una entidad se mide a través del logaritmo de su activo total. Normalmente, los bancos más grandes gozan de mayores tasas de crecimiento de préstamos, por lo que se espera que esta variable posea un signo positivo (Kashyap y Stein, 1995a; 1995b; 2000).

LIQUIDEZ: se calcula como el ratio de tesorería e inversiones financieras temporales sobre el activo total. Las entidades con grandes volúmenes de liquidez son

\footnotetext{
${ }^{39} \mathrm{Al}$ igual que la mayoría de los trabajos previos, estas cuatro variables específicas de cada entidad se incluyen retardadas un período para evitar problemas de endogeneidad (Kashyap y Stein, 1995a; 1995b; 2000; Ehrmann et al., 2003).
} 
capaces de incrementar en mayor medida su oferta de crédito, por lo que se espera un signo positivo para esta variable (DeBondt, 1999a; Kashyap y Stein, 2000).

CAPITAL: es el cociente entre el capital y el activo total. Las instituciones de crédito más capitalizadas ofrecen un mayor volumen de préstamos, así que debiera existir una relación positiva entre el capital y la variable dependiente (Kishan y Opiela, 2000; 2006).

RIESGO: representa el ratio de las provisiones por préstamos fallidos sobre el total de la cartera de préstamos y es un indicador del riesgo de crédito de una entidad. Los bancos con mayor riesgo de crédito poseen tasas más bajas de crecimiento de préstamos, por lo que el signo esperado de esta variable es negativo (Altunbas et al., 2010; Bogoev, 2010; Gambacorta y Marques-Ibanez, 2011).

Se incluye, además, la interacción entre los indicadores de política monetaria $\left(\Delta i_{m, t}\right.$ y $\left.\Delta i_{m, t-1}\right)$ y las características específicas de cada entidad (TAMAÑN, LIQUIDEZ, CAPITAL y RIESGO) para medir los efectos que dichas características específicas tienen sobre la reacción de la oferta de crédito a variaciones de política monetaria.

En primer lugar, introducimos la interacción entre la variable TAMAÑO y los indicadores de política monetaria $\left(\Delta i_{m, t} \mathrm{y} \Delta i_{m, t-1}\right)$. Varios trabajos obtienen una relación positiva entre esta variable interaccionada y el crecimiento de la oferta de préstamos, puesto que las entidades más pequeñas son más sensibles a las restricciones monetarias que las entidades grandes (Kashyap y Stein, 1995a; 1995b; 2000; Kishan y Opiela, 2000; Kakes y Sturm, 2002).

En segundo lugar se introducen los términos de interacción entre LIQUIDEZ y las variables de política monetaria $\left(\Delta i_{m, t}\right.$ y $\left.\Delta i_{m, t-1}\right)$. Numerosos trabajos muestran que las 
entidades más líquidas son menos sensibles a los shocks monetarios, ya que tienen más facilidad para evitar una reducción de préstamos durante una contracción monetaria a través de sus reservas de liquidez (Kashyap y Stein, 2000; Ehrmann et al., 2003; Gambacorta, 2005). Por el contrario, otros trabajos han encontrado el resultado opuesto, lo cual puede deberse a la existencia de un exceso estructural de liquidez (Jimborean, 2009; Bogoev, 2010).

En tercer lugar, incluimos las interacciones entre CAPITAL y las medidas de política monetaria $\left(\Delta i_{m, t}\right.$ y $\left.\Delta i_{m, t-1}\right)$. Diversos trabajos muestran que las entidades con bajos niveles de capital tienen más dificultades para acceder a financiación no proveniente de depósitos, por lo que contraen en mayor medida su oferta de préstamos ante una política monetaria restrictiva que las entidades mejor capitalizadas (Peek y Rosengren, 1995; Kishan y Opiela, 2000; 2006; Altunbas et al., 2002).

Finalmente, se construyen los términos de interacción entre RIESGO y los indicadores monetarios $\left(\Delta i_{m, t}\right.$ y $\left.\Delta i_{m, t-1}\right)$. Las entidades con mayor riesgo de crédito reducen más su oferta de préstamos que las entidades con menores niveles de riesgo ante una política monetaria contractiva (Altunbas et al., 2010; Bogoev, 2010; Gambacorta y Marques-Ibanez, 2011).

Se han utilizado variables continuas para construir las interacciones descritas. En aras de poder interpretar dichas interacciones correctamente, las cuatro variables específicas de cada entidad (TAMAÑO, LIQUIDEZ, CAPITAL y RIESGO) se han normalizado con respecto a la media del total de entidades de la muestra ${ }^{40}$.

$$
\text { TAMAÑ } O_{i t}=\log A_{i t}-\frac{\sum_{i=1}^{N} \log A_{i t}}{N_{t}}
$$

\footnotetext{
${ }^{40}$ Numerosos trabajos previos han seguido este mismo enfoque (Ehrmann et al., 2003; Gambacorta, 2005; Pruteanu-Podpiera, 2007; Jimborean, 2009).
} 


$$
\begin{gathered}
\text { LIQUIDEZ }_{i t}=\frac{\mathrm{L}_{\mathrm{it}}}{\mathrm{A}_{\mathrm{it}}}-\frac{\sum_{\mathrm{t}=1}^{\mathrm{T}}\left(\sum_{\mathrm{i}=1}^{\mathrm{N}}\left(\mathrm{L}_{\mathrm{it}} / \mathrm{A}_{\mathrm{it}}\right) / \mathrm{N}_{\mathrm{t}}\right)}{\mathrm{T}} \\
\text { CAPITAL }_{\mathrm{it}}=\frac{\mathrm{C}_{\mathrm{it}}}{\mathrm{A}_{\mathrm{it}}}-\frac{\sum_{\mathrm{t}=1}^{\mathrm{T}}\left(\sum_{\mathrm{i}=1}^{\mathrm{N}}\left(\mathrm{C}_{\mathrm{it}} / \mathrm{A}_{\mathrm{it}}\right) / \mathrm{N}_{\mathrm{t}}\right)}{\mathrm{T}} \\
\text { RIESGO }_{\mathrm{it}}=\frac{\text { PPF }_{\mathrm{it}}}{\text { Prestam }_{\mathrm{it}}}-\frac{\sum_{\mathrm{t}=1}^{\mathrm{T}}\left(\sum_{\mathrm{i}=1}^{\mathrm{N}}\left(\mathrm{PPF}_{\mathrm{it}} / \text { Prestam }_{\mathrm{it}}\right) / \mathrm{N}_{\mathrm{t}}\right)}{\mathrm{T}}
\end{gathered}
$$

Donde $A_{i t}$ representa el activo total, $L_{i t}$ es la tesorería y las inversiones financieras temporales de la entidad de crédito, $C_{i t}$ es el capital total, $P P F_{i t}$ son las provisiones por préstamos fallidos, Prestam $_{i t}$ es el total de préstamos y $N_{t}$ es el total de entidades de crédito.

La normalización implica que en la ecuación (1), la media de los términos de interacción es cero y los parámetros $\beta_{j}$ se interpretan como el efecto promedio de la política monetaria sobre el crecimiento de préstamos bancarios. Los coeficientes de las características específicas de cada entidad $\left(\rho_{j} ; \mathrm{j}: 1, \ldots, 4\right)$ describen el efecto que dichas características tienen sobre el incremento de la oferta de crédito cuando la variación de los tipos de interés a corto plazo $\left(\Delta i_{m, t} \mathrm{y} \Delta i_{m, t-1}\right)$ es cero. Los coeficientes de los términos de interacción $\left(\tau_{j}, \theta_{j}, \mu_{j}, \varphi_{j}\right)$ indican si la característica específica en cuestión, afecta al modo en el que el crecimiento de la oferta de préstamos reacciona a los cambios de política monetaria.

La concentración del mercado bancario del país de cada entidad viene representada por la variable CONC. Se ha calculado a través del Índice de Herfindahl (HHI), medido en términos de activo, que publica el BCE. Al igual que sucedía con las características específicas de cada entidad, esta variable también se interacciona con los indicadores de política monetaria $\left(\Delta i_{m, t}\right.$ y $\left.\Delta i_{m, t-1}\right)$. En general, estudios empíricos previos 
revelan que existe una relación positiva entre dicha interacción y el crecimiento de la oferta de préstamos (Adams y Amel, 2005; 2011; Olivero et al., 2011a).

El riesgo soberano viene denotado por $R S$ y se mide a través de la prima de riesgo, ésto es, la diferencia entre el rendimiento de los bonos a 10 años del país donde se ubica un banco y el rendimiento de los bonos alemanes al mismo plazo. Este último se suele considerar el rendimiento de referencia porque la deuda soberana de Alemania ha gozado tradicionalmente de una elevada calificación crediticia y, por tanto, su rentabilidad es considerada una buena aproximación de los activos libres de riesgo (Codogno et al., 2003; Hallerberg y Wolff, 2008; Bernoth y Wolff, 2008; Gerlach et al., 2010; Favero et al., 2010; Bernoth et al., 2012).

Para analizar cómo el riesgo soberano determina los efectos que la política monetaria tiene sobre el crecimiento de la oferta de préstamos, se incluye en el modelo (1) las interacciones entre los indicadores de política monetaria y el riesgo soberano $\left(\Delta i_{m, t} * R S_{m, t}\right.$ y $\left.\Delta i_{m, t-1} * R S_{m, t}\right)$

Anteriormente, hemos propuesto que el riesgo soberano condiciona la transmisión de la política monetaria. En este sentido, las entidades que operan en países con mayor riesgo soberano se ven más afectadas por las restricciones monetarias y menos beneficiadas de las expansiones monetarias. Para capturar este efecto distinto en países con riesgo soberano alto, hemos incluido en el modelo (1) el cuadrado de las variables de interacción entre política monetaria y riesgo soberano: $\left(\Delta i_{m, t} * R S_{m, t}\right)^{2}$ y $\left(\Delta i_{m, t-1} * R S_{m, t}\right)^{2}$. Si existe este efecto diferente, el cuadrado de dichas variables debiera poseer un coeficiente negativo. Esto implicaría que cuando los tipos de interés a corto plazo aumentan, la reducción de préstamos bancarios asociada a una contracción monetaria se verá amplificada en los países con riesgo soberano alto. Pero además, cuando los tipos 
de interés a corto plazo disminuyen, el crecimiento de la oferta de crédito provocado por una política monetaria expansiva, se verá mermado en países con elevado riesgo soberano $^{41}$.

Se han incluido dummies temporales y de país como variables de control. El término de error viene representado por el indicador $\varepsilon_{i, t} ; i=1,2, \ldots, N$ hace referencia a una entidad específica $i ; m=1,2, \ldots, M$ indica un país concreto $m ; t=1,2, \ldots, T$ denota un año particular $t$ y $j$ se refiere al número de retardos.

La Tabla 2.6 resume las variables independientes empleadas en nuestro análisis, así como las relaciones esperadas con el crecimiento de la oferta de préstamos bancarios. La Tabla 2.7 recoge los estadísticos descriptivos y la Tabla 2.8 muestra las correlaciones con el objeto de identificar potenciales problemas de colinealidad.

El modelo propuesto en la ecuación (1) se estima a través de la metodología System-GMM (Método Generalizado de Momentos) en dos etapas de datos de panel dinámicos, el cual permite el control de problemas de endogeneidad (Arellano y Bond, 1991; Arellano y Bover, 1995; Blundell y Bond, 1998). La utilización de esta metodología es muy apropiada para la estimación de nuestro modelo, ya que en la relación entre la política monetaria y el crédito bancario surgen problemas de endogeneidad. La política monetaria afecta a la oferta de crédito de las entidades, pero la situación del sector bancario también puede afectar a las decisiones de política monetaria (Gambacorta y Marques-Ibanez, 2011). La estimación es robusta y considera las variables de política monetaria y los indicadores macroeconómicos como variables exógenas, mientras que las características específicas de los bancos y sus interacciones

\footnotetext{
${ }^{41} \mathrm{La}$ introducción de variables cuadráticas para capturar asimetrías se ha utilizado en otras áreas de investigación financiera, tales como los "market timing" de fondos de inversión (Treynor y Mazuy, 1966).
} 
con la política monetaria se consideran endógenas (Jimborean, 2009). Asimismo, se ha seguido una estrategia de estimación para las variables endógenas que emplea entre el segundo y el cuarto retardo como instrumentos.

Tabla 2.6: Variables determinantes del crecimiento de la oferta de préstamos bancarios

\begin{tabular}{|c|c|c|}
\hline Variable & Aproximación & $\begin{array}{l}\text { Relación esperada con el } \\
\text { crecimiento de la oferta de } \\
\text { préstamos bancarios }\end{array}$ \\
\hline$\Delta \ln (\text { Prestam })_{i, t-1}$ & $\begin{array}{l}\text { Retardo del crecimiento de la } \\
\text { oferta de préstamos }\end{array}$ & POSITIVA/NEGATIVA \\
\hline$\Delta \ln (\mathrm{PIB})$ & Tasa de crecimiento del PIB & POSITIVA \\
\hline$\Delta \mathrm{i}$ & $\begin{array}{l}\text { Variación de tipos de interés a } \\
\text { corto plazo del mercado } \\
\text { monetario }\end{array}$ & NEGATIVA \\
\hline TAMAÑO & Logaritmo del Activo. & POSITIVA \\
\hline TAMAÑO* $\Delta \mathrm{i}$ & $\begin{array}{c}\text { Interacción entre el tamaño y } \\
\text { la política monetaria }\end{array}$ & POSITIVA \\
\hline LIQUIDEZ & $\begin{array}{c}\text { (Tesorería }+ \text { Inversiones } \\
\text { financieras temporales)/Activo }\end{array}$ & POSITIVA/NEGATIVA \\
\hline LIQUIDEZ* $\Delta \mathrm{i}$ & $\begin{array}{c}\text { Interacción entre la liquidez y } \\
\text { la política monetaria }\end{array}$ & POSITIVA/NEGATIVA \\
\hline CAPITAL & Capital/Activo & POSITIVA \\
\hline CAPITAL $* \Delta \mathrm{i}$ & $\begin{array}{c}\text { Interacción entre el capital y la } \\
\text { política monetaria }\end{array}$ & POSITIVA \\
\hline RIESGO & $\begin{array}{l}\text { Provisiones por préstamos } \\
\text { fallidos/Préstamos }\end{array}$ & NEGATIVA \\
\hline $\mathrm{RIESGO}^{*} \Delta \mathrm{i}$ & $\begin{array}{l}\text { Interacción entre el riesgo de } \\
\text { crédito y la política monetaria }\end{array}$ & NEGATIVA \\
\hline CONC & $\begin{array}{c}\text { Índice de Herfindahl (HHI) en } \\
\text { términos de activo }\end{array}$ & POSITIVA \\
\hline $\mathrm{CONC}^{*} \Delta \mathrm{i}$ & $\begin{array}{c}\text { Interacción entre la } \\
\text { concentración y la política } \\
\text { monetaria }\end{array}$ & POSITIVA \\
\hline RS & $\begin{array}{l}\text { Diferencial del rendimiento } \\
\text { del bono soberano de un país } \\
\text { respecto a Alemania }\end{array}$ & NEGATIVA \\
\hline $\mathrm{RS}^{*} \Delta \mathrm{i}$ & $\begin{array}{c}\text { Interacción lineal entre el } \\
\text { riesgo soberano y la política } \\
\text { monetaria }\end{array}$ & NEGATIVA \\
\hline$\left(\mathrm{RS}^{*} \Delta \mathrm{i}\right)^{2}$ & $\begin{array}{c}\text { Interacción cuadrática entre el } \\
\text { riesgo soberano y la política } \\
\text { monetaria }\end{array}$ & NEGATIVA \\
\hline
\end{tabular}


Tabla 2.7: Estadísticos descriptivos

\begin{tabular}{|c|c|c|c|c|}
\hline Variable & Media & Desviación típica & Mínimo & Máximo \\
\hline$\Delta \ln ($ Prestam $)$ & 0,0290 & 0,1419 & $-1,8127$ & 1,2901 \\
$\Delta \ln (\mathrm{PIB})$ & 0,0339 & 0,0872 & $-0,1670$ & 0,2780 \\
$\Delta \mathrm{i}$ & $-0,2454$ & 1,2532 & $-3,4059$ & 1,4418 \\
TAMAÑO & 13,6421 & 1,6650 & 9,1551 & 21,6704 \\
LIQUIDEZ & 0,2394 & 0,1274 & 0,0000 & 0,8619 \\
CAPITAL & 0,0854 & 0,0499 & 0,0008 & 0,9704 \\
RIESGO & 0,0072 & 0,0123 & $-0,2466$ & 0,3906 \\
RS & 0,2902 & 0,9021 & $-1,1954$ & 21,0025 \\
CONC & 0,0320 & 0,0280 & 0,0140 & 0,3700 \\
\hline
\end{tabular}

Los estadísticos de las variables TAMAÑO, LIQUIDEZ, CAPITAL y RIESGO se han calculado antes de la normalización para mostrar información más comprensible.

Tabla 2.8: Correlaciones

\begin{tabular}{|c|c|c|c|c|c|c|c|c|}
\hline & $\Delta \ln (\mathrm{PIB})$ & $\Delta \mathrm{i}$ & TAMAÑO & LIQUIDEZ & CAPITAL & RIESGO & RS & CONC \\
\hline$\Delta \ln (\mathrm{PIB})$ & 1 & & & & & & & \\
\hline$\Delta \mathrm{i}$ & 0,3981 & 1 & & & & & & \\
\hline TAMAÑO & $-0,0095$ & $-0,0144$ & 1 & & & & & \\
\hline LIQUIDEZ & $-0,0032$ & 0,0321 & 0,0003 & 1 & & & & \\
\hline CAPITAL & $-0,0154$ & $-0,0244$ & $-0,1462$ & $-0,1543$ & 1 & & & \\
\hline RIESGO & 0,1010 & $-0,0131$ & $-0,0472$ & 0,0517 & 0,0178 & 1 & & \\
\hline RS & $-0,1889$ & $-0,0713$ & 0,0776 & $-0,1372$ & 0,2596 & 0,0628 & 1 & \\
\hline CONC & 0,0070 & $-0,0130$ & 0,2789 & $-0,1147$ & 0,1832 & $-0,0556$ & 0,2710 & 1 \\
\hline
\end{tabular}

\subsection{3.- Metodología del análisis}

El análisis empírico se realiza a través de una metodología de datos de panel dinámicos. En concreto, se utiliza el estimador System-GMM (Método Generalizado de Momentos) en dos etapas con errores robustos desarrollado por Blundell y Bond (1998), consistente ante la presencia de cualquier patrón de heterocedasticidad y autocorrelación. Dicha metodología permite, además, controlar los problemas de endogeneidad y obtener estimadores consistentes e insesgados mediante la utilización de retardos de las variables independientes como instrumentos (Arellano y Bond, 1991). 


\subsubsection{1.- Estimador GMM de la metodología de datos de panel dinámicos}

La notación general de un modelo econométrico de datos de panel dinámicos se corresponde con la siguiente expresión (Arellano y Bond, 1991):

$$
\mathrm{y}_{\mathrm{it}}=\sum_{\mathrm{j}=1}^{\mathrm{q}} \alpha_{\mathrm{j}} \mathrm{y}_{\mathrm{i}(\mathrm{t}-\mathrm{j})}+\beta^{\prime} \mathrm{x}_{\mathrm{it}}+\eta_{\mathrm{i}}+\mathrm{v}_{\mathrm{it}}=\delta^{\prime} \mathrm{w}_{\mathrm{it}}+\eta_{\mathrm{i}}+v_{\mathrm{it}}
$$

$\left(t=q+1, \ldots, ; T_{i} i=1, \ldots, N\right) ;|\alpha|<1$

$\eta_{i}$ son los efectos individuales.

$x_{i}$ es un vector $k_{1} x 1$ de variables explicativas.

$\beta$ es un vector $k_{1} \times 1$ de parámetros a estimar.

$q$ es la máxima longitud del retardo en el modelo.

El máximo número de períodos de tiempo disponible para el individuo i-ésimo, $T_{i}$, es pequeño y $N$, que se refiere al número de individuos, es grande.

$\delta$ es un vector $k \times 1$ de parámetros que comprende tanto los distintos $\alpha_{\mathrm{j}}$, como a los parámetros incluidos en $\beta$. Siendo $k=k_{1}+q$.

$W_{i}$ es una matriz $k \times 1$ de variables dependientes y explicativas.

Se asume que $v_{i t}$ es independiente e idénticamente distribuida (iid) sobre los individuos con media cero. Adicionalmente, se supone que $\eta_{i}$ es iid., y que $v_{i t}$ y $\eta_{i}$ son independientes para todo $i$ sobre el período muestral.

Las variables que pertenecen a $x_{i t}$ pueden estar o no correlacionadas con los efectos individuales $\eta_{i}$. 
Inicialmente se supone que todas las variables que forman parte de $x_{i t}$ están correlacionadas con $\eta_{i t}$ y que no se dispone de instrumentos externos. De este modo, la forma de la matriz óptima de instrumentos va a depender de si las variables que integran $x_{i t}$ son predeterminadas o estrictamente exógenas con respecto a $v_{i t}$ (se volverá a tratar este tema cuando se defina la matriz óptima de instrumentos).

El estimador de Arellano-Bond de una etapa del vector $\delta$ de $\mathrm{k}$ x 1 coeficientes es el siguiente:

$$
\hat{\delta}=\left[\left(\sum_{i} W_{i}^{*} Z_{i}\right) A_{N}\left(\sum_{i} Z_{i}^{\prime} W_{i}^{*}\right)\right]^{-1}\left(\sum_{i} W_{i}^{*^{\prime}} Z_{i}\right) A_{N}\left(\sum_{i} Z_{i}^{\prime} y_{i}^{*}\right)
$$

donde $\quad A_{N}=\left(\frac{1}{N} \sum_{i} Z_{i}^{\prime} H_{i} Z_{i}\right)^{-1}$

$W_{i}^{*}$ y $y_{i}^{*}$ denotan una transformación de $W_{i}$ e $y_{i}$ respectivamente ${ }^{42}$.

A su vez $\quad H_{\mathrm{i}}=\left(\begin{array}{cccccc}2 & -1 & 0 & \cdots & 0 & 0 \\ -1 & 2 & -1 & \cdots & 0 & 0 \\ \vdots & \vdots & \vdots & \ddots & \vdots & \vdots \\ 0 & 0 & 0 & \cdots & 2 & -1 \\ 0 & 0 & 0 & \cdots & -1 & 2\end{array}\right)$

es una matriz $(\mathrm{T}-\mathrm{q}-1) \times(\mathrm{T}-\mathrm{q}-1)$

$Z_{i}$ representa la matriz óptima de instrumentos. Dicha matriz ha de elegirse adecuadamente, puesto que debe ser coherente con la teoría económica, los trabajos empíricos previos y las características de la muestra. Su forma dependerá de si las variables de $x_{i t}$ son predeterminadas o estrictamente exógenas con respecto a $v_{i t}$. Esto supone lo siguiente:

\footnotetext{
${ }^{42}$ Estas desviaciones pueden ser, entre otras muchas, desviaciones ortogonales o primeras diferencias (Arellano y Bover, 1990).
} 
- Para las variables predeterminadas, es decir $E\left(x_{i t} v_{i s}\right)=0$ para todo $s>t$, sólo serían instrumentos válidos $x_{\mathrm{i} 1}, \ldots, x_{\mathrm{i}(\mathrm{T}-1)}$.

- Para las variables estrictamente exógenas, es decir $E\left(x_{i t} v_{i s}\right)=0$ para todo t, s, todas las $x$ serían instrumentos válidos.

En el caso de que las perturbaciones no sean homocedásticas puede obtenerse un estimador de segunda etapa eficiente utilizando una especificación diferente de la matriz de ponderaciones.

$$
\hat{\delta}_{2}=\left[\left(\sum_{i} W_{i}^{*^{\prime}} Z_{i}\right) A_{N}\left(\sum_{i} Z_{i}^{\prime} W_{i}^{*}\right)\right]^{-1}\left(\sum_{i} W_{i}^{*^{\prime}} Z_{i}\right) A_{N 2}\left(\sum_{i} Z_{i}^{\prime} y_{i}^{*}\right)
$$

siendo $A_{N 2}=\left(\frac{1}{N} \sum_{i} Z_{i}^{\prime} G_{i} Z_{i}\right)^{-1} \quad ; \quad G_{i}=\hat{v}_{i}^{*} \hat{v}_{i}^{\prime}$

$\hat{v}_{i}^{*}$ son los residuos del estimador de una etapa, es decir: $\hat{v}_{i}^{*}=y_{i}^{*}-W_{i}^{*} \hat{\delta}$

Supuestos adicionales sobre la relación entre los efectos individuales $\left(\eta_{\mathrm{i}}\right)$, y las variables explicativas $\left(x_{\mathrm{it}}\right)$ o sobre estacionariedad permiten explotar condiciones adicionales.

Asimismo, es importante destacar que la presencia de errores $\left(v_{\mathrm{it}}\right)$ autorregresivos invalida el uso de cualquier retardo de la variable dependiente como instrumento. Así, el test de autocorrelación de los residuos diferenciados del orden m viene expresado por:

$$
A R_{m}=\frac{\sum_{i=1}^{N}\left(\mathcal{O}_{m i}^{*}{ }^{\prime} \mathcal{O}^{*}{ }_{i}\right)}{B_{1}^{1 / 2}} \quad \text { donde } \quad{\mathcal{O}^{*}}_{m i}=L_{m}\left(\mathcal{O}^{*}{ }_{i}\right)
$$

siendo $L_{m}$ el operador retardo de orden m, y

$$
\begin{aligned}
& B_{1}=\sum_{i=1}^{N} \hat{0}_{m i}^{*} H_{i} \hat{0}_{m i}^{*}-2\left(\sum_{i=1}^{N} \hat{0}_{m i}^{*} X_{i}^{*}\right) Q_{1}^{-1}\left(\sum_{i=1}^{N} X_{i}^{* \prime} Z_{i}\right) A_{1}\left(\sum_{i=1}^{N} Z_{i}^{\prime} H_{i} \hat{\vartheta}_{m i}^{*}\right) \\
& +\left(\sum_{i=1}^{N} \hat{v}_{m i}^{*} X_{i}^{*}\right) \hat{V}_{1}\left(\sum_{i=1}^{N} X_{i}^{\prime} \hat{0}_{m i}^{*}\right)
\end{aligned}
$$


A su vez, el test de Hansen de sobre identificación de los instrumentos se corresponde con la siguiente expresión (Hansen, 1982) ${ }^{43}$ :

$$
H=\left(\frac{1}{N} Z^{\prime} \hat{E}\right)^{\prime} \operatorname{Var}(\mathrm{z} \varepsilon)^{-1} \frac{1}{N} Z^{\prime} \hat{E}=\frac{1}{N}\left(Z^{\prime} \hat{E}\right)^{\prime} \mathrm{A}_{\mathrm{EGMM}} Z^{\prime} \hat{E}
$$

Siendo $Z^{\prime}$ una matriz de instrumentos $j ; \hat{E}$ los residuos; $\varepsilon$ el término de error y $A_{E G M M}$ la matriz de ponderaciones eficiente GMM. El test de Hansen se distribuye como una chi-cuadrado con $j-k$ grados de libertad, siendo $j$ el número de instrumentos y $k$ el número de variables explicativas.

\subsubsection{2.- Estimador System-GMM de la metodología de datos de panel dinámicos}

El estimador GMM en diferencias desarrollado por Arellano y Bond (1991) puede proporcionar instrumentos débiles (Alonso-Borrego y Arellano, 1996; Blundell y Bond, 1998). Esto sucede cuando el parámetro $\alpha$ se aproxima a la unidad o cuando la varianza de los efectos individuales $\left(\eta_{i}\right)$ aumenta en relación a la varianza del término de perturbación $\left(v_{i t}\right)$. Para solucionar estas limitaciones, Blundell y Bond (1998) desarrollaron una extensión del estimador GMM denominada System-GMM, la cual se corresponde con la metodología empleada en este trabajo. La metodología SystemGMM utiliza como instrumentos, además de los utilizados en el estimador GMM en diferencias, las diferencias retardadas de las variables predeterminadas en las ecuaciones en niveles.

Para obtener un estimador GMM más adecuado en la estimación de modelos con datos de panel, Blundell y Bond (1998) consideran el siguiente supuesto adicional:

$$
E\left(\Delta y_{i 2} \eta_{i t}\right)=0 \text { donde } i=1, \ldots, N
$$

\footnotetext{
${ }^{43}$ El test de Hansen también se conoce en la literatura como el estadístico-J.
} 
La condición de la ecuación anterior se mantiene si las medias de la serie $y_{i t}$, aunque difieran entre individuos, son constantes en el tiempo por períodos $1,2, \ldots, T$ para cada individuo. Este supuesto combinado con las suposiciones iniciales de datos de panel $^{44}$ da lugar a $T-2$ nuevas condiciones de momentos:

$$
E\left(\Delta y_{i, t-1} u_{i t}\right)=0 \text { donde } i=1, \ldots, N \mathrm{y} t=3, \ldots, T
$$

siendo $u_{i t}=\eta_{i}+v_{i t}$

Estas condiciones de momentos permiten combinar ecuaciones en diferencias con ecuaciones en niveles (Arellano y Bover, 1995). En consecuencia, se puede construir un estimador GMM que utilice un sistema de $(T-2)$ ecuaciones en diferencias y $(T-2)$ ecuaciones en niveles correspondientes a los períodos $3, \ldots, T$. La matriz de instrumentos para este sistema adopta la siguiente forma:

$$
Z_{i}^{+}=\left(\begin{array}{lr}
Z_{i} & 0 \\
0 & \mathrm{~W}_{\mathrm{i}}
\end{array}\right) \text { donde } W_{i}=\left(\begin{array}{cccc}
\Delta y_{i 2} & 0 & \ldots & 0 \\
& \Delta y_{i 3} & \\
& & \ldots & 0 \\
& & & 0 \\
0 & \ldots & 0 & \Delta y_{i, T-1}
\end{array}\right)
$$

Finalmente, es preciso señalar que la metodología System-GMM requiere que las primeras $\Delta \mathrm{y}_{\text {it }}$ diferencias no estén correlacionadas con los efectos individuales $\left(\eta_{i}\right)$. La validez de esta metodología se puede verificar mediante el test de autocorrelación de los residuos diferenciados de orden m y el test de Hansen de sobre identificación (Hansen, 1982):

donde $A R_{m}=\frac{\sum_{i=1}^{N}\left(0_{m i}^{*}{ }^{\prime}{ }^{*}{ }_{i}\right)}{B_{1}{ }^{1 / 2}} \quad 0^{*}{ }_{m i}=L_{m}\left(O^{*}{ }_{i}\right)$

siendo $L_{m}$ el operador retardo de orden m, y

\footnotetext{
${ }^{44} v_{i t}$ es independiente e idénticamente distribuida (iid) sobre los individuos con media cero. Además, $\eta_{i}$ es iid., y $v_{i t}$ y $\eta_{i}$ son independientes para todo $i$ sobre el período muestral.
} 


$$
\begin{aligned}
& B_{1}=\sum_{i=1}^{N}{v_{m i}^{*}}^{\prime} H_{i} v_{m i}^{*}-2\left(\sum_{i=1}^{N}{v_{m i}^{*}}^{\prime} X_{i}^{*}\right) Q_{1}^{-1}\left(\sum_{i=1}^{N} X_{i}^{*} Z_{i}\right) A_{1}\left(\sum_{i=1}^{N} Z_{i}^{\prime} H_{i} v_{m i}^{*}\right) \\
& +\left(\sum_{i=1}^{N} \hat{v}_{m i}^{*} X_{i}^{*}\right) \hat{V}_{1}\left(\sum_{i=1}^{N} X_{i}^{\prime} \hat{v}_{m i}^{*}\right) \\
& H=\left(\frac{1}{N} Z^{\prime} \hat{E}\right)^{\prime} \operatorname{Var}(\mathrm{z} \varepsilon)^{-1} \frac{1}{N} Z^{\prime} \hat{E}=\frac{1}{N}\left(Z^{\prime} \hat{E}\right)^{\prime} \mathrm{A}_{\mathrm{EGMM}} Z^{\prime} \hat{E}
\end{aligned}
$$

Siendo $Z^{\prime}$ una matriz de instrumentos $j ; \hat{E}$ los residuos; $\varepsilon$ el término de error y $A_{E G M M}$ la matriz de ponderaciones eficiente GMM. El test de Hansen se distribuye como una chi-cuadrado con $j-k$ grados de libertad, siendo $j$ el número de instrumentos y $k$ el número de variables explicativas.

\subsection{4.- Resultados obtenidos}

La Tabla 2.9 recoge los resultados obtenidos en el contraste de las hipótesis 1 y 2. En el modelo (a) se han introducido únicamente las características más utilizadas en la literatura tradicional: tamaño (TAMAÑO), liquidez (LIQUIDEZ) y capitalización (CAPITAL). En el modelo (b) se ha añadido la variable RIESGO para controlar por el riesgo de crédito de las entidades. En el modelo (c) se ha incluido la concentración del mercado bancario (CONC) como medida de control adicional.

Por lo que respecta al modelo (a), la respuesta de los préstamos bancarios a los shocks de política monetaria $(\Delta i)$ tiene el signo negativo esperado, pero solo en el indicador de política monetaria actual $\left(\Delta i_{t}\right)$ y no en el retardado $\left(\Delta i_{t-1}\right)$. Esto implica que un incremento de los tipos de interés da lugar a una reducción inmediata de la oferta de crédito. 
Tabla 2.9: Resultados

\begin{tabular}{|c|c|c|c|c|c|c|}
\hline & (a) & & (b) & & (c) & \\
\hline$\Delta \ln (\text { Prestam })_{\mathrm{t}-1}$ & $0,1098(1,14)$ & & $0,1083(1,36)$ & & $0,1178(1,43)$ & \\
\hline$\Delta \ln (\mathrm{PIB})_{\mathrm{t}}$ & $0,3086(0,99)$ & & $0,4007(1,54)$ & & $0,3421(1,07)$ & \\
\hline$\Delta \ln (\mathrm{PIB})_{\mathrm{t}-1}$ & $-0,0793(-0,28)$ & & $-0,0741(-0,30)$ & & $-0,1038(-0,39)$ & \\
\hline$\Delta \mathrm{i}_{\mathrm{t}}$ & $-0,0546(-2,46)$ & $* *$ & $-0,0518(-2,43)$ & $* *$ & $-0,0509(-2,21)$ & $* *$ \\
\hline$\Delta \mathrm{i}_{\mathrm{t}-1}$ & $0,0324(1,12)$ & & $0,0342(1,24)$ & & $-0,0312(1,06)$ & \\
\hline TAMAÑO $_{\mathrm{t}-1}$ & $0,0025(1,32)$ & & $0,0029(1,98)$ & $* *$ & $0,0015(1,16)$ & \\
\hline LIQUIDEZ $_{\mathrm{t}-1}$ & $0,0118(0,51)$ & & $0,0098(0,46)$ & & $-0,0131(0,62)$ & \\
\hline CAPITAL $_{\mathrm{t}-1}$ & $-0,0357(-0,48)$ & & $0,0608(0,74)$ & & $0,0707(0,85)$ & \\
\hline RIESGO $_{\mathrm{t}-1}$ & & & $-1,4350(-2,50)$ & $* *$ & $-1,5810(-3,02)$ & $* * *$ \\
\hline$\Delta \mathrm{i}_{\mathrm{t}} * \mathrm{TAMAÑO}_{\mathrm{t}-1}$ & $0,0020(5,82)$ & $* * *$ & $0,0017(4,00)$ & $* * *$ & $0,0013(2,97)$ & $* * *$ \\
\hline$\Delta \mathrm{i}_{\mathrm{t}-1} * \mathrm{TAMAÑO}_{\mathrm{t}-1}$ & $0,0002(0,75)$ & & $0,0000(0,02)$ & & $-0,0002(-0,65)$ & \\
\hline$\Delta \mathrm{i}_{\mathrm{t}}^{*}$ LIQUIDEZ $_{\mathrm{t}-1}$ & $-0,0243(-3,74)$ & $* * *$ & $-0,0226(-3,26)$ & $* * *$ & $-0,1871(-2,75)$ & $* * *$ \\
\hline$\Delta \mathrm{i}_{\mathrm{t}-1} *$ LIQUIDEZ $_{\mathrm{t}-1}$ & $-0,0073(-1,40)$ & & $-0,0032(-0,58)$ & & $-0,0016(-0,29)$ & \\
\hline$\Delta \mathrm{i}_{\mathrm{t}} *$ CAPITAL $_{\mathrm{t}-1}$ & $0,0360(1,14)$ & & $0,0738(1,55)$ & & $0,0572(1,18)$ & \\
\hline$\Delta \mathrm{i}_{\mathrm{t}-1} *$ CAPITAL $_{\mathrm{t}-1}$ & $0,0298(1,37)$ & & $0,0096(0,39)$ & & $0,0088(0,35)$ & \\
\hline$\Delta \mathrm{i}_{\mathrm{t}}^{*} \mathrm{RIESGO}_{\mathrm{t}-1}$ & & & $-0,4994(-2,28)$ & $* *$ & $-0,4634(-2,22)$ & $* *$ \\
\hline$\Delta \mathrm{i}_{\mathrm{t}-1} * \mathrm{RIESGO}_{\mathrm{t}-1}$ & & & $-0,2241(-0,86)$ & & $-0,2399(-0,90)$ & \\
\hline $\mathrm{CONC}_{t}$ & & & & & $0,3892(0,97)$ & \\
\hline$\Delta \mathrm{i}_{\mathrm{t}} * \mathrm{CONC}_{\mathrm{t}}$ & & & & & $0,1320(3,82)$ & $* * *$ \\
\hline$\Delta \mathrm{i}_{\mathrm{t}-1} * \mathrm{CONC}_{\mathrm{t}}$ & & & & & $0,0126(0,39)$ & \\
\hline $\mathrm{RS}_{\mathrm{t}}$ & $-0,0238(-3,03)$ & $* * *$ & $-0,0175(-2,72)$ & $* * *$ & $-0,0123(-1,86)$ & $*$ \\
\hline $\mathrm{RS}_{\mathrm{t}}{ }^{*} \mathrm{PC}_{\mathrm{t}}$ & & & & & & \\
\hline$\Delta \mathrm{i}_{\mathrm{t}}^{*} \mathrm{RS}_{\mathrm{t}}$ & $-0,0128(-2,28)$ & $* *$ & $-0,0161(-3,22)$ & $* * *$ & $-0,0198(-3,94)$ & $* * *$ \\
\hline$\Delta \mathrm{i}_{\mathrm{t}-1} * \mathrm{RS}_{\mathrm{t}}$ & $-0,0036(-0,75)$ & & $-0,0008(-0,32)$ & & $-0,0022(-0,87)$ & \\
\hline$\left(\Delta \mathrm{i}_{\mathrm{t}}^{*} \mathrm{RS}_{\mathrm{t}}\right)^{2}$ & $-0,0036(-2,25)$ & $* *$ & $-0,0037(-2,38)$ & $* *$ & $-0,0044(-2,75)$ & $* * *$ \\
\hline$\left(\Delta \mathrm{i}_{\mathrm{t}-1} * \mathrm{RS}_{\mathrm{t}}\right)^{2}$ & $-0,0011(-2.44)$ & $* *$ & $-0,0008(-2,23)$ & $* *$ & $-0,0010(-2,81)$ & $* * *$ \\
\hline CONS & $-0,1047(-4,96)$ & $* * *$ & $-0,1044(-6,00)$ & $* * *$ & $-0,1151(-7,12)$ & $* * *$ \\
\hline Dummies País & Sí & & Sí & & Sí & \\
\hline Dummies Temporales & Sí & & Sí & & Sí & \\
\hline $\mathrm{m}_{2}$ & 0,292 & & 0,292 & & 0,262 & \\
\hline Hansen & 0,196 & & 0,104 & & 0,101 & \\
\hline
\end{tabular}

Para cada variable se muestra su coeficiente y entre paréntesis la T-student; *** indica un nivel de significatividad del 99\%, ** indica un nivel de significatividad del $95 \%$, * indica un nivel de significatividad del 90\%; $\mathrm{m}_{2}$ es el estadístico de correlación serial de segundo orden distribuido como una $\mathrm{N}(0,1)$ bajo la hipótesis nula de no correlación serial. Hansen es el test de sobre-identificación, distribuido como una chi-cuadrado bajo la hipótesis nula de no relación entre los instrumentos y el término de error.

El término de interacción entre la variable TAMAÑ $O$ y la variación actual de tipos de interés $\left(\Delta i_{t}\right)$ es positivo y significativo. Por lo tanto, el crecimiento de la oferta de préstamos de las entidades más grandes es menos sensible a las variaciones de política monetaria. Por su parte, la interacción entre LIQUIDEZ y la política monetaria actual 
$\left(\Delta i_{t}\right)$ es negativa y significativa, por lo que los bancos con un ratio de liquidez mayor se ven más afectados por los shocks monetarios. Estos resultados están en sintonía con otros trabajos que analizan bancos europeos (Jimborean, 2009; Bogoev, 2010). Gambacorta y Marques-Ibanez (2011) muestran que las entidades más líquidas en Europa tienden a ser más sensibles a los movimientos de política monetaria en épocas de crisis. La crisis financiera condujo a las entidades de crédito a acaparar mayores reservas de liquidez por cautela en lugar de destinarlas a actividades de préstamo, lo cual podría explicar este resultado.

Finalmente, tal y como hemos propuesto, la variable de riesgo soberano $(R S)$ es negativa y significativa, así como su interacción con la política monetaria $\left(\Delta i_{t} * R S\right)$. Las entidades que operan en países con mayores primas de riesgo tienen menos oportunidades de expandir su oferta de préstamos, puesto que el acceso a financiación y su coste dependen en buena medida del riesgo soberano del país de origen de estas entidades.

En el caso de las interacciones cuadráticas entre el riesgo soberano y la política monetaria actual y retardada, $\left(\Delta i_{t} * R S_{t}\right)^{2}$ y $\left(\Delta i_{t-1} * R S_{t}\right)^{2}$, el signo es negativo y significativo, tal y como esperábamos. Sin embargo, dado que estamos interaccionando dos variables continuas (riesgo soberano y política monetaria), el efecto marginal de la política monetaria sobre el crecimiento de la oferta de préstamos va a depender del valor que tome la variable de riesgo soberano $(R S)$. Para capturar dicho efecto marginal, es preciso calcular la primera derivada de la ecuación (1) de la página 79 con respecto a la política monetaria $^{45}$ :

\footnotetext{
${ }^{45}$ Las variables RIESGO y CONC no aparecen en la ecuación (1.1) porque no están incluidas en el modelo (a).
} 


$$
\begin{aligned}
& \frac{\partial \Delta \ln \left(\text { Prestam }_{\mathrm{i}, \mathrm{t}}\right.}{\partial \Delta \mathrm{i}_{\mathrm{m}, \mathrm{t}}}=\beta_{0}+\tau_{0} \text { TAMAÑO }_{\mathrm{i}, \mathrm{t}-1}+\theta_{0} \text { LIQUIDEZ }_{\mathrm{i}, \mathrm{t}-1}+\mu_{0} \text { CAPITAL }_{\mathrm{i}, \mathrm{t}-1} \\
& \quad+\gamma_{0} \mathrm{RS}_{\mathrm{m}, \mathrm{t}}+2 \epsilon_{0} \Delta \mathrm{i}_{\mathrm{m}, \mathrm{t}}\left(\mathrm{RS}_{\mathrm{m}, \mathrm{t}}\right)^{2}
\end{aligned}
$$

Dado que las variables TAMAÑO, LIQUIDEZ y CAPITAL están normalizadas con respecto a la media, el efecto marginal para una entidad de tipo medio será el siguiente:

$$
\frac{\partial \Delta \ln (\text { Prestam })_{\mathrm{i}, \mathrm{t}}}{\partial \Delta \mathrm{i}_{\mathrm{m}, \mathrm{t}}}=\beta_{0}+\gamma_{0} \mathrm{RS}_{\mathrm{m}, \mathrm{t}}+2 \epsilon_{0} \Delta \mathrm{i}_{\mathrm{m}, \mathrm{t}}\left(\mathrm{RS}_{\mathrm{m}, \mathrm{t}}\right)^{2}
$$

El efecto marginal de la ecuación (1.2) depende de la variable de política monetaria $\left(\Delta i_{m, t}\right)$, por lo que hemos estimado los efectos marginales para una entidad bancaria de tipo medio en dos escenarios diferentes: un incremento del $0,75 \%$ y una disminución del $0,75 \%$ del indicador de política monetaria respectivamente (tipo de interés a corto plazo del mercado monetario). La elección de este porcentaje responde a ser el múltiplo de $0,25 \%$ más cercano al incremento/decremento anual medio del tipo de interés a corto plazo del mercado monetario entre 1999 y $2012^{46}$. El efecto marginal también varía con el nivel de riesgo soberano $(R S)$, por lo que es preciso construir gráficos para interpretar los resultados correctamente.

\footnotetext{
${ }^{46}$ Hemos elegido múltiplos de $0,25 \%$ porque varios bancos centrales (incluido el BCE) generalmente modifican sus tipos de interés objetivo empleando dichos múltiplos. Recientemente el BCE ha realizado variaciones de tipos de interés inferiores, debido a que éstos se sitúan actualmente en valores cercanos al cero. Si bien es cierto, estas variaciones las ha realizado fuera de nuestro período de análisis. También se ha estimado el efecto marginal utilizando diferentes incrementos/disminuciones del tipo de interés a corto plazo del mercado monetario. En concreto, se ha empezado utilizando la mínima variación de tipos de interés de la muestra y se ha añadido progresivamente un $0,25 \%$ a la variación anterior hasta alcanzar la variación máxima de tipos de interés de la muestra. Los resultados obtenidos son similares a los conseguidos cuando se emplea un aumento/disminución de tipos de interés del $0,75 \%$.
} 
La Figura 2.1 refleja el efecto marginal de la política monetaria sobre la variación del logaritmo de préstamos, $\Delta \ln ($ Prestam), en función de la prima de riesgo cuando los tipos de interés a corto plazo aumentan un 0,75\%. Las líneas discontinuas representan el intervalo de confianza al $90 \%{ }^{47}$.

Figura 2.1. Efecto marginal de la política monetaria ( $\Delta$ tipos de interés $0,75 \%$ ) sobre la variación del logaritmo de los préstamos bancarios

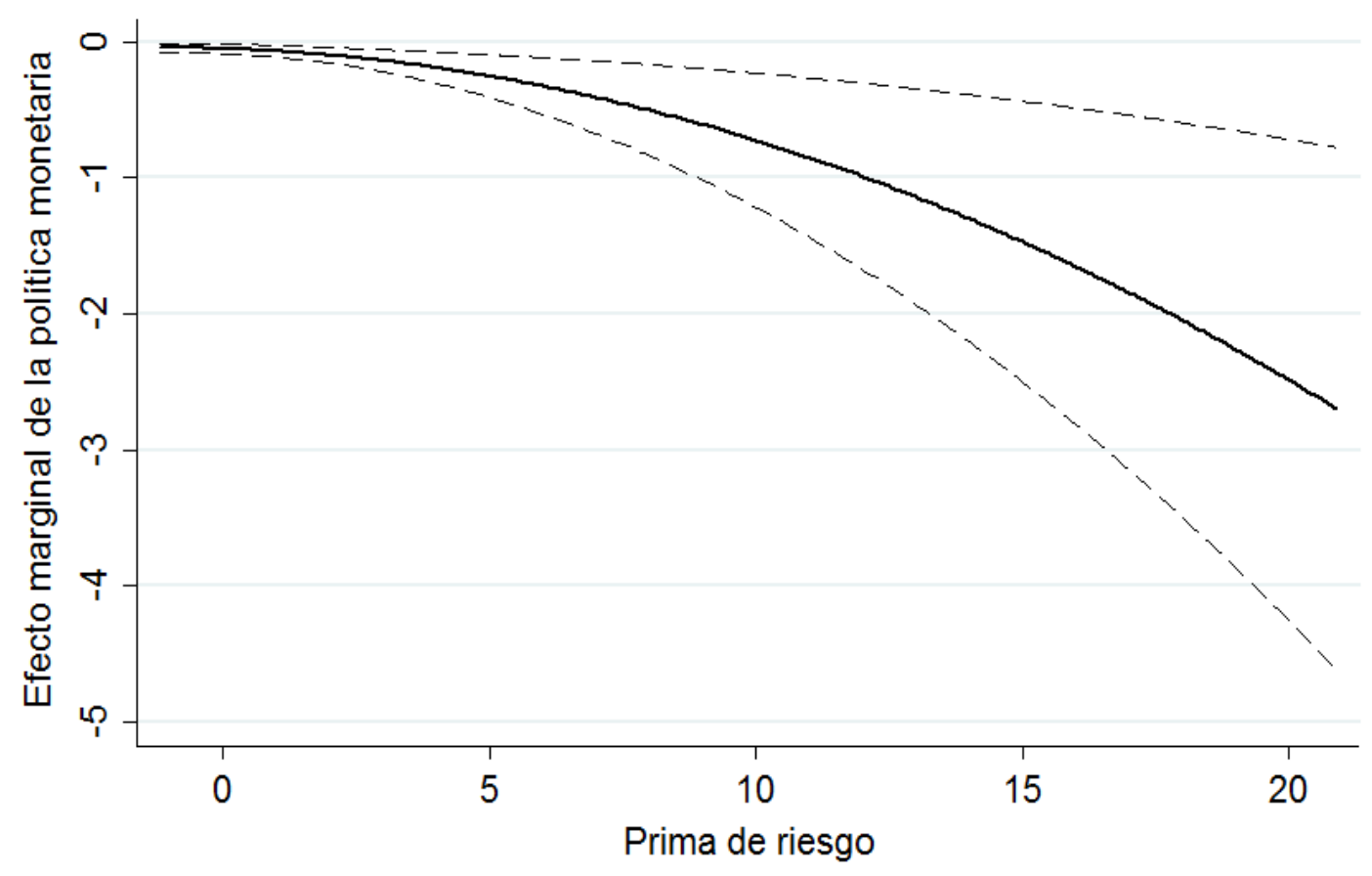

Modelo (a)

- Efecto marginal

- - - - Intervalo superior de confianza al $90 \%$

- - - Intervalo inferior de confianza al $90 \%$

Los resultados muestran un efecto marginal negativo, pero cercano a cero para las entidades que operan en países con una prima de riesgo muy baja. Concretamente, la mínima reducción de préstamos se produciría cuando la prima de riesgo es igual a $-1,19 \%$. En ese punto, el efecto marginal es de $-0,047$. Sin embargo, a medida que la prima de riesgo aumenta, este efecto marginal se vuelve cada vez más negativo. Por lo

\footnotetext{
${ }^{47}$ Se ha seguido el enfoque planteado en el estudio de Aiken y West (1991) para la construcción de los intervalos de confianza. El efecto marginal es significativo cuando los extremos inferior y superior del intervalo de confianza poseen el mismo signo.
} 
tanto, tal y como proponíamos en la hipótesis 1, las entidades que operan en países con primas de riesgo más altas son más sensibles a las restricciones monetarias y, por lo tanto, contraen en mayor medida su oferta de crédito.

La Figura 2.2 muestra el efecto marginal de la política monetaria sobre la variación del logaritmo de préstamos en función de la prima de riesgo, cuando los tipos de interés se reducen en un $0,75 \%$. En este caso debemos interpretar el efecto marginal cuidadosamente. Dado que estamos evaluando el efecto de una reducción de los tipos de interés del mercado monetario, si el efecto marginal es negativo, una disminución de los tipos de interés dará lugar a un incremento de la oferta de préstamos. En cambio, si el efecto marginal es positivo, una reducción de los tipos de interés conducirá a una disminución de la oferta de préstamos.

Figura 2.2. Efecto marginal de la política monetaria ( $\nabla$ tipos de interés $0,75 \%$ ) sobre la variación del logaritmo de los préstamos bancarios

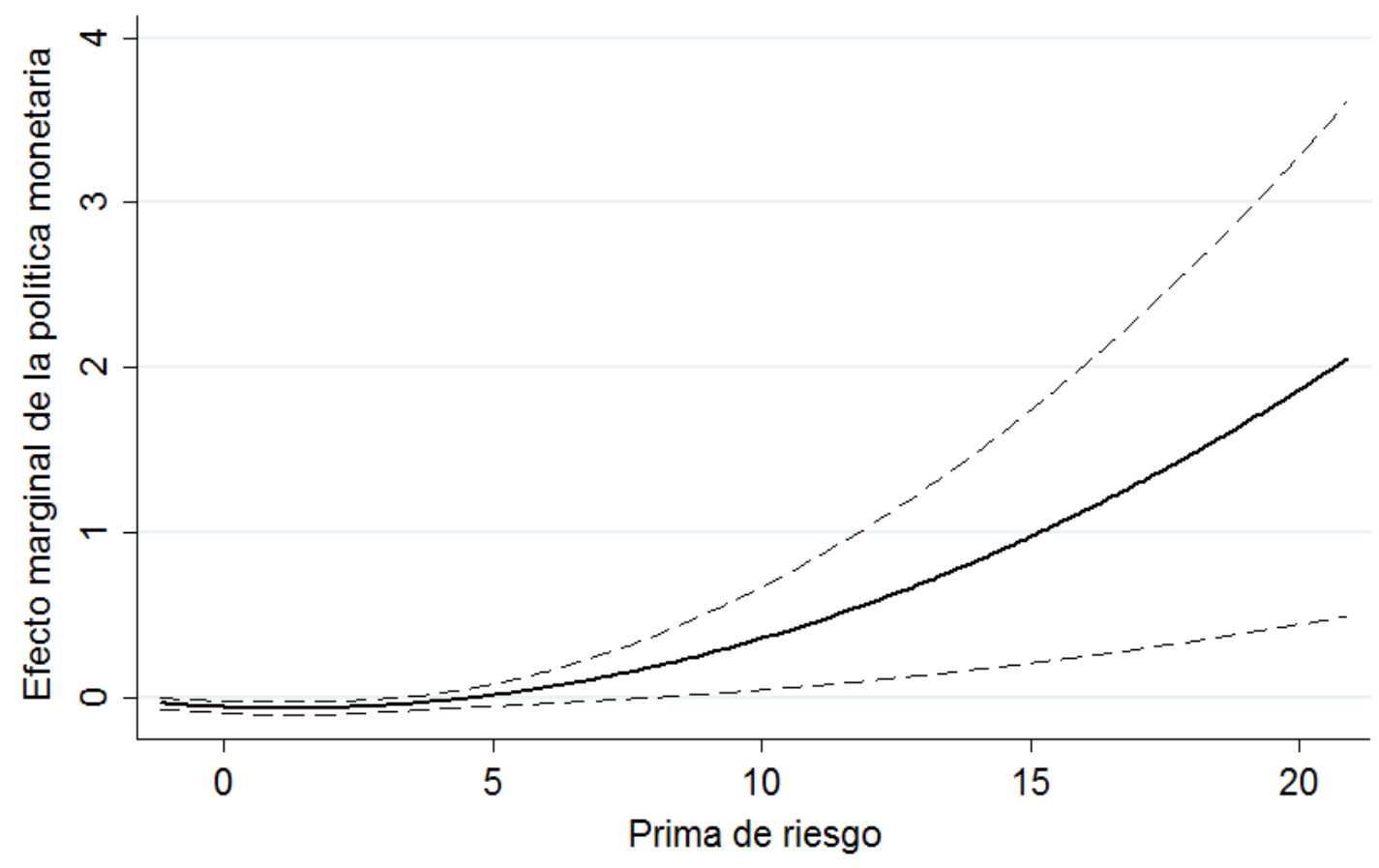

Modelo (a)

- Efecto marginal

- - - Intervalo superior de confianza al $90 \%$

- - - Intervalo inferior de confianza al $90 \%$ 
Los resultados de la Figura 2.2 revelan que la relación entre la política monetaria y el crecimiento de la oferta de crédito es significativa cuando la prima de riesgo se sitúa entre $-0,99 \%$ y $3,11 \%$. El efecto marginal en este intervalo es negativo, pero dado que estamos analizando una reducción de tipos de interés, el efecto final será el contrario (positivo en este caso), es decir, una reducción de tipos de interés da lugar a un aumento de los préstamos. Sin embargo, el efecto marginal de la política monetaria sobre los préstamos es bajo para esos niveles de prima de riesgo (concretamente se sitúa entre un 0,0366 y un 0,0417), pero además, nuestros resultados no muestran que ante una reducción de tipos de interés, las entidades en países con primas de riesgo más altas incrementen sustancialmente menos su oferta de crédito en relación a los países con primas de riesgo más bajas, lo cual no sustentaría la hipótesis 2.

Asimismo, la relación entre la política monetaria y el crecimiento de la oferta de préstamos es negativa y significativa a partir de una prima de riesgo del $7,81 \%$. Esto implica que en países con un riesgo soberano elevado, una reducción de tipos de interés disminuye la oferta de crédito, probablemente debido al alto riesgo de impago y a las fuertes restricciones financieras de esos países. Solamente Grecia y Portugal, que solicitaron el rescate en el año 2010 y 2011 respectivamente, poseen una prima de riesgo superior a ese porcentaje. En el caso de Grecia dicho porcentaje se supera en los años 2011 y 2012, mientras que Portugal únicamente lo sobrepasa en $2012^{48}$.

En la Tabla 2.9, modelo (b), hemos añadido la variable RIESGO para controlar por el riesgo de crédito de las entidades. Los resultados son similares a los obtenidos en el modelo (a). Todas las variables significativas del modelo (a) lo son también con el

\footnotetext{
${ }^{48}$ Para comprobar la robustez de nuestros resultados, hemos estimado el modelo de la ecuación (1) de la página 79 sin incluir los países que han tenido que ser rescatados durante la crisis. Los resultados de este modelo, que se presentarán en un apartado posterior, son similares a los obtenidos con el modelo que incluye dichos países.
} 
mismo signo en el modelo (b). Así, el indicador de política monetaria sigue siendo negativo y significativo en el momento actual y no en el retardado un período. La variable TAMAÑO es ahora significativa y positiva, lo que nos indica que los bancos más grandes gozan de mayores tasas de crecimiento de préstamos. Por su parte, la interacción entre TAMAÑO y la política monetaria actual es significativa y positiva, esto es, las entidades más pequeñas contraen en mayor medida su oferta de crédito ante políticas monetarias restrictivas. La interacción entre la variable LIQUIDEZ y el indicador de política monetaria actual es por su parte significativa y negativa.

La variable que mide el riesgo de crédito de la entidad (RIESGO) posee un signo negativo y significativo, por lo que influye negativamente en la oferta de préstamos. Asimismo, la interacción entre RIESGO y el tipo de interés actual de la política monetaria es negativa y significativa. Por lo tanto, las entidades con elevado riesgo de crédito son más sensibles a los shocks monetarios debido a las mayores dificultades que soportan para acceder a fuentes de financiación.

La variable de riesgo soberano es nuevamente significativa y negativa. Asimismo, las interacciones lineal y cuadrática entre la política monetaria y el riesgo soberano poseen un signo negativo y significativo.

Para el cálculo del efecto marginal de la política monetaria sobre el crecimiento de la oferta de préstamos en el modelo (b), calculamos la derivada de la ecuación (1) de la página 79 con respecto a la variable de política monetaria ${ }^{49}$ :

\footnotetext{
${ }^{49}$ La variable CONC no aparece en la ecuación (1.3) debido a que no está incluida en el modelo (b).
} 


$$
\begin{aligned}
& \frac{\partial \Delta \ln \left(\text { Prestam }_{\mathrm{i}, \mathrm{t}}\right.}{\partial \Delta \mathrm{i}_{\mathrm{m}, \mathrm{t}}}=\beta_{0}+\tau_{0} \text { TAMAÑO }_{\mathrm{i}, \mathrm{t}-1}+\theta_{0} \text { LIQUIDEZ }_{\mathrm{i}, \mathrm{t}-1}+\mu_{0} \text { CAPITAL }_{\mathrm{i}, \mathrm{t}-1} \\
& \quad+\varphi_{0} \text { RIESGO }_{\mathrm{i}, \mathrm{t}-1}+\gamma_{0} \mathrm{RS}_{\mathrm{m}, \mathrm{t}}+2 \epsilon_{0} \Delta \mathrm{i}_{\mathrm{m}, \mathrm{t}}\left(\mathrm{RS}_{\mathrm{m}, \mathrm{t}}\right)^{2}
\end{aligned}
$$

Dado que la variable RIESGO, al igual que las variables TAMAÑO, LIQUIDEZ y CAPITAL, está normalizada con respecto a la media de las entidades de la muestra, el efecto marginal para una entidad de tipo medio sería el mismo que utilizamos en la ecuación (1.2) de la página 96:

$$
\frac{\partial \Delta \ln (\text { Prestam })_{i, t}}{\partial \Delta i_{m, t}}=\beta_{0}+\gamma_{0} R S_{m, t}+2 \epsilon_{0} \Delta i_{m, t}\left(R S_{m, t}\right)^{2}
$$

La Figura 2.3 muestra, para el modelo (b), el efecto marginal de la política monetaria sobre la variación del logaritmo de los préstamos en función de la prima de riesgo cuando el tipo de interés a corto plazo aumenta un 0,75\%. Al igual que ocurría con el modelo (a), el efecto marginal de una política monetaria restrictiva sobre los préstamos está cerca de cero en países con bajo riesgo soberano. La reducción de préstamos alcanza su valor mínimo cuando la prima de riesgo es igual a -1,19\%. En este punto, el efecto marginal toma un valor de $-0,0406$. Sin embargo, a medida que el riesgo soberano aumenta, la reducción de préstamos es mayor. Por lo tanto, estos resultados sustentan nuevamente la hipótesis 1 , al mostrar que la oferta crediticia de las entidades bancarias que operan en países con mayor riesgo soberano es más sensible a las restricciones monetarias. 
Figura 2.3: Efecto marginal de la política monetaria ( $\Delta$ tipo de interés $0,75 \%$ ) sobre la variación del logaritmo de los préstamos bancarios

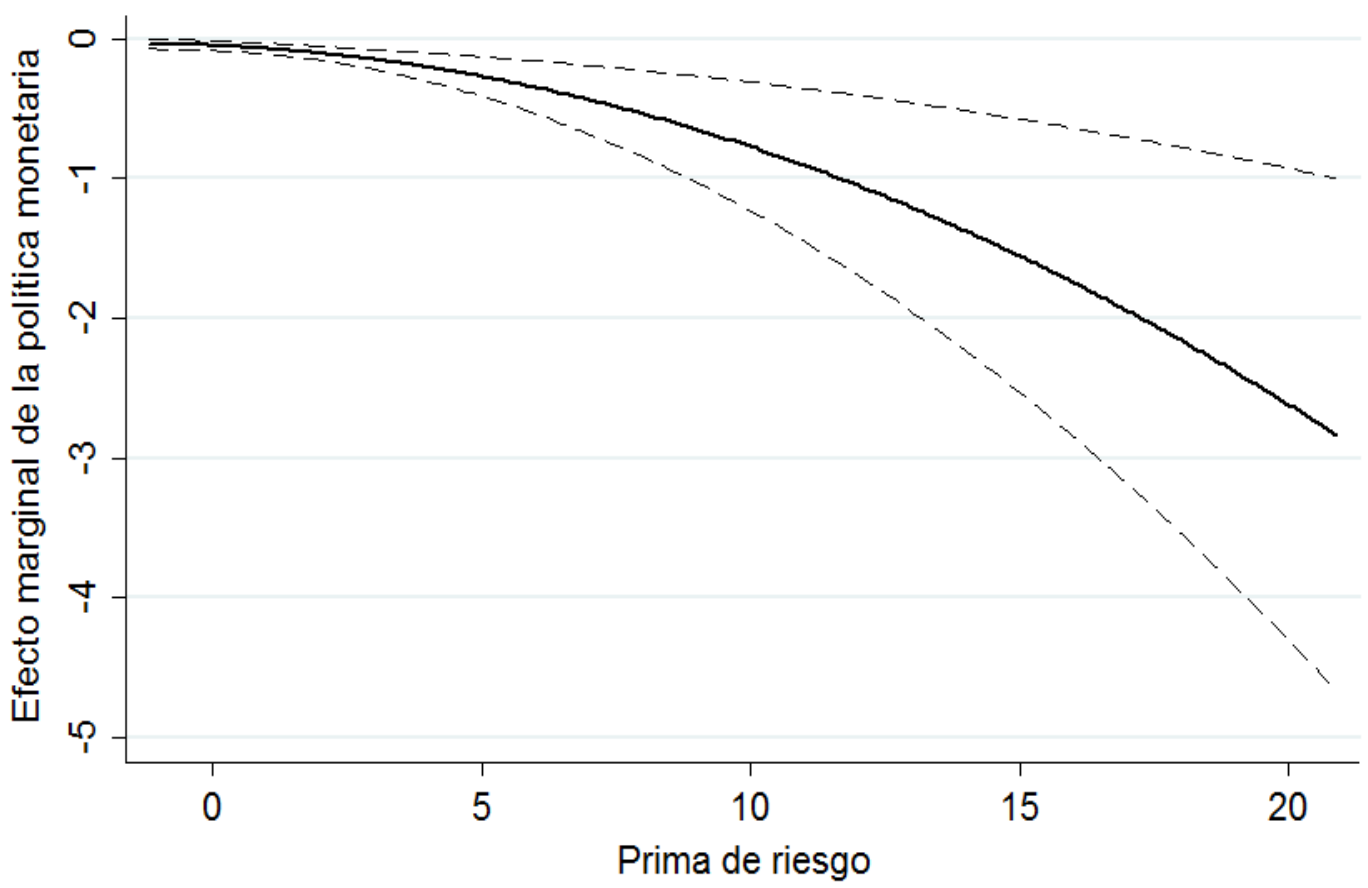

Modelo (b)

- Efecto marginal

- - - - Intervalo superior de confianza al $90 \%$

- - - Intervalo inferior de confianza al $90 \%$

La Figura 2.4 recoge el efecto marginal de la política monetaria sobre la variación del logaritmo de los préstamos en función de la prima de riesgo cuando el tipo de interés baja un $0,75 \%$ para el caso del modelo (b). En este caso, una política monetaria expansiva solamente genera un incremento de la oferta de préstamos en países con una prima de riesgo comprendida entre $-0,79 \%$ y $3,31 \%$. No obstante, el efecto marginal está cerca de cero (entre 0,0356 y 0,0437 ) y no presenta diferencias sustanciales para esos valores de prima de riesgo. Sin embargo, en países con una prima de riesgo muy elevada, una expansión monetaria reduce la oferta de crédito. En concreto, esto sucede en países con una prima de riesgo igual o superior al 9,01\%. Estos resultados son muy similares a los obtenidos en el modelo (a) y nuevamente muestran que no existen suficientes evidencias a favor de la hipótesis 2 , la cual proponía que las entidades que 
operan en países con mayor riesgo soberano incrementan su oferta crediticia en menor medida cuando se relajan las condiciones monetarias.

Figura 2.4: Efecto marginal de la política monetaria ( $\nabla$ tipo de interés $0,75 \%$ ) sobre la variación del logaritmo de los préstamos bancarios

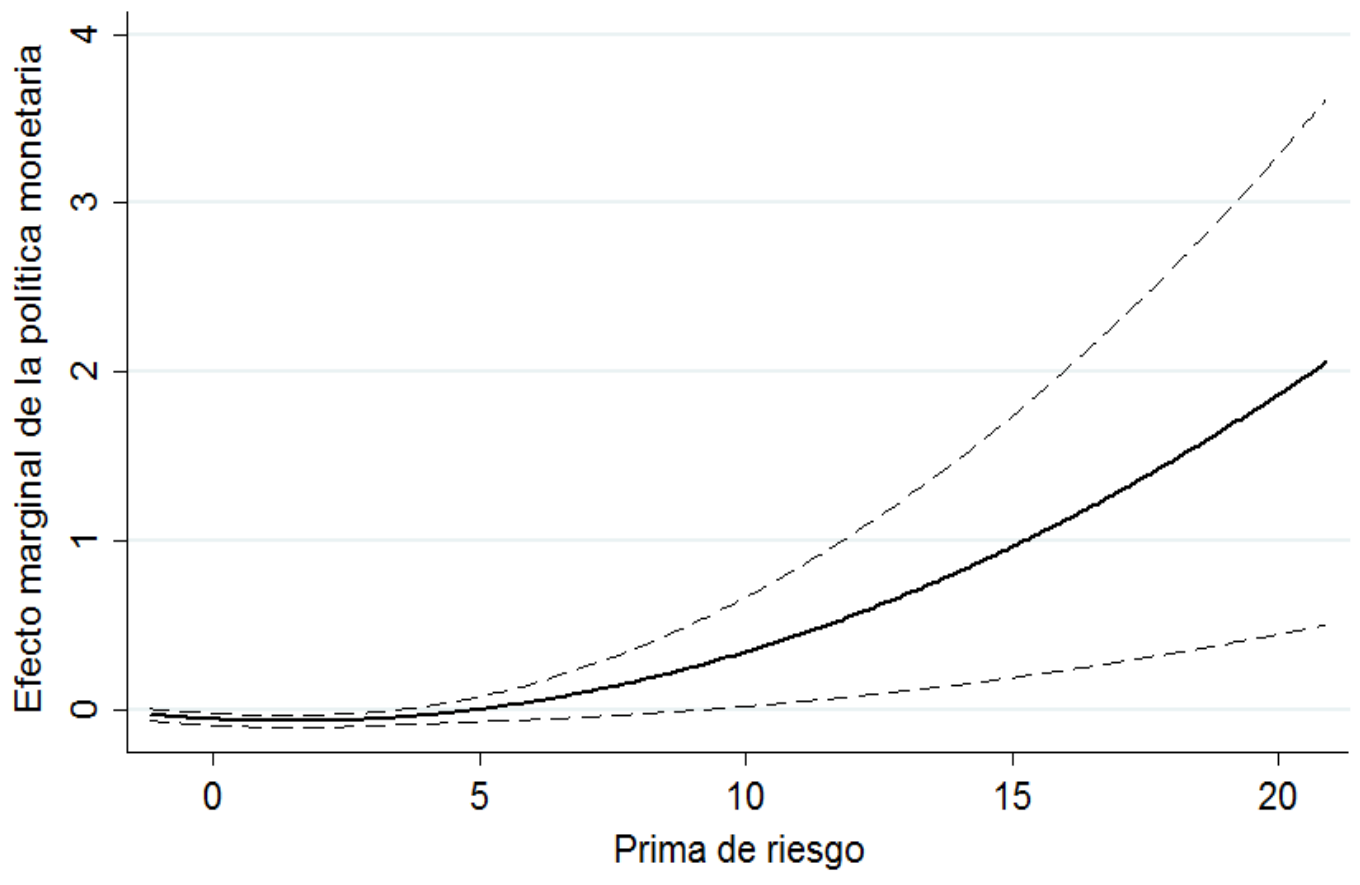

Modelo (b)

- Efecto marginal

- - - Intervalo superior de confianza al $90 \%$

- - - - Intervalo inferior de confianza al $90 \%$

En la Tabla 2.6, modelo (c), se incluye la concentración del mercado a través de la variable CONC. Todas las variables significativas en el modelo (b) lo son también con el mismo signo en el (c). Los resultados de la política monetaria en este caso indican un efecto negativo y significativo sobre la variación de préstamos. La interacción entre TAMAÑO y la política monetaria sigue siendo positiva y significativa, mientras que el término de interacción entre LIQUIDEZ y política monetaria también lo es, pero con signo negativo. Al igual que sucedía en el modelo (b), la variable RIESGO y la 
interacción entre RIESGO y el indicador actual de política monetaria son significativas y negativas.

En este modelo la interacción entre CONC y la política monetaria actual es significativa y positiva. Esto indica que los mercados bancarios más concentrados se ven menos afectados por restricciones monetarias, debido probablemente a que el mayor tamaño de sus entidades las permite obtener condiciones más ventajosas de financiación, tal y como muestran otros trabajos previos (Adams y Amel, 2005; 2011; Olivero et al., 2011a).

Finalmente, la variable de riesgo soberano es, de nuevo, significativa y negativa. Asimismo, las interacciones lineal y cuadrática entre la política monetaria y el riesgo soberano son también significativas y negativas.

Dado que la variable $C O N C$ no está normalizada con respecto a la media, para estimar el efecto marginal en este modelo (c) usamos la siguiente ecuación, a partir de la derivada de la ecuación (1) de la página 79 con respecto a la política monetaria:

$$
\frac{\partial \Delta \ln (\text { Prestam })_{\mathrm{i}, \mathrm{t}}}{\partial \Delta \mathrm{i}_{\mathrm{m}, \mathrm{t}}}=\beta_{0}+\gamma_{0} \mathrm{RS}_{\mathrm{m}, \mathrm{t}}+2 \epsilon_{0} \Delta \mathrm{i}_{\mathrm{m}, \mathrm{t}}\left(\mathrm{RS}_{\mathrm{m}, \mathrm{t}}\right)^{2}+\omega_{0} \mathrm{CONC}_{\mathrm{m}, \mathrm{t}}
$$

Para el cálculo del efecto marginal se ha sustituido la variable $C O N C$ con el valor medio de los países de la muestra ${ }^{50}$.

La Figura 2.5 recoge el efecto marginal de la política monetaria sobre la variación del logaritmo de préstamos cuando el tipo de interés aumenta en un 0,75\% y para un nivel de concentración bancaria equivalente a la media de los países de la muestra.

\footnotetext{
${ }^{50}$ También se ha sustituido la variable $C O N C$ con el valor de la mediana, del percentil 25 y del percentil 75 de los países que componen la muestra y los resultados obtenidos son similares.
} 
Figura 2.5: Efecto marginal de la política monetaria ( $\Delta$ tipo de interés $0,75 \%$ ) sobre la variación del logaritmo de los préstamos bancarios

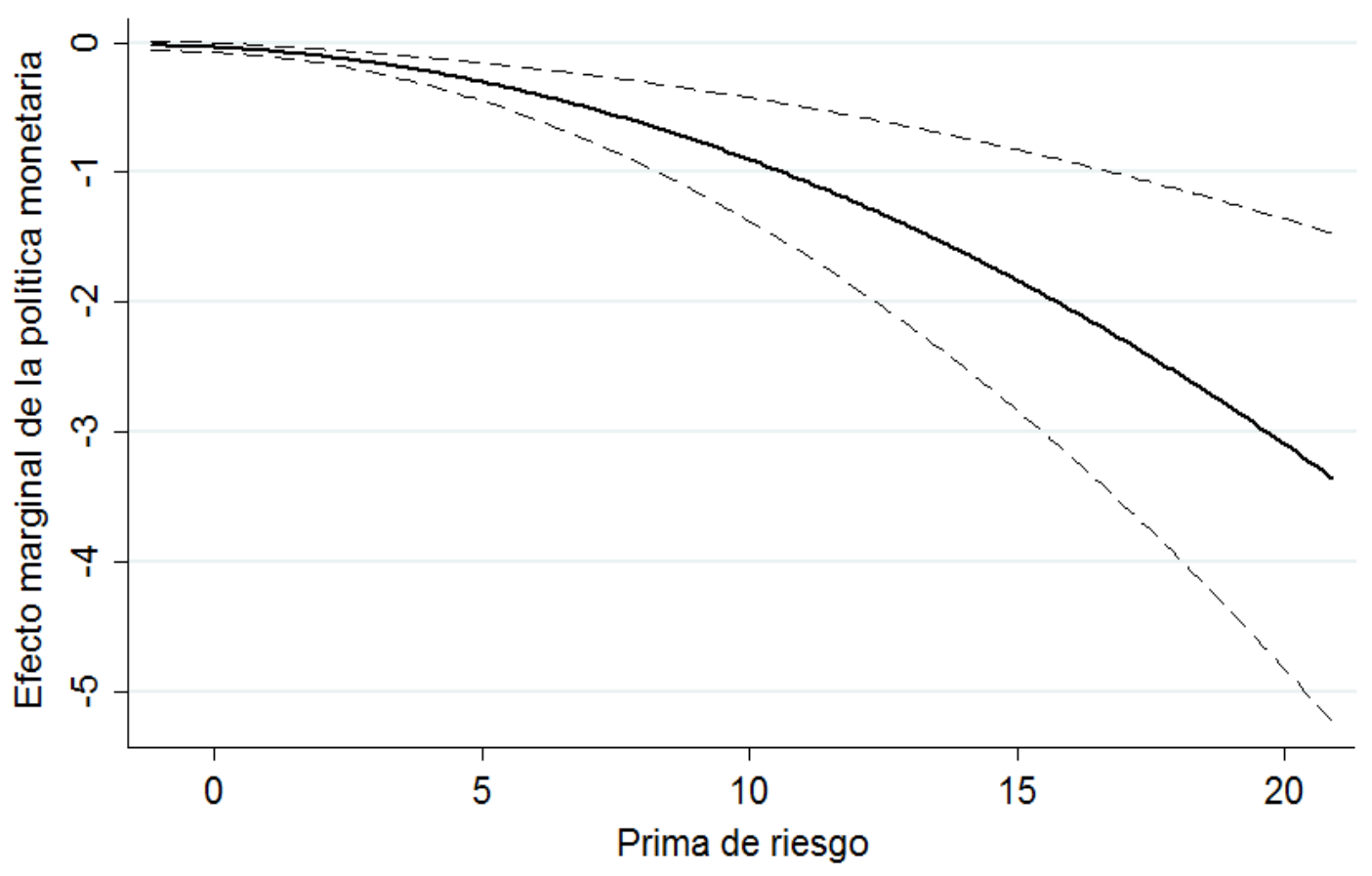

\footnotetext{
Modelo (c) - Concentración media

- Efecto marginal

- - - Intervalo superior de confianza al $90 \%$

- - - Intervalo inferior de confianza al $90 \%$
}

Al igual que en los modelos anteriores, el efecto marginal es negativo y cercano a cero en países con una prima de riesgo baja y se va haciendo cada vez más negativo a medida que ésta se eleva. Estos resultados vuelven a sustentar la hipótesis 1, ya que nuevamente indican que la contracción de préstamos que se produce tras una política monetaria restrictiva, es más pronunciada en los países con un mayor nivel de riesgo soberano.

La Figura 2.6 refleja el efecto marginal de la política monetaria sobre la variación del logaritmo de los préstamos ante una bajada de tipos de interés del 0,75\% y empleando la concentración media de la muestra. 
Figura 2.6: Efecto marginal de la política monetaria ( $\nabla$ tipo de interés $0,75 \%$ ) sobre la variación del logaritmo de los préstamos bancarios

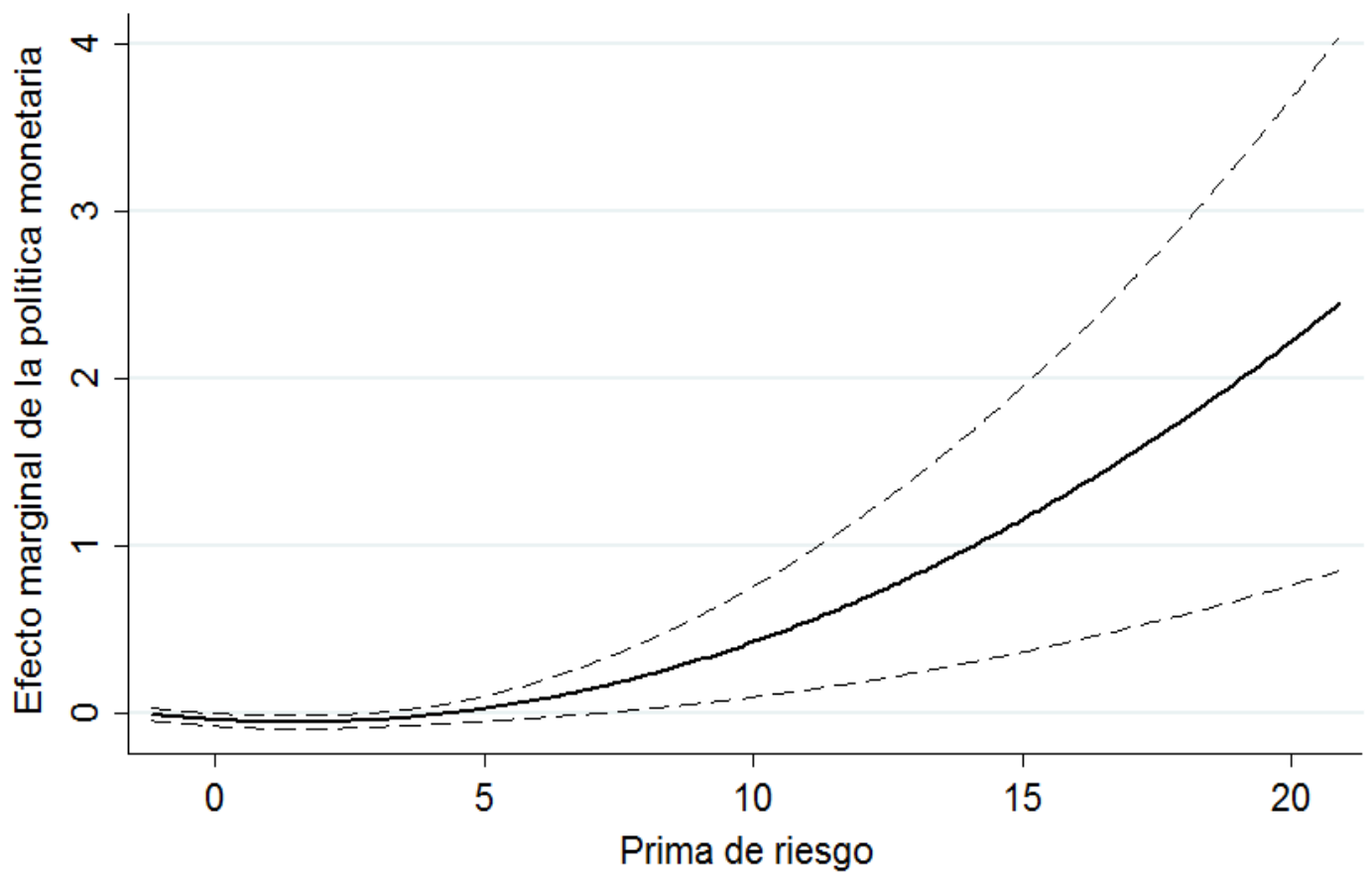

Modelo (c) - Concentración media

- Efecto marginal

- - - Intervalo superior de confianza al $90 \%$

. - . - Intervalo inferior de confianza al $90 \%$

Una disminución del tipo de interés del mercado monetario en un $0,75 \%$ genera un aumento de la oferta de préstamos para las entidades localizadas en países con primas de riesgo entre $0,01 \%$ y $2,81 \%$. No obstante, tal y como sucedía en modelos anteriores, para dichos niveles el incremento de la oferta crediticia es bajo y no existen diferencias sustanciales, dado que el efecto marginal se sitúa en valores muy cercanos a cero (entre 0,0383 y 0,0415 ). Cuando la prima de riesgo es elevada, en este caso igual o superior al 7,11\%, la relajación de las condiciones monetarias origina una disminución del crédito bancario. Tal y como apuntábamos anteriormente, esto se debe probablemente a que las grandes dificultades de financiación y el alto riesgo de impago de estos países generan una contracción de la oferta de préstamos bancarios independientemente del signo de la política monetaria. Por lo tanto, estos resultados no proporcionan suficientes evidencias de que tras una expansión monetaria, la oferta 
crediticia se incremente menos en países con mayores niveles de riesgo soberano, tal y como se planteaba en la hipótesis 2 .

\subsection{5.- Análisis de robustez}

Para comprobar la robustez de los resultados, hemos realizado dos análisis adicionales reflejados en la Tabla 2.10. En el modelo (a) hemos estimado el modelo completo $(\mathrm{c})^{51}$ del análisis anterior sin los países que han sido rescatados durante la crisis financiera (Grecia, Irlanda y Portugal). En el modelo (b) se ha controlado la existencia de cambios estructurales generados por la crisis para comprobar si los efectos que ejerce el riesgo soberano sobre los préstamos son distintos antes y durante la crisis. Así, se ha añadido al modelo (c) del análisis anterior la interacción entre el riesgo soberano $(R S)$ y una variable dummy $P C_{t}$. Dicha dummy toma el valor 1 durante el período 1999-2007 y 0 en caso contrario, por lo que representa los años previos al estallido de la crisis.

Atendiendo a los resultados del modelo (a), la variación actual de tipos de interés posee un coeficiente negativo y significativo, al igual que sucedía en los análisis anteriores. Nuevamente, la interacción entre LIQUIDEZ y política monetaria es significativa y negativa. La variable RIESGO también es significativa con coeficiente negativo. Asimismo, la interacción entre CONC y la política monetaria es significativa y positiva. Finalmente, la prima de riesgo y su interacción cuadrática con la política monetaria son negativas y significativas.

\footnotetext{
${ }^{51}$ El modelo (c) del análisis anterior controla todas las variables generalmente utilizadas en la literatura del canal de préstamos bancarios, estas son, tamaño (TAMAÑO), liquidez (LIQUIDEZ), capital (CAPITAL), riesgo de crédito (RIESGO) y concentración bancaria $(C O N C)$.
} 
Tabla 2.10: Resultados (Análisis de robustez)

\begin{tabular}{|c|c|c|c|c|}
\hline & (a) & & (b) & \\
\hline$\Delta \ln (\text { Prestam })_{\mathrm{t}-1}$ & $0,1091(1,32)$ & & $0,0716(0,91)$ & \\
\hline$\Delta \ln (\mathrm{PIB})_{\mathrm{t}}$ & $0,6693(1,06)$ & & $0,2433(0,71)$ & \\
\hline$\Delta \ln (\mathrm{PIB})_{\mathrm{t}-1}$ & $-0,5019(-0,84)$ & & $-0,2227(-0,69)$ & \\
\hline$\Delta \mathrm{i}_{\mathrm{t}}$ & $-0,1697(-2,11)$ & $* *$ & $-0,0554(-2,33)$ & $* *$ \\
\hline$\Delta \mathrm{i}_{\mathrm{t}-1}$ & $-0,0265(-0,67)$ & & $0,0360(1,18)$ & \\
\hline TAMAÑO $\mathrm{t}_{\mathrm{t}-1}$ & $0,0008(0,73)$ & & $0,0011(0,88)$ & \\
\hline LIQUIDEZ $_{\mathrm{t}-1}$ & $0,0038(0,23)$ & & $0,0127(0,62)$ & \\
\hline CAPITAL $_{t-1}$ & $0,0262(0,47)$ & & $0,0731(1,20)$ & \\
\hline RIESGO $_{\mathrm{t}-1}$ & $-1,1552(-2,14)$ & $* *$ & $-1,5675(-2,83)$ & $* * *$ \\
\hline$\Delta \mathrm{i}_{\mathrm{t}} *$ TAMAÑO ${ }_{\mathrm{t}-1}$ & $-0,0001(-0,16)$ & & $0,0001(0,13)$ & \\
\hline$\Delta \mathrm{i}_{\mathrm{t}-1} * \mathrm{TAMAÑO}_{\mathrm{t}-1}$ & $-0,0001(-0,41)$ & & $0,0000(0,05)$ & \\
\hline$\Delta \mathrm{i}_{\mathrm{t}}^{*}$ LIQUIDEZ $_{\mathrm{t}-1}$ & $-0,0012(-1,66)$ & $*$ & $-0,0162(-2,12)$ & $* *$ \\
\hline$\Delta \mathrm{i}_{\mathrm{t}-1} * \mathrm{LIQUIDEZ}_{\mathrm{t}-1}$ & $-0,0020(-0,37)$ & & $-0,0023(-0,41)$ & \\
\hline$\Delta \mathrm{i}_{\mathrm{t}} *$ CAPITAL $_{\mathrm{t}-1}$ & $-0,0413(-1,46)$ & & $0,0029(0,08)$ & \\
\hline$\Delta \mathrm{i}_{\mathrm{t}-1} *$ CAPITAL $_{\mathrm{t}-1}$ & $0,0189(1,10)$ & & $0,0167(0,86)$ & \\
\hline$\Delta \mathrm{i}_{\mathrm{t}}{ }^{*} \mathrm{RIESGO}_{\mathrm{t}-1}$ & $-0,0194(-0,08)$ & & $-0,2773(-1,13)$ & \\
\hline$\Delta \mathrm{i}_{\mathrm{t}-1} * \mathrm{RIESGO}_{\mathrm{t}-1}$ & $-0,1800(-0,86)$ & & $-0,2220(-0,91)$ & \\
\hline $\mathrm{CONC}_{t}$ & $0,4635(0,90)$ & & $1,0128(2,18)$ & $* *$ \\
\hline$\Delta \mathrm{i}_{\mathrm{t}} * \mathrm{CONC}_{\mathrm{t}}$ & $0,2980(2,53)$ & $* *$ & $0,3885(3,47)$ & $* * *$ \\
\hline$\Delta \mathrm{i}_{\mathrm{t}-1} * \mathrm{CONC}_{\mathrm{t}}$ & $0,0249(0,60)$ & & $0,0369(1,00)$ & \\
\hline $\mathrm{RS}_{\mathrm{t}}$ & $-0.0206(-1,78)$ & $*$ & $-0,0151(-2,19)$ & $* *$ \\
\hline $\mathrm{RS}_{\mathrm{t}} * \mathrm{PC}_{\mathrm{t}}$ & & & $-0,0353(-1,38)$ & \\
\hline$\Delta \mathrm{i}_{\mathrm{t}} * \mathrm{RS}_{\mathrm{t}}$ & $-0,0131(-1,12)$ & & $-0,0192(-4,61)$ & $* * *$ \\
\hline$\Delta \mathrm{i}_{\mathrm{t}-1} * \mathrm{RS}_{\mathrm{t}}$ & $0,0034(0,49)$ & & $-0,0037(-1,45)$ & \\
\hline$\left(\Delta \mathrm{i}_{\mathrm{t}} * \mathrm{RS}_{\mathrm{t}}\right)^{2}$ & $-0,0060(-1,70)$ & $*$ & $-0,0031(-2,58)$ & $* *$ \\
\hline$\left(\Delta \mathrm{i}_{\mathrm{t}-1} * \mathrm{RS}_{\mathrm{t}}\right)^{2}$ & $0,0004(0,21)$ & & $-0,0008(-3,20)$ & $* * *$ \\
\hline CONS & $-0,1952(-4,74)$ & $* * *$ & $-0,1234(-7,79)$ & $* * *$ \\
\hline Dummies País & Sí & & Sí & \\
\hline Dummies Temporales & Sí & & Sí & \\
\hline Test lineal & & & $-0,0504(-1,95)$ & $*$ \\
\hline $\mathrm{m}_{2}$ & 0,347 & & 0,597 & \\
\hline Hansen & 0,101 & & 0,113 & \\
\hline
\end{tabular}

Para cada variable se muestra su coeficiente y entre paréntesis la T-student; $* * *$ indica un nivel de significatividad del 99\%, ** indica un nivel de significatividad del $95 \%$, $*$ indica un nivel de significatividad del $90 \% ; \mathrm{m}_{2}$ es el estadístico de correlación serial de segundo orden distribuido como una $\mathrm{N}(0,1)$ bajo la hipótesis nula de no correlación serial. Hansen es el test de sobre-identificación, distribuido como una chi-cuadrado bajo la hipótesis nula de no relación entre los instrumentos y el término de error. Test lineal es el test de significatividad conjunta de los coeficientes asociados con $R S_{t}$ y $R S_{t} * P C_{t}$, bajo la hipótesis nula de no relación.

La Figura 2.7 refleja el efecto marginal de la política monetaria sobre la variación del logaritmo de préstamos cuando el tipo de interés aumenta en un 0,75\% para nuestra 
muestra sin países intervenidos ${ }^{52}$. Dicho efecto marginal se ha calculado a partir de la ecuación (1.5) de la página 104.

Figura 2.7: Efecto marginal de la política monetaria ( $\Delta$ tipo de interés $0,75 \%$ ) sobre la variación del logaritmo de los préstamos bancarios

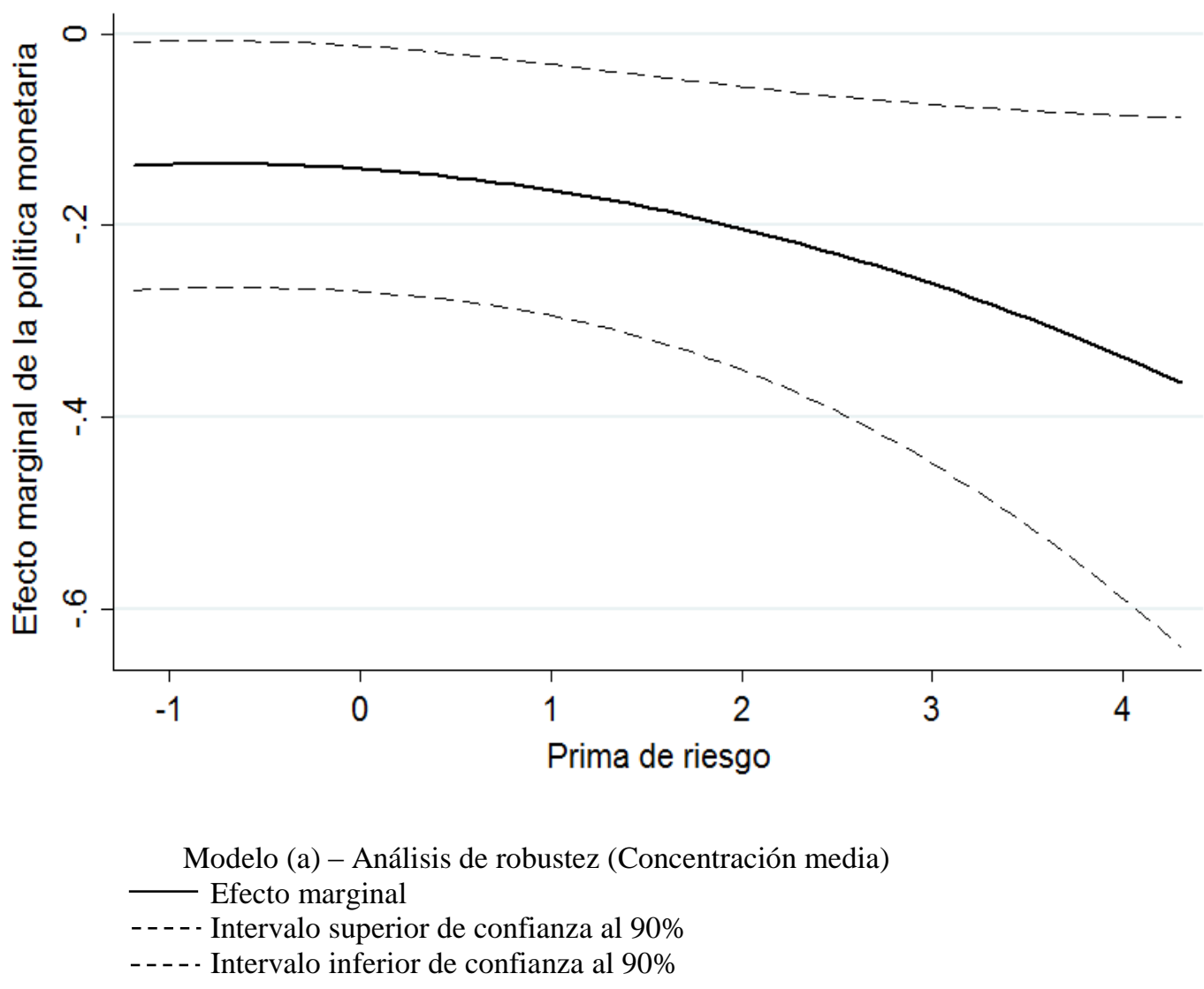

La reducción en la oferta de préstamos que provoca una contracción monetaria, aumenta a medida que lo hace la prima de riesgo. La menor reducción de préstamos se produce en países con una prima de riesgo de $-1,19 \%$, donde el efecto marginal es de un $-0,14$. Sin embargo, a medida que aumenta la prima de riesgo el efecto marginal es cada vez más negativo. Estos resultados soportarían de nuevo la hipótesis 1, al mostrar que las restricciones monetarias dan lugar a descensos más pronunciados de la oferta de préstamos en países con mayor riesgo soberano, si bien es cierto que el efecto es más reducido que en los análisis previos.

\footnotetext{
${ }^{52}$ Para el cálculo del efecto marginal se ha reemplazado la concentración del mercado por la media de la muestra utilizada en este análisis.
} 
La Figura 2.8 muestra el efecto marginal de la política monetaria sobre la variación del logaritmo de préstamos ante una reducción de tipos de interés del 0,75\%.

Figura 2.8: Efecto marginal de la política monetaria ( $\nabla$ tipo de interés $0,75 \%$ ) sobre la variación del logaritmo de los préstamos bancarios

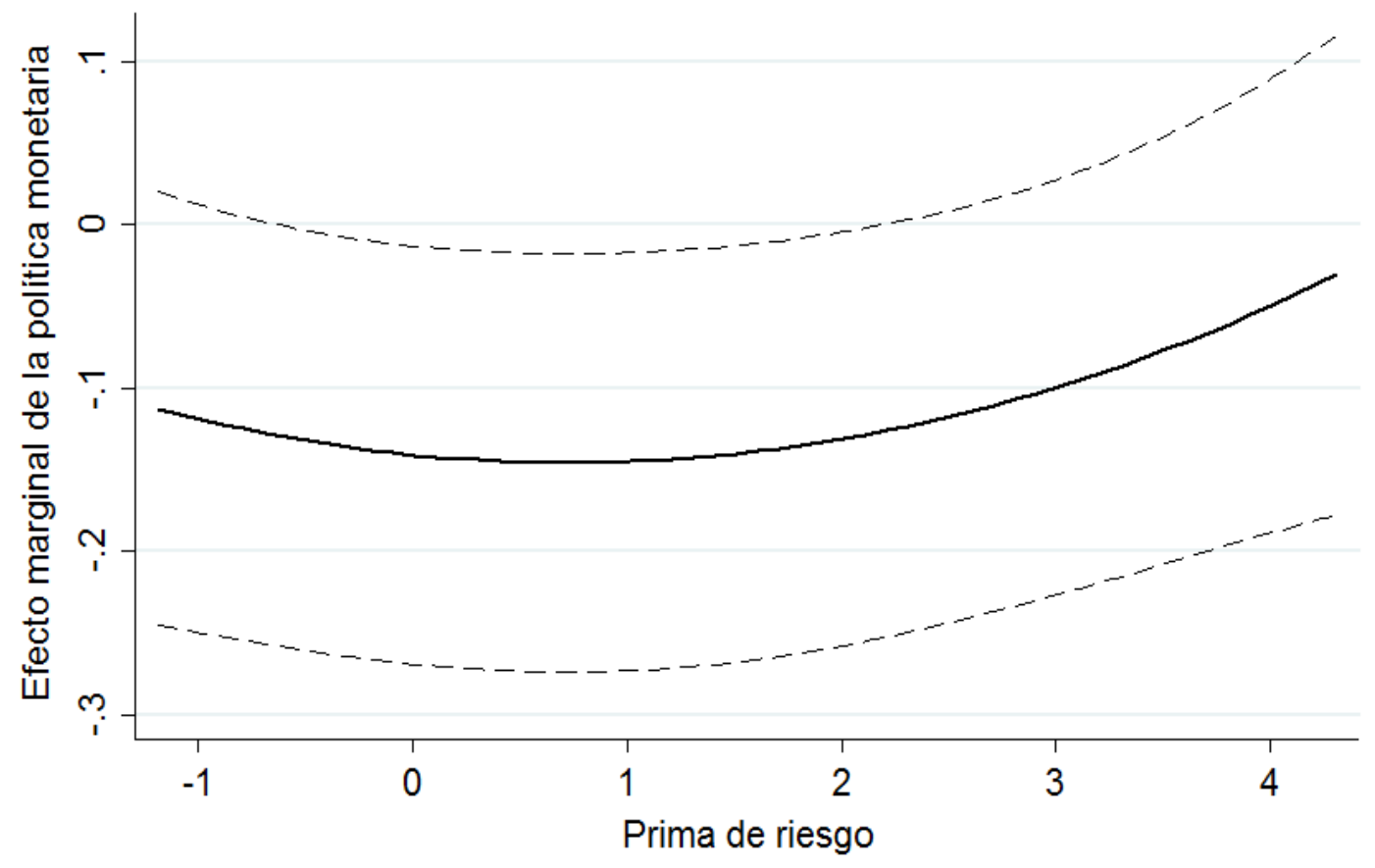

Modelo (a) - Análisis de robustez (Concentración media)

Efecto marginal

- - - - Intervalo superior de confianza al $90 \%$

- - - - Intervalo inferior de confianza al $90 \%$

En este caso, nuevamente, la prima de riesgo no da lugar a diferencias pronunciadas en el crecimiento de préstamos durante expansiones monetarias. Particularmente, la relajación de las condiciones monetarias sólo produce un aumento de la oferta de préstamos cuando la prima de riesgo se sitúa entre $-0,59 \%$ y $2,11 \%$. Si bien es cierto, el efecto marginal no varía mucho entre países (entre 0,129 y 0,13). Por otro lado, en este modelo (a) no existe un nivel de prima de riesgo a partir del cual se produzca una restricción del crédito bancario. Esto se debe a la ausencia de los países intervenidos en esta nueva muestra, que son los que poseen un riesgo soberano muy alto. Nuevamente estos resultados no aportan evidencias suficientes para sustentar la 
hipótesis 2, ya que no existen indicios de que los bancos en países con mayor riesgo soberano expandan su oferta crediticia en menor medida cuando se reducen los tipos de interés del mercado monetario.

En la Tabla 2.10 modelo (b), se controla la existencia de cambios estructurales ocasionados por la crisis, mediante la inclusión de una variable de interacción entre el riesgo soberano $(R S)$ y una dummy de crisis $P C_{t}$. Dicha variable dummy toma el valor 1 durante los años previos a la crisis financiera, es decir entre 1999 y 2007, y el valor 0 en caso contrario ${ }^{53}$.

En este modelo (b), la política monetaria actual es nuevamente negativa y significativa. También lo es la interacción entre LIQUIDEZ y la política monetaria con un coeficiente negativo. Las entidades con mayor riesgo de crédito obtienen menores tasas de crecimiento de préstamos al ser la variable RIESGO significativa y negativa. La concentración bancaria, así como la interacción entre ésta y la política monetaria, poseen un signo positivo y significativo.

Por lo que respecta a la prima de riesgo, ésta continúa siendo significativa y negativa. De la misma manera, las interacciones lineal y cuadrática entre la prima de riesgo y la política monetaria son significativas y con coeficientes negativos. Asimismo, el test lineal de significación conjunta entre las variables de riesgo soberano $(R S)$ y la interacción entre el riesgo soberano y la dummy de crisis $\left(R S^{*} P C_{t}\right)$, también posee un coeficiente negativo y significativo.

La Figura 2.9 muestra el efecto marginal de la política monetaria sobre la variación del logaritmo de préstamos para el modelo (e) cuando el tipo de interés se

\footnotetext{
${ }^{53} \mathrm{El}$ análisis se realiza para todos los países de la muestra.
} 
incrementa en un $0,75 \%{ }^{54}$. Para el cálculo de dicho efecto marginal se ha utilizado la ecuación (1.5) de la página 104.

Figura 2.9: Efecto marginal de la política monetaria ( $\Delta$ tipo de interés $0,75 \%$ ) sobre la variación del logaritmo de los préstamos bancarios

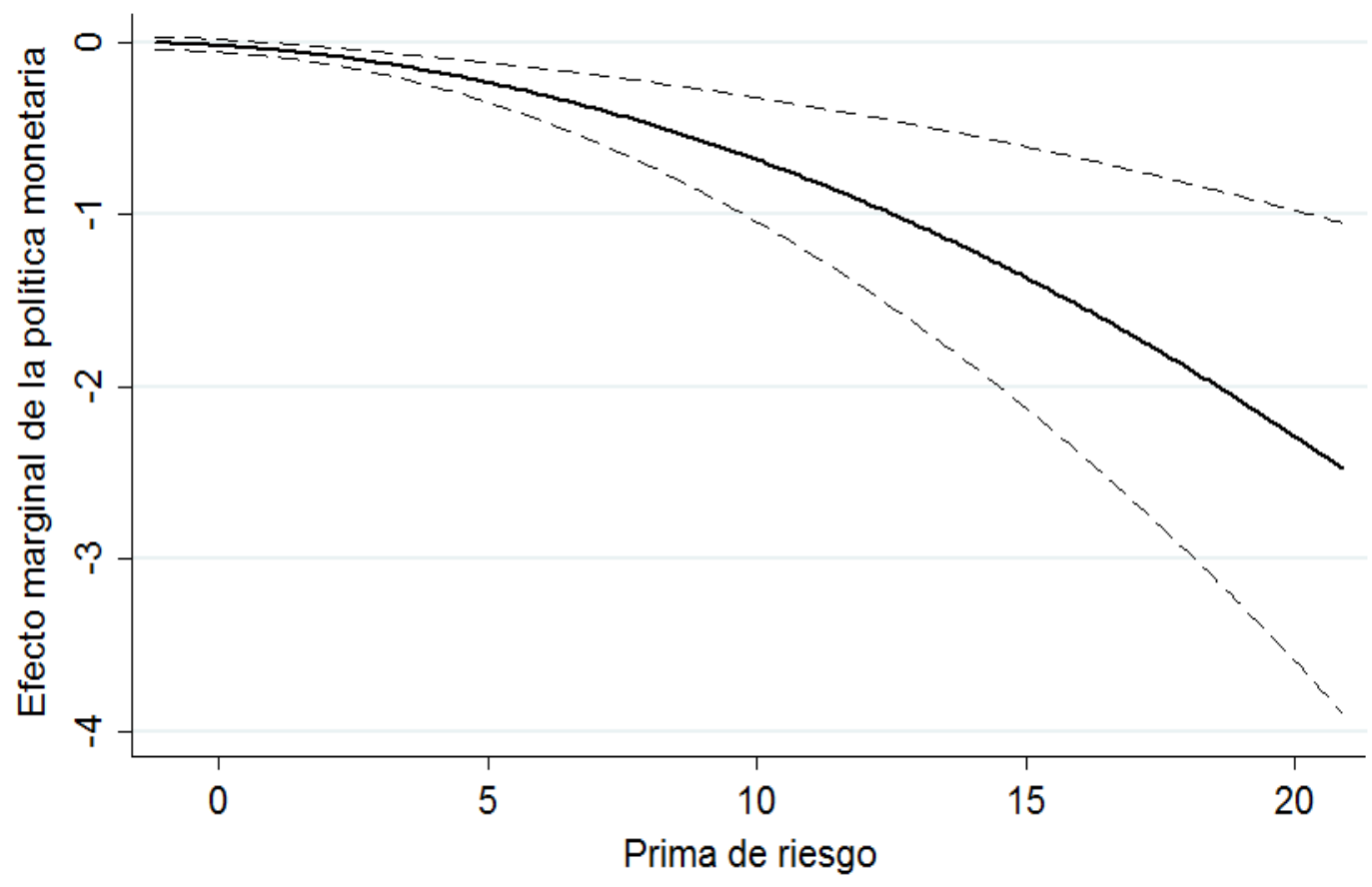

Modelo (b) - Análisis de robustez (Concentración media)

- Efecto marginal

- - - - Intervalo superior de confianza al 90\%

- - - - Intervalo inferior de confianza al $90 \%$

Nuestros resultados muestran nuevamente que las entidades que operan en países con mayor riesgo soberano contraen más su oferta de préstamos. En este modelo (b), un aumento de los tipos de interés en un $0,75 \%$ no afecta a la oferta de crédito bancario en países con una prima de riesgo inferior al $1,01 \%$, ya que el efecto marginal no es significativo. No obstante, a partir de este nivel, aumentos de la prima de riesgo causan descensos más pronunciados de la oferta crediticia. Por tanto, estos resultados vuelven a soportar la hipótesis 1, ya que muestran que las entidades localizadas en países con

\footnotetext{
${ }^{54}$ Para el cálculo del efecto marginal se ha sustituido la concentración bancaria por el valor medio de la muestra.
} 
mayor riesgo soberano reducen su oferta crediticia en mayor medida cuando se contrae la política monetaria.

La Figura 2.10 representa el efecto marginal de la política monetaria sobre la variación del logaritmo de los préstamos ante una bajada de tipos de interés del 0,75\%.

Figura 2.10: Efecto marginal de la política monetaria ( $\nabla$ tipo de interés $0,75 \%$ ) sobre la variación del logaritmo de los préstamos bancarios

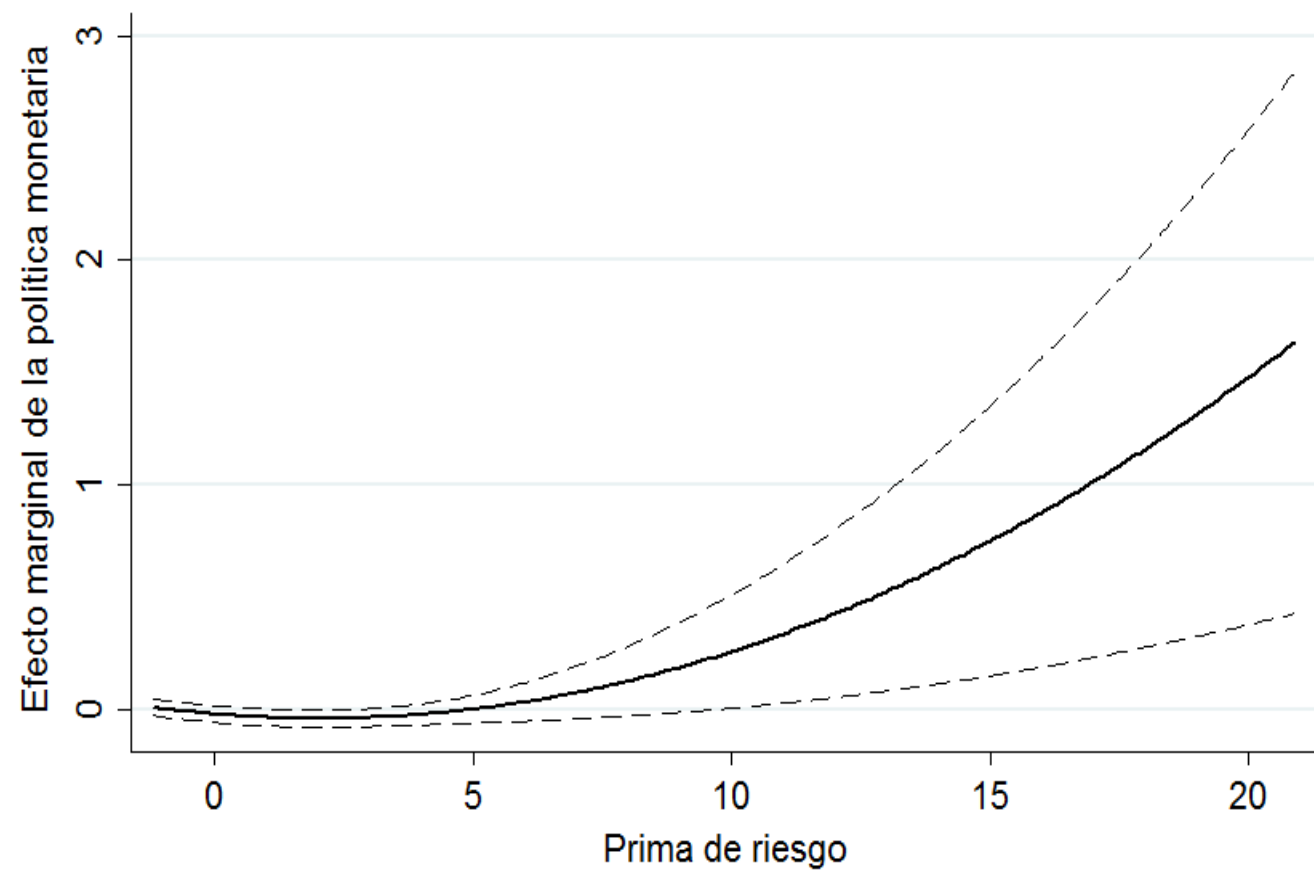

Modelo (b) - Análisis de robustez (Concentración media)

Efecto marginal

- - - Intervalo superior de confianza al $90 \%$

- - - - Intervalo inferior de confianza al $90 \%$

De nuevo, los resultados no muestran evidencias a favor de una relación entre el riesgo soberano y la variación del crédito bancario ante medidas de política monetaria expansiva. En este caso no existe un intervalo de prima de riesgo significativo para el que una disminución de tipos de interés del $0,75 \%$ genere un aumento de la oferta de préstamos. Al igual que en modelos previos, las entidades que operan en países con elevadas primas de riesgo reducen su oferta de préstamos pese a que se relaje la política 
monetaria. En este modelo (b), son los países con una prima de riesgo igual o mayor que $9,61 \%$ donde se produce esta situación. Estos resultados nuevamente no sustentan la hipótesis 2.

En conclusión, del análisis realizado en este capítulo 2 se deriva que cuando se produce una política monetaria restrictiva, los bancos que operan en países con mayores niveles de riesgo soberano contraen su oferta crediticia en mayor medida que los bancos localizados en países con un riesgo soberano más bajo. Este resultado puede deberse, probablemente, a que las entidades situadas en países con un elevado riesgo soberano soportan mayores costes de financiación, a la vez que tienden a acumular niveles más altos de liquidez, por precaución, para protegerse de las restricciones financieras causadas por el riesgo soberano. Sin embargo, nuestros resultados no nos permiten concluir que el riesgo soberano de lugar a diferencias significativas en el incremento de la oferta de préstamos cuando se relajan las condiciones monetarias. Si bien es cierto, que en países donde el riesgo soberano es muy elevado, los bancos nacionales reducen su oferta de préstamos, tanto durante políticas monetarias restrictivas como expansivas. Posiblemente, las grandes dificultades financieras que soportan los bancos de estos países, junto con la intervención que sufrieron, han contrarrestado los efectos positivos que, sobre el crédito, tienen las políticas monetarias expansivas. 
CAPITULO III

RELACIÓN ENTRE EL RIESGO SOBERANO

Y EL CANAL DE CRÉDITO COMERCIAL 



\section{1.- INTRODUCCIÓN}

El objetivo de este tercer capítulo es analizar cómo el riesgo soberano afecta al volumen de crédito comercial entre empresas no financieras, tanto de manera directa como a través de la política monetaria.

Tal y como se ha mostrado en el capítulo anterior, la crisis ha puesto de manifiesto la importancia que tienen las instituciones bancarias en el proceso de transmisión de la política monetaria, lo que ha reavivado el interés por el estudio del canal de préstamos bancarios. No obstante, la efectividad de dicho canal se reduce si existen fuentes de financiación alternativas. Una fuente de financiación a la que las empresas suelen recurrir cuando sufren restricciones de crédito es el crédito comercial. Su importancia ha propiciado la aparición de un nuevo mecanismo de transmisión de la política monetaria: el canal de crédito comercial, trade credit channel, (Meltzer, 1960; Kohler et al., 2000; Mateut et al., 2006). Así, resulta necesario complementar el análisis de los efectos del riesgo soberano sobre el canal de préstamos bancarios con otro que considere los efectos del crédito comercial. 
Con ese objetivo, este capítulo se estructura como sigue. En primer lugar, se desarrolla el marco teórico referente al crédito comercial como fuente alternativa de financiación. En segundo lugar, se explica la influencia que ejerce el riesgo soberano sobre el canal de crédito comercial con el objetivo de proponer las hipótesis a contrastar. En tercer lugar, se procede a realizar el análisis empírico necesario para el contraste de las hipótesis planteadas.

\section{2.- EL CRÉDITO COMERCIAL}

\subsection{1.- Motivos que justifican la existencia del crédito comercial}

El crédito comercial es un préstamo a corto plazo que los proveedores proporcionan a sus clientes a través de aplazamientos en los pagos por una transacción de bienes o prestación de servicios que sean objeto del negocio típico de la empresa. Se caracteriza por ser un instrumento de financiación no negociable, al no existir un mercado organizado para este tipo de deuda (Cuñat-Martínez y García-Appendini, 2012). Representa un importante porcentaje en la financiación externa de las empresas no financieras ${ }^{55} \mathrm{y}$ destaca como aspecto esencial su doble naturaleza, es decir, su implicación en el activo y en el pasivo. En este sentido, la mayoría de las empresas no financieras, especialmente aquellas situadas en puntos intermedios de la cadena de valor, obtienen crédito comercial por parte de sus proveedores a la vez que conceden crédito a su clientela.

Son varios los motivos que tratan de explicar por qué las empresas conceden créditos comerciales a sus clientes, a la vez que obtienen esta financiación por parte de sus proveedores, cuando existen instituciones especializadas en conceder financiación.

\footnotetext{
${ }^{55}$ Rajan y Zingales (1995) afirman que el volumen de crédito comercial representa el 17,8\% del activo total de las empresas americanas a principios de los 90 , mientras que supone más del $25 \%$ del activo total en varios países europeos (Kohler et al., 2000; Guariglia y Mateut, 2006). Asimismo, en países emergentes como China, el crédito comercial representa un 30\% de la deuda de las empresas no estatales debido al limitado apoyo que reciben de las entidades bancarias (Ge y Qiu, 2007).
} 
De acuerdo con la literatura, estos motivos se dividen en dos grupos: los motivos transaccionales y los motivos financieros (Kohler et al. 2000; Nilsen, 2002; Mateut, 2005).

Los motivos transaccionales se centran en justificar la existencia del crédito comercial como parte del ciclo de operación de las empresas y lo argumentan sobre seis razones.

En primer lugar, el crédito comercial permite disminuir los costes de transacción puesto que, al existir unos costes fijos en cada operación de pago, éste puede comportarse como un mecanismo reductor de costes al posibilitar la acumulación de facturas en pagos periódicos (Nadiri, 1969; Ferris, 1981; Emery, 1984).

En segundo lugar, el crédito comercial es una herramienta útil de gestión de tesorería, puesto que, al retrasar el pago de las compras, una empresa puede equilibrar su calendario de cobros y el de pagos (Schwartz, 1974).

En tercer lugar, el crédito comercial también contribuye a facilitar una mejor gestión de existencias, sobre todo en productos con una gran estacionalidad o en mercados con incertidumbre en la demanda. Las empresas que ofertan productos estacionales o que soportan grandes incertidumbres en su demanda tienen que contar con grandes inventarios a fin de mantener sus niveles de producción. Mediante la concesión de crédito comercial, las empresas pueden gestionar mejor sus niveles de inventario y reducir los costes de almacenamiento, especialmente si sus clientes tienen una mayor capacidad para llevar inventarios (Emery, 1984; Long et al., 1993).

En cuarto lugar, el crédito comercial posibilita la venta del mismo producto a precios distintos según se conceda o no aplazamientos en el pago o si se aplican o no 
descuentos por pronto pago, eludiendo las restricciones legales que prohíben la discriminación de precios (Schwartz y Whitcomb, 1979; Brennan et al., 1988; Mian y Smith, 1992; Petersen y Rajan, 1994). Las leyes antimonopolio suelen impedir la discriminación directa de precios, pero el crédito comercial a un alto precio puede ser una barrera contra los clientes con mayor riesgo. En esta situación, los clientes solventes lo considerarán costoso y preferirán pagar inmediatamente, mientras que los clientes con alto riesgo de crédito lo verán como su única fuente de financiación disponible.

En quinto lugar, el crédito comercial contribuye a garantizar la supervivencia y la lealtad a largo plazo de los clientes pues, aunque los proveedores no desean conceder financiación a los clientes con mayor riesgo, suelen valorar los beneficios potenciales de mantener una relación a largo plazo con ellos a la hora de extender créditos comerciales (Smith, 1987; Wilner, 2000).

En sexto lugar, el crédito comercial es una herramienta que permite reducir las asimetrías de información entre el vendedor y el comprador al actuar como una señal de calidad para ambas partes (Deloof y Jegers, 1996; Wilson y Summers, 2002). Por un lado, a través del uso del crédito comercial, la empresa compradora puede verificar la calidad del producto adquirido antes de pagarlo (Long et al., 1993; Lee y Stowe, 1993; Chee et al., 1999). Por otro lado, ciertos términos de crédito comercial, como los descuentos por pronto pago, permiten al vendedor conocer la calidad crediticia de sus clientes a través de sus prácticas de pago (Smith, 1987).

Además de los motivos transaccionales, la literatura señala una serie de motivos financieros para justificar la existencia del crédito comercial. Los proveedores poseen una ventaja comparativa sobre las entidades bancarias a la hora de determinar la valía 
crediticia de sus clientes y, por tanto, pueden concederles crédito cuando tienen dificultades para acceder a otras fuentes de financiación (Schwartz, 1974; Emery, 1984).

En primer lugar, los proveedores poseen ventajas en la obtención de información sobre sus clientes y sus costes de supervisión suelen ser menores. Esto se debe a que pueden conocer mejor la situación del negocio de su cliente a través del volumen y la frecuencia de sus compras, pero además, pueden obtener información más rápidamente que las entidades bancarias durante el transcurso habitual de las relaciones comerciales con el cliente (Freixas, 1993; Petersen y Rajan, 1997; Jain 2001). Esta ventaja es especialmente relevante cuando los clientes son empresas pequeñas, de reciente creación, con más asimetrías informativas y/o que operan en países con instituciones financieras poco desarrolladas (Berger y Udell, 1995; Wilner, 2000; Fishman y Love, 2003).

En segundo lugar, el vendedor posee un mayor control sobre el comprador, ya que puede exigir de forma más efectiva el pago de la deuda con la amenaza de retirar el suministro futuro de materias primas. Esta amenaza resultará especialmente creíble cuando el comprador posea pocas alternativas de suministro de las materias primas que emplea para su negocio (Smith, 1987).

Finalmente, dado que los proveedores tienen mayor experiencia en la venta de bienes que las entidades bancarias, pueden recuperar y revender los productos con más facilidad en caso de impago por parte de los clientes (Frank y Maksimovic, 2005). Asimismo, los proveedores poseen un conocimiento superior del mercado, lo que les permite distinguir mejor entre un comprador con dificultades financieras y un mercado en declive (Ng et al., 1999; Nilsen, 2002; Mateut, 2005). 
La Tabla 3.1 recoge, de forma esquematizada, un resumen de los principales motivos que justifican la existencia del crédito comercial.

Tabla 3.1: Motivos que justifican la existencia del crédito comercial

\begin{tabular}{|c|c|c|}
\hline Motivos & $\begin{array}{c}\text { Justificación de la existencia del } \\
\text { crédito comercial }\end{array}$ & Autores \\
\hline $\begin{array}{c}\text { Motivos } \\
\text { transaccionales }\end{array}$ & $\begin{array}{l}\text { - Reducción de los costes de } \\
\text { transacción. } \\
\text { - Herramienta útil de gestión de } \\
\text { tesorería y de existencias. } \\
\text { - Elusión de las restricciones legales que } \\
\text { prohíben la discriminación de precios. } \\
\text { - Protección de la relación a largo plazo } \\
\text { con los clientes. } \\
\text {-Reducción de las asimetrías } \\
\text { informativas entre el comprador y el } \\
\text { vendedor. }\end{array}$ & $\begin{array}{l}\text { Nadiri (1969), Schwartz } \\
\text { (1974), Schwartz y Whitcomb } \\
\text { (1979), Ferris (1981), Emery } \\
\text { (1984), Smith (1987), Brennan } \\
\text { et al. (1988), Mian y Smith } \\
\text { (1992), Long et al. (1993), Lee } \\
\text { y Stowe (1993), Petersen y } \\
\text { Rajan (1994), Deloof y Jegers } \\
\text { (1996), Chee et al. (1999), } \\
\text { Wilner (2000), Wilson y } \\
\text { Summers (2002). }\end{array}$ \\
\hline $\begin{array}{c}\text { Motivos } \\
\text { financieros }\end{array}$ & $\begin{array}{l}\text { Ventaja comparativa de los proveedores } \\
\text { respecto a las entidades bancarias: } \\
\text { - Mejor conocimiento del cliente. } \\
\text { - Mayor control del comprador. } \\
\text {-Mayor facilidad de recuperación y } \\
\text { reventa de los productos. } \\
\text { - Mayor conocimiento del mercado. }\end{array}$ & $\begin{array}{l}\text { Schwartz (1974), Emery } \\
\text { (1984), Smith (1987), Berger y } \\
\text { Udell (1995), Freixas (1993), } \\
\text { Petersen y Rajan (1997), Ng et } \\
\text { al. (1999), Wilner (2000), Jain } \\
\text { (2001), Nilsen (2002), Fishman } \\
\text { y Love (2003), Mateut (2005), } \\
\text { Frank y Maksimovic (2005). }\end{array}$ \\
\hline
\end{tabular}

Fuente: elaboración propia.

\subsection{2.- El canal de crédito comercial}

El canal de crédito comercial destaca el potencial del mismo como fuente alternativa de financiación ante shocks monetarios. En virtud de este canal, durante una política monetaria restrictiva, las empresas aumentan su uso del crédito comercial como sustituto del crédito bancario para contrarrestar la caída de préstamos (Meltzer, 1960; Kohler et al., 2000; Mateut et al., 2006). En este contexto, las empresas menos vulnerables a los shocks monetarios, en términos de un mejor acceso a fuentes financieras, redistribuyen la financiación mediante la concesión de crédito comercial a las empresas más débiles. 
El crédito comercial es una fuente de financiación más costosa que el crédito bancario, especialmente si los clientes no hacen uso del descuento por pronto pago y se decantan por pagar precios más elevados en pagos aplazados ${ }^{56}$, lo cual hace que sea una fuente de financiación menos deseable para las empresas y se sitúe por detrás del crédito bancario en la teoría del "pecking order" (Myers y Majluf, 1984) ${ }^{57}$. No obstante, el coste es también superior al de los préstamos bancarios aún cuando no existan descuentos por pronto pago, debido a que los proveedores tienden a incluir en el precio de venta un coste adicional derivado de la financiación concedida, el mayor riesgo de cobro y la no existencia de un colateral explícito en el contrato (Cuñat-Martínez, 2007).

A pesar de ello, el canal de crédito comercial de la política monetaria asume que su coste es relativamente más estable a lo largo del tiempo ( $\mathrm{Ng}$ et al., 1999). En consecuencia, cuando las restricciones monetarias contraen los préstamos y el coste efectivo de la financiación bancaria aumenta, el crédito comercial pasa a ser relativamente más barato para algunas empresas o, incluso, la única fuente de financiación disponible. Así, las empresas más afectadas por la disminución de los préstamos bancarios incrementarán el uso del crédito comercial. Por el contrario, durante una política monetaria expansiva, el coste de la financiación bancaria disminuirá en relación al coste del crédito comercial, por lo que las empresas preferirán financiarse con préstamos bancarios. El Gráfico 3.1 muestra el esquema de Atanasova y

\footnotetext{
${ }^{56}$ Danielson y Scott (2000) realizan un estudio donde muestran que las empresas, aunque consideran el crédito comercial como una importante fuente de financiación, son conscientes de su alto coste y, por tanto, tratan de acogerse a los descuentos por pronto pago.

${ }^{57}$ La teoría del "pecking order" sostiene que, en presencia de información asimétrica, las empresas tienen un orden de prioridad en el momento de decidir financiar una inversión, prefiriendo la financiación con menor coste y menor riesgo. En este sentido, Myers y Majluf (1984) establecen el siguiente orden de preferencias: en primer lugar las empresas prefieren las fuentes de financiación interna (beneficios retenidos), ya que están menos expuestas a problemas de información asimétrica y generan menos costes de transacción, en segundo lugar prefieren la emisión de deuda y, por último, prefieren el aumento de capital.
} 
Wilson (2003) para ilustrar el uso que las empresas hacen del crédito comercial en comparación con la financiación bancaria dependiendo del régimen monetario.

\section{Gráfico 3.1: Uso del crédito comercial frente al crédito bancario ante expansiones y} restricciones monetarias.

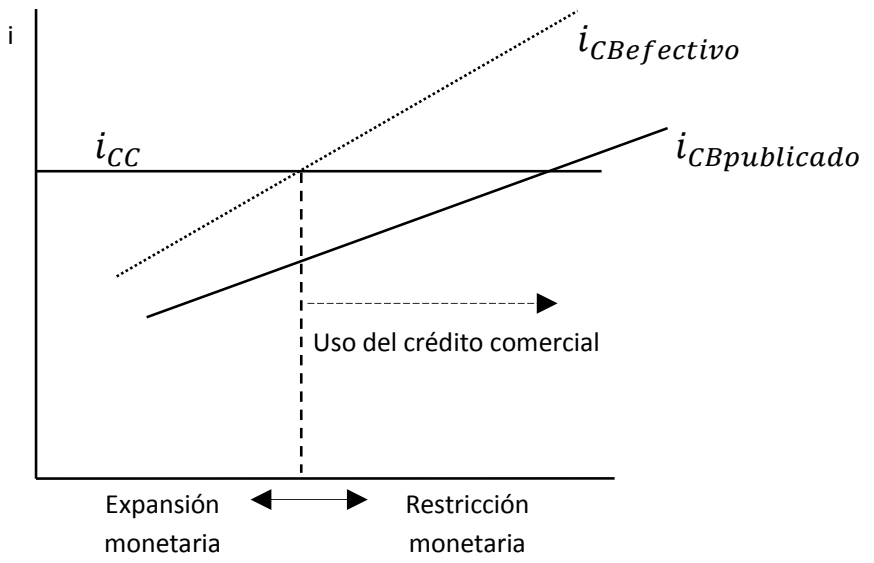

El coste del crédito comercial $\left(i_{C C}\right)$ es más estable que el coste efectivo del crédito bancario $\left(i_{C B e f e c t i v o}\right)$ cuando varían las condiciones monetarias. Las empresas recurrirán al crédito comercial cuando el coste efectivo del crédito bancario $\left(i_{C B e f e c t i v o}\right)$ se incremente hasta situarse por encima del coste del crédito comercial $\left(i_{C C}\right)$, lo cual es más probable que ocurra durante restricciones monetarias.

Fuente: Atanasova y Wilson, 2003.

La literatura previa que analiza la relación existente entre el crédito comercial y el crédito bancario, así como los efectos que la política monetaria ejerce sobre el volumen de crédito comercial, se puede dividir en dos grupos: en primer lugar, existe un conjunto de trabajos que sostienen que el crédito comercial se incrementa cuando desciende el crédito bancario, avalando su importancia como fuente de financiación sustitutiva a los préstamos bancarios, mientras que otra línea de trabajos sugiere que las empresas usan indistintamente crédito bancario y crédito comercial, detacando la importancia del crédito comercial como vía de financiación complementaria a los préstamos. 


\subsubsection{1.- El crédito comercial como fuente de financiación sustitutiva a los préstamos bancarios}

Meltzer (1960) fue el primero en sugerir que el crédito comercial y el crédito bancario se comportan como fuentes de financiación sustitutivas y que el canal de crédito comercial sirve para mitigar los efectos del canal de préstamos bancarios de la política monetaria. Una contracción monetaria empeora las condiciones de financiación bancaria para las empresas. Sin embargo, las empresas con acceso a los mercados de capitales y con menores dificultades para obtener crédito bancario, pueden redistribuir los fondos obtenidos hacia las empresas con restricciones financieras en forma de crédito comercial. De esta manera, se reduciría el impacto ejercido por la política monetaria sobre la economía real.

Los resultados de Meltzer (1960) pronto recibieron apoyo empírico, ya que diversos estudios, encontraron que las empresas confiaban más en el crédito comercial cuando las restricciones monetarias endurecían las condiciones del crédito bancario. Así, Brechling y Lipsey (1963) muestran que durante los períodos de política monetaria contractiva de los años 50 en Reino Unido, las empresas que más habían sufrido los efectos de la restricción monetaria incrementaban sus niveles de crédito comercial recibido. Nadiri (1969), por su parte, considera diversos indicadores de crédito comercial para analizar los efectos de la política monetaria en Estados Unidos. Así, y de acuerdo a sus resultados, ante una política monetaria restrictiva los créditos comerciales extendido y recibido se incrementan, mientras que el crédito comercial neto (la diferencia entre el crédito comercial extendido y recibido) permanece inalterado.

A partir de estas evidencias, varios trabajos han encontrado que el tamaño empresarial influye sobre la capacidad de las empresas para extender y recibir créditos comerciales. Así, Schwartz (1974) revela que, en períodos de restricción monetaria, las 
empresas grandes incrementan sus concesiones de crédito comercial, mientras que las pequeñas aumentan su uso del mismo, lo que eliminaría la eficacia de la política monetaria. Myers (1977) obtiene resultados similares, si bien es cierto no considera que el crédito comercial elimine completamente el impacto de una política monetaria contractiva sobre la economía. Por su parte, Petersen y Rajan (1997) encuentran que las empresas pequeñas en Estados Unidos tienden a recurrir al crédito comercial cuando la financiación bancaria es limitada o inexistente. Mateut y Mizen (2002) muestran que en Reino Unido las restricciones monetarias provocan un descenso del crédito bancario y un aumento del crédito comercial, especialmente para las empresas pequeñas, de reciente creación y con mayor riesgo. Mateut et al. (2006) encuentran un resultado parecido y, además, durante expansiones monetarias se produce el efecto opuesto, al aumentar los préstamos bancarios y reducirse el crédito comercial. A su vez, Özlü y Yalçin (2012) muestran que en Turquía las empresas pequeñas y con poca actividad exportadora utilizan más crédito comercial durante una política monetaria contractiva. Recientemente, Gama et al. (2014) revelan que las pequeñas y medianas empresas portuguesas, cuyos proveedores pueden evaluar su riesgo de crédito, reciben más crédito comercial.

Sin embargo, no todos los trabajos obtienen que el tamaño empresarial sea un determinante importante del crédito comercial que extienden y reciben las empresas. Así, Marotta (1997) y De Blasio (2005) no encuentran que las empresas pequeñas italianas utilicen de manera significativa crédito comercial en sustitución al crédito bancario cuando se produce una contracción monetaria. Harhoff y Korting (1998) revelan que las pequeñas y medianas empresas de Alemania con relaciones duraderas con sus bancos y préstamos concentrados pueden evitar las restricciones de crédito y, por tanto, recurren al crédito comercial en menor medida. Por su parte, Nilsen (2002) 
muestra que en Estados Unidos, las empresas acuden a la financiación vía crédito comercial durante períodos de restricción monetaria, independientemente de su tamaño. Únicamente las empresas con elevada calidad crediticia (bond rating) son capaces de mantener el acceso a la financiación bancaria y a los mercados de capitales, evitando emplear el costoso crédito comercial. Del mismo modo, Choi y Kim (2005) encuentran que las empresas americanas incrementan su crédito comercial extendido y recibido durante una política monetaria restrictiva, si bien es cierto, no existen indicios de que las empresas grandes redistribuyan más financiación vía créditos comerciales que las pequeñas.

Además del tamaño, otra variable fundamental que afecta al crédito comercial son las restricciones financieras. En este sentido, Calomiris et al. (1995) encuentran que las empresas de Estados Unidos que emiten títulos a corto plazo, y por lo tanto tienen mejor acceso a financiación, conceden más crédito comercial. De la misma manera, Preve (2003) muestra que las empresas americanas con dificultades financieras reciben más crédito comercial de sus proveedores, a la vez que extienden menos crédito a sus clientes $^{58}$. Por su parte, Atanasova y Wilson (2003) y Kohler et al. (2000) encuentran que las contracciones monetarias producen un aumento del crédito comercial recibido y neto respectivamente por parte de las empresas inglesas con restricciones financieras. A su vez, Valderrama (2003), a partir de una muestra de empresas de Austria, revela que la utilización del crédito comercial como sustituto al crédito bancario reduce la dependencia de la financiación interna, lo cual mitiga los efectos del canal de préstamos bancarios de la política monetaria. Asimismo, Guariglia y Mateut (2006) muestran que el canal de crédito comercial reduce la influencia del canal de préstamos bancarios en Reino Unido, especialmente para las empresas con dificultades de financiación. En un

\footnotetext{
${ }^{58}$ Molina y Preve (2012) obtienen un resultado similar, especialmente para las empresas pequeñas con restricciones financieras, menor poder de mercado y productos más exclusivos.
} 
trabajo más reciente, Ferrando y Mulier (2013) indican que las empresas europeas con restricciones financieras suelen utilizar el crédito comercial como parte de su estrategia de crecimiento.

Puesto que en épocas de crisis es más frecuente la aparición de restricciones financieras, ciertos estudios han analizado la redistribución de recursos vía crédito comercial desde las empresas menos vulnerables hacia aquellas más débiles en dichos períodos. Así, Martínez-Trigueros (2002) muestra que la oferta de crédito comercial se incrementa durante la crisis de México de 1995, si bien no es suficiente para contrarrestar la reducción de otras fuentes de financiación. Por su parte, Santos et al. (2012) revelan que las empresas pequeñas recurren al crédito comercial como sustituto del crédito bancario durante períodos de crisis en Latinoamérica. Carbó-Valverde et al. (2012) encuentran que la relación de sustitución entre los préstamos bancarios y el crédito comercial es más intensa en épocas de crisis en España ${ }^{59}$. A su vez, GarcíaAppendini y Montoriol-Garriga (2013), a través de una muestra de empresas de Estados Unidos, revelan que las empresas más vulnerables financieramente incrementan el uso del crédito comercial durante la crisis financiera de $2008-2009^{60}$. Por su parte, Ogawa y Tanaka (2013) muestran que durante estos años, las empresas japonesas con relaciones más duraderas con sus proveedores recurren al crédito comercial para hacer frente a la contracción de préstamos. En un trabajo reciente, Casey y O’Toole (2014) indican que las pequeñas y medianas empresas de la zona euro con más restricciones financieras durante la crisis han sido más propensas a utilizar créditos comerciales, sobre todo cuanto mayor es el tamaño y la edad de la empresa.

\footnotetext{
${ }^{59}$ Huang et al. (2011) obtienen un resultado similar para períodos de bajo crecimiento económico en China.

${ }^{60}$ Coulibaly et al. (2013) encuentran la misma evidencia para una muestra de empresas de países emergentes.
} 


\subsubsection{2. - El crédito comercial como fuente de financiación complementaria a los préstamos bancarios}

Los estudios que apoyan la importancia del crédito comercial como fuente de financiación complementaria a los préstamos, sostienen que las empresas utilizan de forma conjunta crédito bancario y crédito comercial. En este sentido, el uso del crédito comercial puede facilitar el acceso a la financiación bancaria, lo que avalaría la existencia de una relación de complementariedad positiva entre ambos tipos de financiación (Duca, 1986; Jaffe y Stiglitz, 1990). Este hecho se debe a que el crédito comercial proporciona una señal a los bancos sobre la calidad crediticia de sus clientes, lo que hará que estén más dispuestos a prestar cuando los proveedores también concedan fondos (Biais y Gollier, 1997). Así, mediante el uso del crédito comercial, las empresas que inicialmente no podían acceder a préstamos bancarios, pueden hacerlo posteriormente.

Burkart y Ellingsen (2004) desarrollan un modelo teórico que muestra la existencia de una correlación positiva entre la disponibilidad de crédito comercial y el importe de los préstamos bancarios extendidos. Esto se debe a que las instituciones financieras reconocen la ventaja informativa de los proveedores y tienen en cuenta esa información a la hora de evaluar la calidad crediticia de sus potenciales clientes. Asimismo, Ono (2001) encuentra que durante una restricción monetaria en Japón los créditos comercial y bancario se comportan como medios de financiación complementarios. En cambio, Yang (2011b) obtiene el mismo resultado, pero para períodos de política monetaria expansiva. Por su parte, Alphonse et al. (2006) muestran que, a medida que aumenta el crédito comercial que reciben las empresas estadounidenses con restricciones financieras, mayor es la deuda que contraen con los bancos, igual que Gama y Mateus (2010) para las empresas de España y Portugal. 
Atendiendo a trabajos más recientes, Cai et al. (2014) indican que la importancia del crédito comercial como fuente de financiación complementaria a los préstamos es más notoria cuando los fondos internos que poseen las empresas son bajos. A su vez, Agostino y Trivieri (2014) encuentran que esta relación de complementariedad es más relevante al comienzo de las relaciones entre la empresa y el banco, cuando éste apenas tiene información sobre aquella.

Por otro lado, también cabe la posibilidad de una reducción del crédito comercial a medida que la oferta crediticia de las instituciones bancarias disminuye, lo que supondría la existencia de una relación de complementariedad negativa entre estas dos fuentes de financiación (Uesugi y Yamashiro, 2008). Esta relación es especialmente relevante en períodos de fuerte crisis y racionamiento de crédito (credit crunch), cuando todas las empresas sufren graves restricciones de financiación, lo que restringe la canalización de recursos entre empresas vía crédito comercial para compensar la bajada de préstamos. Así, Love et al. (2007), a partir de una muestra de grandes empresas públicas durante la crisis asiática de los 90 , encuentran que a medida que se agrava la crisis, la oferta de crédito comercial cae drásticamente ${ }^{61}$. Por su parte, Lemmon y Roberts (2010) muestran que las empresas con una calificación crediticia por debajo del grado de inversión, no incrementan su uso del crédito comercial tras la fuerte contracción del crédito bancario que se produjo en Estados Unidos, a raíz de la caída del banco de inversión Drexel a finales de los 80 .

La relación de complementariedad negativa entre los préstamos bancarios y el crédito comercial parece haber sido muy intensa en la crisis actual. Así, Yang (2011a) refleja que existe una relación de complementariedad negativa entre los préstamos

\footnotetext{
${ }^{61}$ Otros estudios obtienen resultados parecidos para los años de crisis en Japón (Fukuda et al., 2006; Taketa y Udell, 2007).
} 
bancarios y el crédito comercial extendido durante la crisis subprime de Estados Unidos. Por su parte, Akbar et al. (2013) indican que en Reino Unido el suministro de crédito comercial se contrae cuando se reduce la disponibilidad de préstamos. Kestens et al. (2012), encuentran un resultado similar en Bélgica, especialmente para las empresas con mayor dependencia de la financiación a corto plazo durante los años previos a la crisis.

Un factor muy relevante que contribuye a la reducción del crédito comercial en épocas de crisis es el contagio de riesgo de crédito de unas empresas a otras. Así, Love y Zaidi (2010) revelan que los shocks de liquidez causados por la crisis asiática de 1998 se propagan a través del crédito comercial, produciéndose un contagio de riesgo de crédito y reduciendo la concesión de esta fuente de financiación. Por su parte, Bastos y Pindado (2013) también encuentra que el contagio de riesgo de crédito durante las crisis financieras de Brasil, Argentina y Turquía disminuyó la disponibilidad de crédito comercial, mientras que Tsuruta (2013) obtiene el mismo resultado durante la crisis de Japón, especialmente para las empresas con mayor volumen de cuentas a cobrar y menores tenencias de efectivo.

La Tabla 3.2 refleja, a modo de resumen, las principales evidencias empíricas relacionadas con el crédito comercial y su relación con los préstamos bancarios. 
Tabla 3.2: Principales evidencias del crédito comercial y su relación con los préstamos.

\begin{tabular}{|c|c|c|}
\hline Evidencias & Resultados & Autores \\
\hline \multirow{4}{*}{$\begin{array}{l}\text { El crédito comercial } \\
\text { como fuente de } \\
\text { financiación sustitutiva } \\
\text { al crédito bancario }\end{array}$} & $\begin{array}{l}\text { Política monetaria: } \\
\text {-Durante una restricción monetaria el crédito comercial } \\
\text { aumenta para compensar la contracción de los préstamos } \\
\text { bancarios. }\end{array}$ & $\begin{array}{l}\text { Meltzer (1960), Brechling y Lipsey (1963), Nadiri (1969), Schwartz } \\
\text { (1974), Myers (1977), Kohler et al. (2000), Nilsen (2002), Mateut y Mizen } \\
\text { (2002), Valderrama (2003), Atanasova y Wilson (2003), Guariglia y } \\
\text { Mateut (2004), Choi y Kim (2005), Mateut et al. (2006), Özlü y Yalçin } \\
\text { (2012). }\end{array}$ \\
\hline & $\begin{array}{l}\text { Tamaño: } \\
\text {-Las empresas pequeñas utilizan más volumen de crédito } \\
\text { comercial, mientras que las grandes conceden más cantidad } \\
\text { del mismo. } \\
\text {-El tamaño no ejerce una influencia relevante sobre el } \\
\text { crédito comercial. }\end{array}$ & $\begin{array}{l}\text { Schwartz (1974), Myers (1977), Petersen y Rajan (1997), Mateut y Mizen } \\
\text { (2002), Mateut et al. (2006), Özlü y Yalçin (2012), Gama et al. (2014). } \\
\text { Marotta (1997), Harhoff y Korting (1998), Nilsen (2002), De Blasio } \\
\text { (2005), Choi y Kim (2005). }\end{array}$ \\
\hline & $\begin{array}{l}\text { Restricciones financieras: } \\
\text {-Las empresas con restricciones financieras emplean más } \\
\text { crédito comercial como sustituto al crédito bancario. }\end{array}$ & $\begin{array}{l}\text { Calomiris et al. (1995), Kohler et al. (2000), Preve (2003), Valderrama } \\
\text { (2003), Atanasova y Wilson (2003), Guariglia y Mateut (2004), Molina y } \\
\text { Preve (2012), Ferrando y Mulier (2013). }\end{array}$ \\
\hline & $\begin{array}{l}\text { Crisis: } \\
\text {-Las restricciones financieras en crisis resaltan la } \\
\text { importancia del crédito comercial como sustituto a los } \\
\text { préstamos. }\end{array}$ & $\begin{array}{l}\text { Martínez-Trigueros (2002), Huang et al. (2011), Santos et al. (2012), } \\
\text { Carbó-Valverde et al. (2012), Coulibaly et al. (2013), García-Appendini y } \\
\text { Montoriol-Garriga (2013), Ogawa y Tanaka (2013), Casey y O`Toole } \\
\text { (2014). }\end{array}$ \\
\hline \multirow{2}{*}{$\begin{array}{l}\text { El crédito comercial } \\
\text { como fuente de } \\
\text { financiación } \\
\text { complementaria al } \\
\text { crédito bancario }\end{array}$} & $\begin{array}{l}\text { Complementariedad positiva: } \\
\text {-El crédito bancario aumenta cuando se incrementa el } \\
\text { crédito comercial, ya que éste proporciona una señal a los } \\
\text { bancos de la calidad crediticia de los prestatarios. }\end{array}$ & $\begin{array}{l}\text { Duca (1986), Jaffe y Stiglitz (1990), Biais y Gollier (1997), Ono (2001), } \\
\text { Burkart y Ellingsen (2004), Alphonse et al. (2006), Gama y Mateus (2010), } \\
\text { Yang (2011b), Cai et al. (2014), Agostino y Trivieri (2014). }\end{array}$ \\
\hline & $\begin{array}{l}\text { Complementariedad negativa: } \\
\text {-El crédito comercial disminuye cuando se reduce el } \\
\text { crédito bancario, principalmente en épocas de fuerte crisis } \\
\text { y racionamiento de crédito (credit crunch), ya que las } \\
\text { graves restricciones de financiación impiden a las empresas } \\
\text { canalizar recursos vía crédito comercial. }\end{array}$ & $\begin{array}{l}\text { Fukuda } \text { et al. (2006), Love } \text { et al. (2007), Taketa y Udell (2007), Uesugi y } \\
\text { Yamashiro (2008), Lemmon y Roberts (2010), Love y Zaidi (2010), Yang } \\
\text { (2011a), Kestens et al. (2012), Akbar } \text { et al. (2013), Tsuruta (2013), Bastos } \\
\text { y Pindado (2013). }\end{array}$ \\
\hline
\end{tabular}

Fuente: elaboración propia. 


\section{3.- INFLUENCIA DEL RIESGO SOBERANO SOBRE EL CANAL DE CRÉDITO COMERCIAL}

La crisis financiera mundial tuvo un serio impacto sobre las condiciones de financiación de la banca. Tal y como se ha estudiado en el capítulo anterior, la apreciación de un mayor riesgo soberano supone un encarecimiento de los costes y una menor disponibilidad de financiación para los bancos a través de diversos canales (Committee on the Global Financial System, 2011). Así, un incremento del riesgo soberano reduce el valor de los títulos de deuda pública que mantienen las entidades en su balance (canal de tenencias de activos), disminuye los colaterales que las entidades de crédito pueden utilizar para obtener financiación mayorista y liquidez del Banco Central (canal de liquidez/colateral), conduce a bajadas en el rating de las entidades nacionales (canal de rating soberano) y merma las garantías que las entidades bancarias obtienen de sus respectivos gobiernos (canal de garantías del gobierno). Todos estos factores, unidos a la mayor aversión al riesgo, incrementan el coste y reducen la disponibilidad de financiación para los bancos, lo cual supone una fuerte restricción de la oferta crediticia ${ }^{62}$.

Esta reducción tiene importantes implicaciones, ya que el crédito bancario juega un papel crucial en la financiación de las empresas de la zona euro (Banco Central Europeo, 2012b). Por lo tanto, el impacto que el riesgo soberano tiene sobre la banca, también afectará significativamente a las condiciones de financiación de las empresas no financieras. En este contexto, la reducción de la oferta de préstamos y su mayor coste ha puesto de manifiesto la importancia del crédito comercial como fuente de

\footnotetext{
${ }^{62}$ Tal y como se mostró en el capítulo anterior, varios estudios empíricos muestran que el riesgo soberano, a través de su impacto sobre los costes de financiación de las entidades bancarias, provoca una disminución de la oferta de préstamos (véase, entre otros, Bofondi et al., 2013; Zoli, 2013; Popov y van Horen, 2013; Albertazzi et al., 2014).
} 
financiación alternativa. Sin embargo, cuanto mayor sea el riesgo soberano, la efectividad del crédito comercial como sustituto del crédito bancario se verá reducida por varios motivos.

En primer lugar, el riesgo soberano ha introducido importantes perturbaciones en otros segmentos de financiación, tales como los mercados de capitales. Los rendimientos de los bonos de deuda pública se utilizan frecuentemente como referencia de los rendimientos de los bonos emitidos por las empresas. Por lo tanto, un incremento de los rendimientos de los bonos de deuda pública, fruto de un elevado riesgo soberano, conducirá a un aumento de los rendimientos de los bonos corporativos. En este sentido, en un estudio realizado por Cavallo y Valenzuela (2010) se refleja que el riesgo soberano afecta significativamente a los diferenciales de los bonos corporativos y, además, éstos responden con más intensidad a los aumentos de riesgo soberano que a los descensos. Díaz et al. (2013) obtienen resultados similares, especialmente durante períodos de restricciones financieras. Eichengreen y Moody (2000) afirman que una mejor calificación de rating soberano reduce el coste e incrementa la probabilidad de emisión de bonos corporativos. A su vez, Fostel y Kaminsky (2007) indican que el riesgo soberano inhibe el acceso de las empresas a los mercados de capitales internacionales. En un trabajo reciente, Pianeselli y Zaghini (2014) muestran que las empresas europeas que operan en países con mayor riesgo soberano pagan una prima adicional en la emisión de bonos a largo plazo. Por lo tanto, como consecuencia del incremento de los costes de financiación empresarial en los mercados de capitales, a raíz de un empeoramiento del riesgo soberano, las empresas tradicionalmente proveedoras de crédito comercial tendrán más dificultades para canalizar recursos financieros hacia sus clientes. 
En segundo lugar, un mayor riesgo soberano acompañado de un elevado nivel de deuda pública, conlleva también mayores necesidades de financiación para el sector público, lo cual incrementa la posibilidad de que se produzca el denominado efecto expulsión de la inversión privada (Banco Central Europeo, 2010a). El efecto expulsión implica que, cuando el déficit fiscal es alto, el sector público tiene que competir en tipos de interés con el sector privado para obtener financiación ${ }^{63}$. A este respecto, Agca y Celasun (2012) indican que los costes de financiación del sector empresarial son más elevados cuando el nivel de deuda del sector público es alto. A su vez, Broner et al. (2014) desarrollan un modelo donde muestran que el efecto expulsión está jugando un papel relevante durante la crisis de deuda soberana europea, desembocando en un fuerte incremento de los costes de financiación del sector privado doméstico. A partir de estos planteamientos, el efecto expulsión ocasionado por una elevada deuda pública y un mayor riesgo soberano, conllevará unas condiciones de financiación más desfavorables para las empresas nacionales, lo cual limitará su capacidad para extender créditos comerciales.

En tercer lugar, un incremento del riesgo soberano va acompañado de un considerable aumento del riesgo de crédito de las empresas nacionales (Durbin y $\mathrm{Ng}$, 2005; Peter y Grandes, 2005; Borenzstein et al., 2013). La relación existente entre el riesgo soberano y el riesgo de crédito individual de las empresas nacionales se explica por dos razones. En primer lugar, los rating soberanos generalmente suponen un límite máximo al rating que pueden obtener las empresas del país (Ferri et al., 2001; Cavallo y Valenzuela, 2010). De esta manera, descensos del rating soberano suponen bajadas en el de las empresas nacionales. En segundo lugar, las dificultades financieras de un

\footnotetext{
${ }^{63}$ El efecto expulsión de la inversión privada por parte de la inversión pública es un fenómeno que ha sido ampliamente estudiado (véase, entre otros, Buiter, 1977; Frankel, 1986; Arnott y Stiglitz, 1991; Frey y Oberholzer-Gee, 1997).
} 
gobierno normalmente suponen importantes cambios en la situación económica del país, lo cual puede afectar negativamente a la solvencia empresarial (Peter y Grandes, 2005; Arteta y Hale, 2008). En relación con estos aspectos, Borenzstein et al. (2013) muestran que el límite que supone el rating soberano para el de las empresas nacionales incrementa su riesgo de crédito, principalmente cuando áquel es relativamente bajo. Por su parte, Bedendo y Colla (2013) obtienen que un incremento del riesgo soberano produce un aumento del riesgo de crédito y, por tanto, de los costes de financiación del sector empresarial. Corsetti et al. (2013) revelan también que el riesgo soberano incrementa el riesgo de crédito y los costes de financiación del sector privado, especialmente si la política monetaria no puede contrarrestar el aumento de los costes de financiación al estar los tipos de interés próximos a cero. De forma análoga, Klein y Stellner (2014), utilizando una muestra de bonos corporativos de varios países de Europa, encuentran que el riesgo soberano ha sido un determinante importante del riesgo de crédito de las empresas durante la reciente crisis de deuda.

A partir de estos argumentos, el incremento del riesgo de crédito, ocasionado por un mayor riesgo soberano, conllevará un aumento de la probabilidad de impago de las empresas nacionales, que se contagiará hacia aquellas empresas que tengan cuentas a cobrar en las empresas incumplidoras, causando un efecto dominó (Boissay, 2006). En este escenario de deterioro de la solvencia empresarial y contagio de riesgo de crédito, las empresas serán más prudentes a la hora de conceder créditos comerciales y, a la vez, tendrán más dificultades para acceder a este medio de financiación (Love y Zaidi, 2010; Bastos y Pindado, 2013; Tsuruta, 2013).

Finalmente, las empresas tienden a incrementar sus niveles de liquidez para hacer frente a la fuerte escasez de crédito y a las incertidumbres financieras causadas por un elevado riesgo soberano, lo que reducirá su propensión a extender crédito comercial. En 
este sentido, varios estudios muestran que las empresas con restricciones financieras tienden a acumular más efectivo. Así, Opler et al. (1999) encuentran que las empresas con mejor acceso a los mercados de capitales mantienen menores niveles de activos líquidos. Almeida et al. (2004), a partir de una muestra de compañías manufactureras entre 1971 y 2000, revelan que las empresas con restricciones financieras son más propensas a acumular liquidez en períodos de shocks macroeconómicos. Asimismo, Faulkender y Wang (2006) indican que una disposición adicional de efectivo es más valorada por parte de las empresas con restricciones de acceso a los mercados financieros. Campello et al. (2010) afirman que durante la crisis actual, las empresas con más problemas para obtener líneas de crédito incrementan sus reservas de liquidez. A su vez, Acharya et al. (2013) muestran que las empresas con mayor exposición al riesgo sistémico tienen un acceso más restringido a las líneas de crédito y, por lo tanto, optan por mantener más recursos líquidos.

La Tabla 3.3 resume los motivos que explican por qué cuando el riesgo soberano es mayor, la efectividad del crédito comercial como sustituto a los préstamos se reduce.

A partir de los argumentos anteriores, planteamos nuestra tesis:

Un aumento del riesgo soberano afecta negativamente al crédito comercial, debido a que áquel acentúa las restricciones de financiación de todas las empresas, incrementa su riesgo de crédito y las induce a aumentar su liquidez, lo cual limita su capacidad para extender y recibir créditos comerciales.

Por lo tanto, proponemos la siguiente hipótesis:

Hipótesis 3: un aumento del riesgo soberano provoca una disminución del volumen de crédito comercial. 
Tabla 3.3: Resumen de motivos por los que la efectividad del crédito comercial como sustituto a los préstamos se reduce cuando aumenta el riesgo soberano

\begin{tabular}{|c|c|c|}
\hline Motivo & Explicación & Evidencias \\
\hline $\begin{array}{c}\text { Graves restricciones } \\
\text { financieras para todas } \\
\text { las empresas que } \\
\text { impiden canalizar } \\
\text { recursos vía crédito } \\
\text { comercial }\end{array}$ & $\begin{array}{l}\text {-Un mayor riesgo soberano incrementa } \\
\text { el rendimiento exigido a los bonos de } \\
\text { deuda pública y, por tanto, el coste de } \\
\text { los bonos corporativos. } \\
\text {-Una excesiva deuda pública produce } \\
\text { el llamado efecto expulsión de la } \\
\text { inversión privada. }\end{array}$ & $\begin{array}{l}\text { Eichengreen y Moody } \\
\text { (2000), Fostel y } \\
\text { Kaminsky (2007), Banco } \\
\text { Central Europeo (2010a), } \\
\text { Cavallo y Valenzuela } \\
\text { (2010), Agca y Celasun } \\
\text { (2012), Díaz et al. (2013), } \\
\text { Pianeselli y Zaghini } \\
\text { (2014), Broner et al. } \\
\text { (2014). }\end{array}$ \\
\hline $\begin{array}{l}\text { Mayor probabilidad de } \\
\text { impago de las empresas } \\
\text { y riesgo de contagio de } \\
\text { crédito a través de los } \\
\text { créditos comerciales que } \\
\text { se concedan }\end{array}$ & $\begin{array}{l}\text {-El rating soberano supone un límite } \\
\text { máximo para el rating de las empresas } \\
\text { nacionales. } \\
\text {-Deterioro de la situación económica } \\
\text { del país que puede afectar } \\
\text { negativamente a la solvencia } \\
\text { empresarial. }\end{array}$ & $\begin{array}{l}\text { Ferri et al. (2001), Durbin } \\
\text { y Ng (2005), Peter y } \\
\text { Grandes (2005), Arteta y } \\
\text { Hale (2008), Cavallo y } \\
\text { Valenzuela (2010), Love } \\
\text { y Zaidi (2010), } \\
\text { Borenzstein et al. (2013), } \\
\text { Bedendo y Colla (2013), } \\
\text { Corsetti et al. (2013), } \\
\text { Bastos y Pindado (2013), } \\
\text { Tsuruta (2013), Klein y } \\
\text { Stellner (2014). }\end{array}$ \\
\hline $\begin{array}{l}\text { Acaparamiento de } \\
\text { liquidez que limita la } \\
\text { oferta de crédito } \\
\text { comercial }\end{array}$ & $\begin{array}{l}\text {-Acumulación de liquidez por parte de } \\
\text { las empresas para hacer frente a las } \\
\text { restricciones de financiación causadas } \\
\text { por el riesgo soberano. }\end{array}$ & 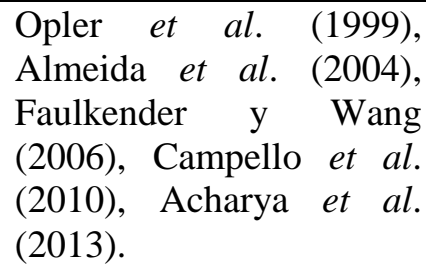 \\
\hline
\end{tabular}

Fuente: elaboración propia.

Teniendo en cuenta los planteamientos propuestos, la reducción del crédito comercial fruto de un mayor riesgo soberano, va a afectar al canal de crédito comercial de la política monetaria. De acuerdo a este canal, una política monetaria restrictiva produce un aumento del crédito comercial para contrarrestar la disminución en la oferta de préstamos bancarios. En este contexto, las empresas menos vulnerables a las restricciones de crédito bancario y con mejor acceso a los mercados de capitales, redistribuirán recursos hacia las empresas más débiles mediante la extensión de crédito comercial (Meltzer, 1960). Sin embargo, las empresas en países con mayor riesgo soberano serán más reticentes a conceder crédito comercial debido al aumento de sus 
problemas de financiación, su riesgo de crédito y su acaparamiento de liquidez (Campello et al., 2010; Banco Central Europeo, 2010a; Agca y Celasun, 2012; Tsuruta, 2013; Acharya et al., 2013; Pianeselli y Zaghini, 2014; Klein y Stellner, 2014). Por lo tanto, cuanto mayor sea el riesgo soberano, menor será el incremento de crédito comercial causado por una restricción monetaria. En consecuencia, proponemos la siguiente hipótesis:

Hipótesis 4: el incremento del volumen de crédito comercial originado por una política monetaria restrictiva se reduce a medida que aumenta el riesgo soberano.

\section{4.- ANÁLISIS EMPÍRICO DEL CANAL DE CRÉDITO COMERCIAL}

\subsection{1.- Composición y características de la muestra}

El contraste empírico de las hipótesis 3 y 4 se efectúa para una muestra de empresas medianas y grandes ${ }^{64}$ pertenecientes a los mismos 12 países del análisis del capítulo anterior entre 2005 y 2012. La selección de estos países nos va a permitir examinar el efecto que ejerce el riesgo soberano sobre el canal de crédito comercial de la política monetaria, evitando el sesgo causado por diferentes políticas monetarias. Además, el período de tiempo seleccionado comprende los años anteriores a la crisis, donde el riesgo soberano fue similar para todos los países, y los años posteriores, donde existen diferencias notorias en el riesgo soberano. La información contable procede de la base de datos Amadeus (Bureau Van Dijk), la cual contiene información económicofinanciera de numerosas empresas de Europa. La información macroeconómica de cada país se ha extraído de la base de datos "World Development Indicators" del Banco Mundial, las estadísticas de la OCDE y EuroStat.

\footnotetext{
${ }^{64}$ De acuerdo a la Recomendación de la Comisión Europea de 6 de mayo de 2003 (2003/361/EC), la categoría de medianas y grandes empresas está compuesta por empresas que poseen más de 50 empleados y cuyo importe neto de la cifra de negocios y/o activo es superior a 10 millones de euros.
} 
Nuestra muestra comprende empresas no financieras pertenecientes a 8 sectores que se corresponden con aquellos cuyo código sectorial de dos dígitos está comprendido entre 11 y 49 de acuerdo a la clasificación sectorial proporcionada por el Sistema de Clasificación Industrial de Norte América (NAICS por sus siglas en inglés) ${ }^{65}$. Es posible que, dado el elevado tamaño de la muestra, puedan existir valores extremos que distorsionen los resultados, por lo que se ha realizado, para las variables independientes, una windsorización del 5\% sobre los extremos superior e inferior de la muestra ${ }^{66}$.

Dado que en el análisis se aplica una metodología de datos de panel y se calculan tasas de variación de ciertas variables, es necesario eliminar también aquellas empresas para las que no se cuenta con datos durante al menos 5 años consecutivos.

La Tabla 3.4 muestra el número de empresas y observaciones por país, así como la distribución temporal de la muestra.

La Tabla 3.5 recoge la distribución de la muestra por sectores. En este sentido, los sectores se han agrupado de acuerdo a la clasificación sectorial de dos dígitos que proporciona el NAICS ${ }^{67}$.

\footnotetext{
${ }^{65}$ De acuerdo al NAICS, los sectores cuyo código sectorial de dos dígitos está comprendido entre 11 y 49 son los siguientes: Agricultura, ganadería, silvicultura y pesca; Industrias extractivas; Suministro de energía eléctrica, gas natural y agua; Construcción; Industria manufacturera; Comercio al por mayor; Comercio al por menor; Transporte y almacenamiento.

${ }^{66}$ La windsorización ha sido ampliamente utilizada por otros trabajos previos (véase, entre otros, Brooke y Oliver, 2005; Brockman y Unlu, 2009; Battaglia y Gallo, 2013).

${ }^{67}$ Los sectores de Comercio al por mayor y Comercio al por menor se han agrupado dentro de la misma categoría sectorial.
} 
Tabla 3.4: Composición de la muestra

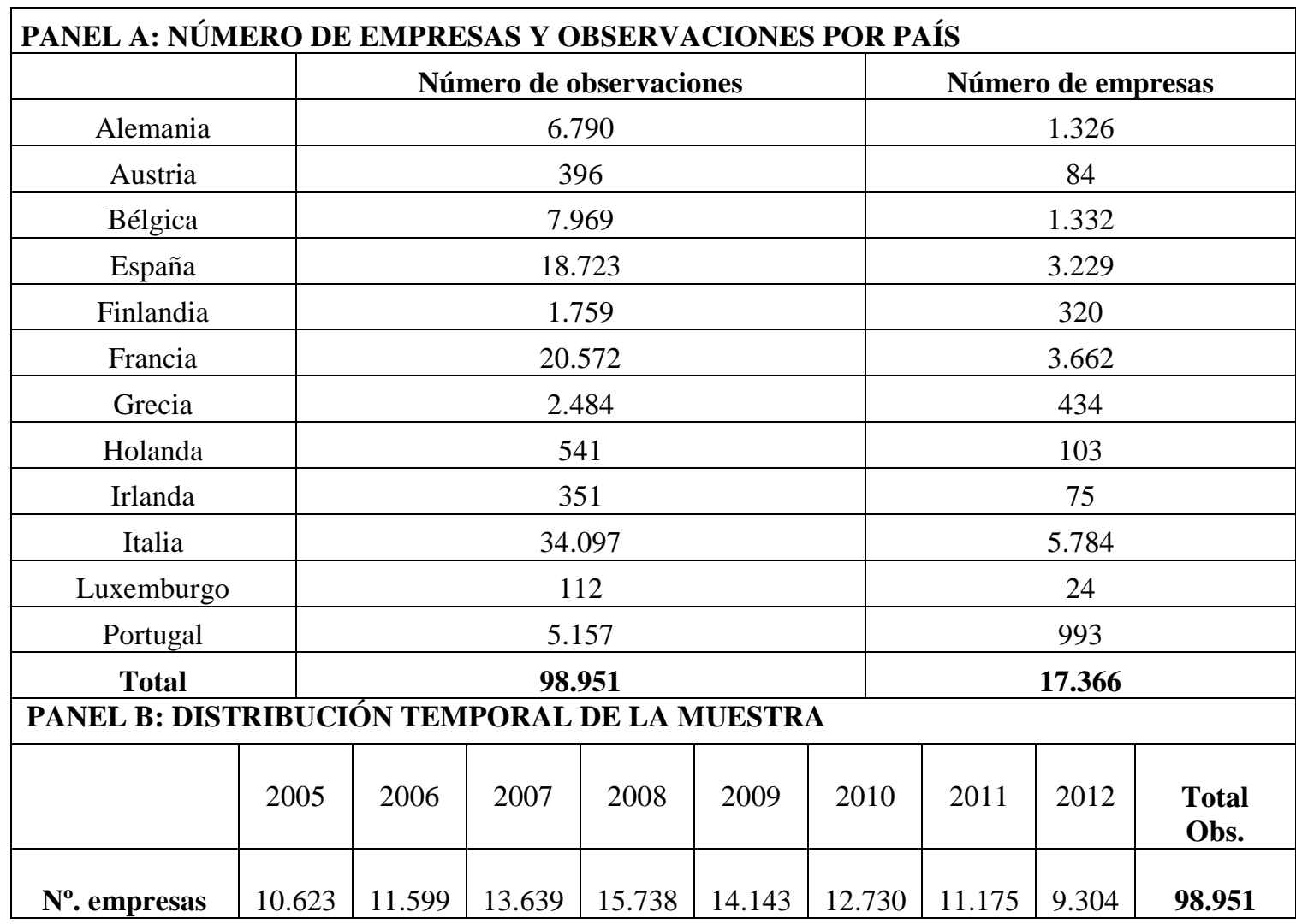

Tabla 3.5: Distribución sectorial de la muestra

\begin{tabular}{|c|c|c|c|}
\hline Sector & $\begin{array}{c}\text { Número de } \\
\text { observaciones }\end{array}$ & Número de empresas & $\begin{array}{c}\text { Proporción de cada } \\
\text { sector sobre el total de } \\
\text { empresas de la } \\
\text { muestra }\end{array}$ \\
\hline $\begin{array}{c}\text { Agricultura, ganadería, } \\
\text { silvicultura y pesca }\end{array}$ & 1.147 & 197 & $1,13 \%$ \\
\hline $\begin{array}{c}\text { Industrias extractivas } \\
\text { Suministro de energía } \\
\text { eléctrica, gas natural y } \\
\text { agua }\end{array}$ & 544 & 96 & $0,55 \%$ \\
\hline Construcción & 1.543 & 274 & $1,58 \%$ \\
\hline \begin{tabular}{c} 
Industria manufacturera \\
\hline $\begin{array}{c}\text { Comercio al por mayor } \\
\text { y al por menor }\end{array}$
\end{tabular}$\quad 6.803$ & 1.245 & $7,17 \%$ \\
\hline $\begin{array}{c}\text { Transporte y } \\
\text { almacenamiento }\end{array}$ & 54.657 & 9.572 & $55,12 \%$ \\
\hline Total & 27.032 & 4.709 & $27,12 \%$ \\
\hline
\end{tabular}

Para el contraste de las hipótesis 3 y 4 se han utilizado tres variables distintas para medir el volumen de crédito comercial: crédito comercial extendido, crédito comercial 
recibido y crédito comercial neto, lo cual responde al hecho de que la mayoría de las empresas pueden a la vez conceder y recibir créditos comerciales. Así, el crédito comercial extendido representa el volumen de crédito comercial que la empresa concede a sus clientes y, por lo tanto, forma parte del activo corriente de la empresa como un derecho de cobro. El crédito comercial recibido hace referencia al volumen de crédito comercial que la empresa obtiene de sus proveedores, por lo que figura dentro de su pasivo corriente como una obligación de pago. Por último, el crédito comercial neto refleja la diferencia entre el volumen de crédito comercial que la empresa otorga a sus clientes y el que recibe de sus proveedores. Es un indicador, por tanto, del crédito comercial que están dispuestas a conceder las empresas una vez descontado el que ellas mismas reciben.

A continuación se realiza el análisis empírico para cada una de estas tres variables de crédito comercial.

\subsection{2.- Desarrollo del modelo econométrico y variables utilizadas en el análisis del crédito comercial extendido}

El contraste de las hipótesis 3 y 4 para el crédito comercial extendido se lleva a cabo a través del siguiente modelo basado en los trabajos tradicionales de crédito comercial, pero incorporando el riesgo soberano y sus interacciones con la política monetaria (Kohler et al., 2000; Love et al., 2007; Kestens et al., 2012):

$$
\begin{aligned}
& \operatorname{CCEXT}_{\mathrm{i}, \mathrm{t}}=\beta_{0}+\left(\beta_{1}+\beta_{2} \text { PRECRISIS }_{\mathrm{t}}\right) \mathrm{RS}_{\mathrm{m}, \mathrm{t}}+\left(\beta_{3}+\beta_{4} \text { PRECRISIS }_{\mathrm{t}}\right) \mathrm{RS}_{\mathrm{m}, \mathrm{t}}^{2}+ \\
& \sum_{\mathrm{j}=0}^{1} \delta_{\mathrm{j}} \Delta \mathrm{i}_{\mathrm{m}, \mathrm{t}-\mathrm{j}}+\sum_{\mathrm{j}=0}^{1} \tau_{\mathrm{j}} \Delta \mathrm{i}_{\mathrm{m}, \mathrm{t}-\mathrm{j}} * \mathrm{RS}_{\mathrm{m}, \mathrm{t}}+\sum_{\mathrm{j}=0}^{1} \theta_{\mathrm{j}} \Delta \mathrm{i}_{\mathrm{m}, \mathrm{t}-\mathrm{j}} * \mathrm{RS}_{\mathrm{m}, \mathrm{t}}^{2}+\beta_{5} \text { CCREC }_{\mathrm{i}, \mathrm{t}}+ \\
& \gamma \mathrm{X}_{\mathrm{i}, \mathrm{t}}+\sum_{\mathrm{t}=1}^{7} \tau_{\mathrm{t}} \text { Año }_{\mathrm{t}}+\sum_{\mathrm{m}=1}^{11} \vartheta_{\mathrm{m}} \text { País }_{\mathrm{m}}+\sum_{\mathrm{s}=1}^{6} \mu_{\mathrm{s}} \text { Sector }_{\mathrm{s}}+\varepsilon_{\mathrm{i}, \mathrm{t}}
\end{aligned}
$$

La variable dependiente, $C C E X T_{i, t}$, refleja el crédito comercial ofertado por las empresas y se calcula como el ratio de las cuentas a cobrar sobre las ventas 
(Cunningham, 2005; Love et al., 2007; Taketa y Udell, 2007; Bougheas et al., 2009). La inclusión de una variable de crédito comercial medida sobre el nivel de ventas nos va a permitir controlar los descensos en la actividad de las empresas, más probables en épocas de crisis (Love et al., 2007; García-Appendini y Montoriol-Garriga, 2013).

$R S$ representa el riesgo soberano y, al igual que en el análisis del capítulo anterior, se calcula como el diferencial en el bono soberano a 10 años de un país con respecto al bono alemán (Codogno et al., 2003; Bernoth y Wolff, 2008; Bernoth et al., 2012). En la hipótesis 3 se ha propuesto que un aumento del riesgo soberano produce una disminución del crédito comercial. Sin embargo, es posible que este descenso sea más importante a medida que se incrementa el riesgo soberano, por lo que se incluye en la ecuación (1) el cuadrado de la variable de riesgo soberano $\left(R S^{2}\right)$.

Para controlar la existencia de posibles cambios estructurales provocados por la crisis, se interaccionan las variables de riesgo soberano $\left(R S\right.$ y $\left.R S^{2}\right)$ con la variable dummy PRECRISIS. Esta variable toma el valor 1 entre 2005-2007 y 0 en caso contrario, lo cual permite analizar si los efectos del riesgo soberano sobre el volumen de crédito comercial difieren durante la crisis comparados con los años anteriores al inicio de la misma.

El indicador de política monetaria $\Delta i$ se mide como la variación de los tipos de interés a corto plazo del mercado monetario (De Bondt, 1999a; Ehrmann et al., 2003; Altunbas et al., 2010; Olivero et al., 2011a). Se incluye el indicador de política monetaria actual y retardado un período, ya que el crédito comercial puede no responder de manera inmediata a las variaciones de política monetaria. Para analizar si el riesgo soberano condiciona los efectos de la política monetaria sobre el crédito comercial, se incluyen también en la ecuación (1) la interacción entre los indicadores de política 
monetaria y los indicadores de riesgo soberano $\left(\Delta i_{t} * R S_{t}, \Delta i_{t-1} * R S_{t}, \Delta i_{t} * R S^{2}\right.$, y $\left.\Delta i_{t-1} * R S^{2}\right)$. En la hipótesis 4 hemos propuesto que el incremento del crédito comercial, causado por una restricción monetaria, es menos pronunciado a medida que aumenta el riesgo soberano. Por lo tanto, se espera que el efecto conjunto de la política monetaria y su interacción con el riesgo soberano tengan un coeficiente negativo.

CCREC representa el volumen de crédito comercial que la empresa recibe de sus proveedores y se calcula como el ratio de cuentas a pagar sobre las ventas. Las empresas que reciben más crédito comercial de sus proveedores extenderán más créditos a sus clientes, ya que las empresas tienden a equiparar los vencimientos de sus cuentas a cobrar con los de sus cuentas a pagar (Fabbri y Klapper, 2008). En consecuencia, cabe esperar una relación positiva entre ambas variables (Atanasova y Wilson, 2003; Bastos y Pindado, 2013).

$X_{i, t,}$ es un vector de variables de control relacionadas con características específicas de las empresas. Dentro de este vector se encuentran incluidas las siguientes variables:

- $\triangle V E N T A S:$ es la tasa de crecimiento de las ventas de una empresa $i$ en el año $t$ con respecto al año $t$-1 (Atanasova y Wilson, 2003; Cunningham, 2005; Gama y Mateus, 2010; Molina y Preve, 2012). Las empresas con un bajo crecimiento de las ventas ofertarán mayores volúmenes de crédito comercial para impulsar las ventas de sus productos (Petersen y Rajan, 1997; Cunningham, 2005). Por lo tanto, se espera que exista una relación negativa entre el crecimiento de las ventas y el crédito comercial extendido.

-TAMAÑO: se corresponde con el logaritmo del activo total (Cuñat-Martínez, 2007; Bougheas et al., 2009; Kestens et al., 2012). La capacidad de las empresas para 
conceder créditos comerciales a su clientela dependerá de la cantidad de fondos externos que puedan obtener (Petersen y Rajan, 1997). Por un lado, las empresas grandes son normalmente más solventes y, por lo tanto, sufren menos restricciones financieras. En consecuencia, son capaces de ofrecer más crédito comercial a sus clientes (Schwartz, 1974). En este sentido, debiera existir una relación positiva entre el tamaño y el crédito comercial extendido.

Por otro lado, las empresas pueden ofrecer garantías de la calidad y reputación de sus productos a través de la extensión de crédito comercial. Las empresas grandes y con buena reputación en el mercado no necesitan aportar garantías adicionales sobre la calidad de sus productos y, por tanto, ofrecerán menos volumen de crédito comercial a su clientela (Deloof y Jegers, 1996). Por el contrario, las empresas pequeñas suelen carecer de reputación en los mercados, por lo que tienden a extender cantidades mayores de crédito comercial en aras de incrementar sus ventas (Long et al., 1993). En consecuencia, también sería posible encontrar una relación negativa entre el tamaño y la oferta de crédito comercial.

-LIQUIDEZ: es el ratio de efectivo sobre el activo total (García-Appendini y Montoriol-Garriga, 2013; Bougheas et al., 2009; Kestens et al., 2012). Las empresas más líquidas pueden ofrecer mayores cantidades de crédito comercial a sus clientes. Por tanto, se espera una relación significativa y positiva entre la liquidez y el crédito comercial extendido (Nadiri, 1969; Ng et al., 1999; Love et al., 2007). Por otro lado, las empresas serán más reacias a conceder crédito comercial si poseen un objetivo de liquidez muy elevado, por lo que también sería posible encontrar una relación negativa entre la liquidez y la oferta de crédito comercial (Bougheas et al., 2009). 
-INVENT: hace referencia al volumen de inventarios sobre el total activo (Atanasova y Wilson, 2003; Cuñat-Martínez, 2007; Kestens et al., 2012). Las empresas con grandes inventarios de productos terminados soportan mayores costes de almacenamiento, y, con el fin de reducir dichos costes, pueden impulsar las ventas a través de la concesión de créditos comerciales (Bougheas et al., 2009). Por lo tanto, la relación entre los inventarios y el crédito comercial ofertado debiera ser positiva. Por el contrario, desde el punto de vista de gestión de activos, cabría esperar una relación negativa entre ambas variables ya que los inventarios y el crédito comercial, al formar parte del activo corriente, pueden considerarse como sustitutos (Choi y Kim, 2005).

-REC_INT: representa el ratio del flujo de caja generado sobre el activo total y es un indicador del volumen de recursos internos que genera la empresa (Atanasova, 2007; Kestens et al., 2012). Las empresas que poseen mayores recursos internos tendrán más fondos a su disposición para poder extender crédito comercial a sus clientes (Petersen y Rajan, 1997; Biais y Gollier, 1997). Se espera, pues, una relación positiva entre esta variable y el volumen de crédito comercial concedido.

-PRESTBANC: refleja el ratio de préstamos bancarios que poseen las empresas con respecto a su activo total (Atanasova y Wilson, 2003; Fukuda et al., 2006; Gama y Mateus, 2010). Un mejor acceso a financiación bancaria permite a las empresas conceder más créditos comerciales a sus clientes (Meltzer, 1960; Nilsen, 2002; Cunningham, 2005; Bougheas et al., 2009). Lo lógico es, por tanto, que exista una relación positiva entre los préstamos bancarios y la oferta de crédito comercial.

Se han introducido dummies de país, temporales y de sector como variables de control. El término de error es $\varepsilon_{i, t} ; i=1,2, \ldots, N$ indica una empresa específica $i ; m=$ 
$1,2, \ldots, M$ indica un país concreto $m ; t=1,2, \ldots, T$ indica un año particular $t ; s=1,2, \ldots$, $S$ indica un sector específico $s$ y $j$ denota el número de retardos.

La Tabla 3.6 resume las variables independientes empleadas en la ecuación (1), así como sus relaciones esperadas con el crédito comercial extendido de acuerdo a los planteamientos estudiados.

Tabla 3.6: Variables determinantes del crédito comercial extendido

\begin{tabular}{|c|c|c|}
\hline Variable & Aproximación & $\begin{array}{l}\text { Relación esperada con el } \\
\text { crédito comercial extendido }\end{array}$ \\
\hline $\mathrm{RS}$ & $\begin{array}{c}\text { Diferencial del rendimiento del bono } \\
\text { soberano de un país respecto a Alemania }\end{array}$ & NEGATIVA \\
\hline $\mathrm{RS}^{2}$ & $\begin{array}{l}\text { Cuadrado del diferencial del rendimiento del } \\
\text { bono soberano de un país respecto a } \\
\text { Alemania }\end{array}$ & $\begin{array}{l}\text { NEGATIVA/ NO } \\
\text { SIGNIFICATIVA }\end{array}$ \\
\hline$\Delta \mathrm{i}$ & $\begin{array}{c}\text { Variación de tipos de interés a corto plazo } \\
\text { del mercado monetario }\end{array}$ & \multirow{3}{*}{$\begin{array}{l}\text { NEGATIVA } \\
\text { (Efecto conjunto) }\end{array}$} \\
\hline$\Delta \mathrm{i} * \mathrm{RS}$ & $\begin{array}{l}\text { Interacción entre la política monetaria y el } \\
\text { riesgo soberano }\end{array}$ & \\
\hline$\Delta \mathrm{i} * \mathrm{RS}^{2}$ & $\begin{array}{l}\text { Interacción entre la política monetaria y el } \\
\text { cuadrado del riesgo soberano }\end{array}$ & \\
\hline CCREC & Cuentas a pagar/Ventas & POSITIVA \\
\hline$\triangle$ VENTAS & Tasa de crecimiento de las ventas & NEGATIVA \\
\hline TAMAÑO & Logaritmo del Activo & POSITIVA/NEGATIVA \\
\hline LIQUIDEZ & Efectivo/Activo & POSITIVA/NEGATIVA \\
\hline INVENT & Inventarios/Activo & POSITIVA/NEGATIVA \\
\hline REC_INT & Flujo de caja/Activo & POSITIVA \\
\hline PRESTBANC & Préstamos bancarios/Activo & POSITIVA \\
\hline
\end{tabular}

La Tabla 3.7 presenta los estadísticos descriptivos de las variables utilizadas en el análisis del crédito comercial extendido. La Tabla 3.8 muestra las correlaciones entre las variables para identificar potenciales problemas de colinealidad. 
Tabla 3.7: Estadísticos descriptivos (Crédito comercial extendido)

\begin{tabular}{|c|c|c|c|c|}
\hline Variable & Media & $\begin{array}{c}\text { Desviación } \\
\text { típica }\end{array}$ & Mínimo & Máximo \\
\hline CCEXT & 0,2357 & 0,1212 & 0,0133 & 0,5931 \\
\hline $\mathrm{RS}$ & 1,0104 & 1,7751 & $-0,9398$ & 21,0025 \\
\hline$\Delta \mathrm{i}$ & $-0,2170$ & 1,4307 & $-3,4059$ & 1,1984 \\
\hline CCREC & 0,1529 & 0,0765 & 0,1476 & 0,3787 \\
\hline$\Delta$ VENTAS & 0,0117 & 0,1211 & $-0,3051$ & 0,3666 \\
\hline TAMANNO & 10,0776 & 1,2650 & 5,4311 & 19,4047 \\
\hline LIQUIDEZ & 0,0650 & 0,0697 & 0,0003 & 0,3206 \\
\hline INVENT & 0,1860 & 0,1271 & 0,0000 & 0,5307 \\
\hline REC_INT & 0,0701 & 0,0454 & $-0,0494$ & 0,1997 \\
\hline PRESTBANC & 0,0981 & 0,1050 & 0,0000 & 0,4044 \\
\hline
\end{tabular}

Tabla 3.8: Correlaciones (Crédito comercial extendido)

\begin{tabular}{|c|c|c|c|c|c|c|c|c|c|}
\hline & RS & $\Delta \mathrm{i}$ & $\triangle$ VENTAS & TAMAÑO & LIQUIDEZ & INVENT & REC_INT & PRESTBANC & CCREC \\
\hline RS & 1 & & & & & & & & \\
\hline$\Delta \mathrm{i}$ & $-0,0995$ & 1 & & & & & & & \\
\hline$\triangle$ VENTAS & $-0,1048$ & 0,3132 & 1 & & & & & & \\
\hline TAMAÑO & $-0,0623$ & 0,0026 & 0,0612 & 1 & & & & & \\
\hline LIQUIDEZ & $-0,0295$ & $-0,0210$ & 0,0111 & $-0,0705$ & 1 & & & & \\
\hline INVENT & $-0,0099$ & 0,0325 & $-0,0134$ & $-0,0675$ & $-0,1131$ & 1 & & & \\
\hline REC_INT & $-0,1077$ & 0,0414 & 0,1179 & 0,0134 & 0,1845 & $-0,1371$ & 1 & & \\
\hline PRESTBANC & 0,0838 & 0,0305 & $-0,0025$ & $-0,0449$ & $-0,3031$ & 0,1711 & $-0,2529$ & 1 & \\
\hline CCREC & 0,0484 & 0,0747 & 0,0539 & 0,0074 & $-0,0635$ & 0,0561 & $-0,2143$ & 0,1589 & 1 \\
\hline
\end{tabular}

El modelo propuesto en la ecuación (1) se estima a través de la metodología System-GMM de datos de panel dinámicos (Arellano y Bover, 1995; Blundell y Bond, 1998) ${ }^{68}$. Este método de estimación resulta muy apropiado para el modelo planteado, dado que permite el control de la endogeneidad. En este sentido, el modelo desarrollado en la ecuación (1) se ve afectado por problemas de endogeneidad, ya que la variable dependiente puede también explicar alguna de las variables independientes. Particularmente, en la relación entre el volumen de crédito comercial extendido y recibido (CCEXT y CCREC) existe una doble dirección, ya que, por un lado, las empresas pueden establecer en primer lugar su política de oferta de crédito comercial y después intentar negociar las condiciones de crédito comercial con sus proveedores. Por

\footnotetext{
${ }^{68}$ Esta metodología ya fue explicada en el capítulo anterior.
} 
otro lado, las empresas pueden adquirir los productos de sus proveedores y, en función del crédito comercial recibido, fijar posteriormente la política de crédito que aplicarán a sus clientes (Bastos y Pindado, 2013). Además, el crédito comercial y los préstamos bancarios también se pueden determinar de manera simultánea, lo que representa otro problema de endogeneidad (Gama y Mateus, 2010; Huang et al., 2011). Las empresas con mejor acceso a los préstamos bancarios tienden a demandar menos crédito comercial (Petersen y Rajan, 1994; Atanasova y Wilson, 2003). Sin embargo, el crédito comercial actúa como una señal de solvencia y, por lo tanto, puede ayudar a las empresas a obtener más créditos bancarios (Biais y Gollier, 1997; Burkart y Ellingsen, 2004).

Los indicadores macroeconómicos (política monetaria, riesgo soberano y sus interacciones) son considerados variables exógenas, mientras que las variables específicas de las empresas se consideran endógenas. Asimismo, se ha seguido una estrategia de estimación para las variables endógenas que emplea entre el segundo y el cuarto retardo como instrumentos.

\subsection{3.- Resultados obtenidos en el análisis del crédito comercial extendido}

La Tabla 3.9 muestra los resultados del análisis del crédito comercial extendido. En el modelo (a) se incluyen únicamente las variables de control y los indicadores de riesgo soberano $\left(R S\right.$ y $\left.R S^{2}\right)$. En el modelo (b) se añaden los indicadores de política monetaria $\left(\Delta i_{t}\right.$ y $\left.\Delta i_{t-1}\right)$ y sus interacciones con las variables de riesgo soberano $\left(\Delta i_{t} * R S\right.$, $\left.\Delta i_{t-1} * R S, \Delta i_{t} * R S^{2}, \mathrm{y} \Delta i_{t-1} * R S^{2}\right)$ 
Tabla 3.9: Resultados (Crédito comercial extendido)

\begin{tabular}{|c|c|c|c|c|}
\hline & (a) & & (b) & \\
\hline $\mathrm{RS}_{\mathrm{t}}$ & $-0,0135(-2,46)$ & $* *$ & $-0,0211(-1,71)$ & $*$ \\
\hline $\mathrm{RS}_{\mathrm{t}}{ }^{*}$ PRECRISIS & $-2,4558(-0,60)$ & & $1,2561(1,87)$ & $*$ \\
\hline$\left(\mathrm{RS}_{\mathrm{t}}\right)^{2}$ & $0,0003(0,70)$ & & $0,0012(1,40)$ & \\
\hline$\left(\operatorname{RS}_{t}\right)^{2 *}$ PRECRISIS & $7,2591(0,63)$ & & $-3,4447(-1,75)$ & $*$ \\
\hline$\Delta \mathrm{i}_{\mathrm{t}}$ & & & $0,0798(1,81)$ & $*$ \\
\hline$\Delta \mathrm{i}_{\mathrm{t}-1}$ & & & $0,1171(1,69)$ & $*$ \\
\hline$\Delta \mathrm{i}_{\mathrm{t}} * \mathrm{RS}_{\mathrm{t}}$ & & & $-0,0027(-1,89)$ & $*$ \\
\hline$\Delta \mathrm{i}_{\mathrm{t}-1} * \mathrm{RS}_{\mathrm{t}}$ & & & $0,0009(0,45)$ & \\
\hline$\Delta \mathrm{i}_{\mathrm{t}} *\left(\mathrm{RS}_{\mathrm{t}}\right)^{2}$ & & & $0,0001(1,15)$ & \\
\hline$\Delta \mathrm{i}_{\mathrm{t}-1} *\left(\mathrm{RS}_{\mathrm{t}}\right)^{2}$ & & & $-0,0006(-0,99)$ & \\
\hline $\operatorname{CCREC}_{\mathrm{i}, \mathrm{t}}$ & $0,2230(1,12)$ & & $0,2941(1,88)$ & $*$ \\
\hline$\Delta$ VENTAS $_{\mathrm{i}, \mathrm{t}}$ & $-0,0314(-0,92)$ & & $0,0013(0,05)$ & \\
\hline TAMAÑO $_{\mathrm{i}, \mathrm{t}}$ & $-0,0016(-0,07)$ & & $-0,0145(-0,94)$ & \\
\hline LIQUIDEZ $_{\mathrm{i}, \mathrm{t}}$ & $-0,2559(-1,95)$ & $*$ & $-0,2775(-2,18)$ & $* *$ \\
\hline INVENT $_{\mathrm{i}, 1}$ & $-0,2640(-2,91)$ & $* * *$ & $-0,1847(-2,34)$ & $* *$ \\
\hline REC_INT $_{\mathrm{i}, \mathrm{t}}$ & $0,1994(0,94)$ & & $0,0130(0,07)$ & \\
\hline PRESTBANC $_{\mathrm{i}, \mathrm{t}}$ & $-0,0077(-0,10)$ & & $0,0392(0,58)$ & \\
\hline CONS & $0,3628(1,27)$ & & $0,2698(1,86)$ & $*$ \\
\hline$\left(\beta_{1}+\beta_{2}\right)$ & $-2,4693(-0,60)$ & & $1,2350(1,83)$ & $*$ \\
\hline$\left(\beta_{3}+\beta_{4}\right)$ & $7,2594(0,63)$ & & $-3,4435(-1,75)$ & $*$ \\
\hline Dummies País & Sí & & Sí & \\
\hline Dummies Temporales & Sí & & Sí & \\
\hline Dummies Sector & Sí & & Sí & \\
\hline $\mathrm{m}_{2}$ & 0,493 & & 0,425 & \\
\hline Hansen & 0,162 & & 0,126 & \\
\hline
\end{tabular}

Para cada variable se muestra su coeficiente y entre paréntesis la T-student; *** indica un nivel de significatividad del 99\%, ** indica un nivel de significatividad del 95\%,* indica un nivel de significatividad del $90 \% ; \mathrm{m}_{2}$ es el estadístico de correlación serial de segundo orden distribuido como una $\mathrm{N}(0,1)$ bajo la hipótesis nula de no correlación serial. Hansen es el test de sobreidentificación, distribuido como una chi-cuadrado bajo la hipótesis nula de no relación entre los instrumentos y el término de error. $(\beta 1+\beta 2)$ es el test de significatividad conjunta bajo la hipótesis nula $\mathrm{H} 0: \delta 2+\gamma 2=0 .(\beta 3+\beta 4)$ es el test de significatividad conjunta bajo la hipótesis nula $\mathrm{H} 0: \delta 2+\chi 2=0$.

En lo que respecta al modelo (a), la variable $R S$, que mide el efecto del riesgo soberano sobre el crédito comercial extendido durante la crisis, es significativa y negativa. Sin embargo, la variable que mide el cuadrado del riesgo soberano $\left(R S^{2}\right)$ no es significativa. De acuerdo a este resultado y sin tener en cuenta otras variables, durante la crisis un incremento del riesgo soberano conlleva una reducción de la oferta de crédito comercial, lo cual apoya la hipótesis 3. Sin embargo los test de significatividad conjunta $\left(\beta_{1}+\beta_{2}\right)$ y $\left(\beta_{3}+\beta_{4}\right)$, que miden respectivamente el impacto del riesgo soberano $(R S) \mathrm{y}$ 
el impacto del cuadrado del riesgo soberano $\left(R S^{2}\right)$ sobre el crédito comercial extendido antes de la crisis, no son significativos. Por tanto, el riesgo soberano no ejerce una influencia significativa sobre el volumen de crédito comercial extendido en los años previos a la crisis.

En relación a las variables de control, la variable LIQUIDEZ es negativa y significativa, indicando que las empresas que poseen un objetivo de liquidez alto tienden a proporcionar menos crédito comercial a sus clientes. Nuestros resultados también muestran un coeficiente negativo y significativo para la variable INVENT. Esto indica que las empresas con mayores niveles de inventario extienden menos crédito comercial y significa que los inventarios y el crédito comercial son sustitutivos tal y como sugieren otros trabajos (Choi y Kim, 2005; Kestens et al., 2012).

En el modelo (b) la variable de riesgo soberano $(R S)$ es también significativa y negativa. Al igual que en el modelo (a) este resultado indicaría que durante la crisis, un incremento del riesgo soberano genera una disminución del crédito comercial extendido, lo cual sustentaría de nuevo la hipótesis 3.

Por su parte, las variables $\left(\beta_{1}+\beta_{2}\right)$ y $\left(\beta_{3}+\beta_{4}\right)$ son significativas en el modelo (b) con un coeficiente positivo y negativo respectivamente. Este resultado indicaría que, antes de la crisis, la oferta de crédito comercial se incrementa cuando aumenta el riesgo soberano hasta un determinado nivel del mismo, a partir del cual el crédito comercial extendido comienza a descender. Sin embargo, este descenso del crédito comercial no es muy relevante, ya que se produce a partir de un nivel de prima de riesgo $(0,18 \%)$ muy próximo al máximo de la muestra para esos años (0,30\%). Además, dado que los test de significatividad conjunta $\left(\beta_{1}+\beta_{2}\right)$ y $\left(\beta_{3}+\beta_{4}\right)$ no son relevantes en el modelo (a), 
no se posee evidencia suficiente para proponer una relación entre el riesgo soberano y la oferta de crédito comercial antes de la crisis.

Para analizar el efecto que tiene la política monetaria sobre el crédito comercial, en el modelo (b) se han introducido dos indicadores de política monetaria $\left(\Delta i_{t} \mathrm{y} \Delta i_{t-1}\right) \mathrm{y}$ sus interacciones con el riesgo soberano. Puesto que se están interaccionando variables continuas, el efecto marginal de la política monetaria sobre el crédito comercial extendido va a depender del valor que tome el riesgo soberano $(R S)$. Para capturar dicho efecto marginal es preciso calcular la derivada de la ecuación (1) de la página 142 con respecto a la política monetaria:

$$
\frac{\partial \operatorname{CCEXT}_{\mathrm{i}, \mathrm{t}}}{\partial \Delta \mathrm{i}_{\mathrm{m}, \mathrm{t}}}=\beta_{0}+\tau_{0} \mathrm{RS}_{\mathrm{m}, \mathrm{t}}+\theta_{0} \mathrm{RS}_{\mathrm{m}, \mathrm{t}}^{2}
$$

Este efecto marginal de la ecuación (1.1) varía con el nivel de riesgo soberano $(R S)$, lo que hace necesario construir un gráfico para poder interpretar los resultados correctamente. La Figura 3.1 muestra el efecto marginal de la política monetaria sobre el crédito comercial extendido en relación a la prima de riesgo cuando se produce un incremento del tipo de interés a corto plazo del mercado monetario (política monetaria restrictiva). Las líneas discontinuas representan el intervalo de confianza al $90 \%{ }^{69}$.

Los resultados muestran que un incremento de los tipos de interés a corto plazo del mercado monetario conducen a un aumento del crédito comercial ofertado en países con una prima de riesgo baja.

\footnotetext{
${ }^{69}$ Se ha seguido el enfoque propuesto por Aiken y West (1991) para la construcción de los intervalos de confianza. El efecto marginal es significativo cuando los extremos inferior y superior del intervalo de confianza tienen el mismo signo.
} 
Figura 3.1: Efecto marginal de la política monetaria ( $\Delta$ tipos de interés) sobre el crédito comercial extendido

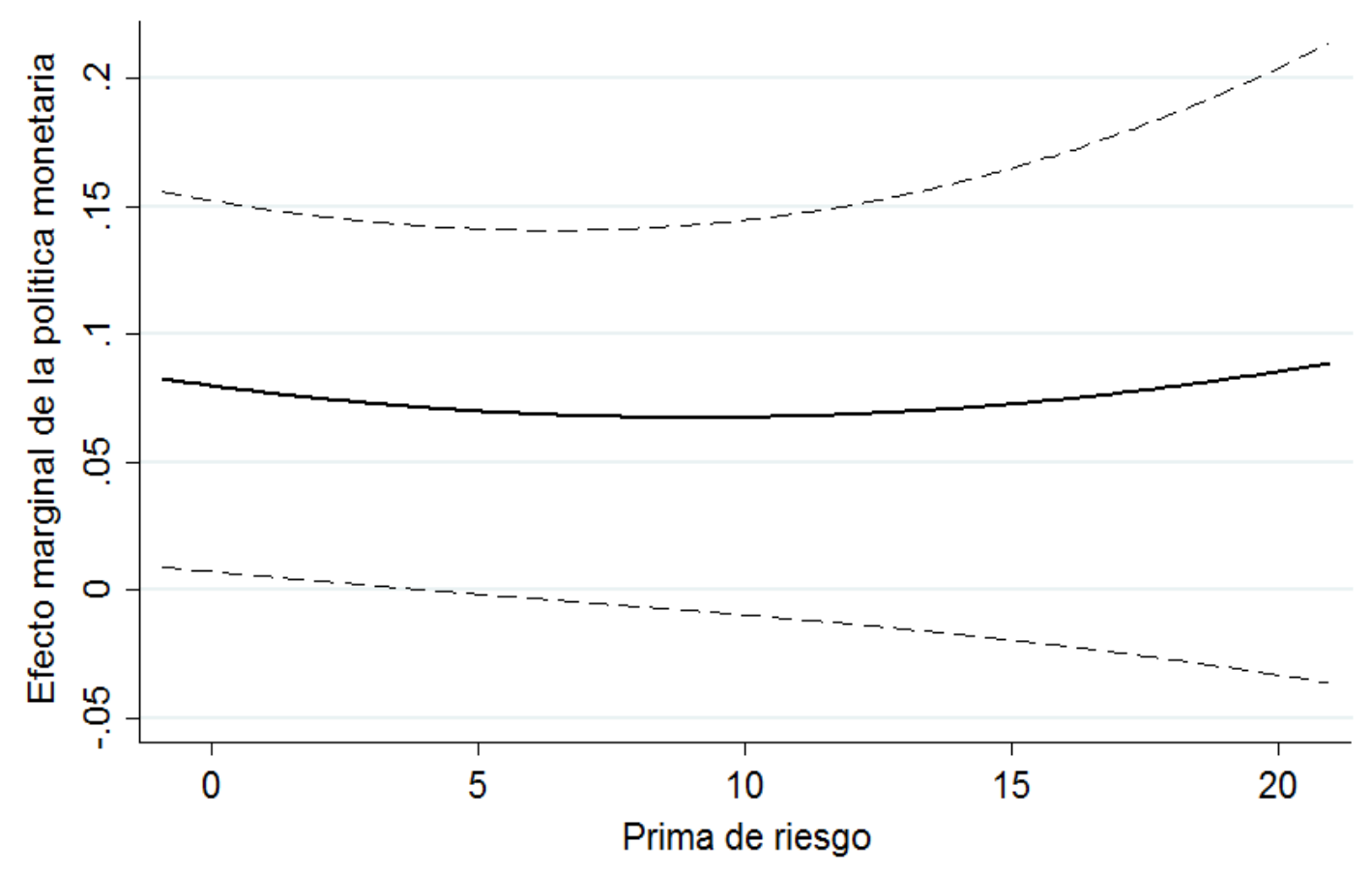

Modelo (b)

- Efecto marginal

- - - - Intervalo superior de confianza al 90\%

- - - - Intervalo inferior de confianza al 90\%

En este sentido, el efecto marginal sobre el crédito comercial extendido es similar (entre 0,0432 y 0,0446 ) en los países con una prima de riesgo inferior a 4,17\%. A partir de este punto, el efecto marginal no es significativo, por lo que en nuestra muestra no hay evidencias de que las empresas en países con riesgo soberano elevado aumenten su oferta de crédito comercial cuando se endurecen las condiciones monetarias, lo cual apoyaría parcialmente la hipótesis 4. En dicha hipótesis, se planteaba que el incremento de crédito comercial causado por una restricción monetaria es menor a medida que aumenta el riesgo soberano. Es posible que el crédito comercial extendido no se incremente en países con riesgo soberano alto debido a que las empresas de dichos países soportan fuertes restricciones financieras, lo que contrarresta el incremento del crédito comercial originado por una política monetaria contractiva. 
En relación a las variables de control, la variable $C C R E C$ es significativa con un coeficiente positivo, lo que implica que las empresas que obtienen más crédito comercial de sus proveedores también ofrecen mayores volúmenes de crédito comercial a sus clientes.

\subsection{4.- Desarrollo del modelo econométrico y variables utilizadas en el análisis del crédito comercial recibido}

El contraste de las hipótesis 3 y 4 para el crédito comercial recibido se efectúa mediante el siguiente modelo apoyado en otros estudios de crédito comercial, pero incorporando el riesgo soberano y su relación con la política monetaria (Kohler et al., 2000; Atanasova y Wilson, 2003; Love et al., 2007; Kestens et al., 2012):

$$
\begin{aligned}
& \text { CCREC }_{\mathrm{i}, \mathrm{t}}=\beta_{0}+\left(\beta_{1}+\beta_{2} \text { PRECRISIS }_{\mathrm{t}}\right) \mathrm{RS}_{\mathrm{m}, \mathrm{t}}+\left(\beta_{3}+\beta_{4} \text { PRECRISIS }_{\mathrm{t}}\right) \mathrm{RS}_{\mathrm{m}, \mathrm{t}}^{2}+ \\
& \sum_{\mathrm{j}=0}^{1} \delta_{\mathrm{j}} \Delta \mathrm{i}_{\mathrm{m}, \mathrm{t}-\mathrm{j}}+\sum_{\mathrm{j}=0}^{1} \tau_{\mathrm{j}} \Delta \mathrm{i}_{\mathrm{m}, \mathrm{t}-\mathrm{j}} * \mathrm{RS}_{\mathrm{m}, \mathrm{t}}+\sum_{\mathrm{j}=0}^{1} \theta_{\mathrm{j}} \Delta \mathrm{i}_{\mathrm{m}, \mathrm{t}-\mathrm{j}} * \mathrm{RS}_{\mathrm{m}, \mathrm{t}}^{2}+\beta_{5} \text { CCEXT }_{\mathrm{i}, \mathrm{t}}+ \\
& \gamma \mathrm{X}_{\mathrm{i}, \mathrm{t}}+\sum_{\mathrm{t}=1}^{7} \tau_{\mathrm{t}} \mathrm{Anno}_{\mathrm{t}}+\sum_{\mathrm{m}=1}^{11} \vartheta_{\mathrm{m}} \text { País }_{\mathrm{m}}+\sum_{\mathrm{s}=1}^{6} \mu_{\mathrm{s}} \text { Sector }_{\mathrm{s}}+\varepsilon_{\mathrm{i}, \mathrm{t}}
\end{aligned}
$$

La variable dependiente, $C C R E C_{i, t}$, refleja el crédito comercial que reciben las empresas de sus proveedores y se calcula como el ratio de las cuentas a pagar sobre el total de ventas (Cunningham, 2005; Bougheas et al., 2009). La ponderación del crédito comercial recibido por las ventas permite controlar la variación en el nivel de actividad de las empresas (Love et al., 2007; García-Appendini y Montoriol-Garriga, 2013).

$R S$ es la variable de riesgo soberano y, como en todos los análisis previos, se calcula como el diferencial entre el rendimiento del bono soberano a 10 años de un país con respecto al bono de Alemania al mismo vencimiento (Codogno et al., 2003; Bernoth y Wolff, 2008; Bernoth et al., 2012). También se incluye el cuadrado de la variable de riesgo soberano $\left(R S^{2}\right)$, ya que es posible que el descenso del crédito comercial sea mayor a medida que se incrementa el riesgo soberano. 
Para controlar posibles cambios estructurales originados por la crisis, se han interaccionado las variables de riesgo soberano con la dummy PRECRISIS que recoge los años previos a la crisis, al tomar el valor 1 durante el período 2005-2007 y 0 en caso contrario.

Los indicadores de política monetaria actual y retardada, $\Delta i_{t}$ y $\Delta i_{t-1}$, se miden a través de la variación de los tipos de interés a corto plazo del mercado monetario (De Bondt, 1999a; Ehrmann et al., 2003; Altunbas et al., 2010; Olivero et al., 2011a). Para analizar cómo el riesgo soberano condiciona los efectos de la política monetaria sobre el crédito comercial recibido, se incluyen los términos de interacción entre las variables de política monetaria y de riesgo soberano $\left(\Delta i_{t} * R S, \Delta i_{t-1} * R S, \Delta i_{t} * R S^{2}\right.$, y $\left.\Delta i_{t-1} * R S^{2}\right)$. Tal y como hemos propuesto en la hipótesis 4 , el incremento del crédito comercial recibido originado por una restricción monetaria debiera ser menos pronunciado en países con riesgo soberano elevado, por lo que se espera que el efecto conjunto de la política monetaria y las interacciones descritas anteriormente posea un coeficiente negativo.

CCEXT representa el cociente entre las cuentas a cobrar y el total de ventas. Las empresas que extienden mayores niveles de crédito comercial también tienden a demandar más este tipo de financiación (Atanasova y Wilson, 2003; Bastos y Pindado, 2013). Por lo tanto, debiera haber una relación positiva entre el crédito comercial extendido y el recibido.

$X_{i, t}$, es un vector de variables de control relacionadas con características específicas de las empresas. Dentro de dicho vector se encuentran las siguientes variables:

$-\triangle V E N T A S:$ es la variación de las ventas de la empresa $i$ en el año $t$ con respecto al año $t-1$ (Atanasova y Wilson, 2003; Cunningham, 2005; Gama y Mateus, 2010). Las 
empresas con grandes tasas de crecimiento de las ventas son percibidas por los proveedores como clientes de rápido crecimiento, por ello reciben mayores volúmenes de crédito comercial (Atanasova y Wilson, 2003; Molina y Preve, 2012). En consecuencia, se espera que exista una relación positiva entre el crecimiento de las ventas y el crédito comercial recibido.

-TAMAÑO: es el logaritmo del activo total (Cuñat-Martínez, 2007; Bougheas et al., 2009; Kestens et al., 2012). Las empresas más grandes tienen más capacidad para acceder a los mercados de capitales y para obtener financiación bancaria, por lo que pueden evitar financiarse con un crédito comercial más costoso (Kestens et al., 2012; Molina y Preve, 2012). Por lo tanto, se espera una relación negativa entre el tamaño y el crédito comercial recibido.

-LIQUIDEZ: recoge el ratio de efectivo sobre el activo total y es una medida de la liquidez de las empresas (Bougheas et al., 2009; Kestens et al., 2012; García-Appendini y Montoriol-Garriga, 2013). Aquellas con bajos niveles de liquidez tienen mayores necesidades de financiación a través del crédito comercial (Kohler et al., 2000; Bougheas et al., 2009). Por lo tanto, se espera una relación negativa entre la liquidez y el crédito comercial recibido. Sin embargo, los proveedores pueden ser reacios a proporcionar créditos comerciales a empresas con problemas de liquidez, por lo que también puede existir una relación positiva entre la liquidez y el crédito comercial recibido (Kestens et al., 2012).

-INVENT: hace referencia al cociente entre los inventarios y el total activo (Atanasova y Wilson, 2003; Cuñat-Martínez, 2007). Las empresas con mayores niveles de inventario recibirán más crédito comercial por parte de sus proveedores, ya que en caso de quiebra, el inventario puede ser liquidado fácilmente (Choi y Kim, 2005; Taketa 
y Udell, 2007). Por tanto, se espera una relación positiva entre los inventarios y el crédito comercial recibido.

-REC_INT: refleja la capacidad de la empresa para generar fondos internamente y se expresa como el cociente entre el flujo de caja y el activo total (Atanasova y Wilson, 2003; Kestens et al., 2012). De acuerdo a la teoría del "pecking order", las empresas tienen una mayor preferencia por los fondos internos que por el crédito comercial (Myers y Majluf, 1984). En este contexto, la capacidad de la empresa para generar recursos internos disminuirá su demanda de crédito comercial. Por lo tanto, se espera una relación negativa entre los fondos internos y el volumen de crédito comercial recibido.

-PRESTBANC: se corresponde con el ratio de préstamos bancarios sobre el activo total (Atanasova y Wilson, 2003; Fukuda et al., 2006; Gama y Mateus, 2010). Las empresas con menos acceso a los préstamos bancarios tienden a recurrir al crédito comercial como vía de financiación (Petersen y Rajan, 1994; Atanasova y Wilson, 2003; Fukuda et al., 2006). Por lo tanto, la relación entre los préstamos bancarios y el crédito comercial recibido debiera ser negativa.

-COL: hace referencia al colateral que poseen las empresas y es el ratio de los activos fijos tangibles sobre el activo total (Cuñat-Martínez, 2007; García-Appendini y Montoriol-Garriga, 2013; Bastos y Pindado, 2013). Las empresas con menores colaterales suelen emplear más crédito comercial, porque tienen más dificultades para acceder a los préstamos bancarios (Tsuruta, 2013). En consecuencia, se espera una relación negativa entre el colateral y el crédito comercial recibido.

Se han introducido dummies de país, temporales y de sector como variables de control. El término de error es $\varepsilon_{i, t} ; i=1,2, \ldots, N$ indica una empresa específica $i ; m=$ 
$1,2, \ldots, M$ indica un país concreto $m ; t=1,2, \ldots, T$ indica un año particular $t ; s=1,2, \ldots$, $S$ indica un sector específico $s$ y $j$ denota el número de retardos.

La Tabla 3.10 resume las variables independientes empleadas en la ecuación (2), así como las relaciones esperadas.

Tabla 3.10: Variables determinantes del crédito comercial recibido

\begin{tabular}{|c|c|c|}
\hline Variable & Aproximación & $\begin{array}{c}\text { Relación esperada con el } \\
\text { crédito comercial recibido }\end{array}$ \\
\hline RS & $\begin{array}{c}\text { Diferencial del rendimiento } \\
\text { del bono soberano de un } \\
\text { país respecto a Alemania }\end{array}$ & NEGATIVA \\
\hline RS $^{2}$ & $\begin{array}{c}\text { Cuadrado del diferencial del } \\
\text { rendimiento del bono } \\
\text { soberano de un país } \\
\text { respecto a Alemania }\end{array}$ & \multirow{2}{*}{$\begin{array}{c}\text { NEGATIVA/ NO } \\
\text { SIGNIFICATIVA }\end{array}$} \\
\hline$\Delta \mathrm{i}$ & $\begin{array}{c}\text { Variación de tipos de interés } \\
\text { a corto plazo del mercado } \\
\text { monetario }\end{array}$ & \\
\hline$\Delta \mathrm{i}^{*} \mathrm{RS}$ & $\begin{array}{c}\text { Interacción entre la política } \\
\text { monetaria y el riesgo } \\
\text { soberano }\end{array}$ & \multirow{2}{*}{ NEGATIVA } \\
\hline Efecto conjunto $)$
\end{tabular}

La Tabla 3.11 presenta los estadísticos descriptivos de las variables utilizadas en el análisis del crédito comercial recibido. La Tabla 3.12 muestra las correlaciones entre las variables para identificar potenciales problemas de colinealidad. 
Tabla 3.11: Estadísticos descriptivos (Crédito comercial recibido)

\begin{tabular}{|c|c|c|c|c|}
\hline Variable & Media & $\begin{array}{c}\text { Desviación } \\
\text { típica }\end{array}$ & Mínimo & Máximo \\
\hline CCREC & 0,1529 & 0,0765 & 0,1476 & 0,3787 \\
\hline RS & 1,0104 & 1,7751 & $-0,9398$ & 21,0025 \\
\hline$\Delta \mathrm{i}$ & $-0,2170$ & 1,4307 & $-3,4059$ & 1,1984 \\
\hline$\Delta$ VENTAS & 0,0117 & 0,1211 & $-0,3051$ & 0,3666 \\
\hline TAMANNO & 10,0776 & 1,2650 & 5,4311 & 19,4047 \\
\hline LIQUIDEZ & 0,0650 & 0,0697 & 0,0003 & 0,3206 \\
\hline INVENT & 0,1860 & 0,1271 & 0,0000 & 0,5307 \\
\hline REC_INT & 0,0701 & 0,0454 & $-0,0494$ & 0,1997 \\
\hline PRESTBANC & 0,0981 & 0,1050 & 0,0000 & 0,4044 \\
\hline COL & 0,2293 & 0,1539 & 0,0067 & 0,6320 \\
\hline CCEXT & 0,2357 & 0,1212 & 0,0133 & 0,5931 \\
\hline
\end{tabular}

Tabla 3.12: Correlaciones (Crédito comercial recibido)

\begin{tabular}{|c|c|c|c|c|c|c|c|c|c|c|}
\hline & RS & $\Delta \mathrm{i}$ & $\triangle$ VENTAS & TAMAÑO & LIQUIDEZ & INVENT & REC_INT & PRESTBANC & $\mathrm{COL}$ & CCREC \\
\hline RS & 1 & & & & & & & & & \\
\hline$\Delta \mathrm{i}$ & $-0,0995$ & 1 & & & & & & & & \\
\hline$\triangle$ VENTAS & $-0,1048$ & 0,3132 & 1 & & & & & & & \\
\hline TAMAÑO & $-0,0623$ & 0,0026 & 0,0612 & 1 & & & & & & \\
\hline LIQUIDEZ & $-0,0295$ & $-0,0210$ & 0,0111 & $-0,0705$ & 1 & & & & & \\
\hline INVENT & $-0,0099$ & 0,0325 & $-0,0134$ & $-0,0675$ & $-0,1131$ & 1 & & & & \\
\hline REC_INT & $-0,1077$ & 0,0414 & 0,1179 & 0,0134 & 0,1845 & $-0,1371$ & 1 & & & \\
\hline PRESTBANC & 0,0838 & 0,0305 & $-0,0025$ & $-0,0449$ & $-0,3031$ & 0,1711 & $-0,2529$ & 1 & & \\
\hline COL & 0,0680 & $-0,0504$ & $-0,0479$ & 0,0344 & $-0,1285$ & $-0,1714$ & 0,1333 & 0,0763 & 1 & \\
\hline CCREC & 0,0484 & 0,0747 & $-0,0355$ & $-0,0916$ & $-0,1222$ & $-0,1612$ & $-0,1126$ & 0,2240 & $-0,1266$ & 1 \\
\hline
\end{tabular}

El modelo de la ecuación (2) se estima, al igual que en el análisis previo, mediante una metodología System-GMM de datos de panel dinámicos (Arellano y Bover, 1995; Blundell y Bond, 1998). Las variables macroeconómicas de la ecuación (2) se consideran exógenas y las variables específicas de cada empresa endógenas y, de nuevo, se ha seguido una estrategia de estimación para las variables endógenas que emplea entre el segundo y el cuarto retardo como instrumentos. 


\subsection{5.- Resultados obtenidos en el análisis del crédito comercial recibido}

La Tabla 3.13 muestra los resultados del análisis del crédito comercial recibido.

En el modelo (a) se incluyen únicamente las variables de control y los indicadores de riesgo soberano $\left(R S\right.$ y $\left.R S^{2}\right)$. En el modelo (b) se añaden los indicadores de política monetaria $\left(\Delta i_{t}\right.$ y $\left.\Delta i_{t-1}\right)$ y sus interacciones con las variables de riesgo soberano $\left(\Delta i_{t} * R S\right.$, $\left.\Delta i_{t-1} * R S, \Delta i_{t} * R S^{2}, \mathrm{y} \Delta i_{t-1} * R S^{2}\right)$.

Tabla 3.13: Resultados (Crédito comercial recibido)

\begin{tabular}{|c|c|c|c|c|}
\hline & (a) & & (b) & \\
\hline $\mathrm{RS}_{\mathrm{t}}$ & $0,0178(2,33)$ & $* *$ & $0,0258(2,77)$ & $* * *$ \\
\hline $\mathrm{RS}_{\mathrm{t}}{ }^{*}$ PRECRISIS & $-0,0711(-0,12)$ & & $0,8249(1,89)$ & $*$ \\
\hline$\left(\mathrm{RS}_{\mathrm{t}}\right)^{2}$ & $-0,0008(-2,01)$ & $* *$ & $-0,0011(-1,74)$ & $*$ \\
\hline$\left(\mathrm{RS}_{\mathrm{t}}\right)^{2 *}$ PRECRISIS & $0,5737(0,35)$ & & $-1,9331(-1,59)$ & \\
\hline$\Delta \mathrm{i}_{\mathrm{t}}$ & & & $0,0989(1,88)$ & $*$ \\
\hline$\Delta \mathrm{i}_{\mathrm{t}-1}$ & & & $0,1296(1,59)$ & \\
\hline$\Delta \mathrm{i}_{\mathrm{t}} * \mathrm{RS}_{\mathrm{t}}$ & & & $-0,0042(-1,82)$ & $*$ \\
\hline$\Delta \mathrm{i}_{\mathrm{t}-1} * \mathrm{RS}_{\mathrm{t}}$ & & & $-0,0052(-2,07)$ & $* *$ \\
\hline$\Delta \mathrm{i}_{\mathrm{t}} *\left(\mathrm{RS}_{\mathrm{t}}\right)^{2}$ & & & $0,0006(1,38)$ & \\
\hline$\Delta \mathrm{i}_{\mathrm{t}-1} *\left(\mathrm{RS}_{\mathrm{t}}\right)^{2}$ & & & $0,0011(1,61)$ & \\
\hline$\Delta$ VENTAS $_{\mathrm{i}, \mathrm{t}}$ & $0,0523(1,53)$ & & $0,0243(0,69)$ & \\
\hline TAMAÑO $_{i, t}$ & $-0,0041(-0,27)$ & & $-0,0024(-0,20)$ & \\
\hline LIQUIDEZ $_{\mathrm{i}, \mathrm{t}}$ & $-0,1825(-1,23)$ & & $-0,1230(-1,03)$ & \\
\hline INVENT $_{\mathrm{i}, 1}$ & $-0,0565(-0,43)$ & & $0,1488(1,79)$ & $*$ \\
\hline REC_INT $_{i, t}$ & $-0,0440(-0,29)$ & & $-0,2195(-1,46)$ & \\
\hline PRESTBANC $_{\mathrm{i}, \mathrm{t}}$ & $-0,1482(-1,70)$ & $*$ & $-0,0994(-1,19)$ & \\
\hline $\mathrm{COL}_{\mathrm{i}, \mathrm{t}}$ & $0,0320(0,67)$ & & $-0,0159(-0,39)$ & \\
\hline $\mathrm{CCEXT}_{\mathrm{i}, \mathrm{t}}$ & $0,2815(2,60)$ & $* * *$ & $0,1407(1,24)$ & \\
\hline CONS & $0,1050(0,73)$ & & $0,0479(0,44)$ & \\
\hline$\left(\beta_{1}+\beta_{2}\right)$ & $-0,0533(-0,09)$ & & $0,8506(1,94)$ & $*$ \\
\hline$\left(\beta_{3}+\beta_{4}\right)$ & $0,5729(0,35)$ & & $-1,9342(-1,59)$ & \\
\hline Dummies País & Sí & & Sí & \\
\hline Dummies Temporales & Sí & & Sí & \\
\hline Dummies Sector & Sí & & Sí & \\
\hline $\mathrm{m}_{2}$ & 0,458 & & 0,131 & \\
\hline Hansen & 0,227 & & 0,104 & \\
\hline
\end{tabular}

Para cada variable se muestra su coeficiente y entre paréntesis la T-student; *** indica un nivel de significatividad del 99\%, ** indica un nivel de significatividad del 95\%,* indica un nivel de significatividad del 90\%; $\mathrm{m}_{2}$ es el estadístico de correlación serial de segundo orden distribuido como una $\mathrm{N}(0,1)$ bajo la hipótesis nula de no correlación serial. Hansen es el test de sobreidentificación, distribuido como una chi-cuadrado bajo la hipótesis nula de no relación entre los instrumentos y el término de error. $(\beta 1+\beta 2)$ es el test de significatividad conjunta bajo la hipótesis nula $\mathrm{H} 0: \delta 2+\gamma 2=0$. $(\beta 3+\beta 4)$ es el test de significatividad conjunta bajo la hipótesis nula $\mathrm{H} 0: \delta 2+\chi 2=0$. 
Atendiendo al modelo (a), las variables de riesgo soberano $(R S)$ y su cuadrado $\left(R S^{2}\right)$, que miden el efecto del riesgo soberano sobre el crédito comercial recibido durante la crisis, son significativas con signos positivo y negativo respectivamente. Estos resultados indican que existe una relación positiva entre el riesgo soberano y el crédito comercial recibido en países con bajo riesgo soberano, mientras que dicha relación es negativa cuando el riesgo soberano es alto. En concreto, y sin tener en cuenta otras variables, el riesgo soberano empieza a tener un efecto negativo a partir de un nivel de prima de riesgo de 11,12\%. Este resultado apoya parcialmente la hipótesis 3 , ya que el crédito comercial recibido desciende ante aumentos del riesgo soberano, pero sólo cuando éste es elevado.

Esta relación cuadrática entre el riesgo soberano y el crédito comercial recibido es diferente de la relación negativa entre el riesgo soberano y el crédito comercial extendido obtenida en el análisis anterior. Esta diferencia entre el crédito comercial extendido y recibido puede deberse al hecho de que nuestra base de datos comprende una economía abierta, donde las empresas pueden tener relaciones comerciales con proveedores internacionales no afectados por el riesgo soberano. En este contexto, es probable que las empresas importadoras en países con un riesgo soberano no muy elevado, puedan contrarrestar la bajada en los préstamos bancarios con crédito comercial a través de sus proveedores internacionales. Por el contrario, estos proveedores internacionales serán reacios a proporcionar crédito comercial a las empresas que operen en países con riesgo soberano muy alto, debido al elevado riesgo de impago y al contagio de crédito causado por un país en dificultades financieras.

Por otro lado, los test de significatividad conjunta $\left(\beta_{1}+\beta_{2}\right)$ y $\left(\beta_{3}+\beta_{4}\right)$, que miden respectivamente el impacto del riesgo soberano $(R S)$ y el impacto del cuadrado del riesgo soberano $\left(R S^{2}\right)$ sobre el crédito comercial recibido antes de la crisis, no son 
significativos. Por tanto, el riesgo soberano no tiene un efecto relevante sobre el volumen de crédito comercial recibido en los años previos a la crisis.

En relación a las variables de control, la variable PRESTBANC es significativa y negativa. Por lo tanto, las empresas con mayores niveles de préstamos bancarios reducen su financiación a través de crédito comercial (Petersen y Rajan, 1997; Cunningham, 2005; Fukuda et al., 2006; Bougheas et al., 2009). Asimismo, la variable CCEXT es también significativa con un coeficiente positivo. De acuerdo a este resultado, las empresas que ofrecen mayores volúmenes de crédito comercial también demandan más este tipo de financiación (Atanasova y Wilson, 2003; Bastos y Pindado, 2013).

En la Tabla 3.13, modelo (b), las variables de riesgo soberano $(R S)$ y su cuadrado $\left(R S^{2}\right)$ son significativas con un coeficiente positivo y negativo respectivamente. De acuerdo a estos resultados y sin considerar otras variables, durante la crisis el crédito comercial recibido aumenta en países cuya prima de riesgo es inferior a $11,73 \%$. Sin embargo, cuando la prima de riesgo supera dicho porcentaje, el crédito comercial recibido desciende. Estos resultados de nuevo apoyarían parcialmente la hipótesis 3, al mostrar que la relación negativa entre el riesgo soberano y el crédito comercial que obtienen las empresas, solamente se produce cuando áquel es elevado.

El test de significatividad conjunta $\left(\beta_{1}+\beta_{2}\right)$, que mide el efecto del riesgo soberano $(R S)$ sobre el crédito comercial recibido antes de la crisis, es significativo con un signo positivo, mientras que el test de significatividad conjunta $\left(\beta_{3}+\beta_{4}\right)$, en relación a los efectos del cuadrado del riesgo soberano $\left(R S^{2}\right)$ no lo es. Este resultado sugeriría que antes de la crisis, un incremento del riesgo soberano conduciría a un aumento del crédito comercial recibido. Sin embargo, dado que la variable $\left(\beta_{1}+\beta_{2}\right)$ no es 
significativa en el modelo (a), no se posee una evidencia sólida para proponer una relación entre el riesgo soberano y el crédito comercial recibido antes de la crisis.

Por lo que respecta a la política monetaria, en el modelo (b) se han incluido dos variables de política monetaria $\left(\Delta i_{t}\right.$ y $\left.\Delta i_{t-1}\right)$ y sus interacciones con el riesgo soberano. Al interaccionar variables continuas, para interpretar los resultados correctamente es necesario calcular el efecto marginal de la política monetaria sobre el crédito comercial recibido, a partir de la primera derivada de la ecuación (2) de la página 154 con respecto a la política monetaria:

$$
\frac{\partial \text { CCREC }_{\mathrm{i}, \mathrm{t}}}{\partial \Delta \mathrm{i}_{\mathrm{m}, \mathrm{t}}}=\beta_{0}+\tau_{0} \mathrm{RS}_{\mathrm{m}, \mathrm{t}}+\theta_{0} \mathrm{RS}_{\mathrm{m}, \mathrm{t}}^{2}
$$

Este efecto marginal de la ecuación (2.1) varía con el nivel de riesgo soberano, por lo que se va a elaborar un gráfico para poder interpretar los resultados. La Figura 3.2 muestra el efecto marginal de la política monetaria sobre el crédito comercial recibido en relación a la prima de riesgo.

Durante una política monetaria restrictiva, el volumen de crédito comercial que las empresas reciben aumenta en países con una prima de riesgo inferior a 11,07\%. A partir de este punto, una contracción monetaria no provoca un incremento del crédito comercial recibido, ya que el efecto marginal deja de ser significativo, lo cual apoya parcialmente la hipótesis 4. Es posible que un riesgo soberano elevado incremente significativamente la probabilidad de impago de las empresas y el riesgo de contagio a lo largo de la cadena de suministro, lo que desincentivaría a los proveedores a conceder créditos comerciales a este tipo de empresas. Por este motivo, el crédito comercial 
recibido no podría aumentar en países con riesgo soberano alto cuando se endurecen las condiciones monetarias.

Figura 3.2: Efecto marginal de la política monetaria ( $\Delta$ tipos de interés) sobre el crédito comercial recibido

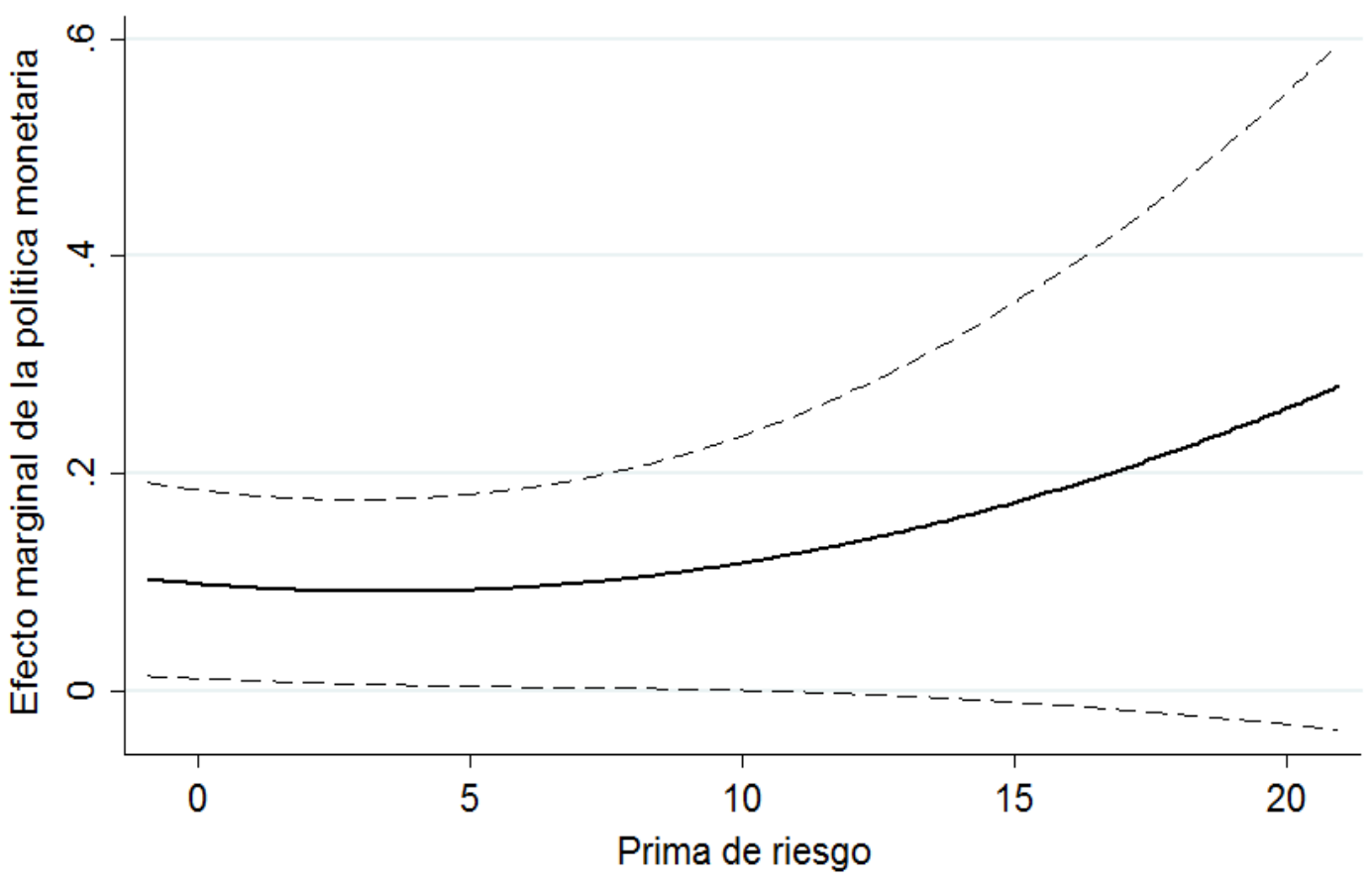

Modelo (b)

- Efecto marginal

- - - - Intervalo superior de confianza al 90\%

- - - - Intervalo inferior de confianza al $90 \%$

Por lo que respecta a las variables de control, la variable INVENT es positiva y significativa. Por tanto, las empresas con mayor disposición de inventarios reciben más créditos comerciales por parte de sus proveedores.

\subsection{6.- Desarrollo del modelo econométrico y variables utilizadas en el análisis del crédito comercial neto}

De manera análoga al crédito comercial extendido y recibido, el contraste de las hipótesis 3 y 4 para el crédito comercial neto se realiza con el siguiente modelo basado en trabajos previos, pero incorporando el riesgo soberano y sus interacciones con la política monetaria (Kohler et al., 2000; Love et al., 2007; Yang, 2011a): 


$$
\begin{aligned}
& \operatorname{CCNET}_{\mathrm{i}, \mathrm{t}}=\beta_{0}+\left(\beta_{1}+\beta_{2} \text { PRECRISIS }_{\mathrm{t}}\right) \mathrm{RS}_{\mathrm{m}, \mathrm{t}}+\left(\beta_{3}+\beta_{4} \text { PRECRISIS }_{\mathrm{t}}\right) \mathrm{RS}_{\mathrm{m}, \mathrm{t}}^{2}+ \\
& \sum_{\mathrm{j}=0}^{1} \delta_{\mathrm{j}} \Delta \mathrm{i}_{\mathrm{m}, \mathrm{t}-\mathrm{j}}+\sum_{\mathrm{j}=0}^{1} \tau_{\mathrm{j}} \Delta \mathrm{i}_{\mathrm{m}, \mathrm{t}-\mathrm{j}} * \mathrm{RS}_{\mathrm{m}, \mathrm{t}}+\sum_{\mathrm{j}=0}^{1} \theta_{\mathrm{j}} \Delta \mathrm{i}_{\mathrm{m}, \mathrm{t}-\mathrm{j}} * \mathrm{RS}_{\mathrm{m}, \mathrm{t}}^{2}+ \\
& \gamma \mathrm{X}_{\mathrm{i}, \mathrm{t}}+\sum_{\mathrm{t}=1}^{7} \tau_{\mathrm{t}} A \tilde{n} \mathrm{o}_{\mathrm{t}}+\quad \sum_{\mathrm{m}=1}^{11} \vartheta_{\mathrm{m}} \text { País }_{\mathrm{m}}+\sum_{\mathrm{s}=1}^{6} \mu_{\mathrm{s}} \text { Sector }_{\mathrm{s}}+\varepsilon_{\mathrm{i}, \mathrm{t}}
\end{aligned}
$$

La variable dependiente, $C C N E T_{i, t}$, se calcula como la diferencia entre el crédito comercial extendido y recibido sobre el total de ventas (Cunningham, 2005; Bougheas et al., 2009). Se emplea un ratio de crédito comercial medido sobre las ventas para controlar los descensos en la actividad de las empresas (Love et al., 2007; GarcíaAppendini y Montoriol-Garriga, 2013).

Al igual que en los modelos anteriores, la variable de riesgo soberano $(R S)$ se mide como la diferencia en el rendimiento de los bonos a 10 años de un país con respecto a los bonos alemanes con el mismo vencimiento (Codogno et al., 2003; Bernoth y Wolff, 2008; Bernoth et al., 2012). Asimismo, se incluye en la ecuación (3) el cuadrado del riesgo soberano $\left(R S^{2}\right)$. Para el control de la existencia de cambios estructurales originados por la crisis se interaccionan las variables de riesgo soberano con la dummy PRECRISIS. Esta dummy vale 1 entre 2005-2007 y 0 en caso contrario.

El indicador de política monetaria $(\Delta i)$ refleja la tasa de variación de los tipos de interés a corto plazo del mercado monetario (De Bondt, 1999a; Ehrmann et al., 2003; Altunbas et al., 2010; Olivero et al., 2011a). Al igual que en análisis previos, se incluye el indicador de política monetaria actual y retardado un período $\left(\Delta i_{t}\right.$ y $\left.\Delta i_{t-1}\right)$. Se incluyen, además, las interacciones entre los indicadores de política monetaria y las variables de riesgo soberano $\left(\Delta i_{t} * R S, \Delta i_{t-1} * R S, \Delta i_{t} * R S^{2}\right.$, y $\left.\Delta i_{t-1} * R S^{2}\right)$. Dado que el crédito comercial neto representa la diferencia entre el crédito comercial que extienden las empresas y el que ellas mismas reciben, el efecto final de la política monetaria y el riesgo soberano 
sobre el mismo va a depender de la magnitud de los efectos que tengan sobre los créditos comerciales extendido y recibido respectivamente.

$X_{i, t}$, es un vector de variables de control, en el que se incluyen las siguientes variables:

- $\triangle V E N T A S:$ se calcula como la tasa de crecimiento de las ventas de la empresa $i$ en el año $t$ con respecto al año $t-1$ (Gama y Mateus, 2010; Molina y Preve, 2012).

-TAMAÑO: se calcula como el logaritmo del activo total (Cuñat-Martínez, 2007; Bougheas et al., 2009; Kestens et al., 2012).

-LIQUIDEZ: se mide como la proporción de efectivo sobre el activo total (Bougheas et al., 2009; García-Appendini y Montoriol-Garriga, 2013).

-INVENT: recoge el ratio de inventarios sobre el activo (Atanasova y Wilson, 2003; Cuñat-Martínez, 2007).

-REC_INT: refleja el flujo de caja generado sobre el total activo (Atanasova y Wilson, 2003; Kestens et al., 2012).

-PRESTBANC: representa el nivel de préstamos bancarios sobre el activo (Fukuda et al., 2006; Gama y Mateus, 2010).

El impacto que ejerza cada una de estas variables de control sobre el crédito comercial neto va a depender de la magnitud del efecto que dichas variables tengan sobre los créditos comerciales extendido y recibido respectivamente en el caso del tamaño (TAMAÑO), la liquidez (LIQ) y los inventarios (INV). En el caso del crecimiento de las ventas $(\triangle V E N T A S)$ se espera que tenga un efecto negativo sobre el crédito comercial neto, ya que las empresas con bajas tasas de crecimiento de las ventas 
tienden a extender más créditos comerciales para atraer clientes y suelen recibir menos créditos por parte de sus proveedores (Petersen y Rajan, 1997; Atanasova y Wilson, 2003). Asimismo, los recursos internos generados (REC_INT) por la empresa y los préstamos bancarios (PRESTBANC) debieran incidir positivamente sobre el crédito comercial neto, ya que las empresas que generan internamente más recursos y con mejor acceso a la financiación bancaria pueden conceder más crédito comercial y, a la vez, pueden evitar financiarse con este tipo de crédito más costoso (Myers y Majluf, 1984; Meltzer, 1960; Petersen y Rajan, 1994; 1997).

Se han introducido dummies de país, temporales y de sector como variables de control. El término de error es $\varepsilon_{i, t} ; i=1,2, \ldots, N$ indica una empresa específica $i ; m=$ $1,2, \ldots, M$ indica un país concreto $m ; t=1,2, \ldots, T$ indica un año particular $t ; s=1,2, \ldots$, $S$ indica un sector específico $s$ y $j$ denota el número de retardos.

La Tabla 3.14 resume las variables independientes empleadas en la ecuación (3), así como las relaciones esperadas. La Tabla 3.15 presenta los estadísticos descriptivos de las variables utilizadas en el análisis del crédito comercial neto. La Tabla 3.16 muestra las correlaciones entre las variables para identificar potenciales problemas de colinealidad.

El modelo propuesto en la ecuación (3) se estima, al igual que en modelos anteriores, a través de la metodología System-GMM de datos de panel desarrollada por Blundell y Bond (1998). Las características específicas de las empresas se consideran variables endógenas y las variables macroeconómicas exógenas. Asimismo, se ha seguido una estrategia de estimación para las variables endógenas que emplea entre el segundo y el cuarto retardo como instrumentos. 
Tabla 3.14: Variables determinantes del crédito comercial neto

\begin{tabular}{|c|c|c|}
\hline Variable & Aproximación & $\begin{array}{c}\text { Relación esperada con el } \\
\text { crédito comercial neto }\end{array}$ \\
\hline RS & $\begin{array}{c}\text { Diferencial del rendimiento } \\
\text { del bono soberano de un } \\
\text { país respecto a Alemania }\end{array}$ & \multirow{2}{*}{ POSITIVA/NEGATIVA } \\
\hline $\mathrm{RS}^{2}$ & $\begin{array}{c}\text { Cuadrado del diferencial del } \\
\text { rendimiento del bono } \\
\text { soberano de un país } \\
\text { respecto a Alemania }\end{array}$ & \multirow{2}{*}{ POSITIVA/NEGATIVA } \\
\hline$\Delta \mathrm{i}$ & $\begin{array}{c}\text { Variación de tipos de interés } \\
\text { a corto plazo del mercado } \\
\text { monetario }\end{array}$ & \multirow{2}{*}{ POSITIVA/NEGATIVA } \\
(Efecto conjunto $)$
\end{tabular}

Tabla 3.15: Estadísticos descriptivos (Crédito comercial neto)

\begin{tabular}{|c|c|c|c|c|}
\hline Variable & Media & $\begin{array}{c}\text { Desviación } \\
\text { típica }\end{array}$ & Mínimo & Máximo \\
\hline CCNET & 0,0827 & 0,1141 & $-0,3597$ & 0,5536 \\
\hline $\mathrm{RS}$ & 1,0104 & 1,7751 & $-0,9398$ & 21,0025 \\
\hline$\Delta \mathrm{i}$ & $-0,2170$ & 1,4307 & $-3,4059$ & 1,1984 \\
\hline$\Delta$ VENTAS & 0,0117 & 0,1211 & $-0,3051$ & 0,3666 \\
\hline TAMAÑO & 10,0776 & 1,2650 & 5,4311 & 19,4047 \\
\hline LIQUIDEZ & 0,0650 & 0,0697 & 0,0003 & 0,3206 \\
\hline INVENT & 0,1860 & 0,1271 & 0,0000 & 0,5307 \\
\hline REC_INT & 0,0701 & 0,0454 & $-0,0494$ & 0,1997 \\
\hline PRESTBANC & 0,0981 & 0,1050 & 0,0000 & 0,4044 \\
\hline
\end{tabular}


Tabla 3.16: Correlaciones (Crédito comercial neto)

\begin{tabular}{|c|cccccccc|}
\hline & RS & $\Delta \mathrm{i}$ & $\Delta$ VENTAS & TAMANO & LIQUIDEZ & INVENT & REC_INT & PRESTBANC \\
\hline RS & 1 & & & & & & & \\
$\Delta \mathrm{i}$ & $-0,0995$ & 1 & & & & & & \\
$\Delta$ VENTAS & $-0,1048$ & 0,3132 & 1 & & & & & \\
TAMAÑO & $-0,0623$ & 0,0026 & 0,0612 & 1 & & & & \\
LIQUIDEZ & $-0,0295$ & $-0,0210$ & 0,0111 & $-0,0705$ & 1 & & & \\
INVENT & $-0,0099$ & 0,0325 & $-0,0134$ & $-0,0675$ & $-0,1131$ & 1 & & \\
REC_INT & $-0,1077$ & 0,0414 & 0,1179 & 0,0134 & 0,1845 & $-0,1371$ & 1 & \\
PRESTBANC & 0,0838 & 0,0305 & $-0,0025$ & $-0,0449$ & $-0,3031$ & 0,1711 & $-0,2529$ & 1 \\
\hline
\end{tabular}

\subsection{7.- Resultados obtenidos en el análisis del crédito comercial neto}

La Tabla 3.17 muestra los resultados del análisis del crédito comercial neto. En el modelo (a) se incluyen únicamente las variables de control y los indicadores de riesgo soberano $\left(R S\right.$ y $R S^{2}$ ). En el modelo (b) se añaden los indicadores de política monetaria $\left(\Delta i_{t}\right.$ y $\left.\Delta i_{t-1}\right)$ y sus interacciones con las variables de riesgo soberano $\left(\Delta i_{t} * R S, \Delta i_{t-1} * R S, \Delta i\right.$ $\left.{ }_{t}^{*} R S^{2}, \mathrm{y} \Delta i_{t-1} * R S^{2}\right)$.

Atendiendo al modelo (a), la variable $R S$, que mide el efecto del riesgo soberano sobre el crédito comercial neto durante la crisis, es negativa y estadísticamente significativa, mientras que la variable $R S^{2}$ no lo es. De acuerdo a los resultados, un aumento de la prima de riesgo en los años de crisis, conduce a una disminución del crédito comercial neto, lo cual sería acorde con la hipótesis 3.

En cambio, los test de significatividad conjunta $\left(\beta_{1}+\beta_{2}\right)$ y $\left(\beta_{3}+\beta_{4}\right)$, que miden respectivamente el impacto del riesgo soberano $(R S)$ y el impacto del cuadrado del riesgo soberano $\left(R S^{2}\right)$ sobre el crédito comercial neto antes de la crisis, no son significativos. 
Tabla 3.17: Resultados (Crédito comercial neto)

\begin{tabular}{|c|c|c|c|c|}
\hline & (a) & & (b) & \\
\hline $\mathrm{RS}_{\mathrm{t}}$ & $-0,0315(-2,89)$ & $* * *$ & $-0,0372(-2,42)$ & $* *$ \\
\hline $\mathrm{RS}_{\mathrm{t}}{ }^{*}$ PRECRISIS & $15,5047(1,22)$ & & $9,8416(1,62)$ & \\
\hline$\left(\mathrm{RS}_{\mathrm{t}}\right)^{2}$ & $0,0007(1,46)$ & & $0,0017(1,36)$ & \\
\hline$\left(\mathrm{RS}_{\mathrm{t}}\right)^{2 *}$ PRECRISIS & $-39,0092(-1,23)$ & & $-28,8396(-1,62)$ & \\
\hline$\Delta \mathrm{i}_{\mathrm{t}}$ & & & $0,5204(1,66)$ & $*$ \\
\hline$\Delta \mathrm{i}_{\mathrm{t}-1}$ & & & $0,7421(1,69)$ & $*$ \\
\hline$\Delta \mathrm{i}_{\mathrm{t}}^{*} \mathrm{RS}_{\mathrm{t}}$ & & & $-0,0044(-1,50)$ & \\
\hline$\Delta \mathrm{i}_{\mathrm{t}-1} * \mathrm{RS}_{\mathrm{t}}$ & & & $0,0004(0,10)$ & \\
\hline$\Delta \mathrm{i}_{\mathrm{t}} *\left(\mathrm{RS}_{\mathrm{t}}\right)^{2}$ & & & $0,0006(0,97)$ & \\
\hline$\Delta \mathrm{i}_{\mathrm{t}-1} *\left(\mathrm{RS}_{\mathrm{t}}\right)^{2}$ & & & $-0,0003(-0,20)$ & \\
\hline$\Delta$ VENTAS $_{\mathrm{i}, \mathrm{t}}$ & $-0,0544(-1,23)$ & & $-0,0328(-0,69)$ & \\
\hline TAMAÑO $_{i, t}$ & $0,0425(1,47)$ & & $0,0015(0,07)$ & \\
\hline LIQUIDEZ $_{\mathrm{i}, \mathrm{t}}$ & $-0,0566(-0,36)$ & & $0,0753(0,48)$ & \\
\hline INVENT $_{i, 1}$ & $-0,2317(-1,69)$ & $*$ & $-0,0605(-0,39)$ & \\
\hline REC_INT $_{i, t}$ & $0,8112(2,13)$ & $* *$ & $0,3355(0,74)$ & \\
\hline PRESTBANC $_{\mathrm{i}, \mathrm{t}}$ & $0,2080(1,39)$ & & $0,1698(0,93)$ & \\
\hline CONS & $-0,7850(-1,38)$ & & $-0,4570(-1,07)$ & \\
\hline$\left(\beta_{1}+\beta_{2}\right)$ & $15,4732(1,22)$ & & $9,8044(1,61)$ & \\
\hline$\left(\beta_{3}+\beta_{4}\right)$ & $-39,0085(-1,23)$ & & $-28,8379(-1,62)$ & \\
\hline Dummies País & Sí & & Sí & \\
\hline Dummies Temporales & Sí & & Sí & \\
\hline Dummies Sector & Sí & & Sí & \\
\hline $\mathrm{m}_{2}$ & 0,211 & & 0,127 & \\
\hline Hansen & 0,255 & & 0,248 & \\
\hline
\end{tabular}

Para cada variable se muestra su coeficiente y entre paréntesis la T-student; *** indica un nivel de significatividad del 99\%, $* *$ indica un nivel de significatividad del $95 \%, *$ indica un nivel de significatividad del 90\%; $\mathrm{m}_{2}$ es el estadístico de correlación serial de segundo orden distribuido como una $\mathrm{N}(0,1)$ bajo la hipótesis nula de no correlación serial. Hansen es el test de sobreidentificación, distribuido como una chi-cuadrado bajo la hipótesis nula de no relación entre los instrumentos y el término de error. $(\beta 1+\beta 2)$ es el test de significatividad conjunta bajo la hipótesis nula $\mathrm{H} 0: \delta 2+\gamma 2=0 .(\beta 3+\beta 4)$ es el test de significatividad conjunta bajo la hipótesis nula $\mathrm{H} 0: \delta 2+\chi 2=0$.

En relación a las variables de control, la variable INVENT es significativa y negativa, por lo que las empresas con mayores niveles de inventario extienden menos crédito comercial neto. REC_INT también es significativa con un signo positivo, lo cual implica que las empresas que generan más recursos internos poseen mayores niveles de crédito comercial neto.

En la Tabla 3.17, modelo (b), la variable de riesgo soberano $(R S)$ es nuevamente significativa y negativa, mientras que la variable cuadrática de riesgo soberano $\left(R S^{2}\right)$ no 
es significativa. Este resultado apoyaría de nuevo hipótesis 3, al mostrar que durante la crisis un aumento del riesgo soberano produce un descenso del crédito comercial neto. No obstante, los test de significatividad conjunta $\left(\beta_{1}+\beta_{2}\right)$ y $\left(\beta_{3}+\beta_{4}\right)$ no son significativos, por lo que el riesgo soberano no ejerce una influencia relevante sobre el crédito comercial neto en los años previos a la crisis.

En relación a los efectos de la política monetaria, en el modelo (b) se añaden dos variables continuas de política monetaria $\left(\Delta i_{t}\right.$ y $\left.\Delta i_{t-1}\right)$ y sus interacciones con el riesgo soberano. Para poder interpretar los resultados, es preciso calcular el efecto marginal de la política monetaria sobre el crédito comercial neto en función del riesgo soberano, a partir de la derivada de la ecuación (3) de la página 165:

$$
\frac{\partial \operatorname{CCNET}_{\mathrm{i}, \mathrm{t}}}{\partial \Delta \mathrm{i}_{\mathrm{m}, \mathrm{t}}}=\beta_{0}+\tau_{0} \mathrm{RS}_{\mathrm{m}, \mathrm{t}}+\theta_{0} \mathrm{RS}_{\mathrm{m}, \mathrm{t}}^{2}
$$

Este efecto marginal de la ecuación (3.1) varía con el valor que tome el riesgo soberano, por lo que se va a construir un gráfico para poder interpretar los resultados. La Figura 3.3 representa el efecto marginal de la política monetaria sobre el crédito comercial neto en relación a la prima de riesgo.

Ante una restricción monetaria, el crédito comercial neto aumenta en países con una prima de riesgo inferior al 2,27\%. A partir de este punto, una subida de tipos de interés no origina un aumento del crédito comercial neto, puesto que el efecto marginal ya no es significativo, lo cual sería parcialmente acorde con la hipótesis 4. Las empresas ubicadas en países con una prima de riesgo elevada poseen fuertes restricciones 
financieras y un elevado riesgo de impago, lo cual impide que el crédito comercial neto se incremente ante una contracción monetaria.

Figura 3.3: Efecto marginal de la política monetaria ( $\Delta$ tipos de interés) sobre el crédito comercial neto

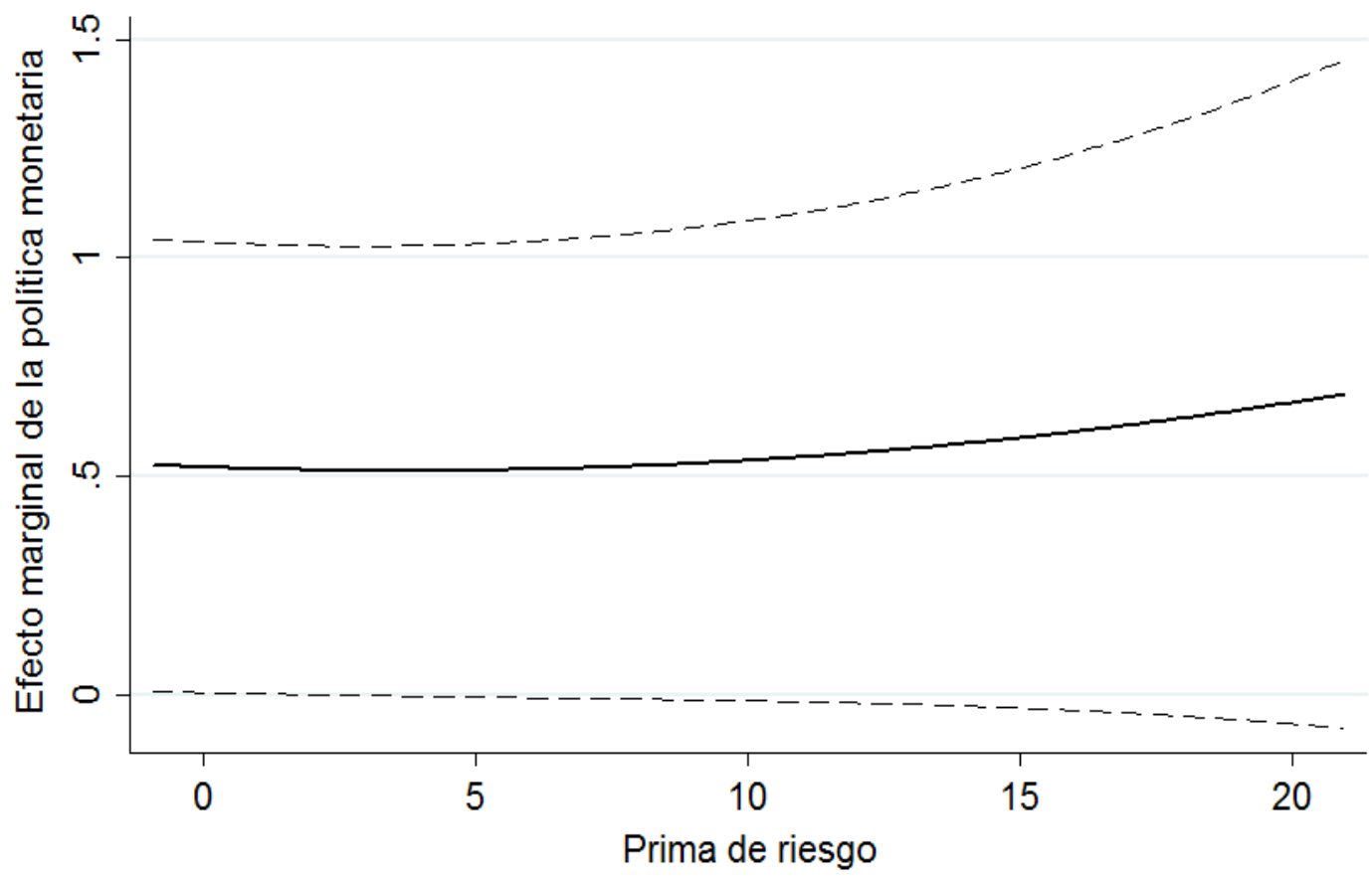

Modelo (b)

_ Efecto marginal

- - - - Intervalo superior de confianza al 90\%

- . - . Intervalo inferior de confianza al $90 \%$

\subsection{8.- Análisis de robustez}

Para comprobar la robustez de nuestros resultados se han repetido los análisis anteriores del crédito comercial extendido, recibido y neto, eliminando de la muestra los países que han sido intervenidos durante la crisis (Grecia, Irlanda y Portugal).

La Tabla 3.18 refleja los resultados que se derivan del análisis de robustez. En los modelos (a), (c) y (e) se analiza el crédito comercial extendido, recibido y neto respectivamente, incluyendo únicamente las variables de control y los indicadores de riesgo soberano $\left(R S\right.$ y $\left.R S^{2}\right)$. En los modelos (b), (d) y (f) se examina el crédito comercial 
extendido, recibido y neto respectivamente, añadiendo los indicadores de política monetaria $\left(\Delta i_{t}\right.$ y $\left.\Delta i_{t-1}\right)$ y sus interacciones con las variables de riesgo soberano $\left(\Delta i_{t} * R S\right.$, $\Delta i_{t-1} * R S, \Delta i_{t} * R S^{2}$ y $\left.\Delta i_{t-1} * R S^{2}\right)$.

Tabla 3.18: Resultados (Análisis de robustez)

\begin{tabular}{|c|c|c|c|c|c|c|}
\hline & \multicolumn{2}{|c|}{ Crédito comercial extendido } & \multicolumn{2}{|c|}{ Crédito comercial recibido } & \multicolumn{2}{|c|}{ Crédito comercial neto } \\
\hline & (a) & (b) & (c) & (d) & (e) & (f) \\
\hline $\mathrm{RS}_{\mathrm{t}}$ & $-0,0284(-2,28) * *$ & $0,0682(1,30)$ & $-0,0113(-1,19)$ & $-0,0429(-1,10)$ & $-0,0265(-2,09) * *$ & $0,1001(1,48)$ \\
\hline $\mathrm{RS}_{\mathrm{t}}^{*}$ PRECRISIS & $-0,1220(-0,54)$ & $2,3595(1,88) *$ & $0,1186(0,26)$ & $0,8849(1,69) *$ & $-1,1415(-0,84)$ & $2,4658(1,45)$ \\
\hline$\left(\mathrm{RS}_{\mathrm{t}}\right)^{2}$ & $0,0008(0,57)$ & $-0,0180(-1,76) *$ & $0,0026(2,24) * *$ & $0,0166(2,28) * *$ & $-0,0003(-0,16)$ & $-0,0238(-1,75) *$ \\
\hline$\left(\mathrm{RS}_{\mathrm{t}}\right)^{2 *}$ PRECRISIS & $0,4806(0,86)$ & $-8,2990(-2,04) * *$ & $0,2657(0,21)$ & $-2,1923(-1,55)$ & $2,6900(0,75)$ & $-8,5277(-1,52)$ \\
\hline$\Delta \mathrm{i}_{\mathrm{t}}$ & & $0,2700(2,48) * *$ & & $0,0141(2,19) * *$ & & $0,2891(1,87) *$ \\
\hline$\Delta \mathrm{i}_{\mathrm{t}-1}$ & & $0,3329(2,33) * *$ & & $0,0068(0,49)$ & & $0,3912(1,81)$ \\
\hline$\Delta \mathrm{i}_{\mathrm{t}}^{*} \mathrm{RS}_{\mathrm{t}}$ & & $-0,0258(-2,65) * * *$ & & $-0,0152(-2,57) * *$ & & $0,0067(0,71)$ \\
\hline$\Delta \mathrm{i}_{\mathrm{t}-1} * \mathrm{RS}_{\mathrm{t}}$ & & $-0,0246(-1,36)$ & & $-0,0076(-0,66)$ & & $0,0119(0,57)$ \\
\hline$\Delta \mathrm{i}_{\mathrm{t}} *\left(\mathrm{RS}_{\mathrm{t}}\right)^{2}$ & & $0,0109(1,80) *$ & & $0,0048(1,34)$ & & $-0,0053(-0,81)$ \\
\hline$\Delta \mathrm{i}_{\mathrm{t}-1} *\left(\mathrm{RS}_{\mathrm{t}}\right)^{2}$ & & $0,0180(1,53)$ & & $-0,0023(-0,32)$ & & $-0,0004(-0,03)$ \\
\hline$\Delta$ VENTAS $_{\mathrm{i}, \mathrm{t}}$ & $-0,0601(-1,74) *$ & $0,0332(1,12)$ & $0,0281(0,94)$ & $0,0123(0,62)$ & $-0,0913(-2,62) * * *$ & $0,0640(1,44)$ \\
\hline TAMAÑO $_{i, t}$ & $-0,0353(-0,86)$ & $-0,0102(-0,53)$ & $0,0052(0,36)$ & $0,0347(1,57)$ & $-0,0130(-1,07)$ & $-0,0178(-1,21)$ \\
\hline LIQUIDEZ $_{\mathrm{i}, \mathrm{t}}$ & $-0,3406(-2,45) * *$ & $0,3503(1,56)$ & $-0,0652(-0,37)$ & $0,0510(0,48)$ & $-0,0503(-0,59)$ & $-0,1411(-1,04)$ \\
\hline INVENT $_{i, 1}$ & $-0,2314(-2,83) * * *$ & $-0,2597(-0,75)$ & $0,0639(0,61)$ & $0,1042(1,14)$ & $-0,2557(-1,26)$ & $-0,0650(-0,34)$ \\
\hline REC_INT $_{\mathrm{i}, \mathrm{t}}$ & $0,2535(1,36)$ & $-0,5528(-1,23)$ & $-0,1442(-1,11)$ & $-0,0037(-0,03)$ & $-0,1155(-0,56)$ & $-0,1269(-0,55)$ \\
\hline PRESTBANC $_{\mathrm{i}, \mathrm{t}}$ & $0,2310(3,04) \quad * * *$ & $0,2073(1,48)$ & $-0,2520(-3,38) * * *$ & $-0,0108(-0,17)$ & $0,0818(0,88)$ & $0,0303(0,29)$ \\
\hline $\mathrm{COL}_{\mathrm{i}, \mathrm{t}}$ & & & $0,0638(1,34)$ & $0,0920(1,54)$ & & \\
\hline $\mathrm{CCEXT}_{\mathrm{i}, \mathrm{t}}$ & & & $0,3137(2,59) \quad * * *$ & $0,5095(3,05) \quad * * *$ & & \\
\hline CCREC $_{\mathrm{i}, \mathrm{t}}$ & $0,5427(3,53) \quad * * *$ & $0,3830(1,28)$ & & & & \\
\hline CONS & $0,6064(1,49)$ & $0,0929(0,37)$ & $-0,0209(-0,14)$ & $-0,3896(-1,43)$ & $0,2686(1,83) *$ & $0,0702(0,44)$ \\
\hline$\left(\beta_{1}+\beta_{2}\right)$ & $-0,1504(-0,65)$ & $2,4287(1,92) *$ & $0,1073(0,23)$ & $0,8419(1,65) *$ & $-1,1680(-0,86)$ & $2,5660(1,50)$ \\
\hline$\left(\beta_{3}+\beta_{4}\right)$ & $0,4813(0,86)$ & $-8,3170(-2,04) * *$ & $0,2682(0,21)$ & $-2,1757(-1,54)$ & $2,6897(0,75)$ & $-8,5515(-1,52)$ \\
\hline Dummies País & Sí & Sí & Sí & Sí & Sí & Sí \\
\hline Dummies Año & Sí & Sí & Sí & Sí & Sí & Sí \\
\hline Dummies Sector & Sí & Sí & Sí & Sí & Sí & Sí \\
\hline $\mathrm{m}_{2}$ & 0,188 & 0,272 & 0,826 & 0,281 & 0,895 & 0,104 \\
\hline Hansen & 0,109 & 0,774 & 0,180 & 0,270 & 0,129 & 0,382 \\
\hline
\end{tabular}

Para cada variable se muestra su coeficiente y entre paréntesis la T-student; *** indica un nivel de significatividad del 99\%, ** indica un nivel de significatividad del 95\%,* indica un nivel de significatividad del 90\%; $\mathrm{m}_{2}$ es el estadístico de correlación serial de segundo orden distribuido como una $\mathrm{N}(0,1)$ bajo la hipótesis nula de no correlación serial. Hansen es el test de sobreidentificación, distribuido como una chi-cuadrado bajo la hipótesis nula de no relación entre los instrumentos y el término de error. $(\beta 1+\beta 2)$ es el test de significatividad conjunta bajo la hipótesis nula $\mathrm{H} 0: \delta 2+\gamma 2=0$. $(\beta 3+\beta 4)$ es el test de significatividad conjunta bajo la hipótesis nula $\mathrm{H} 0: \delta 2+\chi 2=0$. 


\subsubsection{1.- Crédito comercial extendido}

En el modelo (a) se analiza el crédito comercial extendido incluyendo únicamente las variables de control y los indicadores de riesgo soberano $\left(R S\right.$ y $\left.R S^{2}\right)$. En este modelo, la variable de riesgo soberano $(R S)$ es negativa y significativa. La variable cuadrática de riesgo soberano $\left(R S^{2}\right)$, por su parte, no es significativa. Esto indica que durante la crisis un aumento de la prima de riesgo provoca una caída de la provisión de crédito comercial. Este resultado es similar al obtenido en el análisis que incluye los países intervenidos para el crédito comercial extendido, lo que nuevamente muestra evidencias en favor de la hipótesis 3. Los test de significatividad conjunta $\left(\beta_{1}+\beta_{2}\right)$ y $\left(\beta_{3}+\beta_{4}\right)$ no son significativos, por lo que el riesgo soberano no ejerce una influencia relevante sobre el crédito comercial extendido antes de la crisis, al igual que ocurría en el análisis previo.

En relación a las variables de control, la variable $\triangle V E N T A S$ es negativa y significativa, por lo que un descenso de la tasa de crecimiento de las ventas produce un aumento de la oferta de crédito comercial. La variable LIQUIDEZ es también significativa con un coeficiente negativo, lo que revela que las empresas que poseen un objetivo elevado de liquidez conceden menos crédito comercial a su clientela. A su vez, la variable INVENT posee un signo negativo y significativo, lo cual implica que las empresas con mayores niveles de inventario poseen menos derechos de cobro en créditos comerciales. Por último, la variable PRESTBANC es significativa y positiva, lo que significa que las empresas con mayor acceso a la financiación bancaria otorgan más créditos a sus clientes.

En cuanto al modelo (b), la variable del cuadrado del riesgo soberano $\left(R S^{2}\right)$ es significativa y negativa, mientras que la variable $R S$ no lo es. En el análisis para la muestra completa, la variable de riesgo soberano $(R S)$ era significativa y negativa, pero 
el cuadrado del riesgo soberano $\left(R S^{2}\right)$ no. Por lo tanto, estos nuevos resultados estarían de acuerdo con la hipótesis 3, pero el efecto negativo entre el riesgo soberano y el crédito comercial extendido se intensifica a medida que aumenta el riesgo soberano. Al igual que en el modelo (a), este resultado indica que después del estallido de la crisis existe una relación negativa entre el riesgo soberano y el crédito comercial extendido.

Los test de significatividad conjunta $\left(\beta_{1}+\beta_{2}\right)$ y $\left(\beta_{3}+\beta_{4}\right)$ son significativos con un signo positivo y negativo respectivamente, lo cual es similar al resultado obtenido en la muestra que incluye los países intervenidos. Dado que estos test no son significativos en el modelo (a), nuevamente no existen suficientes evidencias a favor de una relación entre el riesgo soberano y el crédito comercial extendido antes de la crisis.

Por lo que respecta a la hipótesis 4 , el efecto marginal que tiene la política monetaria sobre el crédito comercial extendido en función del riesgo soberano, se calcula a través de la ecuación (1.1) de la página 152, el cual aparece reflejado en la Figura 3.4. En ésta se observa que existe una relación positiva entre la política monetaria y el crédito comercial extendido. Este resultado es muy similar al obtenido para la muestra que incluye los países intervenidos cuando el riesgo soberano es bajo ${ }^{70}$.

\footnotetext{
${ }^{70}$ En este caso el rango de la prima de riesgo que aparece en la Figura 3.4 es más pequeño, debido a que se han eliminado de la muestra los países intervenidos.
} 
Figura 3.4: Efecto marginal de la política monetaria ( $\Delta$ tipos de interés) sobre el crédito comercial extendido

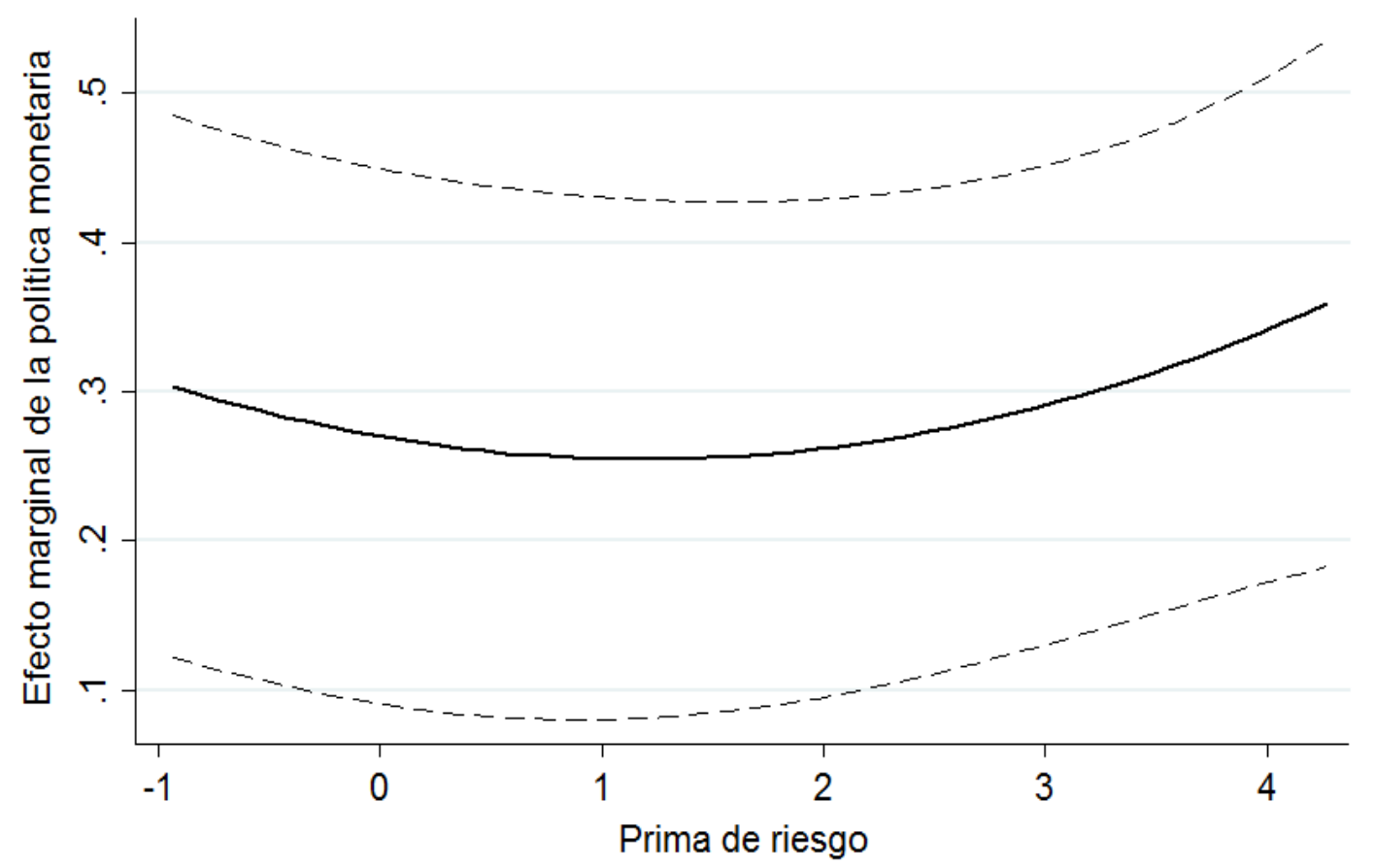

Modelo (b) - Eliminando países intervenidos

- Efecto marginal

- - - Intervalo superior de confianza al $90 \%$

- - - - Intervalo inferior de confianza al $90 \%$

\subsubsection{2.- Crédito comercial recibido}

En el modelo (c) se analiza el crédito comercial recibido incluyendo únicamente las variables de control y los indicadores de riesgo soberano $\left(R S\right.$ y $\left.R S^{2}\right)$. En este modelo (c), la variable cuadrática de riesgo soberano $\left(R S^{2}\right)$ es estadísticamente significativa con un coeficiente positivo, mientras que la variable lineal de riesgo soberano $(R S)$ no es significativa. Este coeficiente positivo para la variable $R S^{2}$ indicaría que durante la crisis existe una relación positiva entre el riesgo soberano y el crédito comercial recibido. Además, al ser significativa la variable cuadrática, ésta es más intensa a medida que se incrementa la prima de riesgo. Este resultado es coherente con los obtenidos en el análisis previo del crédito comercial recibido, que mostraba una relación positiva cuando el riesgo soberano era relativamente bajo y una relación negativa cuando era 
alto. En el análisis de robustez se han eliminado los países intervenidos, que son los que poseen primas de riesgo elevadas, y se estudian los países con menor riesgo para los que existe, por tanto, una relación positiva.

Los test de significatividad conjunta $\left(\beta_{1}+\beta_{2}\right)$ y $\left(\beta_{3}+\beta_{4}\right)$ no son significativos, por lo que no existe una relación relevante entre el riesgo soberano y el crédito comercial recibido antes de la crisis, al igual que sucedía con los resultados obtenidos en el caso anterior.

En relación a las variables de control, la variable PRESTBANC posee un coeficiente significativo y negativo, lo que implica que las empresas con mayor volumen de préstamos bancarios demandan menos crédito comercial. La variable CCEXT es también significativa con un signo positivo, por lo que las empresas que extienden más crédito a sus clientes, demandan a su vez más crédito a sus proveedores.

Atendiendo al modelo (d), la variable cuadrática de riesgo soberano $\left(R S^{2}\right)$ es, al igual que en el modelo (c), estadísticamente significativa con signo positivo, lo que nuevamente indica que el efecto positivo que tiene el riesgo soberano sobre el crédito comercial recibido se incrementa a medida que sube la prima de riesgo. El test de significatividad conjunta $\left(\beta_{1}+\beta_{2}\right)$ posee un coeficiente positivo, lo que denotaría que antes de la crisis existe una relación positiva entre el riesgo soberano y el crédito comercial recibido. Sin embargo, dado que dicha variable no es significativa en el modelo (c), no existen evidencias concluyentes que soporten una relación entre el riesgo soberano y el crédito comercial recibido en los años previos a la crisis, tal y como sucedía en el análisis que incluía los países intervenidos.

En el modelo (d), el efecto marginal que tiene la política monetaria sobre el crédito comercial recibido dependiendo del riesgo soberano, se calcula a través de la 
ecuación (2.1) de la página 163 y aparece reflejado en la Figura 3.5. Los resultados revelan que ante una restricción monetaria, existe una relación positiva entre el riesgo soberano y el crédito comercial recibido cuando la prima de riesgo es inferior al 0,17\%. A partir de ese punto, no hay evidencias de que el crédito comercial recibido se incremente. Este resultado, al igual que en el análisis completo, es parcialmente consistente con la hipótesis 4.

Figura 3.5. Efecto marginal de la política monetaria ( $\Delta$ tipos de interés) sobre el crédito comercial recibido

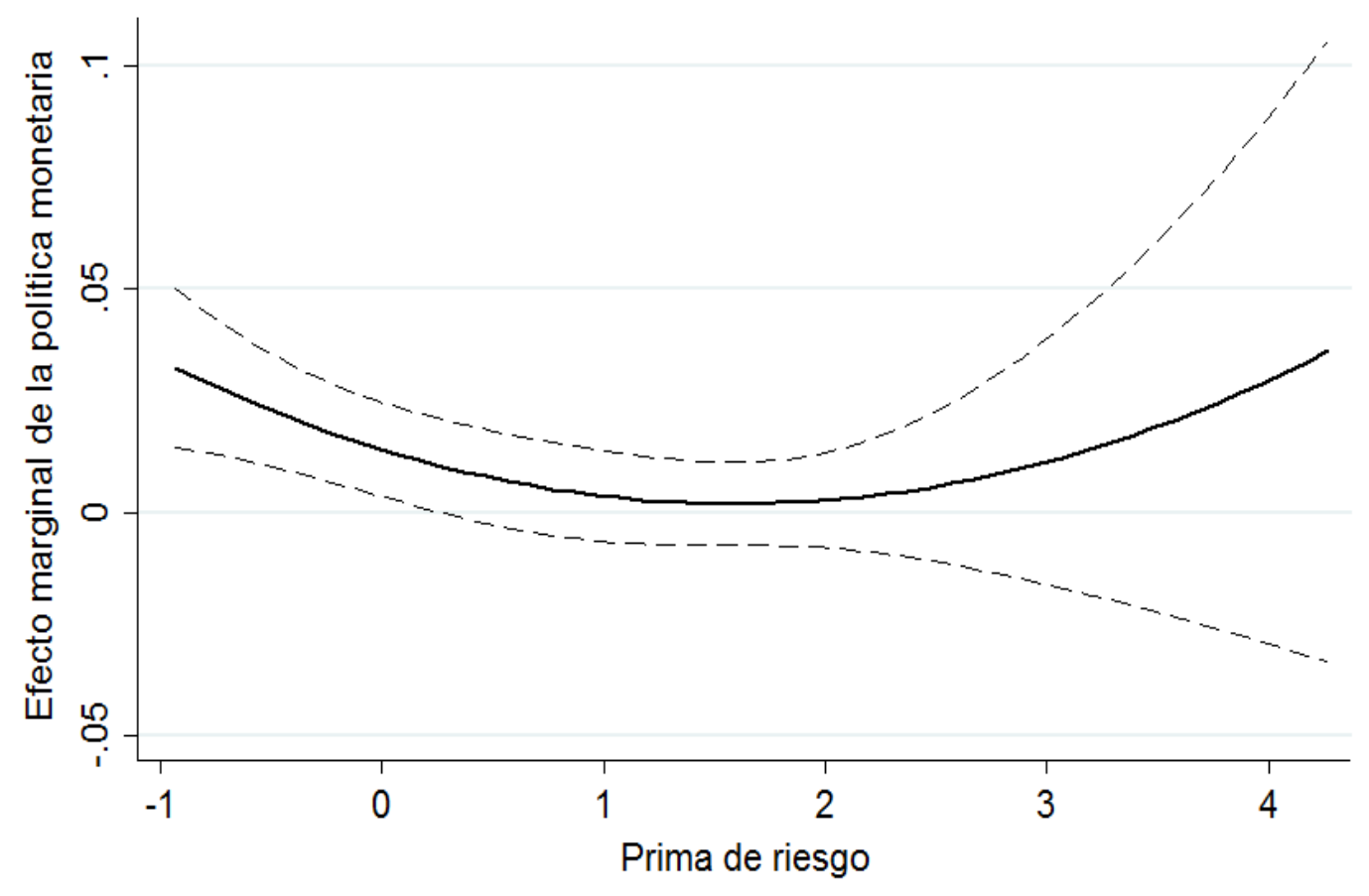

Modelo (d) - Eliminando países intervenidos

Efecto marginal

- - - Intervalo superior de confianza al $90 \%$

- - - Intervalo inferior de confianza al $90 \%$

Por lo que respecta a las variables de control, la variable CCEXT es significativa y positiva, al igual que ocurría en el modelo (c), lo que denota que las empresas que conceden más créditos a su clientela, también demandan más crédito comercial a sus proveedores. 


\subsubsection{3.- Crédito comercial neto}

En el modelo (e) se analiza el crédito comercial neto incluyendo únicamente las variables de control y los indicadores de riesgo soberano $\left(R S\right.$ y $\left.R S^{2}\right)$. En este sentido, la variable de riesgo soberano $(R S)$ es significativa y negativa, mientras que la variable cuadrática $R S^{2}$ no lo es, lo que indica que en los años de crisis un aumento del riesgo soberano origina un descenso del crédito comercial neto. Este resultado es acorde con la hipótesis 3, al igual que el obtenido en el análisis del crédito comercial neto para la muestra que incluye los países intervenidos. Los test de significatividad conjunta $\left(\beta_{1}+\right.$ $\left.\beta_{2}\right)$ y $\left(\beta_{3}+\beta_{4}\right)$ no son significativos, por lo que, al igual que el análisis anterior, el riesgo soberano no ejerce una influencia significativa sobre el crédito comercial neto antes de la crisis.

Atendiendo al modelo (f), la variable cuadrática de riesgo soberano $\left(R S^{2}\right)$ es significativa y negativa, mientras que la variable lineal de riesgo soberano $(R S)$ no es significativa. Al igual que en el modelo (e), este resultado indicaría que durante la crisis un aumento del riesgo soberano conduce a una disminución del crédito comercial neto. No obstante, al ser en este caso significativa la variable cuadrática $\left(R S^{2}\right)$ y no la lineal $(R S)$, los resultados del modelo (f) sugerirían que la relación negativa entre el riesgo soberano y el crédito comercial neto es más intensa a medida que sube la prima de riesgo. Los test de significatividad conjunta $\left(\beta_{1}+\beta_{2}\right)$ y $\left(\beta_{3}+\beta_{4}\right)$ no son significativos, por lo que no existe una relación significativa entre el riesgo soberano y el crédito comercial neto antes de la crisis.

En el modelo (f), el efecto marginal que tiene la política monetaria sobre el crédito comercial neto en función del riesgo soberano, se calcula a través de la ecuación (3.1) de la página 171 y aparece reflejado en la Figura 3.6. En este sentido, existe una relación positiva entre la política monetaria y el crédito comercial neto cuando la prima 
de riesgo es inferior al 3,07\%. A partir de dicho nivel, no existen evidencias en nuestra muestra de países no intervenidos de que el crédito comercial neto se incremente, puesto que el efecto marginal ya no es significativo. Este resultado es similar al obtenido para el análisis del crédito comercial neto que incluye los países intervenidos. Asimismo, este resultado muestra de nuevo evidencias parciales a favor de la hipótesis 4 .

Figura 3.6: Efecto marginal de la política monetaria ( $\Delta$ tipos de interés) sobre el crédito comercial neto

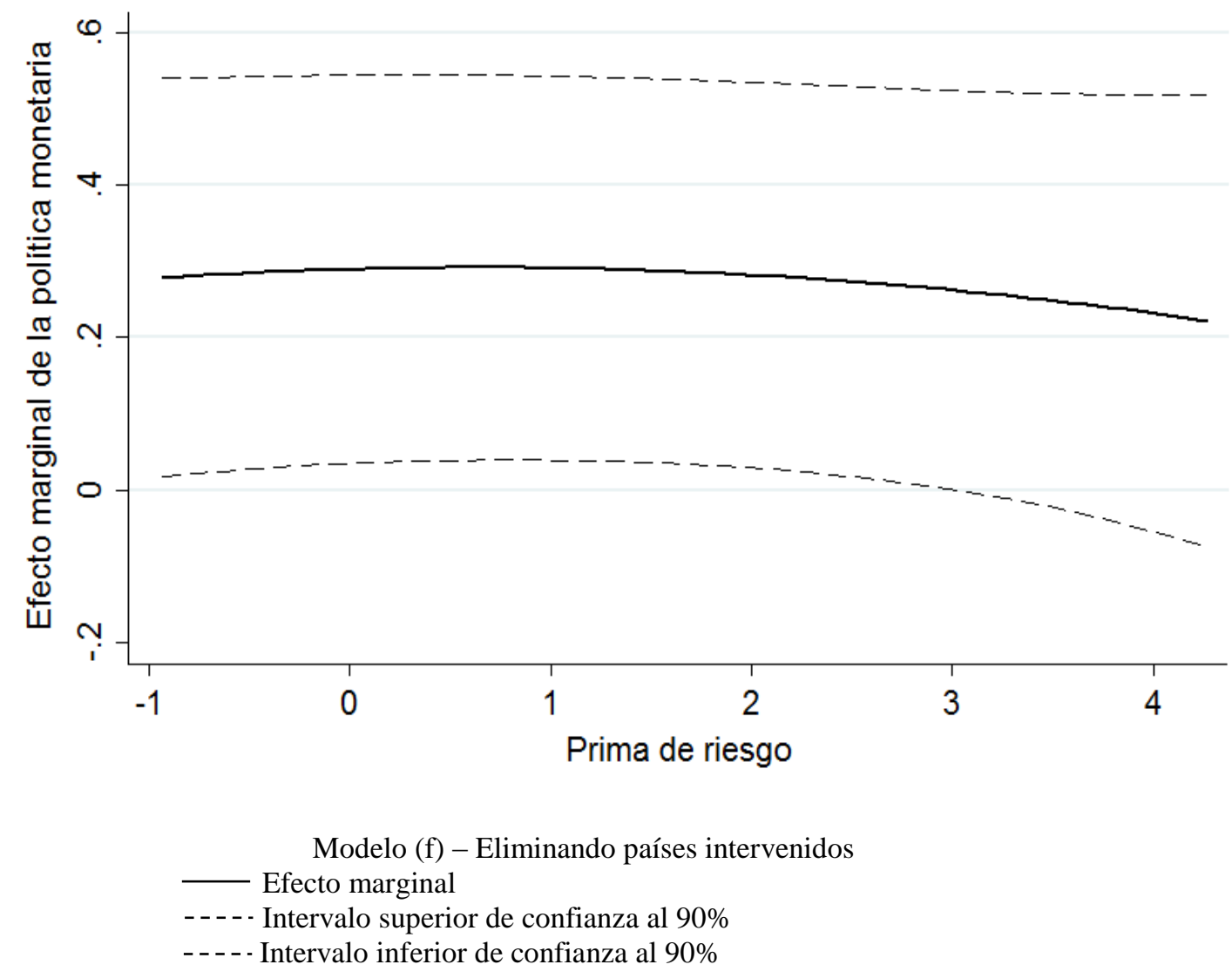

Respecto a las variables de control, la variable $\triangle V E N T A S$ posee un signo negativo y significativo, lo que revela que las empresas con menores tasas de crecimiento de las ventas extienden una mayor cantidad de crédito comercial neto.

En conclusión, del análisis realizado en este capítulo 3 se deriva que un aumento del riesgo soberano conduce a una disminución de los créditos comerciales extendido y 
neto durante la crisis, tal y como proponía la hipótesis 3. Este resultado se puede deber al fuerte incremento de las restricciones financieras, del riesgo de crédito y de la acumulación de liquidez ocasionado por el riesgo soberano, lo que limitaría la propensión de las empresas a conceder créditos a sus clientes. Por otro lado, en los años de crisis el crédito comercial recibido aumenta a medida que se incrementa el riesgo soberano, pero sólo cuando éste es bajo. Sin embargo, cuando el riesgo soberano es elevado, aumentos del mismo conducen a una disminución del crédito comercial obtenido, lo que soportaría parcialmente la hipótesis 3. En cambio, los resultados antes de la crisis para los tres tipos de crédito comercial no son concluyentes.

Por otro lado, una restricción monetaria solamente conduce a un incremento del crédito comercial en países con riesgo soberano bajo, lo que constituye una evidencia parcial a favor de la hipótesis 4. Este resultado puede responder al hecho de que los graves problemas de financiación, ocasionados por un riesgo soberano elevado, han contrarrestado los efectos positivos que, sobre el crédito comercial, tienen las políticas monetarias restrictivas.

La Tabla 3.19 muestra un resumen de los principales resultados obtenidos en el análisis empírico del crédito comercial. 
Tabla 3.19: Resumen de los resultados obtenidos en el análisis del crédito comercial

\begin{tabular}{|c|c|c|}
\hline Variable & Resultados & Hipótesis \\
\hline \multirow{2}{*}{$\begin{array}{l}\text { Crédito comercial } \\
\text { extendido }\end{array}$} & $\begin{array}{l}\text { Un incremento del riesgo soberano produce } \\
\text { un descenso del crédito comercial extendido } \\
\text { durante la crisis. }\end{array}$ & Apoya la hipótesis 3. \\
\hline & $\begin{array}{l}\text { Ante una política monetaria restrictiva, el } \\
\text { crédito comercial extendido sólo aumenta en } \\
\text { países con una prima de riesgo relativamente } \\
\text { baja. }\end{array}$ & $\begin{array}{l}\text { Sustenta parcialmente la } \\
\text { hipótesis } 4 \text {. }\end{array}$ \\
\hline \multirow[t]{2}{*}{$\begin{array}{l}\text { Crédito comercial } \\
\text { recibido }\end{array}$} & $\begin{array}{l}\text { Durante la crisis, el crédito comercial } \\
\text { recibido se incrementa con el nivel de riesgo } \\
\text { soberano cuando éste es bajo o moderado, } \\
\text { mientras que cuando es alto, aumentos del } \\
\text { mismo producen un descenso del crédito } \\
\text { comercial recibido. }\end{array}$ & $\begin{array}{l}\text { Avala la hipótesis } 3 \text { cuando } \\
\text { el riesgo soberano es } \\
\text { elevado solamente. }\end{array}$ \\
\hline & $\begin{array}{l}\text { Durante una restricción monetaria, el crédito } \\
\text { comercial recibido sólo se incrementa en } \\
\text { países con una prima de riesgo baja o } \\
\text { moderada. }\end{array}$ & $\begin{array}{l}\text { Apoya parcialmente la } \\
\text { hipótesis } 4 .\end{array}$ \\
\hline \multirow{2}{*}{$\begin{array}{c}\text { Crédito comercial } \\
\text { neto }\end{array}$} & $\begin{array}{l}\text { Un aumento del riesgo soberano ocasiona un } \\
\text { descenso del crédito comercial neto durante } \\
\text { la crisis. }\end{array}$ & Sustenta la hipótesis 3. \\
\hline & $\begin{array}{l}\text { Una política monetaria restrictiva sólo genera } \\
\text { un aumento del crédito comercial neto en } \\
\text { países con primas de riesgo relativamente } \\
\text { bajas. }\end{array}$ & $\begin{array}{l}\text { Avala parcialmente la } \\
\text { hipótesis } 4 .\end{array}$ \\
\hline
\end{tabular}


CONCLUSIONES 

En este trabajo de investigación se ha estudiado cómo el riesgo soberano afecta al canal de crédito de la política monetaria mediante dos análisis. En el primero se ha examinado cómo el riesgo soberano determina los efectos de la política monetaria sobre el crédito bancario, distinguiendo entre regímenes monetarios contractivos y expansivos. En el segundo se ha estudiado la influencia del riesgo soberano sobre el crédito comercial, directamente y a través de la política monetaria.

La crisis financiera, y el posterior aumento del riesgo soberano, han puesto de manifiesto la especial importancia que tiene el canal de crédito en la transmisión de los impulsos monetarios a la economía real. Por ello, aunque son varios los canales de transmisión de la política monetaria, en este trabajo nos hemos centrado en el canal de crédito a través de dos fuentes de financiación: el crédito bancario y el crédito comercial.

Respecto al crédito bancario, el canal de préstamos bancarios (bank lending channel) sostiene que una restricción monetaria repercute negativamente sobre las condiciones de financiación de las entidades bancarias, a través de los depósitos y la 
financiación vía mercados, lo cual desemboca en una disminución de la oferta crediticia (Bernanke y Blinder, 1988). La intensidad de esta disminución crediticia va a depender de la capacidad que tengan los bancos para acceder a fuentes de financiación, medida en la literatura a través de cuatro indicadores: tamaño, liquidez, capital, riesgo de crédito y concentración bancaria. En este sentido, la mayor parte de los trabajos concluyen que las entidades más pequeñas, ilíquidas, menos capitalizadas, con mayores niveles de riesgo de crédito y presencia en mercados bancarios menos concentrados y más competitivos, son más sensibles a las políticas monetarias restrictivas (Kashyap y Stein, 1995a; 1995b; 2000; Kishan y Opiela, 2000; 2006; Altunbas et al., 2010; Olivero et al., 2011a).

La crisis financiera que comenzó en 2008 ha generado una creciente preocupación por el impacto que el riesgo soberano puede ejercer sobre los bancos, sus balances y su capacidad para proporcionar préstamos. El incremento del riesgo soberano en algunos países de la zona euro tiene un efecto adverso sobre las condiciones de financiación de sus bancos, traduciéndose en una gran reducción de la oferta de crédito (Committee on the Global Financial System, 2011). Asimismo, el empeoramiento de las condiciones de financiación a causa de un mayor riesgo soberano, puede incentivar a los bancos a acumular mayores niveles de liquidez, por cautela, en detrimento de su oferta crediticia (Freixas et al., 1999; Davies y Ng, 2011; Banco Central Europeo, 2012a). Este contexto pone de manifiesto que la capacidad de los bancos para acceder a fuentes de financiación no solo depende de las variables tradicionales (tamaño, liquidez, capital, riesgo de crédito y concentración bancaria), sino también del riesgo soberano de su país de origen, por lo que éste es un factor que va a afectar negativamente a su oferta de préstamos cuando se produzcan variaciones de la política monetaria.

A partir de esta tesis se han propuesto las siguientes hipótesis: 
Hipótesis 1: cuanto mayor es el riesgo soberano, mayor es la reducción de préstamos bancarios originada por una política monetaria restrictiva.

Hipótesis 2: cuanto mayor es el riesgo soberano, menor es el incremento de préstamos bancarios originado por una política monetaria expansiva.

Para el contraste de las hipótesis 1 y 2 se ha utilizado una muestra de 3.028 entidades de crédito de 12 países de la zona euro (UE-11 más Grecia) en el período 1999-2012. Se ha empleado un modelo econométrico en el que se explican los préstamos bancarios a través de una serie de variables de control, la política monetaria, el riesgo soberano y las interacciones entre estos dos últimos. El modelo se estima con la metodología System-GMM de datos de panel dinámicos.

Los resultados del contraste de las hipótesis 1 y 2 indican que, cuando se produce una política monetaria restrictiva, los bancos que operan en países con mayor riesgo soberano reducen su oferta de préstamos en mayor medida, sustentando la hipótesis 1. En cambio, no existen suficientes indicios de que durante políticas monetarias expansivas, los bancos localizados en países con un riesgo soberano superior incrementen su oferta crediticia en menor medida, lo cual no apoyaría la hipótesis 2. Si bien es cierto, que los bancos en países con un riesgo soberano muy alto reducen su oferta de préstamos tanto durante restricciones como expansiones monetarias, posiblemente debido a los fuertes problemas de financiación que soportan y a la intervención que sufrieron.

La efectividad del canal de préstamos bancarios descrito anteriormente va a depender de la existencia de fuentes de financiación alternativas, lo cual ha dado lugar a un nuevo mecanismo de transmisión de la política monetaria denominado canal de crédito comercial (trade credit channel). De acuerdo a este canal, una política monetaria 
restrictiva conduce a un aumento del volumen de crédito comercial para compensar la reducción de préstamos bancarios, ya que las empresas financieramente menos vulnerables transfieren recursos hacia las más débiles en forma de créditos comerciales (Meltzer, 1960; Kohler et al., 2000; Mateut et al., 2006). La disminución de la oferta de préstamos durante la crisis ha obligado a las empresas no financieras a recurrir al crédito comercial como medio de financiación alternativo. Sin embargo, el crédito comercial puede verse negativamente afectado en países con mayor riesgo soberano, debido a que sus empresas soportan graves problemas de financiación y un fuerte incremento de su riesgo de crédito, a la vez que tienden a acumular mayores niveles de efectivo para protegerse de las restricciones financieras, lo cual reduce su capacidad para extender y recibir créditos comerciales (Banco Central Europeo, 2010a; 2012b; Campello et al., 2010; Corsetti et al., 2013; Pianeselli y Zaghini, 2014).

Esta tesis nos ha llevado a proponer las siguientes hipótesis:

Hipótesis 3: un aumento del riesgo soberano provoca una disminución del volumen de crédito comercial.

Hipótesis 4: el incremento del volumen de crédito comercial originado por una política monetaria restrictiva se reduce a medida que aumenta el riesgo soberano.

Para el contraste de las hipótesis 3 y 4 se ha recurrido a una muestra de 17.366 empresas no financieras pertenecientes a 12 países de la zona euro (UE-11 más Grecia) entre 2005 y 2012. Se han tenido en cuenta tres tipos de indicadores para medir el crédito comercial: el crédito comercial extendido, el recibido y el neto (diferencia entre el crédito comercial extendido y recibido). Por ello, se han estimado tres modelos que explican cada indicador de crédito comercial a través de un conjunto de variables de control, la política monetaria, el riesgo soberano y las interacciones entre ambos. Al 
igual que en el contraste de las hipótesis 1 y 2, se ha aplicado la metodología SystemGMM de datos de panel dinámicos.

Los resultados indican que, durante la crisis, un aumento del riesgo soberano conduce a una disminución de los créditos comerciales extendido y neto, lo cual avalaría la hipótesis 3. En cambio, en los años de crisis el crédito comercial recibido aumenta a medida que se incrementa el riesgo soberano cuando éste es bajo o moderado, mientras que desciende cuando éste es alto. Nuevamente, este resultado apoyaría la hipótesis 3, pero solamente cuando el riesgo soberano es elevado. Sin embargo, no existen evidencias concluyentes sobre la relación entre el riesgo soberano y el crédito comercial antes de la crisis. Asimismo, el crédito comercial sólo aumenta ante una restricción monetaria en países con riesgo soberano relativamente bajo, lo cual sería parcialmente acorde con la hipótesis 4. Las empresas que operan en países con riesgo soberano elevado poseen fuertes restricciones financieras y un alto riesgo de impago, y eso ha podido contrarrestar los efectos positivos que, sobre el crédito comercial, tiene una política monetaria restrictiva.

Los resultados obtenidos en esta tesis doctoral muestran que la política monetaria única que existe en Europa desde 1999 no está afectando de la misma manera a todos los países.

En este sentido, el Banco Central Europeo ya parece estar considerando los distintos niveles de riesgo soberano a la hora de adoptar sus decisiones de política monetaria. Así, ya se han llevado a cabo diversas medidas que pueden contribuir a reducir las distorsiones observadas en el proceso de transmisión de la política monetaria. Por un lado, las mayores exigencias de capital y el conjunto de reformas vinculadas a la adopción de Basilea III permitirán que los bancos cuenten con una base 
de recursos mayor para hacer frente a las restricciones de financiación ocasionadas por el riesgo soberano y conseguir una transmisión más fluida y homogénea de la política monetaria. Por otro lado, la reciente Unión Bancaria podría contribuir a romper el vínculo entre los riesgos soberano y bancario y a reducir las divergencias en las condiciones de financiación de los países, al crear un espacio único donde se apliquen las mismas normas a todos los bancos de la zona euro con independencia de su país de origen. Para ello, se articula en torno a tres mecanismos que básicamente consisten en el establecimiento del Banco Central Europeo como supervisor común de todos los bancos de la zona euro, la existencia de un mecanismo común de intervención de las entidades con problemas, financiado mediante un Fondo Único de Resolución Bancaria creado con aportaciones del sector bancario, y, finalmente, la implantación de un sistema de garantía de depósitos común para todos los bancos de la zona euro.

Sin embargo, pese a que la Unión Bancaria es un objetivo sumamente ambicioso que podría ayudar a restablecer una transmisión más adecuada de la política monetaria, aún plantea ciertas incógnitas. La entrada en vigor de algunos de sus mecanismos se está dilatando mucho en el tiempo y puede que el Fondo Único de Resolución Bancaria no cuente con suficientes recursos. Además, la supervisión única del Banco Central Europeo puede todavía generar numerosas interferencias con la consecución de los objetivos de política monetaria, pese a las medidas adoptadas al respecto. 
CONCLUSIONS 

In this research we have studied how sovereign risk affects the credit channel of monetary policy through two analyses. In the first one, we have examined how sovereign risk determines the effects of monetary policy on bank loans during monetary restrictions and expansions. In the second one, we have studied the influence of sovereign risk on trade credit, both directly and through the monetary policy.

The financial crisis and the later increase in sovereign risk have highlighted the special importance of the credit channel in the transmission of monetary impulses to the real economy. Therefore, although there are various monetary policy transmission channels, in this work we have focused on the credit channel through two sources of funding: bank loans and trade credit.

Regarding bank loans, the bank lending channel states that monetary tights have a negative impact on the financing conditions of banks through deposits and market funding, which leads to a decrease in loan supply (Bernanke and Blinder, 1988). The intensity of this loan supply reduction will depend on the ability of banks to access to 
funding sources, which has been measured in the literature through four indicators: size, liquidity, capital, credit risk and banking concentration. In this regard, most studies conclude that smaller, illiquid, less capitalized, higher credit risk banks and those which operate in less concentrated and more competitive banking markets, are more sensitive to monetary restrictions (Kashyap and Stein, 1995a; 1995b; 2000; Kishan and Opiela, 2000; 2006; Altunbas et al., 2010; Olivero et al., 2011a).

The financial crisis that started in 2008 has led to a growing concern about the impact that sovereign risk can have on banks ${ }^{\prime}$ balance sheets and their ability to grant credit. The increase in sovereign risk in some euro zone countries has an adverse effect on the financing conditions of their banks, which leads to a reduction in loan supply (Committee on the Global Financial System, 2011). In addition, the deterioration of funding conditions due to a higher sovereign risk may encourage banks to increase their levels of precautionary liquidity, which will limit their credit supply (Freixas et al., 1999; Davies and Ng, 2011; European Central Bank, 2012a). This context shows that not only does the ability of banks to access to funding sources depend on the traditional variables (size, liquidity, capital, credit risk and market concentration), but also on the sovereign risk of their home country. This factor will negatively affect loan supply when monetary policy varies.

Considering this thesis, we propose the following hypotheses:

Hypothesis 1: the higher the sovereign risk, the greater the reduction in bank loans caused by a restrictive monetary policy.

Hypothesis 2: the higher the sovereign risk, the lower the increase in bank loans caused by an expansionary monetary policy. 
To test the hypothesis 1 and 2, we have used a sample of 3,028 credit institutions from 12 euro zone countries (EU-11 plus Greece) over the period 1999-2012. We have employed an econometric model where bank loans are explained through a set of control variables, monetary policy, sovereign risk and the interactions between both of them. The model is estimated through the System-GMM methodology for dynamic panel data. The results of the hypothesis 1 and 2 indicate that during monetary restrictions banks in countries with higher sovereign risk reduce their loan supply more, which supports hypothesis 1 . However, there is not enough evidence to conclude that during monetary expansions banks in countries with higher sovereign risk increase their credit supply to a lesser extent, which does not support hypothesis 2 . Nevertheless, banks in high sovereign risk countries reduce their loan supply both during monetary contractions and expansions, possibly due to their severe funding problems and the bailout they required.

The effectiveness of the bank lending channel described above will depend on the existence of alternative sources of funding to bank credit, which has led to a new monetary policy transmission mechanism called the trade credit channel. According to this channel, a restrictive monetary policy leads to an increase in the volume of trade credit to offset the reduction in bank loans, since less financially vulnerable firms transfer resources to the weakest ones by extending trade credit (Meltzer, 1960; Kohler et al., 2000; Mateut et al., 2006). The decline in loan supply during the crisis has forced non-financial firms to resort to trade credit as an alternative source of finance. However, trade credit may be adversely affected in countries with higher sovereign risk because firms have serious funding problems, greater credit risk and tend to keep higher levels of precautionary liquidity, which limits their ability to extend and receive trade credit 
(European Central Bank, 2010a; 2012b; Campello et al., 2010; Corsetti et al., 2013; Pianeselli and Zaghini, 2014).

This thesis has led us to propose the following hypotheses:

Hypothesis 3: an increase in sovereign risk leads to a decline of the volume of trade credit.

Hypothesis 4: the increase in the volume of trade credit caused by a monetary restriction declines as sovereign risk rises.

To test the hypotheses 3 and 4, we have used a sample of 17,366 non-financial firms from 12 euro zone countries (EU-11 plus Greece) between 2005 and 2012. We have considered three indicators of trade credit: trade credit supplied, trade credit received and net trade credit (the difference between trade credits supplied and received). Therefore, we have estimated three models where we explain each indicator of trade credit through several control variables, monetary policy, sovereign risk and the interactions between both of them. As in hypotheses 1 and 2, we have estimated the models with the System-GMM methodology for dynamic panel data.

The results indicate that during the crisis an increase in sovereign risk leads to a reduction of trade credit supplied and net trade credit, which supports hypothesis 3 . However, during the crisis trade credit received increases with the level of sovereign risk when it is low and moderate, but when it is high, an increase in sovereign risk causes a reduction in trade credit received. Again, this result supports hypothesis 3 , but only when sovereign risk is high. Nevertheless, there is no conclusive evidence about the relationship between sovereign risk and trade credit before the crisis. Additionally, trade credit only increases in countries with relatively low sovereign risk following a 
tight monetary policy, which is partially consistent with hypothesis 4. Firms which operate in countries with high sovereign risk have strong financial constraints and a higher risk of default, and this may outweigh the positive effects that monetary restrictions have on trade credit.

The results of this thesis show that the single monetary policy which exists in Europe since 1999 is not affecting all the countries equally.

In this regards, it seems that the European Central Bank is already considering the sovereign risk differences between countries when adopting its monetary policy decisions. Therefore, several measures have already taken which may help to reduce the distortions in the monetary policy transmission process. On the one hand, higher capital requirements and the set of reforms linked to the adoption of Basel III will allow banks to have a larger base of resources to address funding constraints caused by sovereign risk and will ensure a smooth and more homogenous monetary policy transmission. On the other hand, the recent Banking Union would contribute to break the link between sovereign and banking risks and reduce disparities in countries' funding conditions, by creating a unique space where the same rules will be applied to all banks, regardless of their country of origin. To achieve this, it has three mechanisms that basically consist of the establishment of the European Central Bank as a single supervisor for all banks in the euro zone, the existence of a single resolution mechanism for failing banks funded with a Single Fund Banking Resolution, which is created with funds from the banking sector and, finally, a common system of deposit protection for all banks in the euro zone.

However, although the Banking Union is an extremely ambitious goal that might help to restablish a better monetary policy transmission, it still presents some doubts. 
The entry into force of some of its mechanisms is taking a long time and the Single Bank Resolution Fund may not have enough resources. Furthermore, the single supervision by the European Central Bank can still generate numerous interferences with the achievement of monetary policy objectives, despite the measures taken. 


\section{BIBLIOGRAFÍA}



Acharya, V.V., Almeida, H. y Campello, M. (2013): Aggregate risk and the choice between cash and lines of credit. The Journal of Finance, 68 (5), 2059-2116.

Acharya, V.V. y Merrouche, O. (2013): Precautionary hoarding of liquidity and interbank markets: evidence from the sup-prime crisis. Review of Finance, 17, 107160.

Acharya, V.V., Shin, H.S. y Yorulmazer, T. (2011): Crisis resolution and bank liquidity. Review of Financial studies, 24 (6), 2166-2205.

Acharya, V.V. y Skeie, D. (2011): A model of liquidity hoarding and term premia in inter-bank markets. Journal of Monetary Economics, 58 (5), 436-447.

Adams, R.M. y Amel, D.F. (2005): The effects of local banking market structure on the bank lending channel of monetary policy. Finance and Economics Discussion Series 2005-16, Board of Governors of the Federal Reserve System.

Adams, R.M. y Amel, D.F. (2011): Market structure and the pass-through of the federal funds rate. Journal of Banking and Finance, 35 (5), 1087-1096.

Adelino, M. and Ferreira, M.A. (2014): Sovereign Rating Downgrades and Bank Lending Supply. SSRN. http://ssrn.com/abstract=2376721

Agca, S. y Celasun, O. (2012): Sovereign debt and corporate borrowing costs in emerging markets. Journal of International Economics, 88 (1), 198-208.

Agostino, M. y Trivieri, F. (2014): Does trade credit play a signaling role? Some evidence from SMEs microdata. Small Business Economics, 42 (1), 131-151.

Aiken, L.S. y West, S.G. (1991): Multiple regression: Testing and interpreting interactions. Sage Publications, Incorporated. 
Akbar, S., Rehman, S. y Ormrod, P. (2013): The impact of recent financial shocks on the financing and investment policies of UK private firms. International Review of Financial Analysis, 26, 59-70.

Albertazzi, U., Ropele, T., Sene, G. y Signoretti, F.M. (2014): The impact of the sovereign debt crisis on the activity of Italian banks. Journal of Banking and Finance, 46, 387-402.

Alesina, A. (1988): Macroeconomics and politics. En Fischer, S. (Eds.), NBER Macroeconomics Annual, Cambridge, Mass.: MIT Press, 17-52.

Alesina, A. y Summers, L.H. (1993): Central Bank Independence and macroeconomic performance: some comparative evidence. Journal of Money, Credit and Banking, $25(2), 151-162$.

Allen, W.A. y Moessner, R. (2012): The liquidity consequences of the euro area sovereign debt crisis. BIS Working Papers, (No 390).

Almeida, H., Campello, M. y Weisbach, M.S. (2004): The cash flow sensitivity of cash. The Journal of Finance, 59 (4), 1777-1804.

Alonso-Borrego, C. y Arellano, M. (1996): Symmetrically normalised instrumental

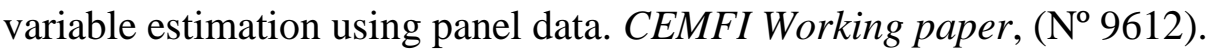

Alphonse, P., Ducret, J. y Séverin, E. (2006): When trade credit facilitates access to bank finance: evidence from US small business data. Mimeograph, University of Lille 2. 
Alsakka, R., ap Gwilym, O. y Vu, T.N. (2014): The sovereign-bank rating channel and rating agencies' downgrades during the European debt crisis. Journal of International Money and Finance, 49, 235-257.

Alter, A. y Schüler, Y.S. (2012): Credit spread interdependencies of European states and banks during the financial crisis. Journal of Banking and Finance, 36 (12), 3444-3468.

Altunbas, Y., Fazylov, O. y Molyneux, P. (2002): Evidence on the bank lending channel in Europe. Journal of Banking and Finance, 26 (11), 2093-2110.

Altunbas, Y., Gambacorta, L. y Marques-Ibanez, D. (2009): Securitisation and the bank lending channel. European Economic Review, 53 (8), 996-1009.

Altunbas, Y., Gambacorta, L. y Marques-Ibanez, D. (2010): Bank risk and monetary policy. Journal of Financial Stability, 6 (3), 121-129.

Amidu, M. y Wolfe, S. (2013): The effect of banking market structure on the lending channel: Evidence from emerging markets. Review of Financial Economics, 22 (4), 146-157.

Anari, A., Kolari, J., Pynnönen, S. y Suvanto, A. (2002): Further evidence on the credit view: the case of Finland. Applied Economics, 34 (3), 267-278.

Angeloni, I., Buttiglione, L., Ferri, G. y Gaiotti, E. (1995): The credit channel of monetary policy across heterogeneous banks: the case of Italy. Banca d'Italia Temi di discussione, $\left(\mathrm{N}^{\circ} 256\right)$.

Angeloni, I., Kashyap, A. y Mojon, B. (2003): Monetary policy transmission in the Euro area, Cambridge University Press, Cambridge. 
Arellano, M. y Bond, S. (1991): Some tests of specification for panel data: Monte Carlo evidence and an application to employment equations. Review of Economic Studies, 58 (2), 277-297.

Arellano, M. y Bover, O. (1990): La econometría de datos de panel. Investigaciones Económicas (Segunda época), 14 (1), 3-45.

Arellano, M. y Bover, O. (1995): Another look at the instrumental-variable estimation of error-components models. Journal of Econometrics, 68, 29-52.

Arena, M., Reinhart, C. y Vazquez, F. (2007): The lending channel in emerging economies: Are foreign banks different?. IMF Working Paper, ( $\mathrm{N}^{\mathrm{o}}$ 07/48).

Arezki, R., Candelon, B. y Sy, A. (2011): Sovereign rating news and financial markets spillovers: evidence from the European debt crisis. International Monetary Fund Working Paper, ( $\left.\mathrm{N}^{\mathrm{o}} 68\right)$.

Arnold, I.J.M. (2012): Sovereign debt exposures and banking risks in the current EU financial crisis. Journal of Policy Modeling, 34, 906-920.

Arnone, M. y Romelli, D. (2013): Dynamic central bank Independence indices and inflation rate: A new empirical exploration. Journal of Financial Stability, 9 (3), 385-398.

Arnott, R. y Stiglitz, J.E. (1991): Moral hazard and nonmarket institutions: dysfunctional crowding out or peer monitoring?. The American Economic Review, $81(1), 179-190$.

Arteta, C. y Hale, G. (2008): Sovereign debt crises and credit to the private sector. Journal of International Economics, 74 (1), 53-69. 
Ashcraft, A.B. (2006): New evidence on the lending channel. Journal of Money, Credit and Banking, 38 (3), 751-775.

Atanasova, C.V. y Wilson, N. (2003): Bank borrowing constraints and the demand for trade credit: evidence from panel data. Managerial and Decision Economics, 24, 503-514.

Babihuga, R. y Spaltro, M. (2014): Bank funding costs for international banks. International Monetary Fund, ( $\left.\mathrm{N}^{\mathrm{o}} 14-71\right)$.

Bagliano, A., Favero, C. (1995): The credit channel of monetary transmission. The case of Italy. Mimeo, Università Cattolica del Sacro Cuore, Milano.

Banco Central Europeo (2008): Informe Anual. European Central Bank, Eurosystem.

Banco Central Europeo (2009): Informe Anual. European Central Bank, Eurosystem.

Banco Central Europeo (2010a): Financial stability review. European Central Bank, Eurosystem, Junio 2010.

Banco Central Europeo (2010b): Informe Anual. European Central Bank, Eurosystem.

Banco Central Europeo (2011a): La política monetaria del BCE. European Central Bank, Eurosystem, Mayo 2011.

Banco Central Europeo (2011b): Informe Anual. European Central Bank, Eurosystem.

Banco Central Europeo (2012a): Financial integration in Europe. European Central Bank, Eurosystem, Abril 2012. 
Banco Central Europeo (2012b): Evaluación de las condiciones de financiación del sector privado de la zona del euro durante la crisis de la deuda soberana. European Central Bank, Eurosystem, Agosto 2012.

Banco Central Europeo (2012c): Informe Anual. European Central Bank, Eurosystem.

Banco Central Europeo (2013): Informe Anual. European Central Bank, Eurosystem.

Banco de España (2014): La construcción de la Unión Bancaria en la UE. Boletín Económico, Noviembre 2014.

Barran, F., Coudert, V. y Mojon, B. (1995): Transmission de la politique monétaire et crédit bancaire. Une application à trois pays de 1' OCDE. En Révue économique, $46(2), 393-413$.

Barth, J.R., Prabha, A.P. y Yun, G. (2012): The Eurozone financial crisis: Role of interdependencies between bank and sovereign risk. Journal of Financial Economic Policy, 4 (1), 76-97.

Bastos, R. y Pindado, J. (2013): Trade credit during a financial crisis: A panel data analysis. Journal of Business Research, 66, 614-620.

Battaglia, F. y Gallo, A. (2013): Securitization and systemic risk: an empirical investigation on Italian banks over the financial crisis. International Review of Financial Analysis, 30, 274-286.

Baum, C., Caglayan, M. y Ozkan, N. (2013): The role of uncertainty in the transmission of monetary policy effects on bank lending. The Manchester School, 81 (2), 202225. 
Bedendo, M. y Colla, P. (2013): Sovereign and corporate credit risk: Spillover effects in the Eurozone. CEPR Working paper.

Bellando, R. y Pollin, J.P. (1996): Le canal du crédit en France depuis la déréglementation financière. Revue Économique, 47, 731-743.

Benmelech, E., y Bergman, N.K. (2012): Credit traps. American Economic Review, 102 (6), 3004-3032.

Berben, R., Locarno, A., Morgan, J. y Vallés, J. (2004): Cross country differences in monetary policy transmission. ECB Working Paper, ( $\left.\mathrm{N}^{\mathrm{o}} 400\right)$.

Berganza, J.C., Hernando, I. y Vallés, J. (2014): Los desafíos para la política monetaria en las economías avanzadas tras la gran recesión. Documento Ocasional Banco de España, ( $\left.{ }^{\circ} 1404\right)$.

Berger, A.N. y Udell, G.F. (1995): Relationship lending and lines of credit in small firm finance. Journal of Business, 351-381.

Bernanke, B.S. (1983): Nonmonetary effects of the financial crisis in the propagation of the great depression. American Economic Review, 73 (2), 257-276.

Bernanke, B.S. (1986): Alternative explanations of the money-income correlation. Carnegie-Rochester Conference Series on Public Policy, 25, 49-100.

Bernanke, B.S. (2007): The financial accelerator and the credit channel. En Remarks at a Conference at the Federal Reserve Bank of Atlanta.

Bernanke, B.S. y Blinder, A.S. (1988): Credit, money and aggregate demand. The American Economic Review, 78 (2), 435-439. 
Bernanke, B.S. y Blinder, A.S. (1992): The federal funds rate and the channels of monetary transmission, The American Economic Review, 901-921.

Bernanke, B.S. y Gertler, M. (1995): Inside the black box: the credit channel of monetary policy transmission. Journal of Economic Perspectives, 9 (4), 27-48.

Bernoth, K. y Wolff, G.B. (2008): Fool the markets? Creative accounting, fiscal transparency and sovereign risk premia.Scottish Journal of Political Economy, 55 (4), 465-487.

Bernoth, K., Von Hagen, J. y Schuknecht, L. (2012): Sovereign risk premiums in the European government bond market. Journal of International Money and Finance, $31(5), 975-995$.

Bessler, W. y Kurmann, P. (2014): Bank risk factors and changing risk exposures: Capital market evidence before and during the financial crisis. Journal of Financial Stability, 13, 151-166.

Biais, B. y Gollier, C. (1997): Trade credit and credit rationing. The Review of Financial Studies, 10 (4), 903-937.

Blum, J.M. (2002): Subordinated debt, market discipline and banks' risk taking. Journal of Banking and Finance, 26 (7), 1427-1441.

Blundell, R. y Bond, S. (1998): Initial conditions and moment restrictions in dynamic panel data models. Journal of Econometrics, 87 (1), 115-143.

Bofondi, M., Carpinelli, L. y Sette, E. (2013): Credit supply during a sovereign crisis. Bank of Italy Working Paper, $\mathrm{N}^{\circ} 909$. 
Bogoev, J. (2010): Banks' risk preferences and their impact on the loan supply function: Empirical investigation for the case of the Republic of Macedonia. Economic Policy and Economic Trends, 20 (124), 63-109.

Boissay, F. (2006): Credit chains and the propagation of financial distress. European Central Bank Working Paper Series, 573. European Central Bank, Frankfurt.

Boivin, J., Kiley, M.T. y Mishkin, F.S. (2010): How has the monetary transmission evolved over time?. National Bureau of Economic Research, ( $\mathrm{N}^{\mathrm{o}}$ w15879).

Borensztein, E., Cowan, K. y Valenzuela, P. (2013): The sovereign ceiling lite and bank credit ratings in emerging markets economies. Journal of Banking and Finance, 37 (11), 4014-4024.

Bougheas, S., Mateut, S. y Mizen, P. (2009): Corporate trade credit and inventories: New evidence of a trade-off from accounts payable and receivable. Journal of Banking and Finance, 33 (2), 300-307.

Bouvatier, V. y Lepetit, L. (2008): Banks’ procyclical behavior: does provisioning matter? Journal of International Financial Markets, Institutions and Money, 18 (5), 513-526.

Brechling, F. P. R. y Lipsey, R.G. (1963): Trade credit and monetary policy. The Economic Journal, 73 (292), 618-641.

Brennan, M.J., Maksimovic, V. y Zechner, J. (1988): Vendor financing. TheJournal of Finance, 43 (5), 1127-1141.

Breton, R., Pinto, C. y Weber, P.F. (2012): Banks, moral hazard and public debts. Financial Stability Review, 16, 57-70. 
Brissimis, S.N. y Delis, M.D. (2009): Identification of a loan supply function: A crosscountry test for the existence of a bank lending channel. Journal of International Financial Markets, Institutions and Money, 19 (2), 321-335.

Brissimis, S.N., Delis, M. y Iosifidi, M. (2012): Bank market power and monetary policy transmission. MPRA Paper 49206, University Library of Munich.

Brissimis, S.N., Kamberoglou, N.C. y Simigiannis, G.T. (2001): Is there a bank lending channel of monetary policy in Greece? Evidence from bank level data. ECB Working Paper Series, ( $\left.{ }^{\circ} 104\right)$.

Brissimis, S.N. y Magginas, N.S. (2005): Changes in financial structure and asset price substitutability: A test of the bank lending channel. Economic Modelling, 22 (5), 879-904.

Brockman, P. y Unlu, E. (2009): Dividend policy, creditor rights, and the agency costs of debt. Journal of Financial Economics, 92, 276-299.

Broner, F., Erce, A., Martin, A. y Ventura, J. (2014): Sovereign debt markets in turbulent times: Creditor discrimination and crowding-out effects. Journal of Monetary Economics, 61, 114-142.

Broner, F., Lorenzoni, G. y Schmukler, S.L. (2013): Why do emerging economies borrow short term? Journal of the European Economic Association, 11 (s1), 67100.

Brooke, J. y Oliver, B. (2005): The source of abnormal returns from strategic alliance announcements. Pacific-Basin Finance Journal, 13, 145-161. 
Brooks, R., Faff, R.W., Hillier, D. y Hillier, J. (2004): The national market impact of sovereign rating changes. Journal of Banking and Finance, 28 (1), 233-250.

Brown, C. y Dinc, I. (2011): Too many to fail? Evidence of regulatory forbearance when the banking sector is weak. Review of Financial Studies, 24 (4), 1378-1405.

Brunner, K. y Meltzer, A.H. (1963): The place of financial intermediaries in the transmission of monetary policy. American Economic Review, 53 (2), 372-382.

Brunnermeier, M.K. y Oehmke, M. (2012): Bubbles, financial crises and systemic risk. National Bureau of Economic Research, ( ${ }^{\circ}$ w18398).

Buiter, W.H. (1977): 'Crowding out' and the effectiveness of fiscal policy. Journal of Public Economics, 7 (3), 309-328.

Burkart, M. y Ellingsen, T. (2004): In-Kind finance: A theory of trade credit. The American Economic Review, 94 (3), 569-590.

Buttiglione, L.y Ferri, G. (1994): Monetary policy transmission via lending rates in Italy: Any lessons from recent experience?. Banca d'Italia Temi di Discussione, $\left(\mathrm{N}^{\mathrm{o}} 224\right)$.

Cáceres, C., Guzzo, V. y Segoviano, M. (2010): Sovereign Spreads: Global risk aversion, contagion or fundamentals?. International Monetary Fund Working Paper 10/120.

Cai, G.G., Chen, X. y Xiao, Z. (2014): The roles of bank and trade credits: Theoretical analysis and empirical evidence. Production and Operations Management, 23 (4), 583-598. 
Calomiris, C.W., Himmelberg, C.P. y Wachtel, P. (1995): Commercial paper, corporate finance, and the business cycle: a microeconomic perspective. En CarnegieRochester Conference Series on Public Policy, 42, 203-250.

Campello, M. (2002): Internal capital markets in financial conglomerates: Evidence from small bank responses to monetary policy. The Journal of Finance, 57 (6), 2773-2805.

Campello, M., Graham, J.R. y Harvey, C.R. (2010): The real effects of financial constraints: Evidence from a financial crisis. Journal of Financial Economics, 97 (3), 470-487.

Cantor, R. y Packer, F. (1996): Determinants and impact of sovereign credit ratings. Economic Policy Review, 2 (2), 37-53.

Cappiello, L., Kadareja, A., Kok Sorensen, C. y Protopapa, M. (2010): Do bank loans and credit standards have an effect on output? A panel approach for the euro area. ECB Working Paper Series ( No 1150), Enero 2010.

Carbó-Valverde, S., Rodríguez-Fernández, F y Udell, G.F. (2012): Trade credit, the financial crisis, and firm access to finance. En Central Bank of Ireland Conference on the SME Lending Market, (2).

Casey, E. y O’Toole, C.M. (2014): Bank lending constraints, trade credit and alternative financing during the financial crisis: Evidence from European SMEs. Journal of Corporate Finance, 27, 173-193.

Cavallo, E.A. y Valenzuela, P. (2010): The determinants of corporate risk in emerging markets: an option-adjusted spread analysis. International Journal of Finance and Economics, 15 (1), 59-74. 
Cecchetti, S.G. (1999): Legal structure, financial structure, and the monetary policy transmission mechanism. Federal Reserve Bank of New York Economic Policy Review, 5, 9-28.

Cetorelli, N. y Goldberg, L.S. (2012): Banking globalization and monetary transmission. The Journal of Finance, 67 (5), 1811-1843.

Chan-Lau, J.A., Liu, E.X. y Schmittmann, J.M. (2014): Equity returns in the banking sector in the wake of the Great Recession and the European sovereign debt crisis. Journal of Financial Stability, In Press.

Chatelain, J.B., Ehrmann, M., Generale, A., Martínez-Pagés, J., Vermeulen, P. y Worms, A. (2003): Monetary policy transmission in the euro área: New evidence from micro data on small firms and banks. Journal of the European Economic Association, 1 (2-3), 731-742.

Chee, K., Smith, J. y Smith, R. (1999): Evidence on the determinants of credit terms used in interfirm trade. The Journal of Finance, 54 (3), 1109-1129.

Chen, F., Zhong, F. y Chen, Y. (2008): Outward foreign direct investment and sovereign risks in developing host country. Economic Modelling, 41, 166-172.

Chiades, P. y Gambacorta, L. (2000): The Bernanke and Blinder model in an open economy: The Italian case. German Economic Review, 5 (1), 1-34.

Chmielewski, T. (2006): Bank risks, risk preferences and lending, MPRA Paper, $\left(\mathrm{N}^{\mathrm{o}}\right.$ 5131), Munich: Munich Personal RePEc Archive. 
Choi, W.G. y Kim, Y. (2005): Trade credit and the effect of macro-financial shocks: evidence from US panel data, Journal of Financial and Quantitative Analysis, 40, 897-925.

Chrystal, A. y Mizen, P. (2002): Modelling credit in the transmission mechanism of the United Kingdom. Journal of Banking and Finance, 26, 2131-2154.

Ciccarelli, M., Maddaloni, A. y Peydro, J.L. (2014): Trusting the bankers: A new look at the credit channel of monetary policy. Review of Economic Dynamics (In Press).

Codogno, L., Favero, C. y Missale, A. (2003): Yield spreads on EMU Government Bonds. Economic Policy, 18 (37), 503-532.

Committee on the Global Financial System (2011): The impact of sovereign credit risk on bank funding conditions. CGFS Papers, (N. 43), Julio 2011.

Correa, R., Lee, H., Sapriza, H. y Suárez, G. (2012): Sovereign credit risk, banks`' government support, and bank stock returns around the world. Board of Governors of the Federal Reserve System.International Finance Discussion Papers, ( $\mathrm{N}^{\mathrm{o}}$ 1069).

Corsetti, G., Kuester, K., Meier, A. y Müller, G.J. (2013): Sovereign risk, fiscal policy, and macroeconomic stability. The Economic Journal, 123 (566), 99-132.

Coulibaly, B., Sapriza, H. y Zlate, A. (2013): Financial frictions, trade credit and the 2008-09 global financial crisis. International Review of Economics and Finance, $26,25-38$. 
Creel, J. y Levasseur, S. (2006): Canaux de transmission de la politique monétaire dans 1`UE: le cas de trois nouveaux entrants. Révue économique, 57 (4), 881-898.

Cuñat-Martínez, V. (2007): Trade credit: suppliers as debt collectors and insurance providers. Review of Financial Studies, 20 (2), 491-527.

Cuñat-Martínez, V. y García-Appendini, E. (2012): Trade credit and its role in entrepreneurial finance. En Cumming, D. (Ed.): Oxford Handbook of Entrepeneurial Finance, Oxford University Press, New York, 526-557.

Cunningham, R. (2005): Trade credit and credit rationing in Canadian firms. Economic Analysis (EA) Research Paper Series, № 036.

Dale, S. y Haldane, A.G. (1993a): Bank behavior and the monetary transmission mechanism. Bank of England Quarterly Bulletin, ( $\left.\mathrm{N}^{\mathrm{o}} 33\right)$.

Dale, S. y Haldane, A.G. (1993b): Interest rate control in a model of monetary policy. Bank of England Working Paper Series, ( $\left.\mathrm{N}^{\circ} 17\right)$.

Dale, S. y Haldane, A.G. (1995): Interest rates and the channels of monetary transmission: some sectoral estimates. European Economic Review, 39 (9), 16111626.

Danielson, M. y Scott, J. (2000): Additional evidence on the use of trade credit by small firms: the role of trade credit discounts. Temple University Working Paper.

Dave, C., Dressler, S.J. y Zhang, L. (2013): The bank lending channel: a FAVAR analysis. Journal of Money, Credit and Banking, 45 (8), 1705-1720.

Davies, M. y Ng, T. (2011): The rise of sovereign credit risk: implications for financial stability. BIS Quarterly Review, 59-70. 
De Blasio, G. (2005): Does trade credit substitute bank credit? Evidence from firm-level data. Economic notes, 34 (1), 85-112.

De Bondt, G.J. (1999a): Banks and monetary transmission in Europe: empirical evidence. Banca Nazionale del Lavoro Quarterly Review, 52 (209), 149-168.

De Bondt (1999b): Credit channels in Europe: a cross-country investigation. Banca Nazionale del Lavoro Quarterly Review, 52 (210), 295-326.

De Bruyckere, V., Gerhardt, M., Schepens, G. y Vander Vennet, R. (2013): Bank/sovereign risk spillovers in the European debt crisis. Journal of Banking and Finance, 37 (12), 4793-4809.

De Haan, L. (2003): Microdata evidence on the bank lending channel in the Netherlands. De Economist, 151 (3), 293-315.

De Marco, F. (2013): Bank lending and the sovereign debt crisis. Boston College Working Paper.

De Santis, R.A. y Surico, P. (2013): Bank lending and monetary transmission in the euro area. Economic Policy, 28 (75), 423-457.

Del Giovane, P., Nobili, A. y Signoretti, F.M. (2013): Supply tightening or lack of demand? An analysis of credit developments during the Lehman Brothers and the sovereign debt crisis. Bank of Italy Working Paper Series, ( $\mathrm{N}^{\circ}$ 942).

Deloof, M. y Jegers, M. (1996): Trade credit, product quality, and intragroup trade: some European evidence, Financial Management, 25, 33-43. 
Demirgüç-Kunt, A. y Huizinga, H. (2013): Are banks too big to fail or too big to save? International evidence from equity prices and CDS spreads. Journal of Banking and Finance, 37 (3), 875-894.

Díaz, A., Groba, J. y Serrano, P. (2013): What drives corporate default risk premia? Evidence from the CDS market. Journal of International Money and Finance, 37, $529-563$.

Disyatat, P. (2011): The bank lending channel revisited. Journal of Money, Credit and Banking, 43 (4), 711-734.

Douglas, W. (1996): Monetary policy and bank portfolios. Journal of Economics and Business, 48 (4), 315-335.

Driscoll, J.C. (2004): Does bank lending affect output? Evidence from the US states. Journal of Monetary Economics, 51 (3), 451-471.

Duca, J. (1986): Trade credit and credit rationing: a theoretical model. Board of Governors of the Federal Reserve System, ( $\left.{ }^{\circ} 94\right)$.

Durbin, E. y Ng., D. (2005): The sovereign ceiling and emerging market corporate bond spreads. Journal of International Money and Finance, 24 (4), 631-649.

Ehrmann, M., Gambacorta, L., Martínez-Pagés, J., Sevestre, P. y Worms, A. (2003): Financial systems and the role of banks in monetary policy transmission in the Euro Area. En: Angeloni, I., Kashyap, A., Mojon, B. (Eds.), Monetary policy transmission in the Euro Area. Cambridge University Press, Cambridge, 235-269.

Eichengreen, B. y Moody, A. (2000): What explains changing spreads on emerging market debt?. En: Edwards, S. (Ed.), Capital flows and the emerging economies: 
Theory, evidence, and controversies. Chicago, IL, USA: University of Chicago Press, 107-136.

Emery, G.W. (1984): A pure financial explanation for trade credit. Journal of Financial and Quantitative Analysis, 19 (3), 271-285.

Escrivá, J.L. y Haldane, A.G. (1994): The interest rate transmission mechanism: sectoral estimates for Spain. Banco de España, Servicio de Estudios, Documento de Trabajo, 9414, Madrid.

Fabbri, D. y Klapper, L. (2008): Market power and the matching of trade credit terms. Policy Research Working Paper (The World Bank), 4754.

Fackler, J.S. y Rogers, J.H. (1993): An empirical open-economy macro model with credit. Journal of Macroeconomics, 15 (2), 203-224.

Fanelli, L. y Paruolo, P. (1999): New evidence on the transmission mechanisms of monetary policy in Italy before Stage III of European Monetary Union. Mimeo, Università di Bologna.

Farinha, L. y Marques, C. (2001): The bank lending channel of monetary policy: Identification and estimation using Portuguese micro bank data. ECB Working Paper Series, ( $\left.{ }^{\circ} 102\right)$.

Faulkender, M. y Wang, R. (2006): Corporate financial policy and the value of cash. The Journal of Finance, 61 (4), 1957-1990.

Favero, C.A., Giavazzi, F. y Flabbi, L. (1999): The transmission mechanism of monetary policy in Europe: evidence from banks’ balance sheets. National Bureau of Economic Research, ( ${ }^{\circ}$ w7231). 
Favero, C.A., Pagano, M. y Von Thadenn, E.L. (2010): How does liquidity affect government bond yields?. Journal of Financial and Quantitative Analysis, 45, 107-134.

Ferrando, A. y Mulier, K. (2013): Do firms use the trade credit cannel to manage growth? Journal of Banking and Finance, 37 (8), 3035-3046.

Ferreira, M.A. y Gama, P.M. (2007): Does sovereign debt ratings news spill over to international stock markets?. Journal of Banking and Finance, 31 (10), 31623182.

Ferri, G., Kalmi, P. y Kerola, E. (2014): Does bank ownership affect bank lending behavior? Evidence from the Euro area. Journal of Banking and Finance, 48, 194209.

Ferri, G., Liu, L.G. y Majnoni, G. (2001): The role of rating agency assessments in less developed countries: Impact of the proposed Basel guidelines. Journal of Banking and Finance, 25 (1), 115-148.

Ferris, J.S. (1981): A transactions theory of trade credit use. Quarterly Journal of Economics, 94 (2), 243-270.

Fishman, R. y Love, I. (2003): Trade credit, financial intermediary development and industry growth. The Journal of Finance, 58 (1), 353-374.

Fostel, A. y Kaminsky, G.L. (2007): Latin America's acess to international capital markets: Good behavior or global liquidity?. NBER Working Paper, 13194.

Frank, M.Z. y Maksimovic, V. (2005): Trade credit, collateral, and adverse selection. University of Maryland. 
Frankel, J.A. (1986): International capital mobility and crowding-out in the US economy: Imperfect integration of financial markets or of goods markets?. En Hafer, R.W. (Ed.), How open is the US economy? Lexington, Mass: Heath.

Freixas, X. (1993): Short term credit versus account receivable financing. Universitat Pompeu Fabra, Economic Working Paper 27.

Freixas, X., Giannini, G., Hoggarth, G. y Soussa, F. (1999): Lender of the last resort: A review of the literature. Financial Stability Review, 7, 151-167.

Frey, B.S. y Oberholzer-Gee, F. (1997): The cost of price incentives: an empirical analysis of motivation crowding-out. The American Economic Review, 87 (4), 746-755.

Friedman, B.M. y Kuttner, K.N. (1993): Economic activity and the short-term credit markets: an analysis of prices and quantities. Brookings Papers on Economic Activity, 2, 193-283.

Fukuda, S.I., Kasuya, M. y Akashi, K. (2006): The role of trade credit for small firms: An implication from Japan's banking crisis. The University of Tokyo: CIRJE Discussion Papers Series.

Fungácová, Z., Solanko, L. y Weill, L. (2014): Does competition influence the bank lending channel in the euro area?. Journal of Banking and Finance, 49, 356-366.

Gama, A.P.M. y Mateus, C. (2010): Does trade credit facilitate access to bank finance? An empirical evidence from Portuguese and Spanish small medium size enterprises. International Research Journal of Finance and Economics, 45, 26-45. 
Gama, M., Paula, A. y Van Auken, H. (2014): The interdependence between trade credit and bank lending: Commitment in Intermediary Firm Relationships. Journal of Small Business Management, In Press.

Gambacorta, L. (2005): Inside the bank lending channel. European Economic Review, 49 (7), 1737-1759.

Gambacorta, L. y Marques-Ibanez, D. (2011): The bank lending channel: lessons from the crisis. Economic Policy, 26 (66), 135-182.

Gambacorta, L. y Mistrulli, P.E. (2004): Does bank capital affect lending behavior?. Journal of Financial Intermediation, 13(4), 436-57.

García-Appendini, E. y Montoriol-Garriga, J. (2013): Firms as liquidity providers: Evidence from the 2007-2008 financial crisis. Journal of Financial Economics, 109 (1), 272-291.

García-Gámez, S. y Vicéns-Otero, J. (2006): Factores condicionantes en la medición del riesgo soberano en los países emergentes. Estudios de Economía Aplicada, 24 (1), 245-272.

Garretsen, H. y Swank, J. (1998): The transmission of interest rate changes and the role of bank balance sheets: a VAR-analysis for the Netherlands. Journal of Macroeconomics, 20 (2), 325-340.

Ge, Y. y Qiu, J. (2007): Financial development, bank discrimination and trade credit. Journal of Banking and Finance, 31 (2), 513-530.

Gennaioli, N., Martin, A. y Rossi, S. (2014): Sovereign default, domestic banks, and financial institutions. The Journal of Finance, 69 (2), 819-866. 
Gerlach, S., Schulz, A. y Wolff, G. (2010): Banking and sovereign risk in the euro area. CEPR Discussion Paper, (Nº DP 7833).

Gibson, M.S. (1997): The bank lending channel of monetary policy transmission: evidence from a model of bank behavior that incorporates long-term customer relationships. Board of Governors of the Federal Reserve System. International Finance Discussion Papers, ( ${ }^{\circ}$ 584).

Goldman Sachs (2010): Rising funding costs in the periphery. European Weekly Analyst Research Report, (№ 10/13), Goldman Sachs Global Economics, New York, NY, November 4.

Goux, J.F. (1996): Le canal étroit du crédit en France: essai de vérification macroéconomique 1970-1994. Revue d'économie politique, 106 (4), 655-681.

Goyal, V.K. (2005): Market discipline of bank risk: evidence from subordinated debt contracts. Journal of Financial Intermediation, 14 (3), 318-350.

Grande, G., Levy, A., Panetta, F. y Zaghini, A. (2011): Public guarantees on bank bonds: effectiveness and distortions. OECD Financial Market Trends, 2011/2.

Gray, D.F. y Malone, S.W. (2012): Sovereign and financial-sector risk: measurement and interactions. Annual Review of Financial Economics, 4 (1), 297-312.

Grilli, V., Donato, M. y Guido, T. (1991): Political and monetary institutions and public finance policies in the industrial countries. Economic Policy, 6 (13), 341-392.

Guariglia, A. y Mateut, S. (2006): Credit channel, trade credit channel, and inventory investment: Evidence from a panel of UK firms. Journal of Banking and Finance, 30 (10), 2835-2856. 
Guender, A. y Moersch, M. (1997): On the existence of a credit channel of monetary policy in Germany. Kredit und Kapital, 2, 173-185.

Gunji, H., Miura, K. y Yuan, Y. (2009): Bank competition and monetary policy. Japan and the World Economy, 21 (1), 105-115.

Haddad, M.M. y Hakim, S. (2007): The cost of sovereign lending in the Middle East after September 11. Journal for Global Business Advancement, 1 (1), 127-139.

Hallerberg, M. y Wolff, G.B. (2008): Fiscal institutions, fiscal policy and sovereign risk premia in EMU. Public Choice, 136 (3-4), 379-396.

Hansen, L.P. (1982): Large sample properties of Generalized Method of Moments Estimators, Econometrica, 50, 1029-1054.

Harhoff, D. y Korting, T. (1998): Lending relationships in Germany-Empirical evidence from survey data. Journal of Banking and Finance, 22 (10), 1317-1353.

Héricourt, J. (2006): Monetary policy transmission in the CEECS: A comprehensive analysis. Economic and Business Review for Central and South-Eastern Europe, 8 (1), 37-81.

Hernando, I. y Martínez-Pagés, J. (2001): Is there a bank lending cannel of monetary policy in Spain?. ECB Working Paper Series, ( $\left.\mathrm{N}^{\circ} 99\right)$.

Holod, D. y Peek, J. (2007): Asymmetric information and liquidity constraints: A new test. Journal of Banking and Finance, 31 (8), 2425-2451.

Holtemöller, O. (2002): Further VAR evidence for the effectiveness of a credit channel in Germany (N² 2002, 66). Discussion Papers, Interdisciplinary Research Project 373: Quantification and Simulation of Economic Processes. 
Hooper, V., Hume, T. y Kim, J. (2008): Sovereign rating changes-do they provide new information for stock markets?. Economic Systems, 32 (2), 142-166.

Huang, H., Shi, X. y Zhang, S. (2011): Counter-cyclical substitution between trade credit and bank credit. Journal of Banking and Finance, 35, 1859-1878.

Hülsewig, O., Winker, P. y Worms, A. (2004): Bank lending and monetary policy transmission: a VECM analysis for Germany. En Jahrbücher für Nationalökonomie und Statistik, 224 (5), 511-529.

Iacoviello, M. y Minetti, R. (2008): The credit channel of monetary policy: evidence from the housing market. Journal of Macroeconomics, 30 (1), 69-96.

Ioannidou, V.P., Ongena, S., y Peydro, J.L. (2009): Monetary Policy, Risk- Taking, and Pricing: Evidence from a Quasi-Natural Experiment. Center Discussion Paper $\mathrm{N}^{\mathrm{o}}$ 2009-31S.

Isakova, A. (2008): Monetary policy efficiency in the economies of Central Asia. Czech Journal of Economics and Finance (Finance a uver), 58 (11-12), 525-553.

Jaffe, D. y Stiglitz, J. (1990): Credit rationing. En Friedman, B.M. y Hahn, F. (eds), Handbook of Monetary Economics. Amsterdam: Elsevier Science Publishers, 837888.

Jain, N. (2001): Monitoring costs and trade credit. Quarterly Journal of Economics and Finance, 41, 89-110.

Jayaratne, J. y Morgan, D.P. (2000): Capital market frictions and deposit constraints at banks. Journal of Money, Credit and Banking, 32 (1), 74-92. 
Jimborean, R. (2009): The role of banks in the monetary policy transmission in the new EU member states. Economic Systems, 33 (4), 360-375.

Jiménez, G. y Ongena, S. (2012): Credit supply and monetary policy: Identifying the bank balance-sheet channel with loan applications. The American Economic Review, 102 (5), 2301-2326.

Jiménez, G., Ongena, S., Peydro, J.L. y Saurina, J. (2008): Hazardous Times for Monetary Policy: What Do Twenty-Three Million Bank Loans Say About the Effects of Monetary Policy on Credit Risk-Taking?. Banco de España Documento de Trabajo 0833.

Jonas, M.R. y King, S.K. (2013): Bank lending channel effectiveness and loan sales in the US. British Journal of Economics, Management and Trade, 4 (1), 16-34.

Kakes, J. (2000): Identifying the mechanism: is there a bank lending channel of monetary transmission in the Netherlands?. Applied Economics Letters, 7 (2), 6367.

Kakes, J. y Sturm, J.E. (2002): Monetary policy and bank lending: Evidence from German banking groups. Journal of Banking and Finance, 26 (11), 2077-2092.

Kashyap, A.K., y Stein, J.C. (1995a): The impact of monetary policy on bank balance sheets. Carnegie-Rochester Conference Series on Public Policy, 42, 151-195.

Kashyap, A.K. y Stein, J.C. (1995b): The role of banks in the transmission of monetary policy. NBER Reporter, Fall, National Bureau of Economic Research. 
Kashyap, A.K. y Stein, J.C. (1997): The role of banks in monetary policy: A survey with implications for the European Monetary Union. Federal Reserve Bank Of Chicago Economic Perspectives, 2-18.

Kashyap, A.K., y Stein, J.C. (2000): What do a million observations on banks say about the transmission of monetary policy?. The American Economic Review, 90 (3), 407-428.

Kashyap, A.K., Stein, J.C. y Wilcox, D.W. (1993): Monetary policy and credit conditions: Evidence from the composition of external finance. American Economic Review, 83, 78-98.

Kashyap, A.K., Stein, J.C. y Wilcox, D.W. (1996): Monetary policy and credit conditions: evidence from the composition of external finance: reply. American Economic Review, 86, (1), 310-314.

Kaufmann, S. (2001): Asymmetries in bank lending behavior: Austria during the 1990s. ECB Working Paper Series, ( $\mathrm{N}^{\circ}$ 97).

Kestens, K., Van Cauwenberge, P. y Bauwhede, H.V. (2012): Trade credit and company performance during the 2008 financial crisis. Accounting and Finance, 52, 11251151.

King, S. (1986): Monetary transmission - through bank loans or bank liabilities? Journal of Money, Credit and Banking, 18, 290-303.

King, S.K. (2000): A credit channel in Europe: Evidence from Bank's balance sheets. Mimeo, University of California, Davis. 
Kishan, R.P. y Opiela, T.P. (2000): Bank size, bank capital and the bank lending channel. Journal of Money, Credit and Banking, 32 (1), 121-141.

Kishan, R.P. y Opiela, T.P. (2006): Bank capital and loan asymmetry in the transmission of monetary policy. Journal of Banking and Finance, 30 (1), 259285.

Kishan, R.P. y Opiela, T.P. (2012): Monetary policy, bank lending and the risk-pricing channel. Journal of Money, Credit and Banking, 44 (4), 573-602.

Klein, C. y Stellner, C. (2014): Does sovereign risk matter? New evidence from Eurozone corporate bond ratings and zero-volatility spreads. Review of Financial Economics, 23, 64-74.

Kohler, M., Britton, E. y Yates, A. (2000): Trade credit and the monetary transmission mechanism. The Bank of England Working Paper, (115).

Küppers, M. (2001): Curtailing the black box: German banking groups in the transmission mechanism of monetary policy. European Economic Review, 45, 1907-1930.

Lee, Y. y Stowe, J. (1993): Product risk, asymmetric information and trade credit. Journal of Financial and Quantitative Analysis, 28 (2), 285-300.

Lee, H.W., Xie, Y.A. y Yau, J. (2011): The impact of sovereign risk on bond duration: Evidence from Asian sovereign bond markets. International Review of Economics and Finance, 20 (3), 441-451. 
Lemmon, M. y Roberts, M.R. (2010): The response of corporate financing and investment to changes in the supply of credit. Journal of Financial and Quantitative Analysis, 45 (3), 555-587.

Leroy, A. (2014): Competition and the bank lending channel in Eurozone. Journal of International Financial Markets, Institutions and Money, 31, 296-314.

L’Hotellerie-Fallois, P. y Vallés, J. (2013): Las políticas monetarias de las economías avanzadas tras la crisis. Cuadernos de Información Económica, ( $\left.\mathrm{N}^{\mathrm{o}} 234\right)$, MayoJunio 2013.

Long, M.S., Malitz, I.B. y Ravid, S.A. (1993): Trade credit, quality guarantees and product marketability. Financial Management, 22 (4), 117-127.

Loupias, C., Savignac, F. y Sevestre, P. (2003): Monetary policy and bank lending in France: Are there asymmetries?. En: Angeloni, I., Kashyap, A., Mojon, B. (Eds.), Monetary policy transmission in the Euro Area. Cambridge University Press, Cambridge, 297-308.

Loutskina, E. (2005): Does securitization affect bank lending? Evidence from bank responses to funding shocks. Working paper, University of Virginia.

Loutskina, E. y Strahan, P.E. (2009): Securitization and the declining impact of bank finance on loan supply: Evidence from mortgage originations. The Journal of Finance, 64 (2), 861-889.

Love, I. y Zaidi, R. (2010): Trade credit, bank credit and financial crisis. International Review of Finance, 10 (1), 125-147. 
Love, I., Preve, L.A. y Sarria-Allende, V. (2007): Trade credit and bank credit: Evidence from recent financial crises. Journal of Financial Economics, 83 (2), 453-469.

Ludvigson, S. (1998): The channel of monetary transmission to demand: evidence from the market for automobile credit. Journal of Money, Credit and Banking, 30, (3), 365-383.

Maddaloni, A., y Peydro, J.L. (2011): Bank Risk-Taking, Securitization, Supervision and Low Interest Rates: Evidence from the Euro Area and U.S. Lending Standards. Review of Financial Studies, 24(6), 2121-165.

Maechler, A.M. y McDill, K.M. (2006): Dynamic depositor discipline in US banks. Journal of Banking and Finance, 30 (7), 1871-1898.

Maliar, L., Maliar, S. y Sebastián, F.P. (2008): Sovereign risk, FDI spillovers, and growth. Review of International Economics, 16 (3), 463-477.

Markidou, A. y Nikolaidou, F. (2008): The reaction of bank lending to macroeconomic fluctuations of monetary policy transmission in Greece. European Journal of Economics, Finance and Administrative Sciences, 13 (10) 98-115.

Marotta, G. (1997): Does trade credit redistribution thwart monetary policy? Evidence from Italian firm-level data. Applied Economics, 29 (1), 619-629.

Martínez-Trigueros, L. (2002): Did the 1995 Mexican crisis affect the financial constraints of listed firms and their role as providers of credit?. Center for Research on Economic Development and Policy Reform, Working Paper No 115. 
Mateut, S. (2005): Trade credit and monetary policy transmission. Journal of Economic Surveys, 19 (4), 655-670.

Mateut, S. y Mizen, P. (2002): Trade credit and bank lending: an investigation into the determinants of UK manufacturing firms' access to trade credit. EUI Working Paper ECO, No 2003/3.

Mateut, S., Bougheas, S. y Mizen, P. (2006): Trade credit, bank lending and monetary policy transmission. European Economic Review, 50, 603-629.

Matousek, R. y Sarantis, N. (2009): The bank lending channel and monetary transmission in Central and Eastern European Countries. Journal of Comparative Economics, 37 (2), 321-334.

Meltzer, A.H. (1960): Mercantile credit, monetary policy, and size of firms. The Review of Economics and Statistics, 42 (4), 429-439.

Menon, J. (1995): Exchange rate pass-through. Journal of Economic Surveys, 9 (2), 197-231.

Mian, S.L. y Smith, C.W. (1992): Accounts receivable management policy: theory and evidence. The Journal of Finance, 47 (1), 169-200.

Milcheva, S. (2013): A bank lending channel or a credit supply shock? Journal of Macroeconomics, 37, 314-332.

Mishkin, F.S. (1995): Symposium on the monetary transmission mechanism. The Journal of Economic Perspectives, 9 (4), 3-10.

Modigliani, F. (1971): Monetary policy and consumption. En Consumer spending and monetary policy: the linkages, 9-84. 
Molina, C.A. y Preve, L.A. (2012): An empirical analysis on the effect of financial distress on trade credit. Financial Management, 41 (1), 187-205.

Morgan, D.P. (1998): The credit effects of monetary policy: evidence using loan commitments. Journal of Money, Credit and Banking, 30, (1), 102-118.

Myers, S. (1977): Determinants of corporate borrowing. Journal of Financial Economics, 5, 147-175.

Myers, S. y Majluf, N.S. (1984): Corporate financing and investment decisions when firms have information that investors do not have. Journal of Financial Economics, 13, 187-221.

Nadiri, M.I. (1969): The determinants of trade credit in the US total manufacturing sector. Econometrica: Journal of Econometric Society, 408-423.

Neri, S. (2013): The impact of the sovereign debt crisis on bank lending rates in the euro area. En Bank of Italy Workshops and Conferences The Sovereign Debt Crisis and the Euro area.

Ng, C.K., Smith, J.K. y Smith, R.L. (1999): Evidence on determinants of trade credit terms used in interfirm trade. The Journal of Finance, 54 (3), 1109-1129.

Nilsen, J.H. (2002): Trade credit and the bank lending channel. Journal of Money, Credit and Banking, 34 (1), 226-253.

Obstfeld, M. y Rogoff, K. (1995): Exchange rate dynamics redux. Journal of Political Economy, 103 (3), 624-660. 
Ogawa, K. y Tanaka, T. (2013): The global financial crisis and small-and medium-sized enterprises in Japan: how did they cope with the crisis?. Small Business Economics, 41 (2), 401-417.

Oliner, S.D. y Rudebusch, G.D. (1995): Is there a broad credit channel for monetary policy?. Board of Governors of the Federal Reserve System.

Olivero, M.P., Li, Y. y Jeon, B.N. (2011a): Consolidation in banking and the lending channel: Evidence from bank-level data in Asia and Latin America. Journal of International Money and Finance, 30 (6) 1034-1054.

Olivero, M.P., Li, Y. y Jeon, B.N. (2011b): Competition in banking and the lending channel: evidence from bank-level data in Asia and Latin America. Journal of Banking and Finance, 35 (3), 560-571.

Ono, M. (2001): Determinants of trade credit in the Japanese manufacturing sector. Journal of the Japanese International Economies, 15, 160-177.

Opiela T. (2008): Differential deposit guarantees and the effect of monetary policy on bank lending. Economic Inquiry, 46 (4) 610-623.

Opler, T., Pinkowitz, L., Stulz, R. y Williamson, R. (1999): The determinants and implications of corporate cash holdings. Journal of Financial Economics, 52 (1), $3-46$.

Özlü, P. y Yalçin, C. (2012): The trade credit channel of monetary policy transmission: evidence from non-financial firms in Turkey. Emerging Markets Finance and Trade, 48 (4), 102-117. 
Paligorova, T., y Santos, J.A.C. (2012): Monetary Policy and Bank Risk-Taking: Evidence from the Corporate Loan Market. Working paper, Federal Reserve Bank of New York.

Papadamou, S. y Siriopoulos, C. (2012): Banks'lending behavior and monetary policy: evidence from Sweden. Review of Quantitative Finance and Accounting, 38 (2), 131-148.

Peek, J. y Rosengren, E.S. (1995): Bank lending and the transmission of monetary policy. En Conference series-Federal Reserve Bank of Boston.Federal Reserve Bank of Boston, 47-68.

Peek, J. y Rosengren, E.S. (2013): The role of banks in the transmission of monetary policy. Public Policy Discussion Papers, Federal Reserve Bank of Boston, ( $\mathrm{N}^{\circ} 13-$ $5)$.

Peltzman (1969): The banking structure and the transmission of monetary policy. Journal of Finance, 24 (3), 387-411.

Perez, S.J. (1998): Causal ordering and the bank lending channel. Journal of Applied Econometrics, 13, 613-626.

Peter, M. y Grandes, M. (2005): How important is sovereign risk in determining corporate default premia? The case of South Africa. International Monetary Fund.

Petersen, M.A. y Rajan, R.G. (1994): The benefits of firm-creditor relationships: evidence from small business data. The Journal of Finance, 49, 3-37.

Petersen, M.A. y Rajan, R.G. (1997): Trade credit: theories and evidence. Review of Financial Studies, 10 (3), 661-691. 
Pianeselli, D. y Zaghini, A. (2014): The cost of firms' debt financing and the global financial crisis. Finance Research Letters, 11 (2), 74-83.

Popov, A. y van Horen, N. (2013): The impact of sovereign debt exposure on bank lending: Evidence from the European debt crisis. DNB Working Paper, (No 382).

Preve, L. (2003): Financial distress and trade credit: an empirical analysis. Mimeograph, University of Texas at Austin.

Pruteanu-Podpiera, A.M. (2007): The role of banks in the Czech monetary policy transmission mechanism. Economics of Transition, 15 (2), 393-428.

Puri, M., Rocholl, J. y Steffen, S. (2011): Global retail lending in the aftermath of the US financial crisis: Distinguishing between supply and demand effects. Journal of Financial Economics, 100 (3), 556-578.

Rajan, R. y Zingales, L. (1995): What do we know about capital structure? Some evidence from international data. TheJournal of Finance, 50, 1421-1460.

Ramey, V. (1993): How important is the credit channel in the transmission of monetary policy?. Carnegie-Rochester Conference Series on Public Policy, 39, 1-45.

Reinhart, C.M. y Rogoff, K.S. (2004): Serial default and the 'paradox' of rich-to-poor capital flows. American Economic Review, 94, 52-58.

Romer, C.D. y Romer, D.H. (1990): New evidence on the monetary transmission mechanism. Brookings Papers on Economic Activity, 1990 (1), 149-213.

Rondorf, U. (2012): Are bank loans important for output growth? A panel analysis of the euro area. Journal of International Financial Markets, Institutions and Money, $22(1), 103-119$. 
Sack, B. y Wieland, V. (2000): Interest-rate smoothing and optimal monetary policy: a review of recent empirical evidence. Journal of Economics and Business, 52 (1), 205-228.

Said, F.F. (2013): The dynamic of bank lending channel: Basel regulatory constraint. Economic Modelling, 31, 606-613.

Santos, G.A., Sheng, H.H. y Bortoluzzo, A. (2012): The use of trade credit by firms: evidence for Latin America. Insper Working Paper, Insper Instituto de Ensino e Pesquisa, ( $\mathrm{N}^{\mathrm{o}}$ wpe_277).

Schich, S. y Lindh, S. (2012): Implicit Guarantees for bank debt: Where do we stand?. OECD Financial Market Trends, 2012/1.

Schnitzer, M. (1999): Expropriation and control rights: a dynamic model of foreign direct investment. International Journal of Industrial Organization, 17 (8), 11131137.

Schnitzer, M. (2002): Debt v. foreign direct investment: the impact of sovereign risk on the structure of international capital flows. Economica, 69 (273), 41-67.

Schwartz, R.A. (1974): An economic model of trade credit. Journal of Financial Quantitative Analysis, 9, 643-657.

Schwartz, R.A. y Whitcomb, D. (1979): The trade credit decision. Handbook of Financial Economics. En Bicksler, J. (Ed.), North-Holland Publishing Co., 257273.

Sims, C. (1980): Macroeconomics and reality. Econometrica, 48, 1-48. 
Smith, J.K. (1987): Trade credit and informational asymmetry. The Journal of Finance, $42(4), 863-869$.

Stein, J.C. (1998): An adverse selection model of bank asset and liability management with implications for the transmission of monetary policy. Rand Journal of Economics, 29 (3), 466-486.

Steudler, O. y Zurlinden, M. (1998): Monetary policy, aggregate demand and the lending behavior of bank groups in Switzerland. En BIS Conference Papers, 6, 279-293.

Taketa, K. y Udell, G.F. (2007): Lending channels and financial shocks: The case of small and medium-sized enterprise trade credit and the Japanese banking crisis. Monetary and Economic Studies, 25 (2), 1-44.

Taylor, J.B. (1995): Monetary policy implications of greater fiscal discipline. En Budget Deficits and Debt: Issues and Options, A Symposium sponsored by the Federal Reserve Bank of Kansas City, Jackson Hole, August 1995.

Thakor, A.V. (1996): Capital requirements, monetary policy, and aggregate bank lending: theory and empirical evidence. The Journal of Finance, 51 (1), 279-324.

Tobin, J. (1969): A general equilibrium approach to monetary theory. Journal of Money, Credit and Banking, 1 (1), 15-29.

Topi, J. y Vilmunen, J. (2001): Transmission of monetary policy shocks in Finland: Evidence from bank level data on loans. ECB Working Paper Series, ( $\left.\mathrm{N}^{\mathrm{o}} 100\right)$.

Tornell, A. y Westermann, F. (2011): Greece: the sudden stop that wasn't, en VOX CEPR's Policy Portal. 
Treynor, J. y Mazuy, K. (1966): Can mutual funds outguess the market? Harvard Business Review, 44 (4), 131-136.

Trichet, J.C. (2010): The ECB's response to the recent tensions in financial markets. En $38^{\text {th }}$ Economic Conference of the Österreichische National bank, Vienna, 31.

Tsatsaronis, C. (1995): Is there a credit channel in the transmission of monetary policy? Evidence from four countries. En BIS Financial Structure and the Monetary Policy Transmission Mechanism, CB Document 394, March, Basle, 154-187.

Tsuruta, D. (2013): Credit contagion and trade credit: evidence from small business data in Japan. Asian Economic Journal, 27 (4), 341-367.

Udell, G.F. (2009): Wall Street, Main Street, and a credit crunch: Thoughts on the current financial crisis. Business Horizons, 52, 117-125.

Uesugi, I. y Yamashiro, G.M. (2008): The relationship between trade credit and loans: Evidence from small business in Japan. International Journal of Business, 13 (2), 142-163.

Unsal, D.F. y Cáceres, C. (2011): Sovereign spreads and contagion risks in Asia. International Monetary Fund, 11.

Valderrama, M. (2003): The role of trade credit and bank lending relationships in the transmission mechanism in Austria. En Angeloni, I. Kashyap, A. y Mojon, B. (eds), Monetary policy transmission in the euro area. Cambridge: Cambridge University Press, 221-232. 
Van Ees, H., Garretsen, H. y Sterken, E. (1999): Some evidence on the relevance of bank behaviour for the lending channel in Netherlands. De Economist, 147 (1), $19-37$.

Van den Heuvel, S.J. (2002): Does bank capital matter for monetary transmission? Economic Policy Review, 8 (1), 259-265.

Van den Heuvel, S.J. (2012): Banking conditions and the effects of monetary policy: evidence from US states. The B.E. Journal of Macroeconomics, 12 (2), 1-31.

Walsh, C.E. (2003): Monetary theory and policy. $2^{\text {nd }}$ ed. Cambridge, MA: MIT Press.

Westerlund, J. (2003): A panel data test of the bank lending channel in Sweden. Lund University, Department of Economics Working Paper Series, ( $\left.\mathrm{N}^{\circ} 16\right)$.

Williams, G., Alsakka, R. y ap Gwilym, O. (2013): The impact of sovereign rating actions on bank ratings in emerging markets. Journal of Banking and Finance, 37 (2), 563-577.

Wilner, B.S. (2000): The exploitation of relationships in financial distress: the case of trade credit. The Journal of Finance, 55 (1), 153-178.

Wilson, N. y Summers, B. (2002): Trade credit terms offered by small firms: survey evidence and empirical analysis. Journal of Business, Finance and Accounting, 29, 317-352.

Woodford, M. (1999): Optimal monetary policy inertia. The Manchester School, 67 (s1), 1-35. 
Wu, J., Luca, A.C. y Jeon, B.N. (2011): Foreign bank penetration and the lending channel in emerging economies: Evidence from bank-level panel data. Journal of International Money and Finance, 30 (6), 1128-1156.

Xie, Y.A., Liu, S., Wu, C. y Anderson, B. (2009): The effects of default and call risk on bond duration. Journal of Banking and Finance, 33, 1700-1708.

Yang, X. (2011a): The role of trade credit in the recent subprime financial crisis. Journal of Economics and Business, 63, 517-529.

Yang, X. (2011b): Trade credit versus bank credit: Evidence from corporate inventory financing. The Quarterly Review of Economics and Finance, 51, 419-434.

Zawadowski, A. (2011): Interwoven lending, uncertainty and liquidity hoarding. Boston U. School of Management Research Paper, (Nº 2011-13).

Zoli, M.E. (2013): Italian sovereign spreads: their determinants and pass-through to bank funding costs and lending conditions. International Monetary Fund Working Paper, (No 84). 